\title{
An Investigation of Diesel PM Particle Morphology Using TEM and SEM
}

Ganesh Vedula

West Virginia University

Follow this and additional works at: https://researchrepository.wvu.edu/etd

\section{Recommended Citation}

Vedula, Ganesh, "An Investigation of Diesel PM Particle Morphology Using TEM and SEM" (2011). Graduate Theses, Dissertations, and Problem Reports. 4809.

https://researchrepository.wvu.edu/etd/4809

This Thesis is protected by copyright and/or related rights. It has been brought to you by the The Research Repository @ WVU with permission from the rights-holder(s). You are free to use this Thesis in any way that is permitted by the copyright and related rights legislation that applies to your use. For other uses you must obtain permission from the rights-holder(s) directly, unless additional rights are indicated by a Creative Commons license in the record and/ or on the work itself. This Thesis has been accepted for inclusion in WVU Graduate Theses, Dissertations, and Problem Reports collection by an authorized administrator of The Research Repository @ WVU. For more information, please contact researchrepository@mail.wvu.edu. 
An Investigation of Diesel PM Particle Morphology Using TEM and SEM

\author{
Ganesh Vedula \\ Thesis submitted to the \\ College of Engineering and Mineral Resources \\ at West Virginia University \\ in partial fulfillment of the requirements \\ for the degree of \\ Master of Science \\ in \\ Mechanical Engineering \\ Dr. Hailin Li, Chair \\ Dr. Scott Wayne \\ Dr. Xueyan Song \\ Department of Mechanical and Aerospace Engineering \\ Morgantown, West Virginia \\ 2011
}

Keywords: Diesel Engine, PM Particles, Morphology, SEM, TEM 


\section{Abstract \\ An Investigation of Diesel PM Particle Morphology Using TEM and SEM \\ Ganesh Vedula}

This research investigates the effect of engine load and combustion mode on the size, shape and microstructure of PM particles of two diesel engines using a scanning mobility particle sizer (SMPS), and electron microscopes including scanning electron microscope (SEM) and transmission electron microscope (TEM). The effect of engine load on the morphology of PM particle was investigated using a 2004 MACK MP7-355E heavy-duty diesel engine. The effect of combustion mode on the morphology of the PM particles was preliminarily examined using 2005 Opel 1.9 L light-duty diesel engine. The SEM images were processed using ImageJ V: 1.44o software to obtain a set of parameters based on the projected area. These include the maximum length, maximum width, project area equivalent diameter, shape descriptor, fractal dimension, and the size of primary PM particles. The TEM images were processed to obtain the micro-structure and chemical composition of PM particles.

The SEM images obtained in this research revealed the diverse morphology of PM particles formed in heavy-duty diesel engine. The operation at low load tends to form small sphere-like PM particles compared to medium and high load operation featured with large and chain-like PM particles. The projected area equivalent diameter of PM particles observed was in the range of 43.7 to $167.4 \mathrm{~nm}$ and 66.4 to $688 \mathrm{~nm}$ for operation at $20 \%$ and $100 \%$ load respectively. The PM particles smaller than $43 \mathrm{~nm}$ observed using SMPS were not observed using SEM methods. The projected area equivalent diameter of PM particles from the light duty engine during PCCI mode was smaller in size compared to the PM particles observed under normal operation. The fractal dimension of this heavy-duty diesel engine observed was 1.82, indicating spherical PM particles. The fractal dimension for the light duty engine was 1.65 and 1.7 for the traditional diesel and PCCI mode, respectively, indicating more spherical particles during PCCI mode.

The TEM images were processed to obtain the compositions and microstructure of the PM particles. The PM particles observed contain mainly carbon as well as inorganic and metallic elements such as $\mathrm{Ca}, \mathrm{Mg}, \mathrm{Zn}, \mathrm{P}$ and $\mathrm{Si}$ from engine oil, $\mathrm{Al}$ and $\mathrm{Fe}$ from engine wear, and $\mathrm{S}$ from fuel and lubricating oil. The compositions of PM particles were also found to vary significantly from particle to particle observed under identical operating conditions indicating the random burning of lubrication oil droplets and its effect on the formation of PM particles. The microstructure of primary particles from the heavy duty diesel engine exhibited two types of 
structure. The first type featured with concentric layers of graphitic layers roughly parallel and equidistant similar to the structure of an onion. The second type had similar concentric structure on the outside but the core region was found to contain multiple spherical nuclei surrounded by graphitic layers. Graphitic structures were observed for the primary particles from high engine loads for the heavy duty engine. The analysis revealed that spherical primary particles were clustered together to form large agglomerates. 


\section{Acknowledgements}

It has been a long, challenging and fun filled graduate program for me. I would like to take this opportunity to show my utmost gratitude to all those people who have influenced and helped me along the way.

I start by thanking my parents for the incredible support they have provided me both financially and morally, especially my mother. Amma thanks for believing in me and supporting me throughout, you are the best love you! Dad thanks for teaching me to be optimistic in life and standing by my side. Special thanks to my brother for his love and support, you are my best friend! Good luck with your career, I know you will be an awesome doctor!

I thank Dr. Hailin Li for your support and believing in me. You have been a good friend and a patient adviser all along. I also thank my advising committee members Dr. Scott Wayne and Dr. Xueyan Song for their valuable knowledge and technical support. My sincere thanks to Dr. Song for processing the TEM images which was a key part of my research. I am grateful to Drs. Seanor, Nix, Li, Sivaneri, Prucz and Greg Puskar for providing me TA funding which not only helped me financially but also improved my basics a lot. Dr. Seanor, I had a lot of fun on the field trips you took me on. You have been more like a friend to me.

I want to thank my friends Harish, Surya, Vamsi, Chandana, Praveen, Kartik, Srinu, Parupati, Pavan, Nambu, Umesh for being great friends and showing incredible support. Life in Morgantown would surely be a drag if it was not for you guys. Thanks for the wonderful time we spent together. I want to thank Harish for helping me with excel and word which made life a lot easier, Vamsi and Anand for helping me whenever I had trouble operating the SEM.

I want to thank the CAFEE crew at WVU especially Brad, Marc and Ross for helping me collecting the samples. Thank you Brad and Marc for your technical support and teaching me the essentials. I am really impressed with the level of knowledge you guys possess. I had a wonderful experience working with you guys and thanks for making my work interesting.

Last but not least I want to thank the crew at WVU nano, especially Dr. Ding, Dr. Brown and Dr. Redigollo for the training and teaching me the essentials of using SEM and TEM. Thank you all! 


\section{Table of Contents}

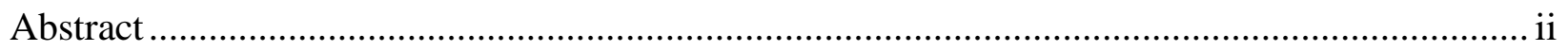

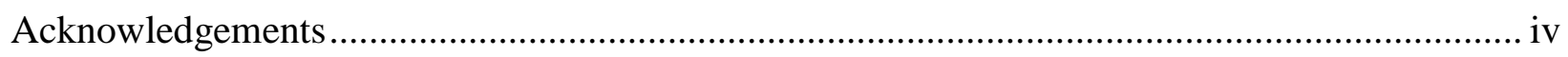

List of Figures:

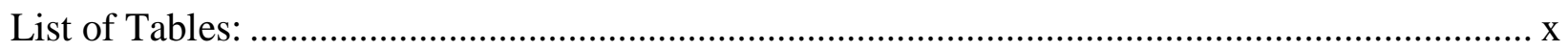

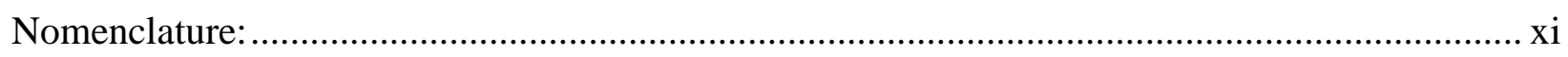

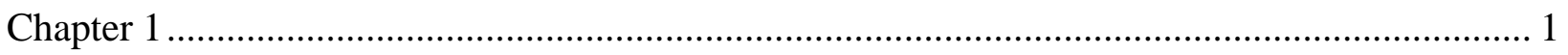

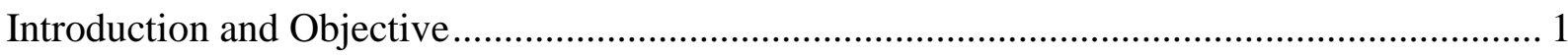

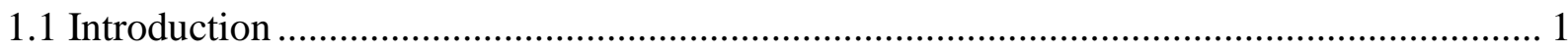

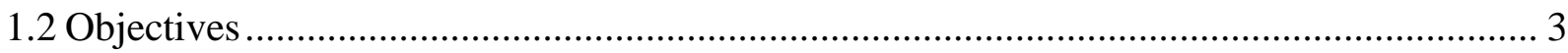

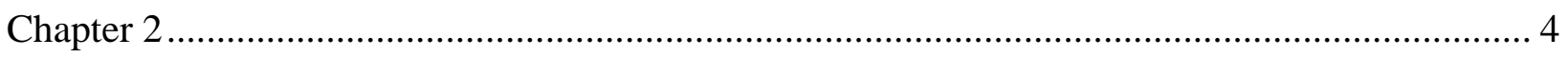

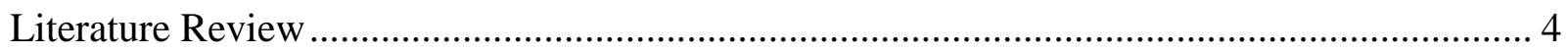

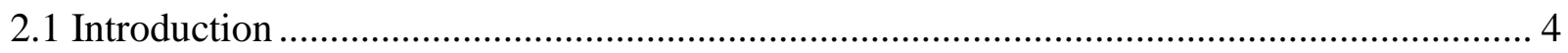

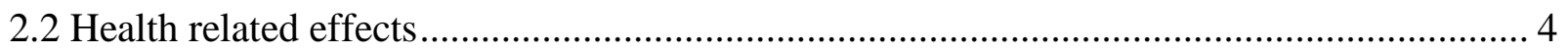

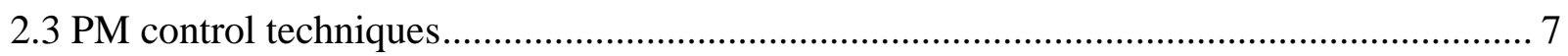

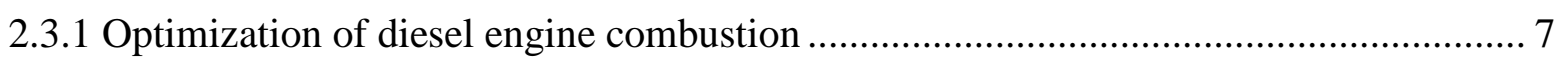

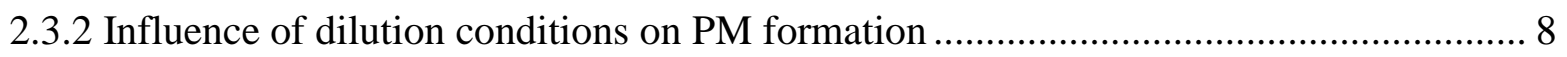

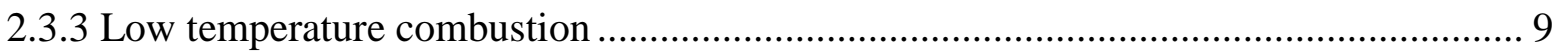

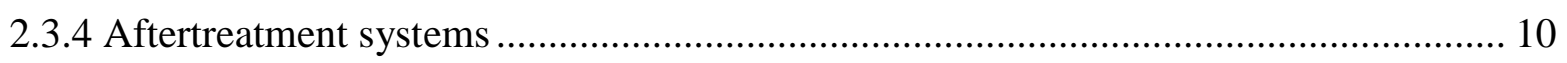

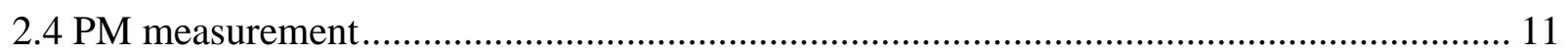

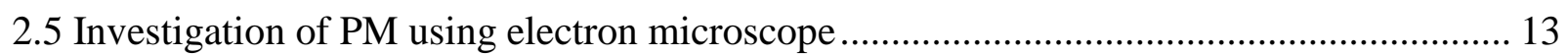

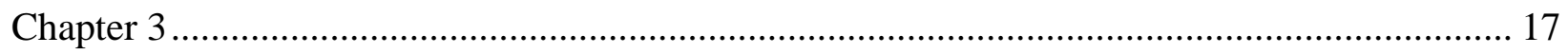

Engine and Experimental Setup …………………….................................................... 17

3.1 Heavy duty diesel engine and dynamometer.............................................................. 17

3.2 Light duty engine and dynamometer........................................................................ 18

3.3 Emission measurements ..................................................................................... 19

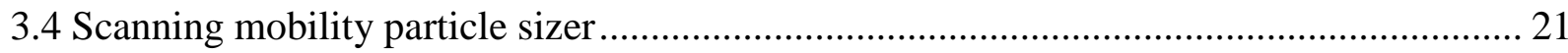

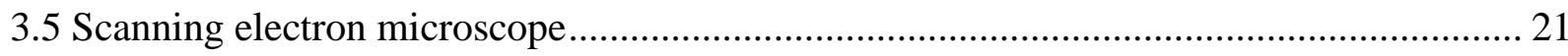

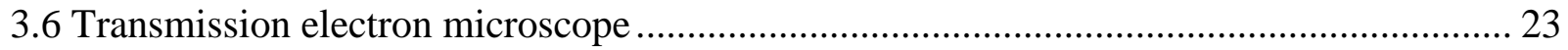

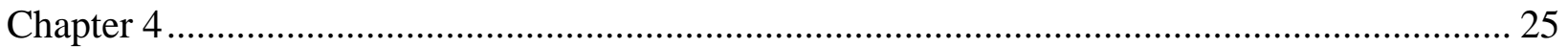

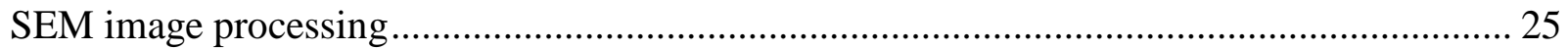

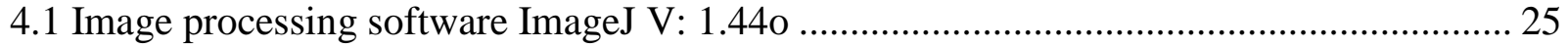

4.2 Calculation of projected area.................................................................................. 26

4.3 Calculation of projected parameters ………………….............................................. 27 


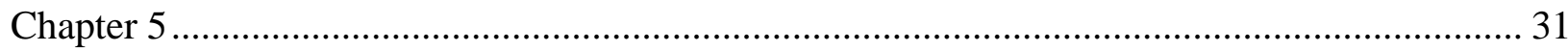

Morphology of PM Particles of Heavy Duty Diesel Engine ……………................................... 31

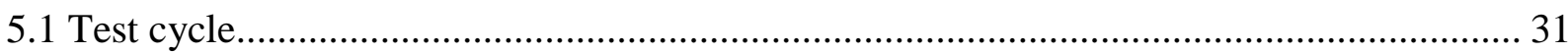

5.2 Featured PM particle morphology of heavy duty engine .................................................. 31

5.3 Projected area equivalent diameter ............................................................................... 41

5.4 Distribution of the primary particle size …………....................................................... 49

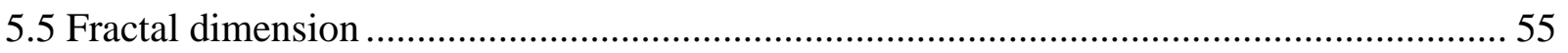

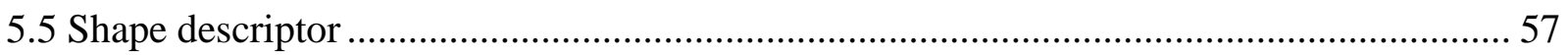

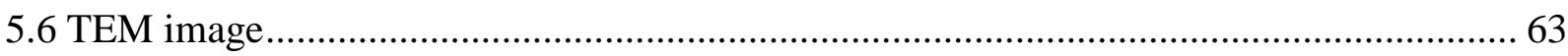

5.7 Scanning mobility particle sizer (SMPS) data for heavy duty engine ………………........ 68

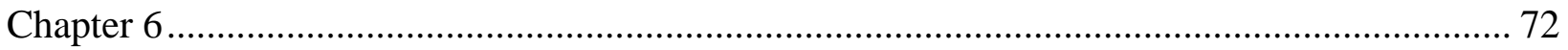

Morphology of PM Particles of Light Duty Engine ……………………………................... 72

6.1 Featured PM particle morphology for light duty engine ................................................ 72

6.2 Projected area equivalent diameter ......................................................................... 76

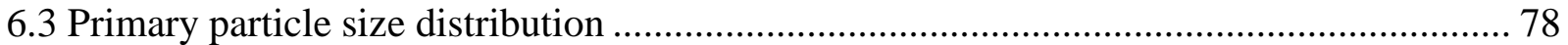

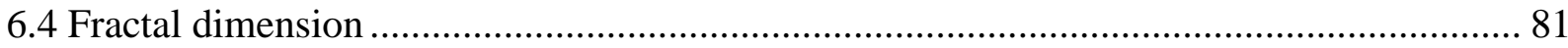

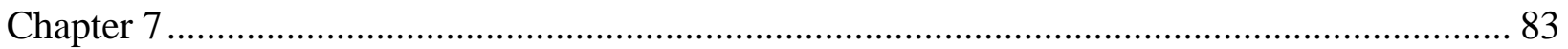

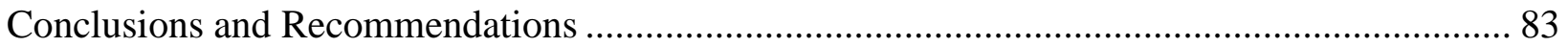

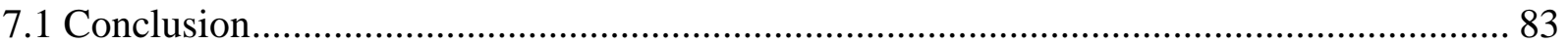

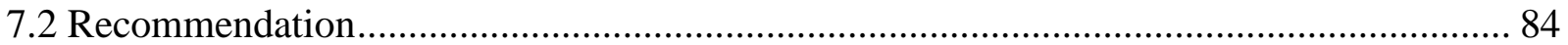

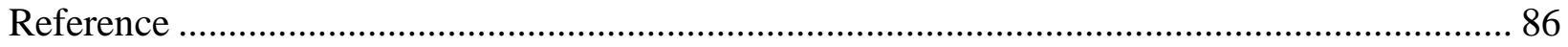




\section{List of Figures:}

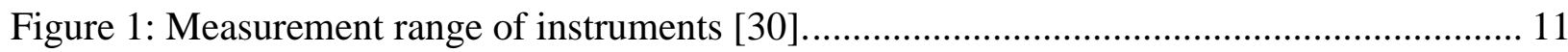

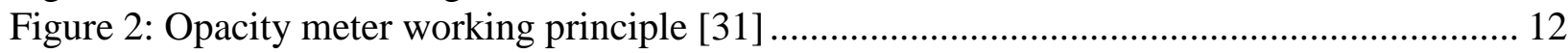

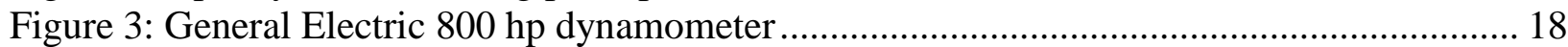

Figure 4: Medsker Electric Inc. Alternating Current Dynamometer ............................................ 19

Figure 5: Full scale dilution tunnel constant volume sampling system ....................................... 20

Figure 6: Secondary dilution tunnel for PM collection ......................................................... 20

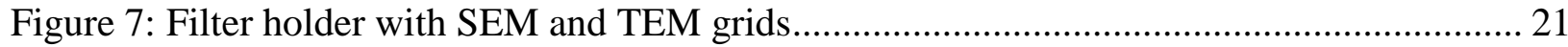

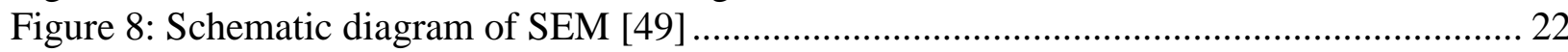

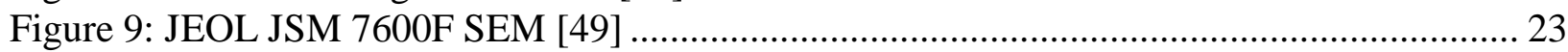

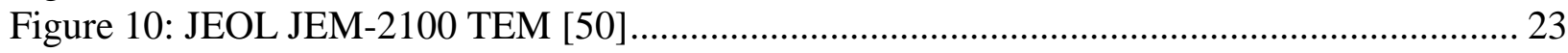

Figure 11: Layout of the TEM [50] ................................................................................... 24

Figure 12: Projected imageand parameters measured: $A_{a}$ : projected area of the agglomerate, $A_{p}$ :area of primary particle, L: maximum length of the PM particle, $\mathrm{W}$ : maximum width of the PM

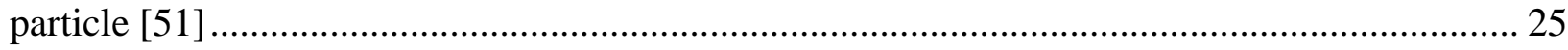

Figure 13: PM particle when operated at 90\% load as seen under SEM ..................................... 26

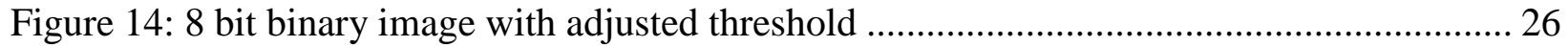

Figure 15: Outline of the binary image with $A_{a}=107396.2 \mathrm{~nm}^{2}$............................................. 27

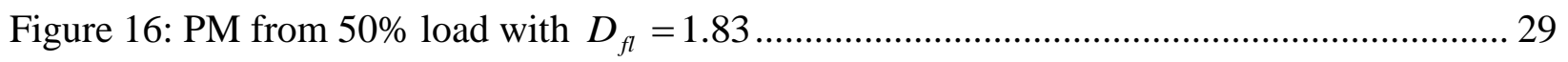

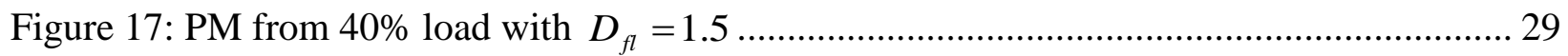

Figure 18: Projected parameters calculated from projected area of PM particle when engine was

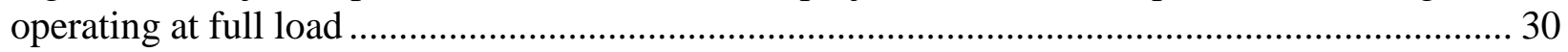

Figure 19: Coarse particle observed at $40 \%$ load $L_{\max }=23.2 \mu \mathrm{m}$ and $D=16.4 \mu \mathrm{m} \ldots \ldots \ldots \ldots \ldots \ldots \ldots . . . . . . .32$

Figure 20: Coarse particle observed at full load $L_{\max }=3.6 \mu \mathrm{m}$ and $D=2.1 \mu \mathrm{m} \ldots \ldots \ldots \ldots \ldots \ldots \ldots \ldots \ldots . . . . . . . . . . .32$

Figure 21: Large PM particle with branches observed at $95 \%$ load with $L_{\max }=1.19 \mu m$ and

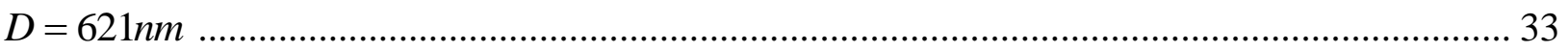

Figure 22: Coarse particle with branches observed at $50 \%$ load is $L_{\max }=1.02 \mu m$ and

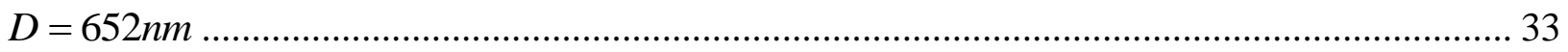

Figure 23: Coarse particle with many branches observed at 50\% load $L_{\max }=773.5 \mathrm{~nm}$ and

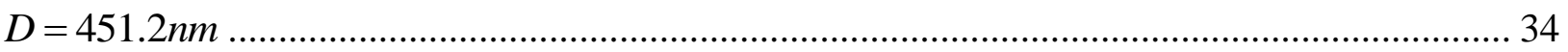

Figure 24: Branched PM particle produced observed at full load $L_{\max }=699 \mathrm{~nm}$ and

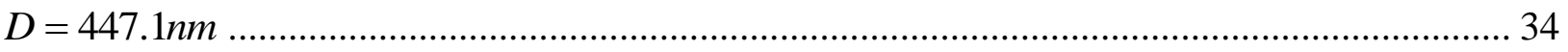

Figure 25: PM particle with many branches observed at $60 \%$ load $L_{\max }=634.9 \mathrm{~nm}$ and

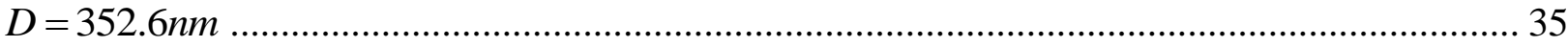

Figure 26: Chain like PM observed at $40 \%$ load $L_{\max }=728.4 \mathrm{~nm}$ and $D=343.2 \mathrm{~nm} \ldots \ldots \ldots \ldots \ldots \ldots . . . . . .35$

Figure 27: Accumulation mode PM observed at full load $L_{\max }=383.8 \mathrm{~nm}$ and $D=233.5 \mathrm{~nm} \ldots . .36$

Figure 28: Long chain like PM observed at full load $L_{\max }=955.7 \mathrm{~nm}$ and $D=380.6 \mathrm{~nm} \ldots \ldots \ldots . .36$

Figure 29: Long chain like PM observed at $60 \%$ load $L_{\max }=383.8 \mathrm{~nm}$ and $D=233.5 \mathrm{~nm} \ldots \ldots \ldots . .37$

Figure 30: PM with small branches observed at $40 \%$ load $L_{\max }=310.2 \mathrm{~nm}$ and $D=172.0 \mathrm{~nm} \ldots 37$

Figure 31: Chain like PM with small branches observed at $75 \%$ load $L_{\max }=276.1 \mathrm{~nm}$ and

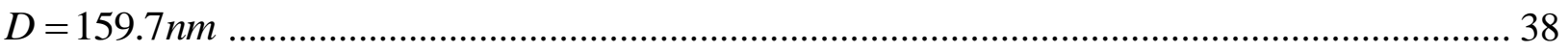


Figure 32: Chain like PM observed at full load $L_{\max }=161.8 \mathrm{~nm}$ and $D=92.9 \mathrm{~nm} \ldots \ldots \ldots \ldots \ldots \ldots . . . . . . . .38$

Figure 33: PM particle observed at $60 \%$ load $L_{\max }=278.2 \mathrm{~nm}$ and $D=152.4 \mathrm{~nm} \ldots \ldots \ldots \ldots \ldots \ldots . . . . . . . .39$

Figure 34: Nano particle observed at $90 \%$ load $L_{\max }=144.7 \mathrm{~nm}$ and $D=105.6 \mathrm{~nm}$................ 39

Figure 35: Nano particle observed at $75 \%$ load $L_{\max }=176.1 \mathrm{~nm}$ and $D=100.3 \mathrm{~nm} \ldots \ldots \ldots \ldots \ldots . . . . . . .40$

Figure 36: Almost Spherical PM observed at 60\% load $L_{\max }=132.5 \mathrm{~nm}$ and $D=107.6 \mathrm{~nm} \ldots . . .40$

Figure 37: Spherical nano particles observed at $50 \%$ load $L_{\max }=62.3 \mathrm{~nm}$ and $D=55.3 \mathrm{~nm} \ldots \ldots .41$

Figure 38: Distribution of maximum length of particle Vs projected area equivalent diameter

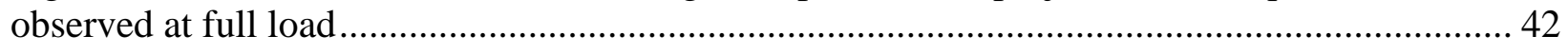

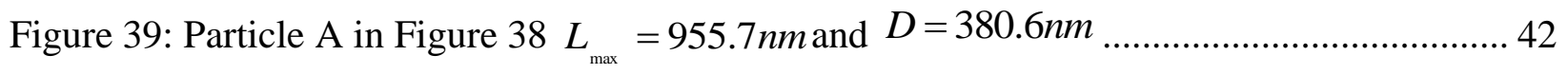

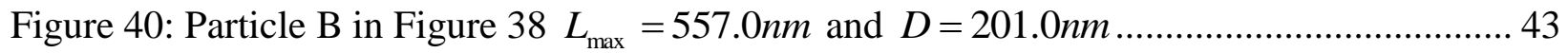

Figure 41: Variation of maximum length of PM particles with changes in the projected area equivalent diameter observed at $95 \%$ load ................................................................. 43

Figure 42: Variation of maximum length of PM particles with changes in the projected area equivalent diameter observed at $90 \%$ load .................................................................. 44

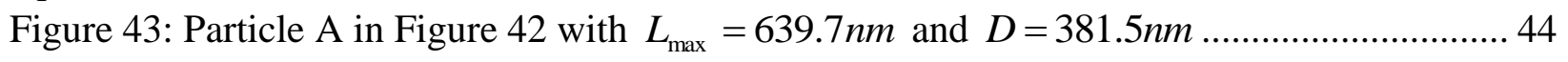

Figure 44: Variation of maximum length of PM particles with changes in the projected area equivalent diameter observed at $75 \%$ load ................................................................. 45

Figure 45: Variation of maximum length of PM particles with changes in the projected area

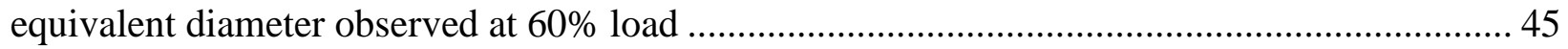
Figure 46: Variation of maximum length of PM particles with changes in the projected area equivalent diameter observed at $50 \%$ load ................................................................. 46 Figure 47: Variation of maximum length of PM particles with changes in the projected area equivalent diameter observed at $40 \%$ load ................................................................. 46 Figure 48: Variation of maximum length of PM particles with changes in the projected area equivalent diameter observed at $20 \%$ load .................................................................. 47

Figure 49: Particle A in Figure $47 L_{\max }=212.7 \mathrm{~nm}$ and $D=68.4 \mathrm{~nm}$ respectively .................. 47

Figure 50: Variation of maximum length of PM particles with changes in the projected area equivalent diameter for heavy duty engine PM ............................................................. 48

Figure 51: Range of projected area equivalent diameter of PM particles during different load .. 49

Figure 52: Distribution of the primary particle diameter observed at 20\% load ....................... 50

Figure 53: Distribution of the primary particle diameter observed at $40 \%$ load ....................... 50

Figure 54: Distribution of the primary particle diameter observed at 50\% load ...................... 51

Figure 55: Distribution of primary particle diameter observed at $60 \%$ load .............................. 51

Figure 56: Distribution of the primary particle diameter observed at 75\% load ...................... 52

Figure 57: Distribution of the primary particle diameter observed at $90 \%$ load ........................ 52

Figure 58: Distribution of the primary particle diameter observed at $95 \%$ load ....................... 53

Figure 59: Distribution of primary particle diameter observed at full load .............................. 53

Figure 60: Comparison of primary particle diameter ........................................................... 54

Figure 61: Variation of the average primary particle diameter with changes in engine load ....... 54

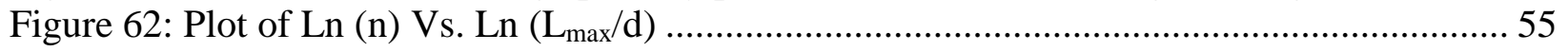

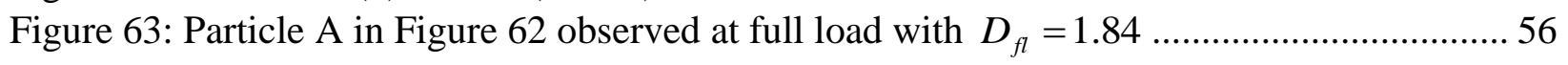

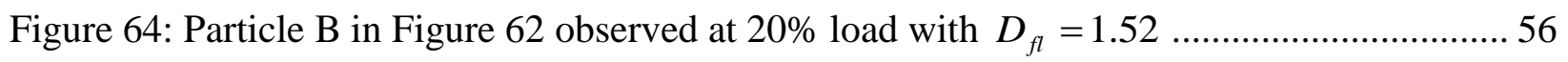


Figure 65: Aspect ratio of PM particles from heavy duty diesel engine ................................. 57

Figure 66: Roundness of PM particles from heavy duty diesel engine ................................... 58

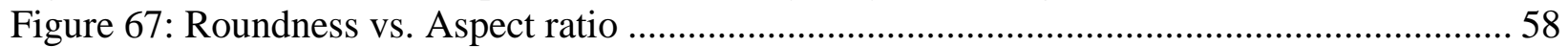

Figure 68: Particle A in Figure 67 observed at 90\% load $A R=0.69$ and $R N=0.22$............ 59

Figure 69: Particle B in Figure 67 observed at 75\% load $A R=0.72$ and $R N=0.36 \ldots \ldots \ldots \ldots . .59$

Figure 70: Particle $\mathrm{C}$ in Figure 67 observed at 20\% load $A R=0.72$ and $R N=0.5$........... 60

Figure 71: Particle D in Figure 67 observed at 40\% load $A R=0.75$ and $R N=0.61 \ldots \ldots \ldots \ldots . . .60$

Figure 72: Particle E in Figure 67 observed at 50\% load $A R=0.75$ and $R N=0.86 \ldots \ldots \ldots \ldots . . .61$

Figure 73: Particle F in Figure 67 observed at full load $A R=0.81$ and $R N=0.28 \ldots \ldots \ldots \ldots \ldots .61$

Figure 74: Particle $\mathrm{G}$ in Figure 67 observed at $40 \%$ load $A R=0.65$ and $R N=0.27$........... 62

Figure 75: Particle $\mathrm{H}$ in Figure 67 observed at $40 \%$ load $A R=0.23$ and $R N=0.20$............ 62

Figure 76: PM agglomerate when operated at full load as seen using TEM ........................... 63

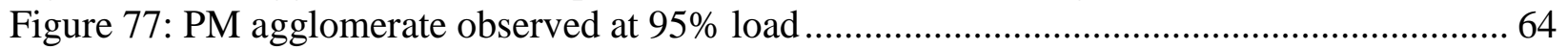

Figure 78: Primary particle with concentric ring structure observed at 75\% load ..................... 64

Figure 79: Primary particle observed at $90 \%$ load with multiple nuclei in the core ................... 65

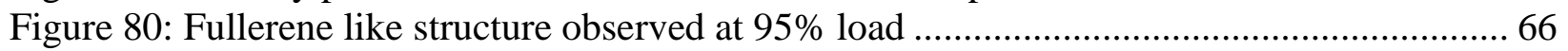

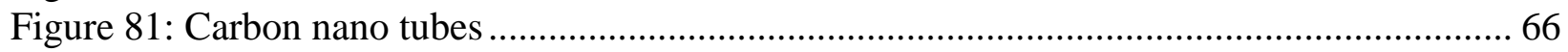

Figure 82: Composition of PM particles observed at full load .............................................. 67

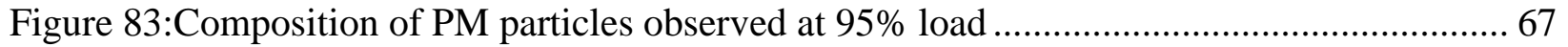

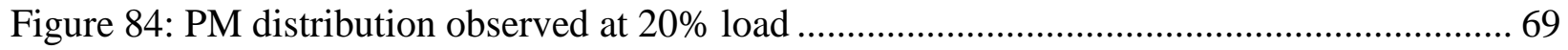

Figure 85: PM distribution observed at full load ............................................................... 70

Figure 86: PM distribution at different loads.................................................................... 70

Figure 87: PM particles observed at baseline 1 test................................................................. 73

Figure 88: Chain like PM particle observed at baseline1 test................................................. 73

Figure 89: Clustered PM particle observed at baseline 1 test ................................................ 74

Figure 90: Chain like PM particle observed at baseline 2 test.............................................. 74

Figure 91: Spherical PM particle observed at baseline 2 test ................................................. 75

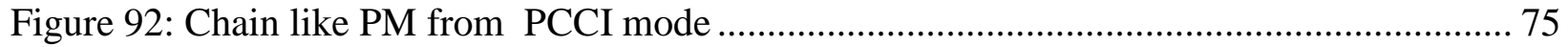

Figure 93: Spherical PM particle from PCCI mode............................................................... 76

Figure 94: PM with branches observed at PCCI mode.......................................................... 76

Figure 95: Variation of maximum length of PM particles with changes in the projected area equivalent diameter observed at baseline 2 ....................................................................... 77

Figure 96: Variation of maximum length of PM particles with changes in the projected area

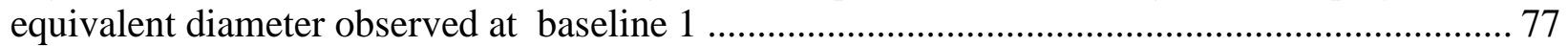

Figure 97: Variation of maximum length of PM particles with changes in the projected area equivalent diameter observed at PCCI mode............................................................... 78

Figure 98: Distribution of the primary particle diameter observed at baseline 1 ...................... 79

Figure 99: Distribution of the primary particle diameter observed at baseline 2 .................... 79

Figure 100: Distribution of the primary particle diameter observed at PCCI mode................... 80

Figure 101: Average diameter of the primary particle of light duty engine ............................. 80

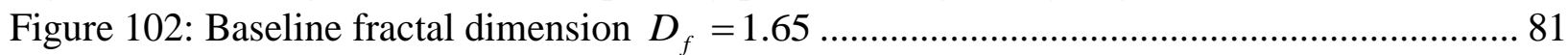

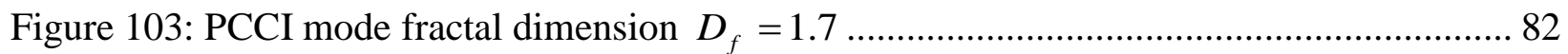

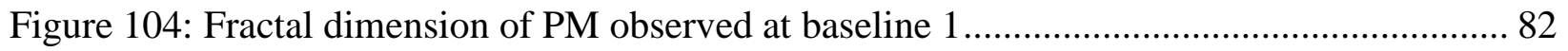




\section{List of Tables:}

Table 1: Specifications of Heavy Duty Diesel Engine ……..................................................... 17

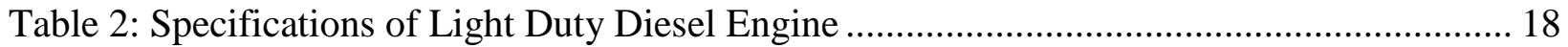

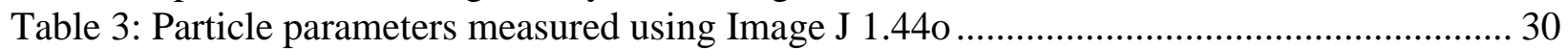

Table 4: Test cycle with performance specification for Mack ${ }^{\circledR}$ MP7-355E engine ...................... 31

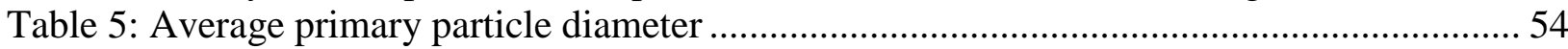

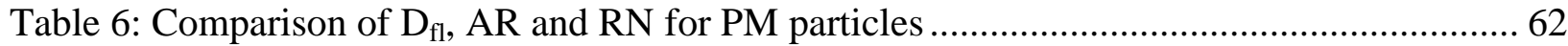

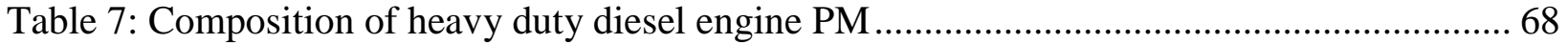

Table 8: Elemental composition of PM particle when operated at full load .................................. 68

Table 9: Number concentration of PM particles ....................................................................... 69

Table 10: Comparison of average size measured by SEM and geometric mean diameter

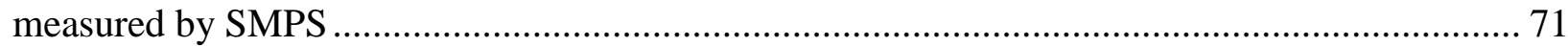

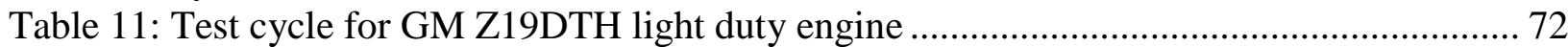

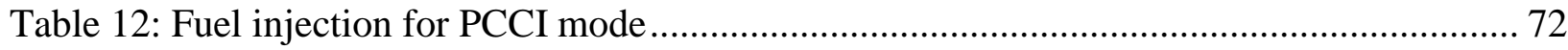

Table 13: Average primary particle diameter for light duty engine ........................................... 81 


\section{Nomenclature:}

$\mu \mathrm{m}$ : Micro meter

A/F: Air fuel ratio

Bhp-hr: Brake horse power hour

BXX: \% of biodiesel in diesel

CA: California

CFR: Code of Federal Regulation

CFV: Critical flow venturi

CMD: Count mean diameter

CO: Carbon monoxide

$\mathrm{CO}_{2}$ : Carbon dioxide

CPC: Condensation particle counter

CVS: Constant volume sampler

DI: Direct injection

DMA: Differential mobility analyzer

DMS: Differential mobility spectrometer

DNA: Deoxyribonucleic acid

DOC: Diesel oxidation catalyst

DPF: Diesel particulate filter

DPM: Diesel particulate matter

E: Light intensity after the smoke column

$\mathrm{E}_{0}$ : Light intensity before the smoke column

EAA: Electrical aerosol analyzer

EC: Elemental carbon

EEPS: Engine exhaust particle sizer

EGR: Exhaust gas recirculation

EGT: Exhaust gas temperature

ELPI: Electrical low pressure impactor

FTP: Federal test procedure

g/bhp-hr: Grams per brake horse power-hour

g/kwh: Grams per kilowatt hour

g/mi: Grams per mile 
HC: Hydrocarbon

HCCI: Homogeneous charge compression ignition

HD: Heavy duty

HEI: Health effects institute

HSDI: High speed direct injection

IARC: International agency for research on cancer

IDI: In-direct injection

ISO: International organization for standardization

$\mathrm{K}$ : Extinction coefficient

KW: Kilo watt

L: Length

LD: Light duty

LII: Laser induced incandescence

L: Liter

LTC: Low temperature combustion

MEXA: Motor exhaust gas analyzer

MOUDI: Micro-orifice uniform deposit impactor

NIOSH: National institute for occupational safety and health

nm: Nano meter

$\mathrm{NO}_{2}$ : Nitrogen dioxide

$\mathrm{NO}_{\mathrm{x}}$ : Oxides of nitrogen

NREL: National Renewable Energy Laboratory

OC: Organic carbon

${ }^{\circ} \mathrm{C}$ : Degree centigrade

OFR: Oxygen to fuel ratio

PAH: Polycyclic aromatic hydrocarbon

PCCI: Premixed Charge Compression Ignition

PM: Particulate matter

PN: Particle number concentration

ppm: Parts per million

ROS: Reactive oxygen species

RPECS: Rapid prototyping electronic control system

SEM: Scanning electron microscope 
SF: Shape factor

SMPS: Scanning mobility particle sizer

$\mathrm{SO}_{2}$ : Sulfur dioxide

$\mathrm{SO}_{3}$ : Sulfur trioxide

SOF: Soluble organic fraction

SUV: Sports utility vehicle

TCM: Temperature control module

TDC: Top dead center

TEM: Transmission electron microscope

THC: Total hydrocarbon

ULSD: Ultra low sulfur diesel

US EPA: United States environmental protection agency

VF: Volatile fraction 


\section{Chapter 1}

\section{Introduction and Objective}

\subsection{Introduction}

Diesel engines have gained popularity among the commercial transport sector because of the high efficiency, high power density, excellent durability and torque characteristic of these engines. The main byproducts of combustion include carbon dioxide $\left(\mathrm{CO}_{2}\right)$, carbon monoxide (CO), total hydrocarbons (THC), oxides of nitrogen $\left(\mathrm{NO}_{\mathrm{x}}\right)$ and particulate matter (PM). PM refers to the exhaust of the diesel engine in air in the form of small particles or liquid droplets. Diesel engines are responsible for the majority of PM produced by internal combustion engines. Diesel PM has a very complex composition and consists of mainly agglomerated solid carbonaceous material, ash, volatile organic and sulfur compounds. PM has complex shapes and is classified according to their aerodynamic diameter [1].

Numerous lung diseases have been linked with PM [2]. Recent health studies have shown evidence that exposure to PM in the atmosphere results in various adverse health effects ranging from aggravated asthma to increased premature mortality. Elemental carbon is also the second biggest contributor to the global warming [3]. Nanoparticles have the potential to accelerate ozone forming reaction both photo catalytically and thermo catalytically [4].

PM is characterized by three distinct modes; coarse mode, agglomeration mode and nuclei mode. The coarse mode consists of particles greater than $1 \mu \mathrm{m}$ in size. The accumulation mode consists of particles in the size range of $50 \mathrm{~nm}$ to $1 \mu \mathrm{m}$ and the nuclei mode contains ultra-fine particle of size less than $50 \mathrm{~nm}$. The accumulation makes up most of the particle mass. The nuclei mode on the other hand does not contribute much to the mass but contains the majority of the particle number [1]. The ultra-fine particle is more harmful to human health than large particles, because when it is inhaled, it reaches deep into the alveolar regions of the lungs where oxygen is exchanged between blood and air and it can remain suspended inside the lungs for a long time. $\mathrm{PM}_{2.5}$ refers to the particles which have aerodynamic diameter less than or equal to 2.5 microns. $\mathrm{PM}_{2.5}$ can travel long distances and remain suspended in the atmosphere for a long period of time. Ultrafine particles are formed due to high saturation ratios of gas phase particles. DPF's remove the agglomerates which would otherwise provide surface for condensation of gas phase particles [5]. 
Diesel engine emissions have raised concern about the human health and environment and have attracted the attention of researchers and various regulatory agencies. The United States (US) Environmental Protection Agency (EPA) has regulated on-road diesel PM emissions since 1970. Engine manufacturers have been required to reduce the engine out emissions through the optimization of engine design and use of aftertreatment systems like diesel PM filter (DPF). As a result modern engines emit about 90\% less PM than was emitted in the 1970's benefitting from technological improvements such as high injection pressure and the application of aftertreatment systems [1]. DPF systems in modern diesel engines remove most of the PM mass. As a result modern diesel engines equipped with DPF system emit very low PM mass [6].

Numerous commercial instruments are available to measure and characterize PM emissions. Traditional instruments measure PM mass, number and size distribution of the PM particle. Some of the most common methods include electrostatic classifiers, smoke meters, gravimetric analysis etc. [6]. Recent health studies describe the importance of particle size on human health [2]. There is increasing interest among researchers to characterize PM according to their size, shape and microstructure, which can be measured using modern imaging techniques such as transmission electron microscope (TEM) and scanning electron microscope (SEM).

Current PM emission regulations in the United States are based on total PM mass emitted per mile or bhp-hr and air quality standards on mass per unit volume. Neither of these gives any information about the size or number concentration or particles emitted. A lot of voice has been raised over the modern diesel engines, the application of aftertreatment system reduced the total mass of PM emitted but significantly increased the number of PM particles emitted [5]. Researchers have proposed that regulatory agencies impose regulations on the number of PM particles emitted from the engines in future emission regulations [Error! Reference source not ound.].

In light of all the negative effects of PM on health and environment, detailed characterization of PM size and morphology is important for the design of new engine after-treatment systems [8]. 


\subsection{Objectives}

The objective of this study was to investigate the effect of engine load on the morphology of PM particles emitted from a conventional heavy duty diesel engine and a light duty diesel engine working on low temperature combustion (LTC) mode and characterize the PM according to their size, shape and microstructure.

The size and number concentration of the PM was measured with a scanning mobility particle sizer (SMPS) and particle count with the help of a condensation particle counter (CPC) for the heavy duty diesel engine. The morphology including size, shape and microstructure was investigated using TEM and SEM. The SEM images were processed using ImageJ v: $1.44 \mathrm{o}$ to obtain a set of parameters including maximum length of the particle and maximum width of the particle, projected area equivalent diameter, size of primary particle and fractal dimension. The TEM images were processed to obtain the microstructure and the composition of the PM particles. 


\section{Chapter 2}

\section{Literature Review}

\subsection{Introduction}

Air pollution has been recognized as one of the major problems of the twenty first century. Thick brown smog is typical among many urban skylines and is becoming more and more severe due to the ever increasing transportation. The ever increasing number of vehicles is one of the major sources of air pollution [9]. Pollutants include regulated emissions of $\mathrm{CO}, \mathrm{NO}_{\mathrm{x}}, \mathrm{HC}, \mathrm{PM}$ and unregulated pollutants such as sulfur dioxide $\left(\mathrm{SO}_{2}\right)$, polycyclic aromatic hydrocarbon (PAH) etc. One of the major pollutants from diesel engines is PM particles [3]. PM not only affects the respiratory system but also acts as a carrier for other toxic substances which condense on the surface of these particles and are carried in the atmosphere. After extensive health studies, the US EPA recognized PM as a toxic substance and has continued to strengthen regulations on PM emissions. Improvements in diesel engine technology have helped to meet ever increasing regulations on PM and other emissions. Improvements in engine technology including high pressure injection, aftertreatment, fuel formulations etc. have significantly changed the characteristics of the modern diesel engine PM emissions. Numerous health studies suggest that measurements should also include number and size of particles and not only the mass [Error! eference source not found.]. The characterization of PM particle morphology is important because of the health effects associated with inhaling PM of different shapes and sizes. This chapter describes the health effects of PM and previous research done to characterize PM. It also describes the health impact of PM emission and parameters that affect the formation of PM in a diesel engine.

\subsection{Health related effects}

It is common sense that inhaling exhaust gas is bad for the health. Extensive research has been conducted on the health related effects of PM. There are many factors which determine the deposition of PM inside the respiratory system. These include air intake and exhalation rates,

methods of inhalation, relative humidity and geometry of the airways. These parameters vary between individuals and hence it is impossible to accurately predict the deposition of PM in the lungs [9]. 
Lung disease is usually caused by the deposition of particles at any site in the respiratory system which initiates or exacerbates a biological response [10]. Aerodynamic diameter is the single most dominant factor for predicting whether the particle will deposit in the lung or not. It is defined as the diameter of a smooth, unit density sphere that has the same settling velocity as the particle in question [10]. The human respiratory system is very effective in trapping the coarse particles at the entrance ways. However, the ultrafine particles can easily pass through the entrance ways and enter the lung [10].

The ultrafine particles emitted from modern diesel engines have significant effect on human health. Stern et al. identified three diseases for the bronchial and upper respiratory tract associated with PM which includes asthma, bronchitis and cancer [2]. Asthma is caused by the narrowing of airways due to swelling and constriction of muscles caused by the immune system response to PM particles. This response is triggered when the presence of hydrocarbons is detected. The hydrocarbons condensed upon the deposited particles causes the immune system to narrow the entranceway which restrict the amount of harmful hydrocarbon inhaled [11].

Bronchitis occurs as an irritation response to the PM deposited in the respiratory system. The body produces mucus when particles are detected in the bronchial region. The mucus is expelled from the esophagus and trachea. Prolonged exposure to PM causes the body to produce excess mucus which begins to fill the airways. PM has been shown to worsen the preexisting conditions of bronchitis [2].

Fine particles in the range of $0.1 \mu \mathrm{m}$ to $2.5 \mu \mathrm{m}$ deposit in the lung predominantly due to inertial impaction in the large bronchial airways by bypassing the collection at the entranceways and have sufficient momentum to escape the streamlines and deposit on inertial impact [11]. Studies have shown that prolonged exposure to particles of this size range causes bronchial cancer [10]. The factors that affect the deposition efficiency of the PM particle into the lungs include: size, particle mass, morphology, settling velocity etc.

Interstitial lung disease refers to a broad category of lung disease. Chronic silicosis is caused due to the exposure to silica particles. Patients with silicosis are at increased risk for lung cancer. Exposure to PM particles increases the chances of getting lung cancer.

The generation of reactive oxygen species (ROS) causes inflammatory response as well as long term chronic disease [12]. ROS contains radicals which act as strong biological oxidizing agents. 
The hydroxyl radical is one of the strongest ROS known. Jung et al. found that the hydroxyl radical is formed by flame soot particle, black carbon and $\mathrm{PM}_{2.5}$ in a surrogate lung fluid [13] Flame soot particles generate ten times more hydroxyl radicals compared to black carbon [13]. Lung cells normally generate ROS concentrations which are easily oxidized by antioxidants in the body [14]. The nano particles penetrate the interstitium and contact the interstitial macrophages which generate excess ROS which cannot be neutralized by the body's antioxidant defense system. This excess ROS enters the blood stream and leads to cardiovascular dysfunction e.g. chronic obstructive pulmonary disorder (COPD). This results in airway inflammation and interstitial fibrosis.

Soto et al. examined the cytotoxic response of immortalized human epithelial cell to PM. An increased cell death was observed as cells were exposed to nano particles, implicating higher cytotoxicity of PM [15]. The cytotoxic response was not correlated with the total PAH content. The nano particles contained the lowest PAH concentration among the particles tested, but cells exposed to PM exhibited greatest number of death.

Morphology of the PM particles affects the deposition efficiency on the respiratory track [16] and increases the respiratory disease and allergies [17]. Asbestosis is a lung disease caused by inhaling asbestos. Asbestos has two distinct structures: serpentine (in which fiber is curly and flexible) and amphibole (in which fiber is straight, stiff and brittle). Amphiboles are serpentine form. The greater pathogenicity of the amphibole is related to its structure. The serpentine form with its curled and flexible structure is likely to become impacted in the upper respiratory passages and removed by the mucociliary elevator. The trapped particles are gradually leached from the tissue because of greater solubility of the serpentine form than the amphibole form. The amphiboles align themselves in the airstream and are deposited deep into the lungs, where they may penetrate the epithelial cells and reach the interstitium [18].

Mutations are thought to be caused by the formation of DNA adducts. Diesel exhaust particles contain various potent carcinogens and mutagens such as PAHs and nitrated PAHs which induce the formation of DNA adducts. Sato et al. showed a significant increase in the mutation frequency in rat lungs after exposure to diesel exhaust, suggesting that mutations accumulated on lung DNA initiate pulmonary cancer in the rats [19]. One of the most detrimental diseases linked to PM is cancer [2]. Fine particles are capable of penetrating living cells. The toxic substances 
that condense upon the particles mix with the contents of the cells. The immune system attempts to repair the damaged cells caused by the foreign substance, but some of the responses may be prone to error. The damaged cells can quickly divide. This can cause errors in the deoxyribonucleic acid (DNA). At localized sites these damaged cells function with the mutated DNA and cause tumors [2]

\subsection{PM control techniques}

With the increasing pressure to meet the stringent emission regulations imposed for the heavy duty engines, manufacturers have come up with ingenious ways to meet the emission standards. The PM can be controlled at the source of formation (in-situ) or using aftertreatment systems.

There are three ways to control PM emissions from diesel engines:

a) PM emission control through optimization of diesel engine combustion system;

b) Application of advanced combustion concepts such as low temperature combustion (LTC);

c) Application of diesel PM filter and its regeneration;

\subsubsection{Optimization of diesel engine combustion}

PM is formed during the diffusion combustion process of diesel fuel due to the presence of the localized fuel rich mixture under high temperature. The decomposition of diesel fuel under extremely high pressure and high temperature under fuel rich mixture forms PM particles. Hence PM emission can be reduced through better atomization of diesel fuel to form relatively leaner fuel air mixture. Changes in engine design helped to reduce PM emissions during the 1990's. There are different ways to reduce PM by optimizing the combustion process as discussed in the subsequent paragraphs [20].

\section{Increase of fuel injection pressure}

Increasing the injection pressure atomizes liquid fuel to small droplets and improves the mixing of fuel and air. This provides better vaporization of fuel and mixing with air to reduce PM formation. The high pressure also reduces the residence time of fuel spray and provides less time for soot formation [20].

\section{Optimization of combustion chamber}

Increasing the turbulence reduces the PM benefitting from the better mixing of fuel and air. This is achieved either by squish or intake air swirl. Squish is generated by geometric patterns on the 
piston crown while the piston moves up during the compression stroke. Swirl is generated by the positioning the intake port at an angle to the cylinder [20].

\section{Charge air system}

Significant portions of PM emissions is produced during heavy accelerations due to turbo lag when excess fuel is injected into the combustion chamber, but the turbocharger is unable to provide the air demand, which results in rich mixture inside the combustion chamber and enhance the formation of PM in combustion chamber. One way to overcome turbo lag is by the use of variable geometry turbocharger (VGT). VGT can be programmed to deliver variable amount of air depending on the operating condition. Another way to increase the supply of air during low engine speeds is to use a small high pressure turbo for low speeds and a larger turbo for increased air flow during high loads [20].

\subsubsection{Influence of dilution conditions on PM formation}

Current U.S regulations for PM emissions from diesel engines are characterized on a mass basis. However the on-road heavy duty diesel engines that are compliant with current PM regulations generally emit increased PM number count in the nano scale range, yet produce less overall PM mass [5]. In order to comply with the mass standards for PM emissions, PM emissions has shifted to much smaller size distribution which are more harmful to human health as they can be easily deposited deep inside the lungs [10].

Wu et al. investigated the PM evolution from a diesel engine equipped with a DPF inside a full scale primary dilution tunnel and a secondary dilution tunnel just upstream of PM sample filter. PM size distribution was investigated by changing the dilution ratios inside the dilution tunnel. Higher dilution ratio in the primary dilution tunnel resulted in higher particle number and mass concentration due to particle nucleation. High secondary dilution ratio resulted in a decrease in total particle count and mass concentration levels. Increasing the residence time in the primary dilution tunnel resulted in a decrease in mass concentration levels because the particle size distribution shifted towards larger mean diameter. Residence time had a similar effect on PM particles in the secondary dilution tunnel [21]. Dilution conditions have a profound influence on the PM formation. Size distribution of accumulation mode is not influenced by the dilution conditions because majority of the particles in accumulation mode are carbon agglomerates. 
However nano particle distribution is affected by the dilution ratio, dilution temperature, residence time, relative humidity and sulfur content in fuel. Influence of residence time is highest at low dilution ratio and low temperature, with large residence time producing highest concentrations in the nano particle size range. At high dilution ratio and temperature, the nano particle growth decreased and the nano particle size range became small. The nuclei mode particles are formed because of the presence of precursors such as sulfuric acid molecules. The growth rates of nucleated particles depend on the amount of hydrocarbon, sulfuric acid and water vapor available (dilution ratio dependent). It also depends on the vapor pressure over the growing particles (time dependent). In a constant temperature process increasing the dilution ratio reduces the vapor phase concentration of all the exhaust species. This weakens the nucleation of new particles and the driving force for growth. Increasing the dilution temperature reduces nucleation by increasing the vapor pressure of volatile species [22]. Newly nucleated particles grow faster at higher temperature. Nucleation is strong at low temperature. The large concentrations of nuclei formed constitute a large surface area which absorbs the condensing species. At higher temperature nucleation is slow and hence less surface area is available for condensing species. High amount of volatile matter increases the particle growth. More material is shared between few particles [23].

\subsubsection{Low temperature combustion}

With ever increasing standards for PM emission control from the regulatory boards across the world, there is increasing interest among researchers and engine manufacturers to find new ways to meet those emission standards. It is not economical for the engine manufacturers to meet future emission standards using conventional diesel engine technology. New forms of diesel combustion concepts are being developed to meet the future regulations. One such area is the low temperature combustion. LTC concepts include premixed charge compression ignition (PCCI) and homogeneous charge compression ignition (HCCI) etc [24]. A lot of research is underway to characterize emissions from these types of engines as the combustion and emission characteristics are different compared to the conventional diesel [25]. LTC operation is often accompanied by high EGR rates. Kolodziej et al. reported LTC case with high injection pressure had the smallest mean particle diameter of $(38.8 \mathrm{~nm})$ and the most particles are in the nuclei mode. Overall PM mass of LTC mode was much lower than the conventional diesel engines 
[25]. Natti et al. characterized the PM particles using a HSDI diesel engine operated under conventional and LTC regime [24]. Swirl ratios were varied to study their effects on the LTC regime. With the increase of swirl from 1.44 to 2.59 there was a sharp decrease in PM emissions. The increase in swirl however increased the number density. With further increase of swirl ratio to 3.77 there is a big drop in number density after which the number density remains constant. Large accumulation mode PM particles were observed at swirl ratio of 1.44 which was characterized by high soot mass [26]. Swirl ratio 2.59 was observed to be the optimum one with respect to premixing versus heat transfer losses with the conditions used [27]. Lean burning during LTC mode produces extremely low quantities of PM which makes measurement of PM during LTC operation difficult using conventional gravimetric method [28].

\subsubsection{Aftertreatment systems}

\section{Diesel oxidation catalyst}

The soluble organic fraction (SOF) in the PM is oxidized by the DOC with the help of catalyst. The DOC can reduce the PM by oxidizing the SOF and volatile fraction in the PM. There is little effect in the carbonaceous portion of the PM in diesel exhaust. Low sulfur diesel fuels are required to limit the formation of sulfate particles by the catalytic oxidation of sulfur dioxide to prevent the PM precursors [20].

\section{Particle oxidation catalyst}

Particle oxidation catalyst (POC) can be considered as a special DOC with capacity to hold solid soot particles. These devices capture and store soot particles for a period of time for sufficient catalytic oxidation. Unlike DPFs which get clogged if there is insufficient regeneration, the POC have flow through passages which allow the passage of the exhaust gases even if the soot holding capacity of the POC is saturated [20].

\section{Diesel particulate filter}

DPF captures PM from exhaust and oxidize them. Pores in the filter collect PM and allow gases to pass. The collected PM is oxidized later-on through a regeneration process. Regeneration can be passive or active [20]. Passive regeneration removes the PM via a catalyst agent applied on the filter media to oxidize the PM to carbon dioxide. During active regeneration the collected soot is oxidized using external heat source such as fuel or electric heater. 
Although DPF's are very effective in reducing PM (in excess of 90\%), regeneration is a challenge especially at low loads when the exhaust temperatures are low. The increased backpressure created by the DPF also has a negative effect on fuel economy [20].

\subsection{PM measurement}

Considering the influence of all the physical and chemical process involved, it is important to monitor all the parameters involved during sampling process to obtain representative samples, interpret the results, and ensure repeatability [29]. Numerous commercial aerosol measuring instruments have been developed to measure the PM emissions of diesel engines. The equipment that qualitatively measure PM emission includes smoke meters and opacity meters. The size and number distribution of PM particles are commonly measured by low pressure impactor including micro-orifice uniform deposit impactor (MOUDI), scanning mobility particle sizer (SMPS), differential mobility spectrometer (DMS), and electric low pressure impactor (ELPI). Measurement of morphology including size, shape and microstructure of PM particles can be measured using advanced imaging techniques like SEM and TEM. Figure 1 shows the measurement ranges of the instruments described. It can be seen that more than one instrument is required to measure the entire range of diesel engine emission [30].

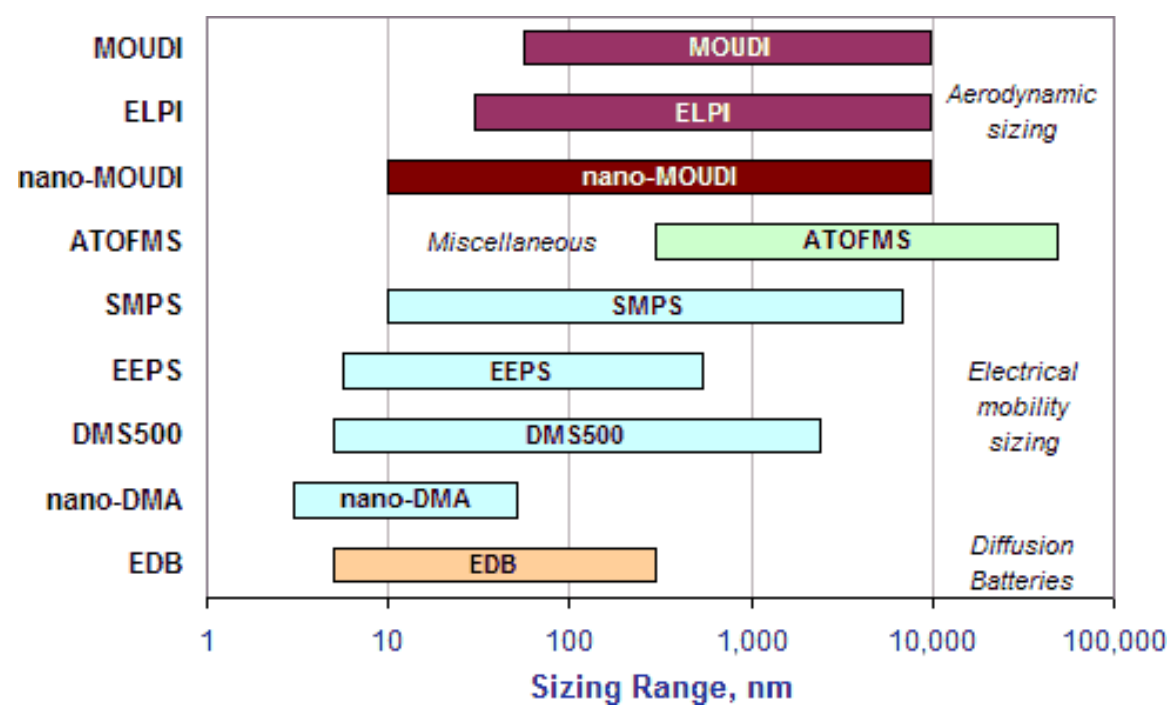

Figure 1: Measurement range of instruments [30].

\section{Smoke meter and opacity meter}

Smoke meter and opacity meter both measure PM emissions by examining the optical properties of diesel engine exhaust. The principle of operation is the extinction of light beam by scattering 
and absorption. These instruments are commonly used in field testing because of low cost and simple design. Opacity is the fraction of incident light which is adsorbed or scattered by the smoke. Opacity is calculated using the Equation 1.

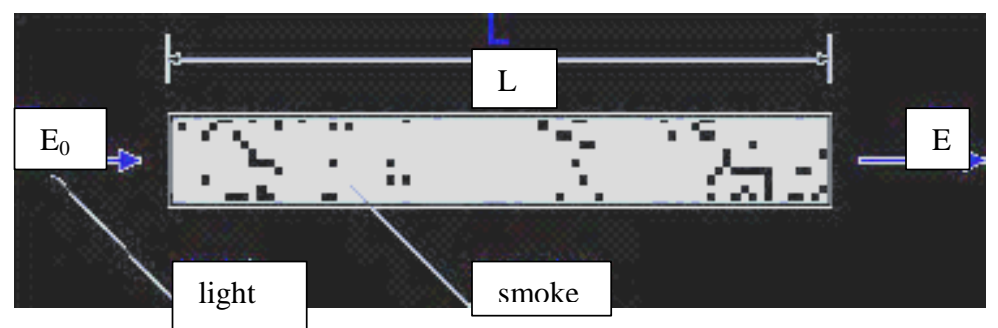

Figure 2: Opacity meter working principle [31]

Opacity $=1-\mathrm{E} / \mathrm{E}_{0}=1-\exp [-\mathrm{KL}]$. Equation 1

Where:

$\mathrm{E}_{0}$ : light intensity before the smoke column, $\mathrm{W} / \mathrm{cm}^{2}$,

$\mathrm{E}$ : light intensity after the smoke column, $\mathrm{W} / \mathrm{cm}^{2}$,

$\mathrm{K}:$ extinction coefficient, $1 / \mathrm{cm}$,

L : light path length, $\mathrm{cm}$.

A zero point reading in the instrument corresponds to clean air and $100 \%$ corresponds to infinite smoke. There are some drawbacks in this type of instrument. These instruments cannot accurately measure emissions from modern low emission engines. Also the aftertreatment systems fitted to modern engines increases the percentage of $\mathrm{NO}_{2}$ which absorb green light from the smoke meter. This produces an error in the reading from the instrument. The opacity meter is insensitive to the ultrafine particles emitted from the modern engines especially when a DPF is employed. The reading from this instrument is not as accurate as measurement from gravimetric analysis especially when the emission of PM is low [31].

\section{Cascade impactor}

MOUDI is a commonly used cascade impactor. It has 10 stages which can be altered that provide mass weighted size distribution of an aerosol [32]. Measurements are not real time. MOUDI measurements are not very accurate and comparison between MOUDI and gravimetric measurements show difference up to a factor of 3 [33]. 
Electrical low pressure impactor (ELPI) uses a cascade impactor and can measure PM in the range of 7- $10000 \mathrm{~nm}$. Not all particles are charged uniquely according to size and not all particles of a given size are collected on each impactor plate which results in error in measurement [34].

\section{SMPS}

SMPS consists of electrostatic classifier and a condensation particle counter (CPC). The electrostatic classifier has a differential mobility analyzer which segregates aerosols based on their electrical mobility diameter. CPC is used to count the number of particles in the mono disperse aerosol stream. The instrument has a scan time of about 2-4 min based on size intervals. The instrument is very sensitive to large particles $>1.0 \mu \mathrm{m}$ in diameter and these must be removed in the pre-classification stage [30].

\section{DMS}

Differential mobility spectrometer measures the size of PM particles based on their electrical mobility. It consists of particle charger, classification column and series of detectors. The classification is done at subatomic pressure to increase the detection range of the instrument. Current readings produced by deposition of charged particles in the electrodes are converted to particle number concentration. Different electrical strength in the electrodes corresponds to different mobility diameter of the particles [35].

\subsection{Investigation of PM using electron microscope}

Further technical improvement of particulate emission control systems require precise information about the micro morphology, microstructure and oxidative behavior of the PM particles emitted from modern diesel engines. Su et al. studied soot from modern diesel engine with Euro 4 standards and a black smoking diesel engine [36]. TEM images revealed that the soot from the modern engine consisted of primary particles with multiple shell structure (fullerene like). The morphology of the soot from the diesel engine consisted of smooth outer structure indicating long reaction time to reach a minimum energy condition. The fullerene like structure of the soot from the modern diesel engine makes it more reactive than the more stable black soot and as a result the oxidation temperature for the fullerene is less than the oxidation temperature of black soot [36]. Greico et al. suggested that the formation of fullerene carbon 
particles by the deposition of gas phase species of HC particularly PAHs on soot particles followed by the internal rearrangement of solid phase carbon. Fullerene formation depends on the residence time in the flame and the formation increases with longer residence time [37]. SEM and TEM can be used to explore the size, shape and microstructure of PM particles emitted from diesel engines. For example, Mustafi et al. investigated the PM from a dual fuel engine using SEM and TEM [38]. SEM is used to determine the number and size distributions, and the shape of the measured PM emitted from the diesel engine operating in both modes. TEM is used to investigate the primary particle diameters of the measured PM. Images obtained were analyzed using public domain image processing software ImageJ, Version 1.381. TEM micrographs revealed that the mean primary diameter was less than $30 \mathrm{~nm}$. As the engine load increased during diesel operation, the primary diameter decreased slightly. The growth of primary particle depends on the competition between oxidation and nucleation [38, 39]. Both nucleation and oxidation depends on combustion temperature. Temperature was the main factor which caused the difference in primary diameter during low load and high load diesel operation. At high load the high temperature enhances the oxidation process which in turn reduces nucleation process, hence the size of the primary particle decreases $(28 \mathrm{~nm}$ to $26.4 \mathrm{~nm}$ ). Number size measurement revealed that all the measurements were bimodal irrespective of the fuel used. All the distributions had a distinct nuclei mode and accumulation mode, except the high load using diesel which had an accumulation mode and a coarse mode. During high load operation a small amount of SOF is produced which contributed to nuclei mode particles.

Shape analysis of the PM agglomerates is done by best fitting ellipses around the PM agglomerates and the calculating the shape factor (SF) from the major and minor axis of the ellipses [40]

$$
\mathrm{SF}=\mathrm{L}_{\text {minor }} / \mathrm{L}_{\text {major } \ldots \ldots \ldots \ldots \ldots \ldots \ldots \ldots \ldots \ldots \ldots \ldots \ldots \ldots \ldots \ldots \ldots \ldots \ldots} 2
$$

Where, $\mathrm{L}_{\text {minor }}=$ length of minor axis

$\mathrm{L}_{\text {major }}=$ length of major axis

A spherical particle has a SF equal to 1.0 and as the SF decreases the particle becomes more elongated and chain like. The SF value of PM particles at high load was about 0.5 indicating more chain like agglomerates. The amount of volatile fraction (VF) in diesel operation at low load was much higher than that of high load operation. During dilution VF cools down and 
causes nucleation. During high load SOF is more effectively oxidized and almost no nucleation mode PM is present [38].

Zhu et al. investigated the particle morphology, microstructures, and fractal geometry for a diesel engine-simulating combustor [41]. A unique thermophoretic sampling device was developed to collect PM samples and a TEM was used to characterize the PM samples [42, 43, 44, 45]. A laboratory scale burner was used to produce the PM particles which had similar characteristics to the PM emitted from a diesel engine. The PM was studied under various air/fuel (A/F) ratio and different flame temperatures. The researchers identified several advantages of using the in house developed thermophoretic device over commercially available instruments. One of the main advantages included direct collection of soot without any air dilutions and external forces during particulate sampling, no extra treatments for subsequent TEM analyses. For each flame condition around 200 primary particles were selected at random.

The average diameter of the primary particle measured under stoichiometric and fuel rich condition were $14.7 \mathrm{~nm}$ and $14.8 \mathrm{~nm}$ respectively. The measured size was smaller than the size of the diesel PM from both heavy duty and light duty diesel engines which produced (28.5-34.4 $\mathrm{nm})$ and (19.4-32.5 nm) respectively. Radius of gyration was used to measure the physical dimension of the aggregate particle. The particles produced under fuel rich conditions were 47.5 $\mathrm{nm}$ which was smaller in size than those produced under stoichiometric condition $83.8 \mathrm{~nm}$. Although the peak flame temperature was highest for the stoichiometric condition, a large number density (295) of the primary particle at stoichiometric condition possibly increased the agglomeration which increased the aggregate particle size. The fractal dimensions of aggregate particles under stoichiometric condition was 1.88 which was similar to that of a heavy duty diesel engine, whereas the fractal dimension under fuel rich condition was 1.65, which was similar to that of a light duty diesel engine [42].

Zhu et al. investigated the effects of exhaust gas recirculation (EGR) on morphology of PM emitted from a light-duty diesel engine [39]. A rapid prototyping electronic control system (RPECS) was developed to operate a 1.7 liter light duty engine at various EGR rates under different conditions (i.e. constant boost pressure, constant oxygen-to-fuel ratio (OFR)). The PM samples were directly collected from the exhaust manifold after the exhaust valves using a unique thermophoretic sampling device [42, 43, 44, 45]. The collected samples were analyzed 
using a TEM and particles were characterized for the primary particle size, aggregate particle size and fractal geometry. In order to study the dilution effect and the thermal effect of EGR on combustion, EGR was varied under constant boost pressure and constant OFR [39].

In this research, the SEM and TEM were used to investigate the size, shape and microstructure of PM particles emitted from heavy duty and light duty diesel engine. SEM was used to study the size and shape of the PM particles, diameter of primary particles and the TEM was used to investigate the microstructure of the PM particles and the composition of PM. 


\section{Chapter 3}

\section{Engine and Experimental Setup}

\subsection{Heavy duty diesel engine and dynamometer}

The test engine used in this study was a MY2004 Mack® MP7-355E heavy-duty diesel engine featuring a high-pressure loop EGR system and a VGT. Detailed engine specifications are provided in Table 1

Table 1: Specifications of Heavy Duty Diesel Engine

\begin{tabular}{|l|l|}
\hline Model & MACK MP7-355E \\
\hline Configuration & 6 cylinders, Inline \\
\hline Aspiration & Sliding Nozzle Variable Turbocharger / Intercooler \\
\hline Injection System & Dual Solenoid Electronic Unit Injector (EUI) \\
\hline Maximum Torque & $1844 \mathrm{Nm} @ 1200 \mathrm{RPM}$ \\
\hline Maximum Power & $355 \mathrm{bhp} @ 1800 \mathrm{RPM}$ \\
\hline Displacement & $10.8 \mathrm{~L}$ \\
\hline Compression Ratio & $16.0: 1$ \\
\hline Bore \& Stroke & $122.94 \mathrm{~mm} \times 151.89 \mathrm{~mm}$ \\
\hline Emission regulation & $\mathrm{NO}_{\mathrm{x}}: \leq 2.5 \mathrm{~g} / \mathrm{bhp}-\mathrm{hr}, \mathrm{PM} \leq 0.1 \mathrm{~g} / \mathrm{bhp}-\mathrm{hr}$ \\
\hline
\end{tabular}

The MY2004 Mack® MP7-355E heavy duty engine was installed on a General Electric direct current dynamometer which was capable of absorbing $800 \mathrm{hp}$ shown in Figure 3 . The drive shaft of the dynamometer was connected to the output shaft of the engine through the flywheel coupling. The power from the engine was converted to direct current electricity by the dynamometer which was then converted to alternating current electricity and fed onto the commercial power grid. The dynamometer measured torque by means of a calibrated load cell located at a known distance from the axis of revolution of the dynamometer. 


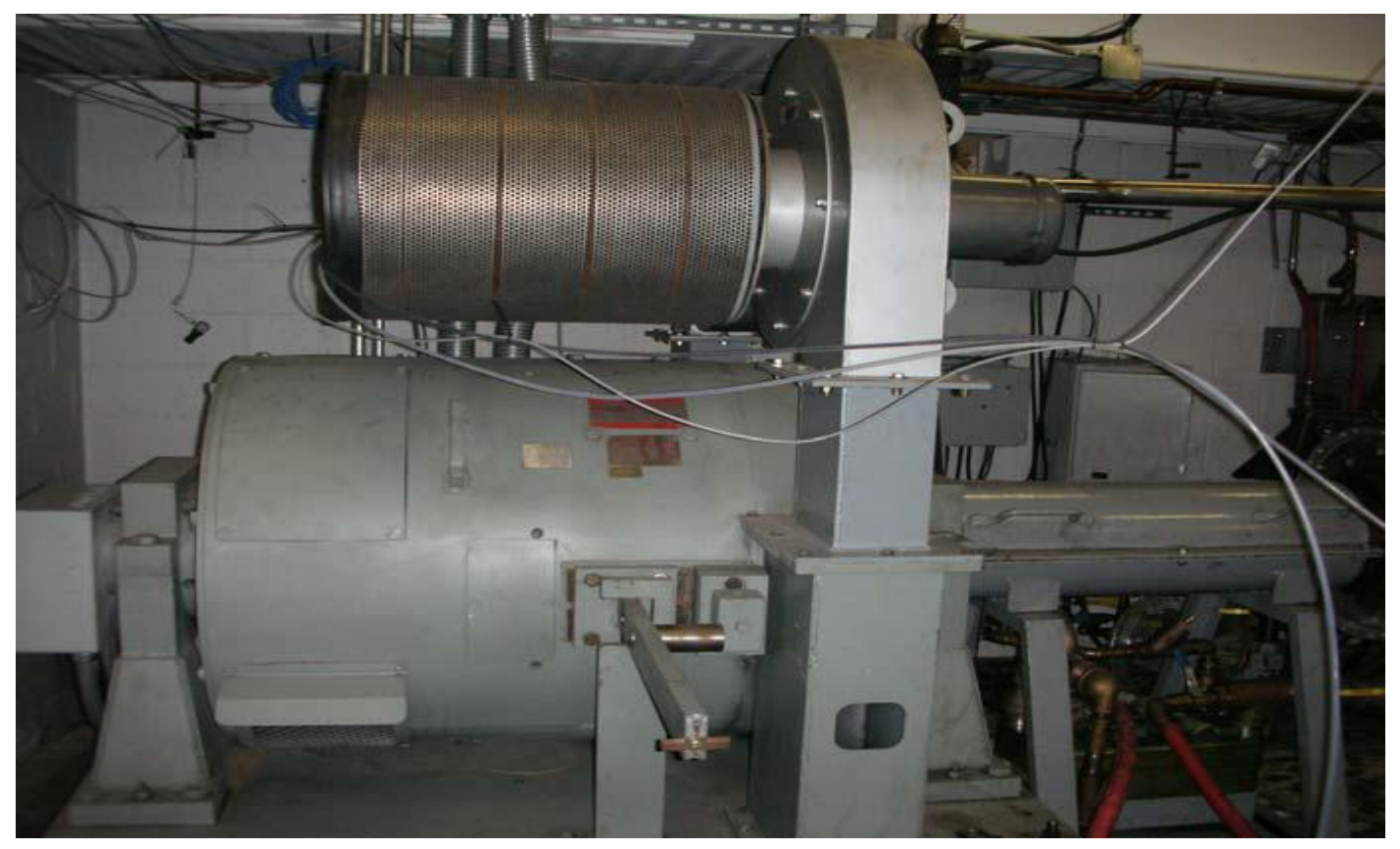

Figure 3: General Electric 800 hp dynamometer

\subsection{Light duty engine and dynamometer}

A General Motors model Z19DTH 1.9L compression ignition engine was chosen as the light duty engine for the experiment. Its rated power is $89 \mathrm{~kW}(119 \mathrm{hp})$. The engine was manufactured by the European division of General Motors and used in small coupes and sedans. The engine was coupled to a Medsker Electric Inc. alternating current dynamometer as shown in Figure 4. The specification of the engine is given in Table 2. The maximum torque produced by the engine was $326 \mathrm{Nm}$ at $2000 \mathrm{rpm}$. The fuel injection used was an electronically controlled Bosch EDC 16C9 high-pressure common rail direct fuel injection system to deliver fuel to each cylinder.

Table 2: Specifications of Light Duty Diesel Engine

\begin{tabular}{|c|c|}
\hline Engine Model & GM Z19DTH \\
\hline Displacement & $1.9 \mathrm{~L}$ \\
\hline Cylinders & 4 \\
\hline Bore \& Stroke & $82 \mathrm{~mm} \times 90.4 \mathrm{~mm}$ \\
\hline Compression Ratio & $18: 1$ \\
\hline Valves/Cylinder & 4 \\
\hline Fuel Injection & Bosch Common Rail \\
\hline Turbocharger & Garret VGT \\
\hline EGR & Cooled \\
\hline
\end{tabular}




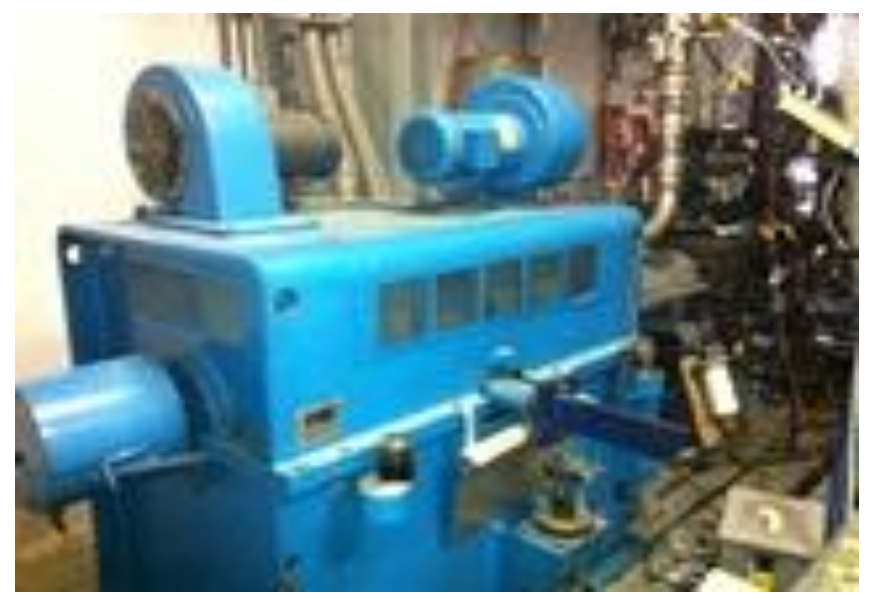

Figure 4: Medsker Electric Inc. alternating current dynamometer

\subsection{Emission measurements}

The sampling system was built according to CFR 40 part 1065 regulations. The total system consisted of full flow dilution tunnel, heated sampling lines, temperature control units and gas analyzers. The temperature of the heated lines was controlled by temperature control modules (TCM) and flow rate of the exhaust gas sampled was controlled by rotameters and magnahelic pressure regulators. The diluted exhaust gas was sampled through probes and transferred through heated lines to Horiba MEXA 7200D to measure the concentration of the exhaust gas.

The exhaust from the engine was mixed with conditioned dilution air in the primary dilution tunnel. The sample extracted from the primary dilution tunnel was used to measure $\mathrm{HC}, \mathrm{CO}$, $\mathrm{NO}_{\mathrm{x}}$ and $\mathrm{CO}_{2}$ emissions from the engine. The dilution tunnel was constructed of 316 stainless steel. A secondary dilution tunnel was used to provide additional conditioning of the exhaust for collecting the PM emissions.

Ambient air was taken from the atmosphere and passed through high efficiency purified air (HEPA) filters to remove as many particles as possible. HEPA filters are capable of removing 99.97\% of airborne particles larger than 0.3 microns. The filtered air was then conditioned by passing through an air conditioning unit to remove humidity by causing the water vapor to condense. The humidity was measured by use of a General Eastern chilled mirror. The intake air was kept at approximately $50 \%$ relative humidity and $25^{\circ} \mathrm{C}$. Figure 5 shows the SSV CVS dilution system. The primary dilution gases were diluted again by passing through a secondary dilution system where the PM was collected. The system consists of a 1 inch heated line that serves as a secondary dilution tunnel. 


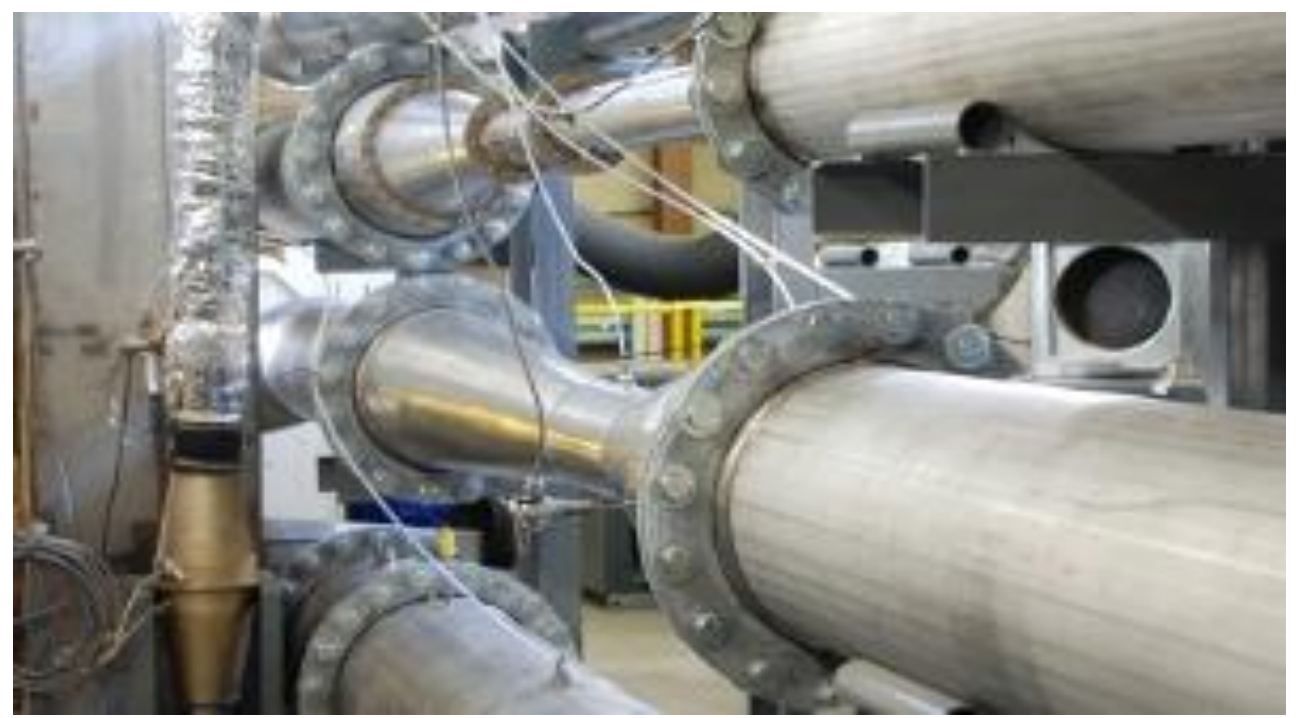

Figure 5: Full scale dilution tunnel constant volume sampling system

The PM sampling system consists of plumbing, cyclone (2.5 micron cut size), $47 \mathrm{~mm}$ filter holder, solenoid valves, bypass system, mass flow controllers and electronics which were placed in a heated enclosure which maintained the filter face temperature at $47 \pm 5{ }^{\circ} \mathrm{C}$ in accordance with 40 CFR 1065.140(e). The secondary dilution system can be seen in Figure 6. The SEM and TEM grids were placed on a $47 \mathrm{~mm}$ filter holder and placed inside the secondary dilution to collect the samples. The filter holder with the grids is shown in Figure 7. The SEM grid was made of silicon. The TEM grid was made of carbon coated copper material.

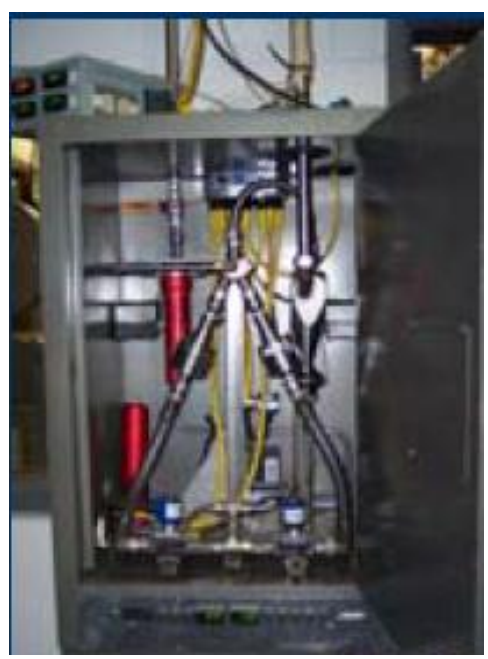

Figure 6: Secondary dilution tunnel for PM collection 


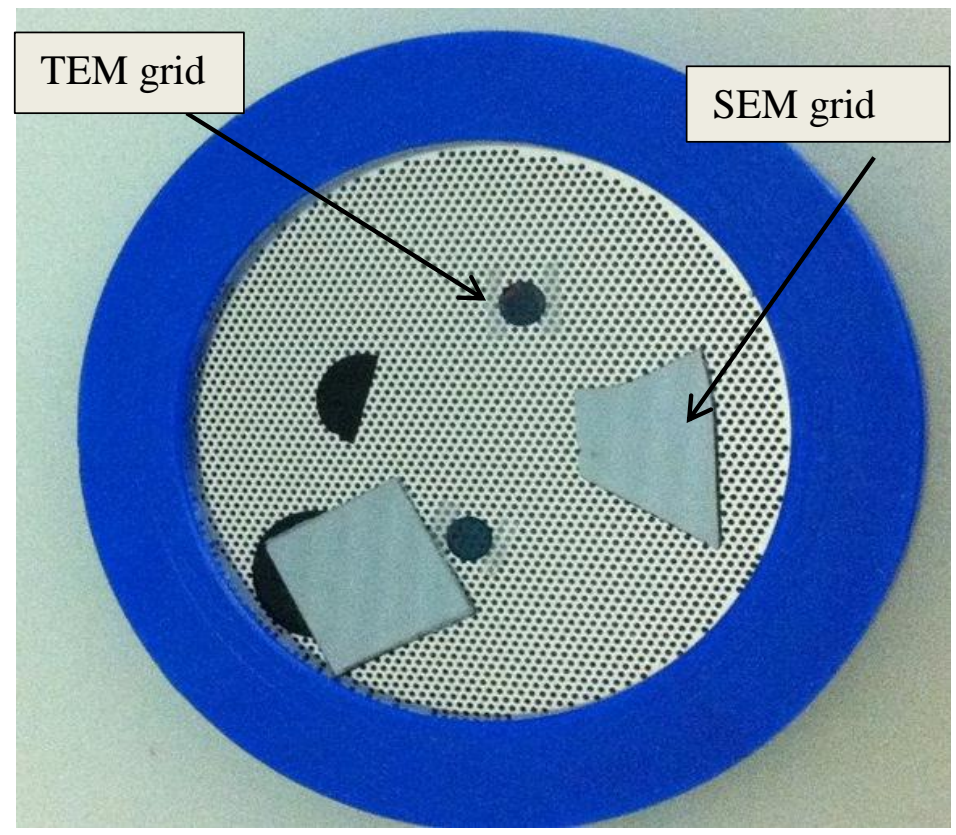

Figure 7: Filter holder with SEM and TEM grids

\subsection{Scanning mobility particle sizer}

An SMPS was used to measure the size distribution of aerosols from the heavy duty engine. The SMPS used a TSI model 3081 long differential mobility analyzer (DMA) as the electrostatic classifier (EC) and a condensation particle counter to measure the concentration of the aerosol. The poly disperse aerosol enters the EC after passing through the impactor which removes particles larger than 1 micron. The aerosols are charged and passed between the electrodes of the EC along with sheath air. The particles get precipitated on the electrode depending on their electrical mobility. The particles are classified by the classifier according to the charge discharged [47]. The aerosols are passed through saturated butanol vapor in the CPC where butanol condenses on the particles and the size of the particles increases. These particles move through a light source thereby scattering it onto a photo detector which in turn produces electrical signal proportional to the number of particles [48].

\subsection{Scanning electron microscope}

A field emission JSM-7600F SEM manufactured by JEOL was used in this study to characterize the morphology of the PM. This SEM employs a field emission (T-FE) electron gun. In contrast to thermionic emission in which electrons are emitted from surface of metals, oxides or borides when they are heated to high temperatures, field emission generates electrons from the surface of 
a sharp pointed emitter made of metals, oxides or carbides when a strong electric field is present at the surface [49].

The SEM magnifies specimens from hundreds to several hundred thousand times. A finely focused electron beam scans and impinges on the surface of the specimen, which emit secondary electrons from the surface. An SEM image is formed by detecting the secondary electrons. The finer the electron probe, the higher is the resolving power. A fine probe can reach deeper into the surface of the specimen and enhance the resolution of the image. As shown in Figure 8, SEM consists of an optical system including electron gun, condenser lens and objective lens for generating electron probe, a specimen stage for supporting the specimen, a secondary electron detector for detecting the secondary electrons, a display apparatus and an operating system for performing the various operations. The optical system and specimen stage is maintained at vacuum. The Figure 9 shows the SEM used to characterize the PM particles from both heavy duty and light duty engine.

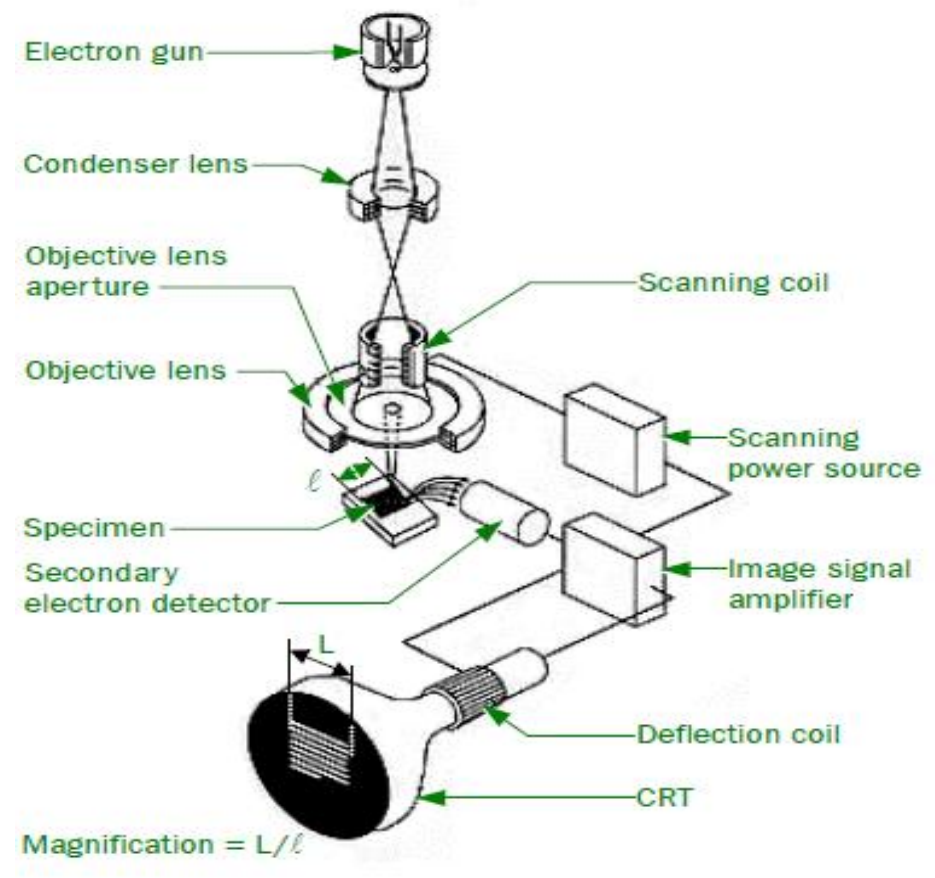

Figure 8: Schematic diagram of SEM [49] 


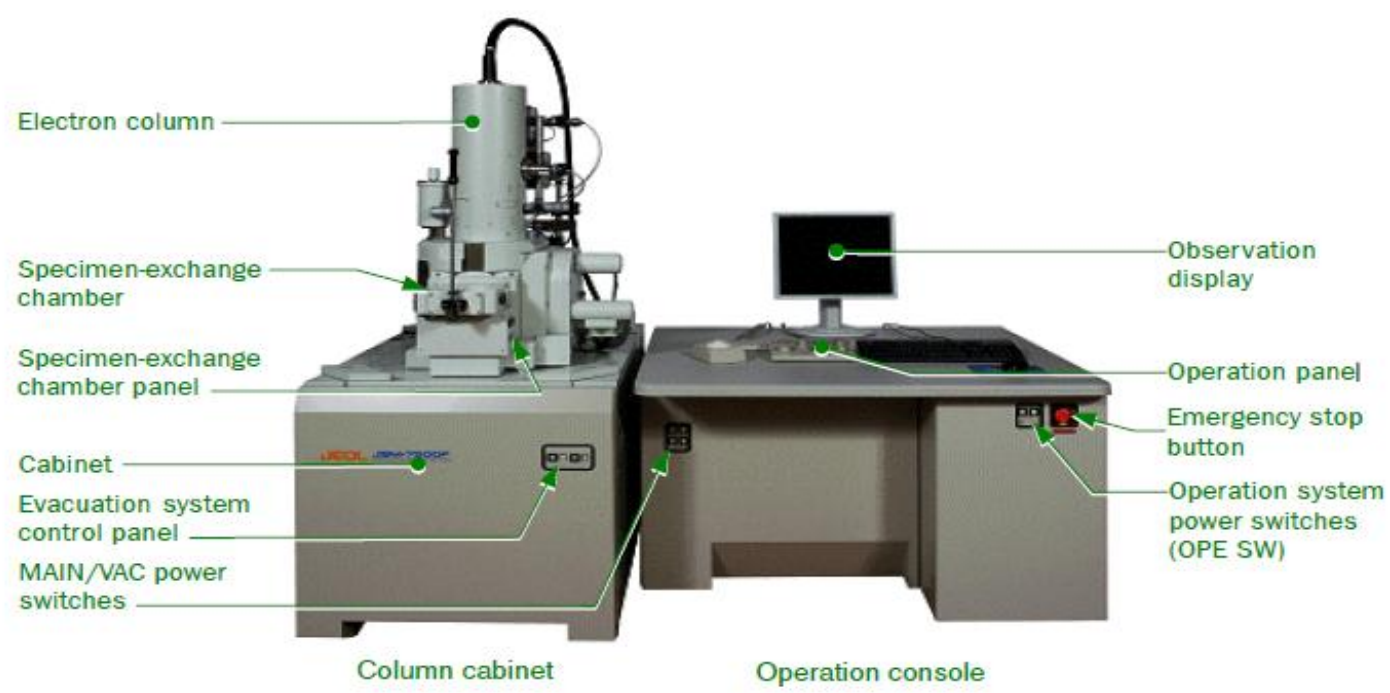

Figure 9: JEOL JSM 7600F SEM [49]

\subsection{Transmission electron microscope}

A JEM 2100 transmission electron microscope manufactured by JEOL as shown in Figure 10 was used to investigate the microstructure PM particles. This TEM has a thermionic $\mathrm{LaB}_{6}$ element filament for the production of the electron beam. The accelerating voltage is $200 \mathrm{kV}$ [50].

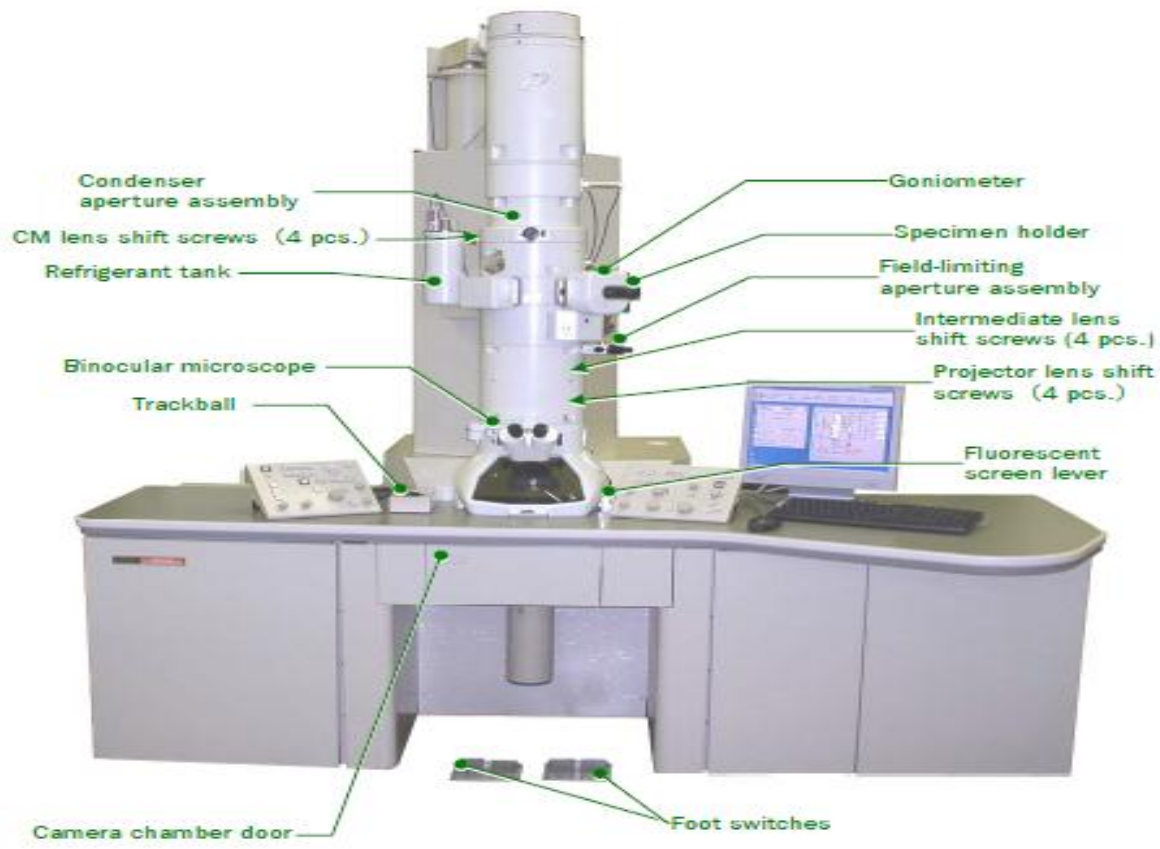

Figure 10: JEOL JEM-2100 TEM [50] 
TEM has very high magnification capabilities because of the operating principle of the device. TEM sends a beam of electrons through an ultra-thin specimen. The image is formed through the interaction of electrons transmitted through the specimen. The image is magnified and focused onto an imaging device, such as a fluorescent film or to be detected by a charge coupled device (CCD) camera. The small wavelength of the electrons allows for high magnification. The Figure 11 shows the layout of the optical system of the TEM used for this study. It consists of emission gun, condenser lens and a CCD camera for viewing.

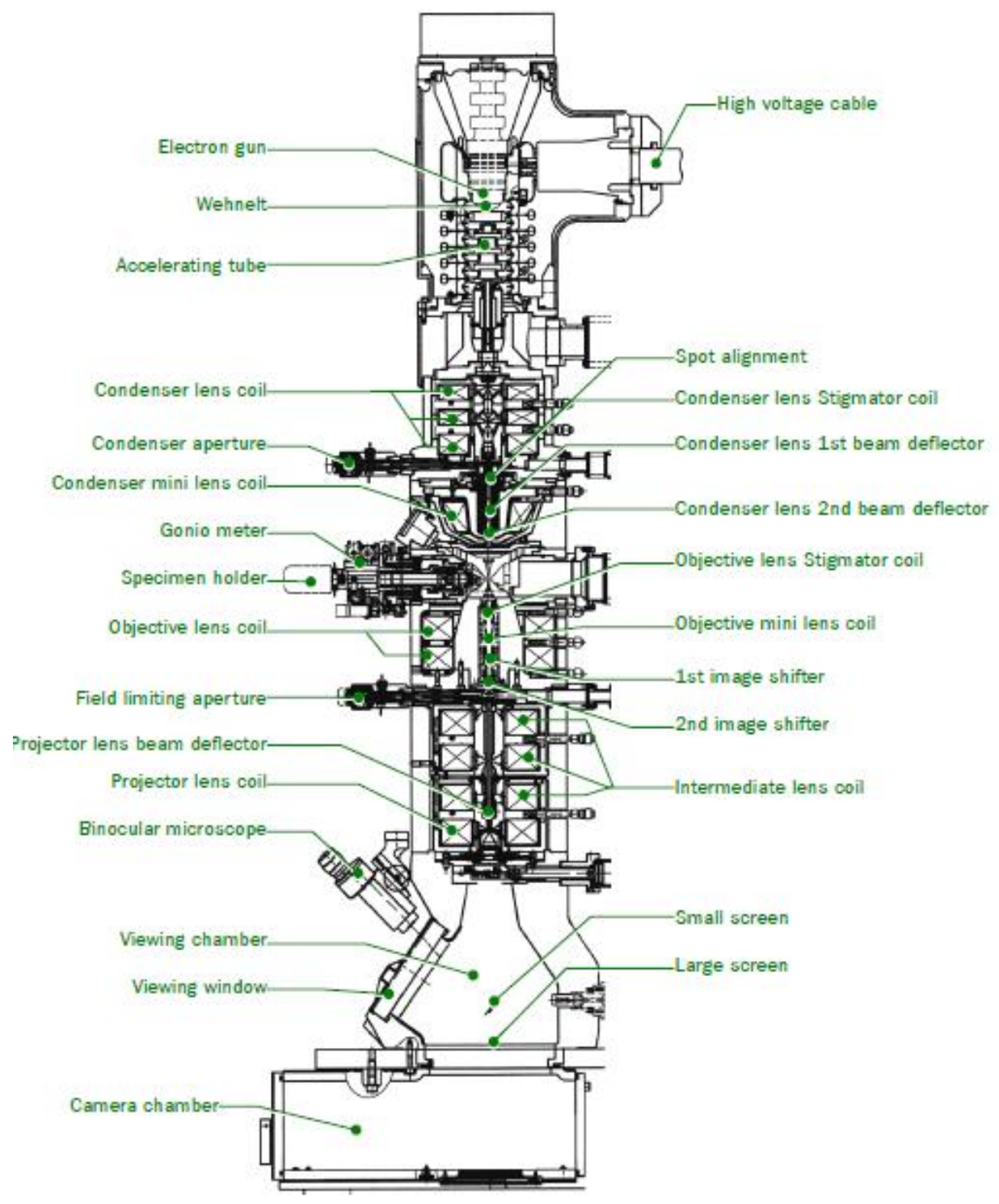

Figure 11: Layout of the TEM [50] 


\section{Chapter 4}

\section{SEM image processing}

\subsection{Image processing software ImageJ V: 1.44o}

The SEM images obtained in this research were analyzed using public domain image processing software Image $\mathrm{J}$ version $1.44 \mathrm{o}$ to obtain a set of PM parameters including the maximum projected length, maximum projected width, projected area and fractal dimension. ImageJ is a java based image processing software developed by the National Institutes of Health (NIH). This software can read the TIFF format of the SEM images and can edit, analyze and process 8bit, 16 bit and 32 bit images. The Figure 12 shows the major parameters measured using ImageJ.

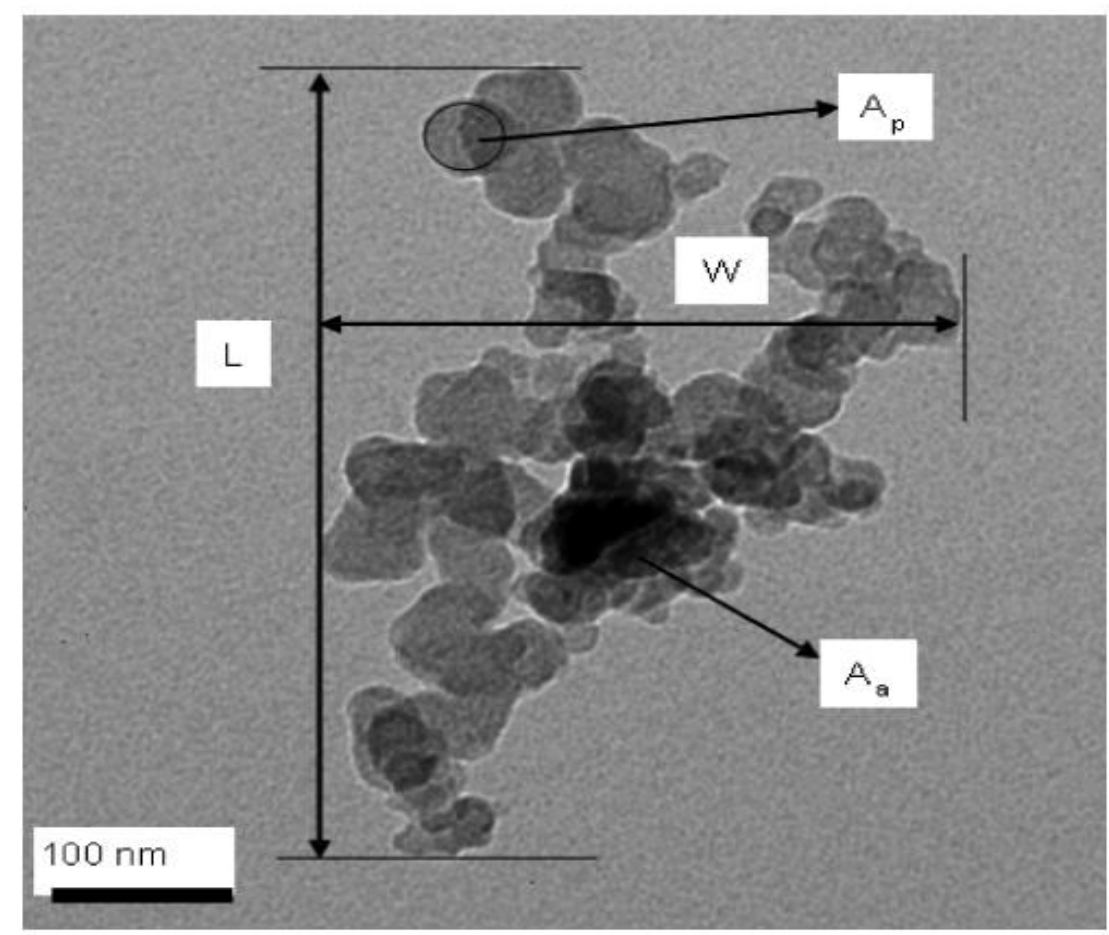

Figure 12: Projected imageand parameters measured: $A_{a}$ : projected area of the agglomerate, $A_{p}$ :area of primary particle, $L$ : maximum length of the PM particle, $W$ : maximum width of the PM particle [51] 


\subsection{Calculation of projected area}

The projected area was used to calculate the projected area equivalent diameter of the PM particle. The diameter calculated in this way was close to the mobility diameter of the particles up to the range of $50-220 \mathrm{~nm}$ [46]. The method of calculating projected area is shown below.

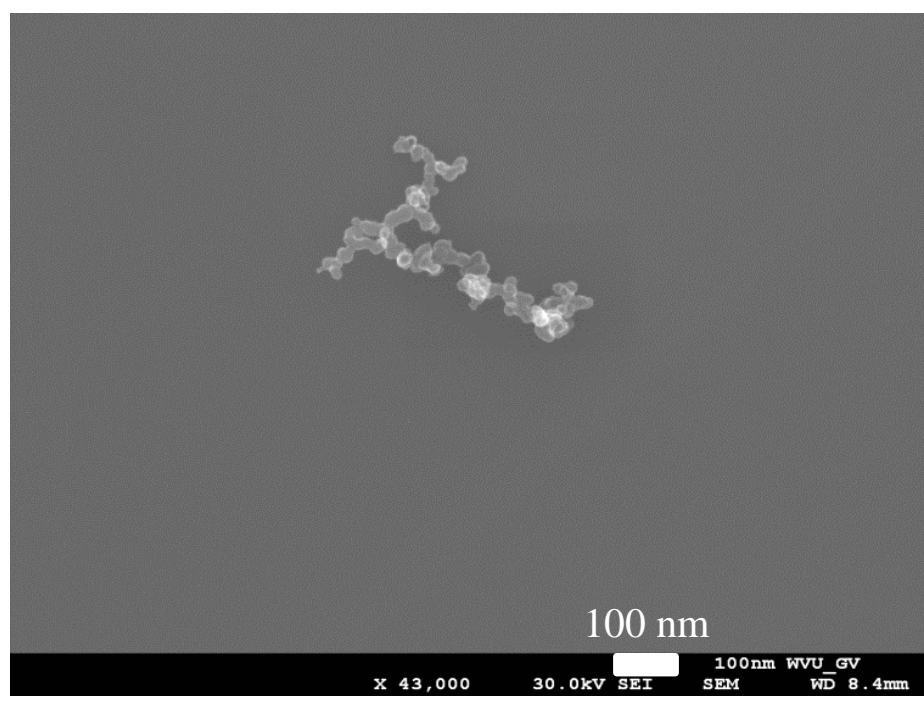

Figure 13: PM particle when operated at 90\% load as seen under SEM

$$
L_{\text {max }}=805.9 \mathrm{~nm} \text { and } W_{\text {max }}=563.0 \mathrm{~nm}
$$

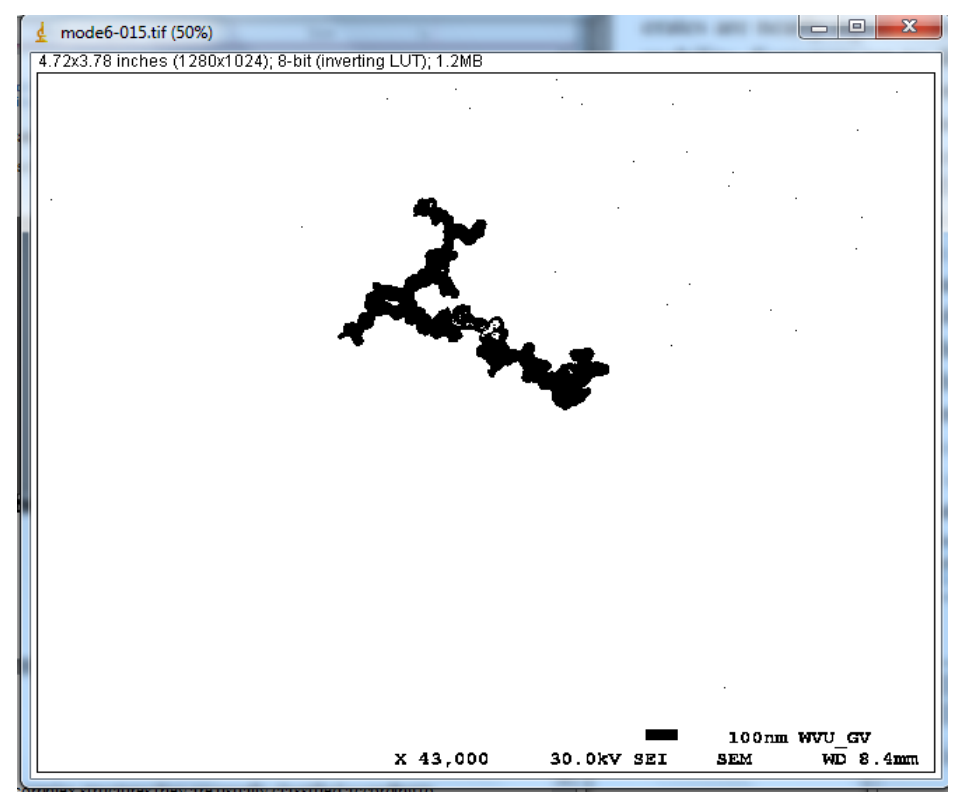

Figure 14: 8 bit binary image with adjusted threshold

First the original image as shown in Figure 13 is converted to 8 bit binary image, which is a black and white image used for calculation. Scale is defined for measurement purpose. Then the threshold of the binary image is adjusted so that the original particle to be analyzed is selected. 
The transformed binary image can be seen in Figure 14. Finally the area of the particle is calculated by selecting the particle and projecting the outline of the image. The area is calculated by using the defined scale. The area of the particle is displayed along with the outline as seen in Figure 15.

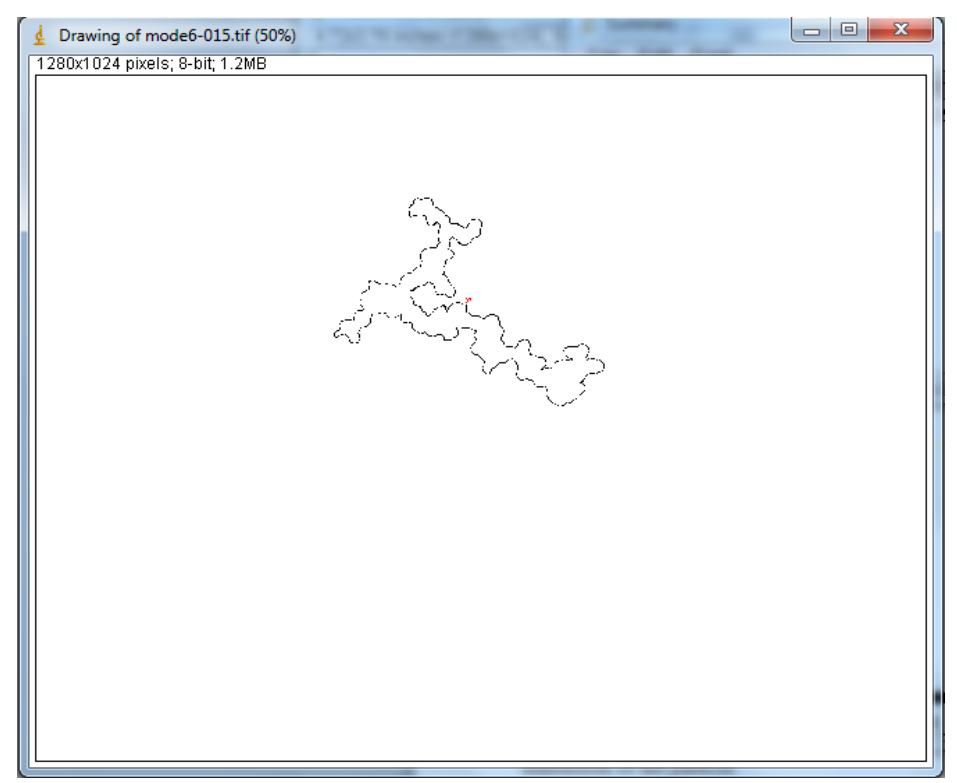

Figure 15: Outline of the binary image with $A_{a}=107396.2 \mathrm{~nm}^{2}$

\subsection{Calculation of projected parameters}

The PM shape parameters calculated from the projected area include: projected area equivalent diameter, fractal dimension, aspect ratio and roundness

\section{Projected area equivalent diameter}

The projected area equivalent diameter is defined as the diameter of an imaginary circle having an area equal to the projected area of the particle in question. In this research the projected area equivalent diameter is calculated using Equation 3.

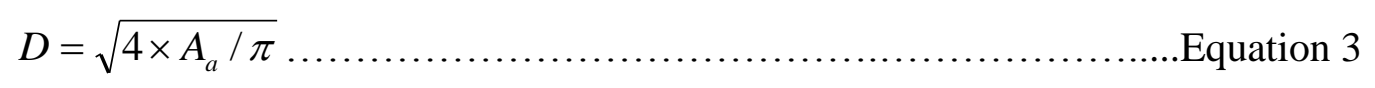

\section{Fractal dimension}

Because the PM particles possess complex structures they are usually classified according to their fractal dimension $D_{f l}$ defined as a statistical quantity that gives an indication of how completely a fractal appears to fill the space. Fractal dimension can be calculated based on either 
the radius of gyration or the maximum projected length of the particle. The fractal dimension of the agglomerates based on the maximum projected length is used in this research.

In this research the fractal dimension is defined as the slope of the linear fit in a plot of $\ln (n) \mathrm{vs}$ $\ln (\mathrm{L} / \mathrm{d})$ [52]. The fractal dimension of the agglomerates based on the maximum projected length is used in this study instead of fractal dimension based on radius of gyration. In order to determine the fractal dimension one has to first find the number of primary particles in the agglomerate. The number of particles can be approximated from the projected image using Equation 4 [52].

$$
n=k_{a}\left(A_{a} / A_{p}\right)^{\alpha}
$$

Where $A_{a}$ is the projected area of the agglomerate, $A_{p}$ is the average projected area of the primary particles, $k_{a}$ an empirical constant and $\alpha$ is an empirical exponent. The value of $\alpha=1.09$ was used in this study, which was determined for cluster- cluster aggregation [53]. The value of $k_{a}$ was taken as 1 [53].

Fractal dimension is calculated using Equation 5. Fractal dimension based on maximum projected length is used in this study instead of fractal dimension based on radius of gyration. The two have related and can be interchanged [54].

$$
D_{f l}=\frac{\ln (n)}{\left[k_{l} \times \ln \left(L_{\max } / d_{p}\right)\right]}
$$

Where $d_{p}$ is the primary particle diameter, $k_{l}$ is the proportionality constant.

Fractal dimension ranges from a scale of 1 to 2 . The value 1 representing elongated chain like structure and the value 2 representing a compact structure. For example, Figure 16 shows a compact PM particle from $50 \%$ load with $D_{f l}=1.83$. The branches in the PM are attached in a way that they form a near spherical structure. Figure 17 shows a long chain like PM particle produced during $40 \%$ load with $D_{f l}=1.5$. 


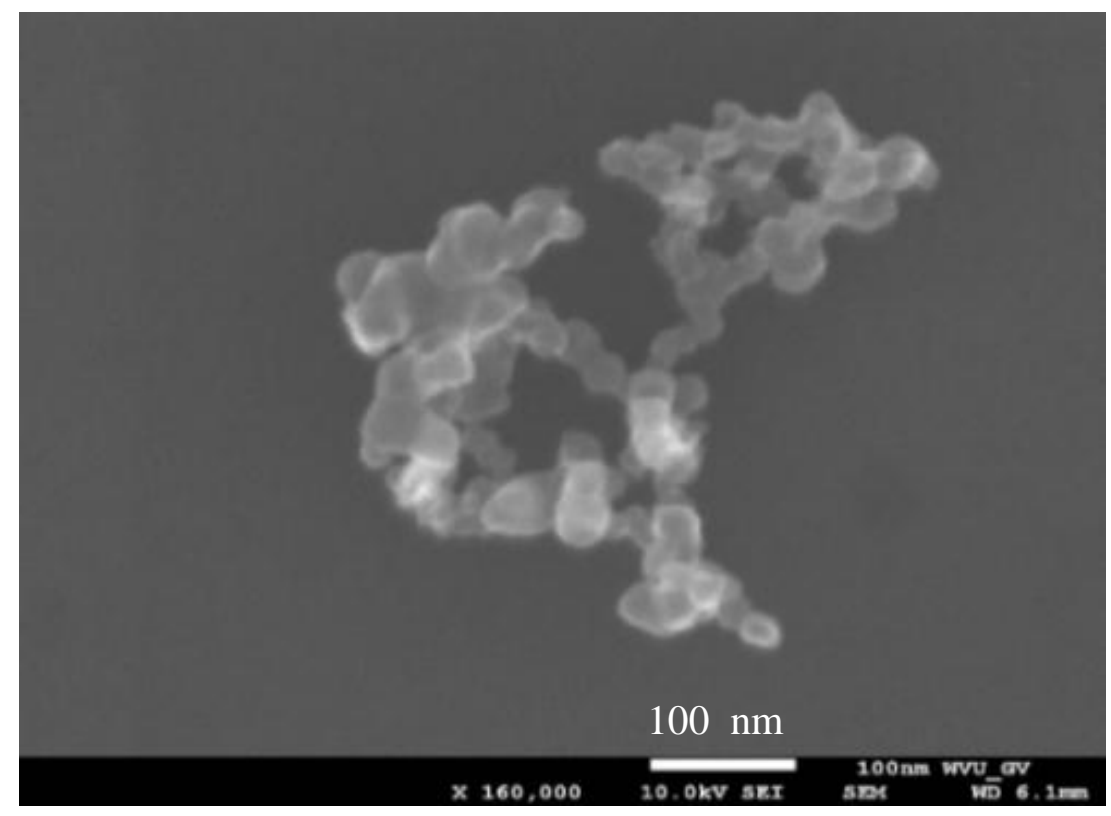

Figure 16: PM from 50\% load with $D_{f l}=1.83$

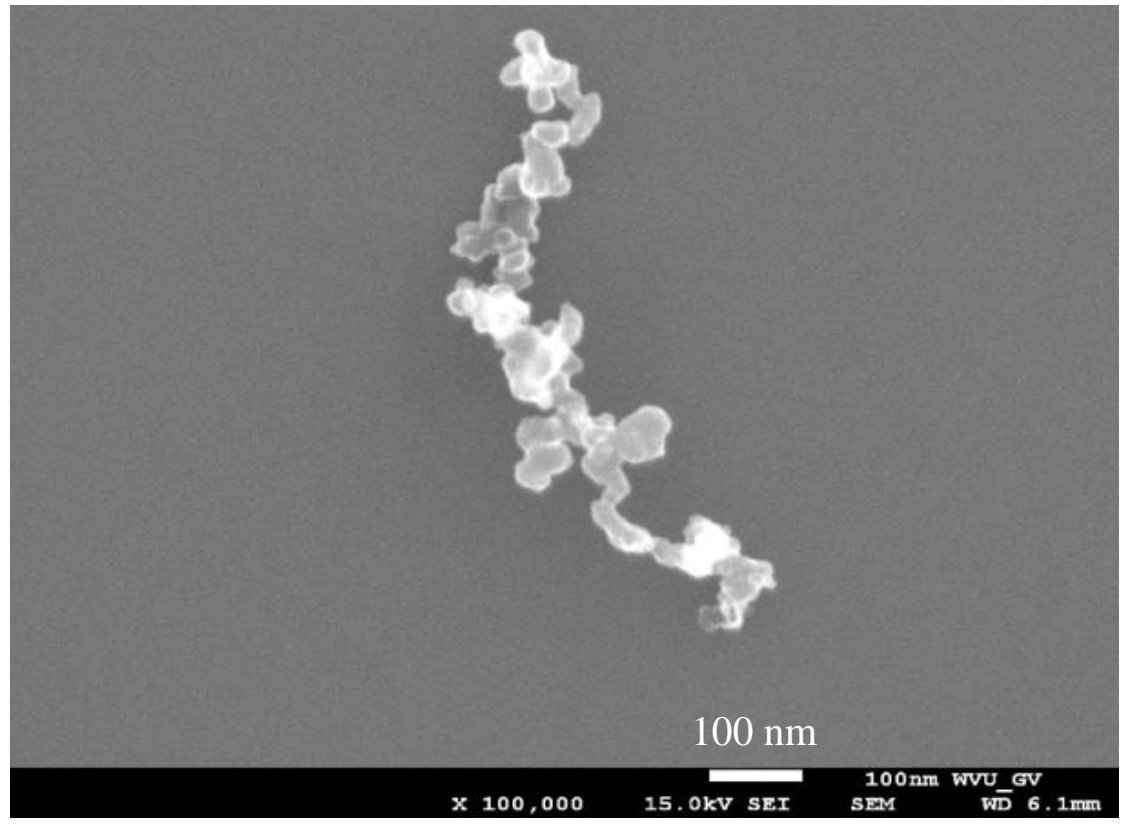

Figure 17: PM from 40\% load with $D_{f l}=1.5$

\section{Aspect ratio}

Aspect ratio is proportional to elongation and is calculated using the Equation 6.

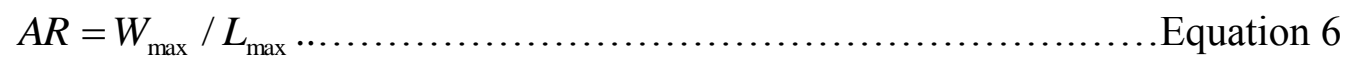

Where $W_{\max }$ is the maximum projected width and $L_{\max }$ is the maximum projected length 


\section{Roundness}

Roundness is also proportional to the elongation of the particle and is calculated as

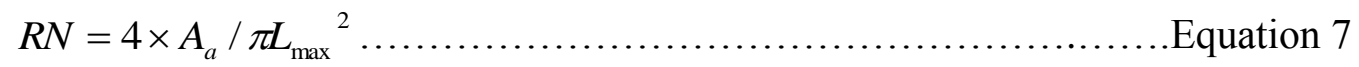

Figure 18 is an example of PM particle where the projected parameters obtained using the software are shown in Table 3.

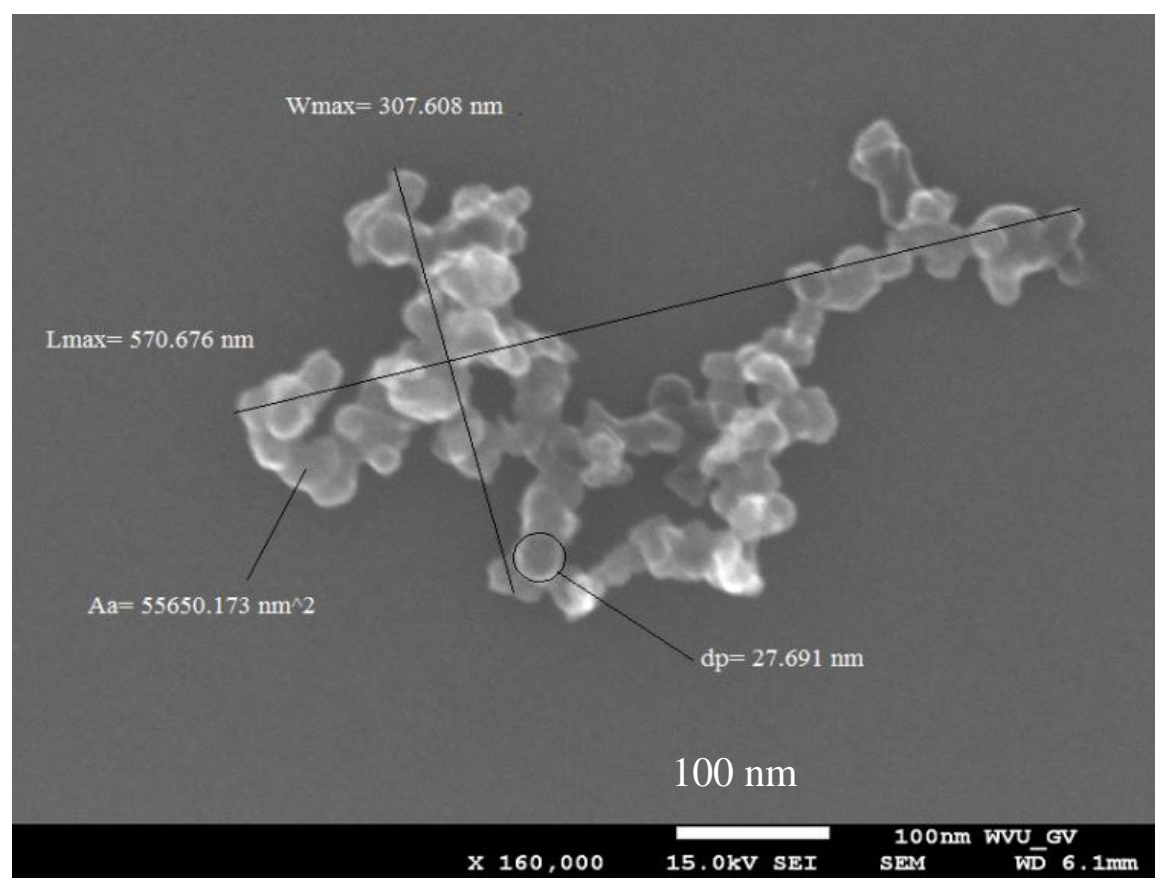

Figure 18: Projected parameters calculated from projected area of PM particle when engine was operating at full load

Table 3: Particle parameters measured using Image J 1.44o

\begin{tabular}{|c|c|c|c|c|c|c|c|}
\hline $\mathrm{L}_{\max }(\mathrm{nm})$ & $\mathrm{W}_{\max }(\mathrm{nm})$ & $\mathrm{A}_{\mathrm{a}}\left(\mathrm{nm}^{2}\right)$ & $\mathrm{d}_{\mathrm{p}}(\mathrm{nm})$ & $\mathrm{D}_{\mathrm{fl}}$ & $\mathrm{n}$ & $\mathrm{AR}$ & $\mathrm{RN}$ \\
\hline 570.6 & 307.6 & 55650.1 & 27.7 & 1.7 & 146 & 0.53 & 0.23 \\
\hline
\end{tabular}




\section{Chapter 5}

\section{Morphology of PM Particles of Heavy Duty Diesel Engine}

\subsection{Test cycle}

Steady state test were conducted for the measurement of PM. An 8 mode steady state test shown in Table 4 was conducted using a Mack® MP7-355E engine.

Table 4: Test cycle with performance specification for Mack® MP7-355E engine

\begin{tabular}{|c|c|c|c|c|c|c|c|c|}
\hline Mode & 1 & 2 & 3 & 4 & 5 & 6 & 7 & 8 \\
\hline Speed(rpm) & 1500 & 1500 & 1500 & 1500 & 1500 & 1500 & 1500 & 1500 \\
\hline Load (\%) & 20 & 40 & 50 & 60 & 75 & 90 & 95 & 100 \\
\hline Torque(Nm) & 332 & 664 & 831 & 997 & 1274 & 1472 & 1548 & 1662 \\
\hline BMEP (KPa) & 386 & 772 & 967 & 1161 & 1482 & 1713 & 1801 & 1933 \\
\hline
\end{tabular}

\subsection{Featured PM particle morphology of heavy duty engine}

The images of diesel PM from the heavy duty engine were observed using a SEM. The typical particles at different loads are shown in Figures 19-36. The images are taken at a magnification of X 160000 and accelerating voltage of $15.0 \mathrm{kV}$. It can be seen that all the PM particles are made up of individual spherical primary particles.

Figure 19 shows a coarse particle having a length of $L_{\max }=23.2 \mu m$ and projection area equivalent diameter of $D=16.4 \mu \mathrm{m}$. This particle is much larger than the PM particles formed inside the engine which usually varies from few nano meters to one micron in size [1]. It was believed that the particle was formed inside the dilution tunnel due to aging and was dislodged from the tunnel due to inertial impact of fast flowing dilution gas during testing. These particles were formed when different accumulation mode PM particles coalesce to form bigger chains accompanied by the condensation of volatile fraction on the surface of accumulation mode PM particles. Figure 20 is a coarse particle observed at full load with $L_{\max }=3.6 \mu m$ and $D=2.1 \mu m$. These large coarse particles will affect the PM mass results measured by gravimetric methods as they are much larger than the PM particles formed inside the engine. The presence of such 
particles will significantly affect the gravimetric analysis of PM from engines equipped with DPF or engine operated with LTC concept.

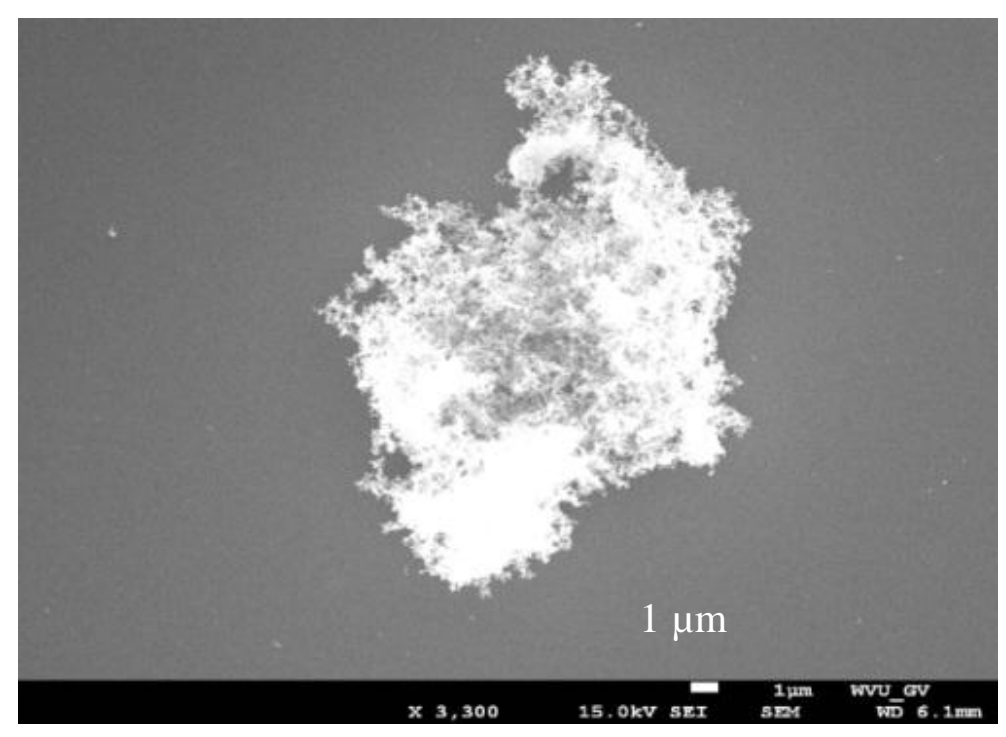

Figure 19: Coarse particle observed at 40\% load $L_{\max }=23.2 \mu \mathrm{m}$ and $D=16.4 \mu \mathrm{m}$

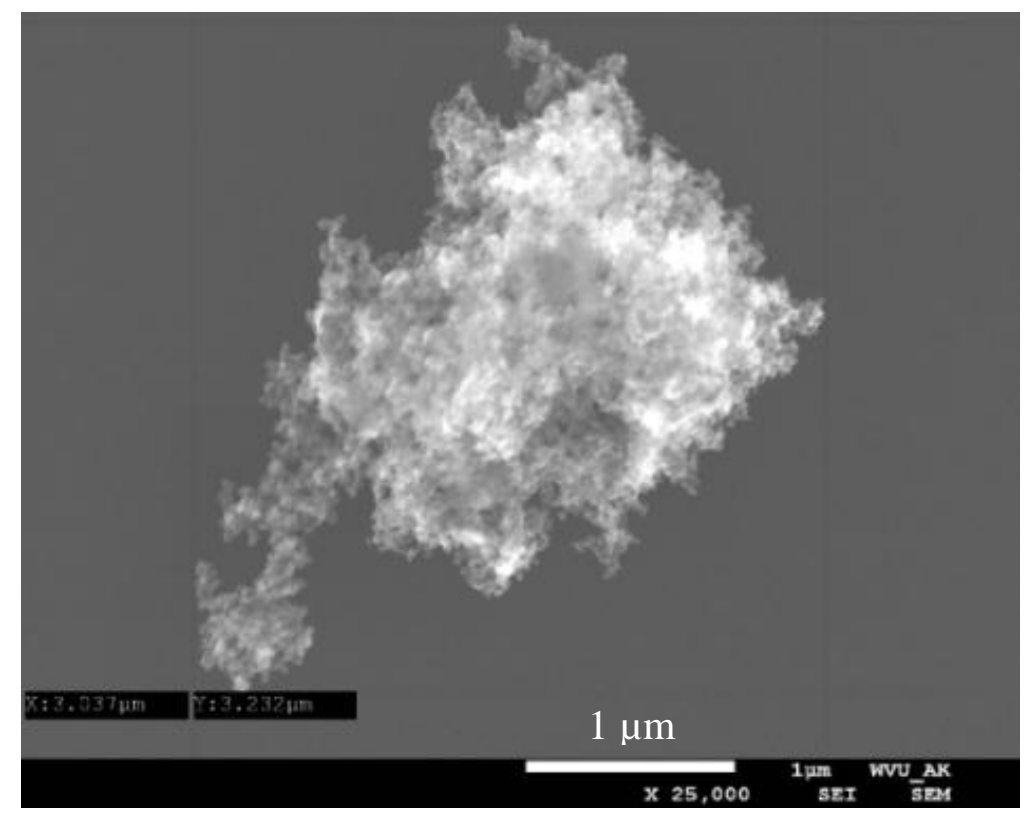

Figure 20: Coarse particle observed at full load $L_{\max }=3.6 \mu \mathrm{m}$ and $D=2.1 \mu \mathrm{m}$

Figure 21 is also coarse mode particle formed inside the tunnel measured at $95 \%$ load with branched chains attached to the main body to form elongated structure with $L_{\max }=1.19 \mu m$ and $D=621 \mathrm{~nm}$. 


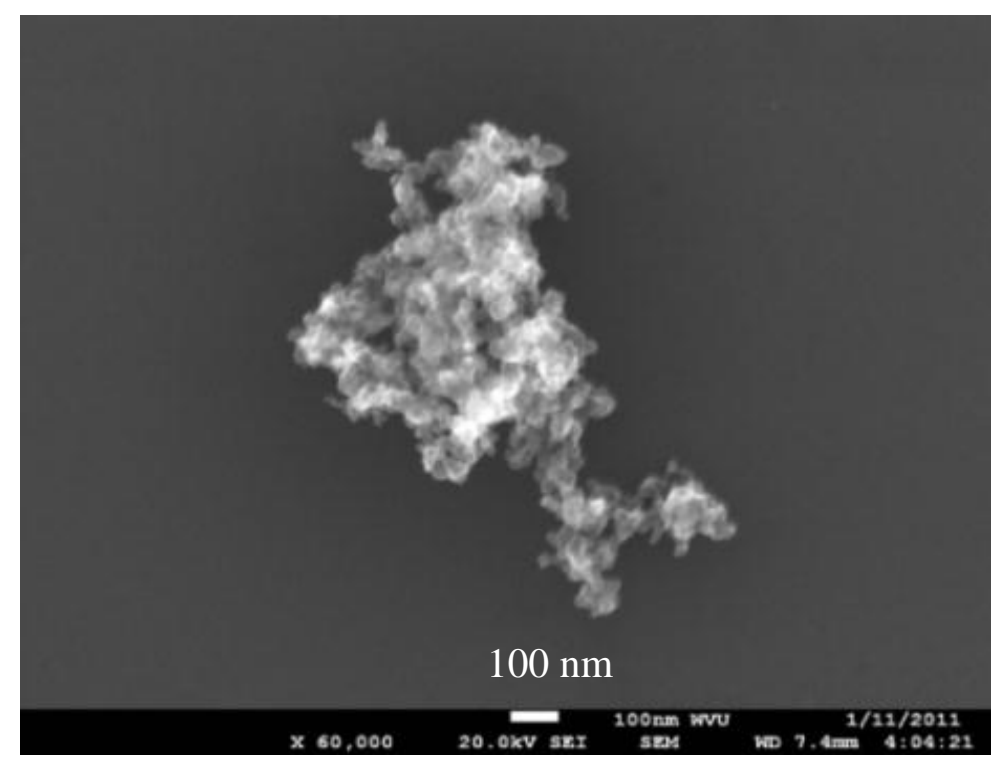

Figure 21: Large PM particle with branches observed at $95 \%$ load with $L_{\max }=1.19 \mu m$ and

$$
D=621 \mathrm{~nm}
$$

Figure 22 is a PM particle observed at 50\% load. There are two distinct bodies attached by a narrow branch. This PM particle may have been formed due to inertial impact of two different particles inside the tunnel. The maximum length of the particle is $L_{\max }=1.02 \mu m$ and the projection equivalent diameter is $D=652 \mathrm{~nm}$.

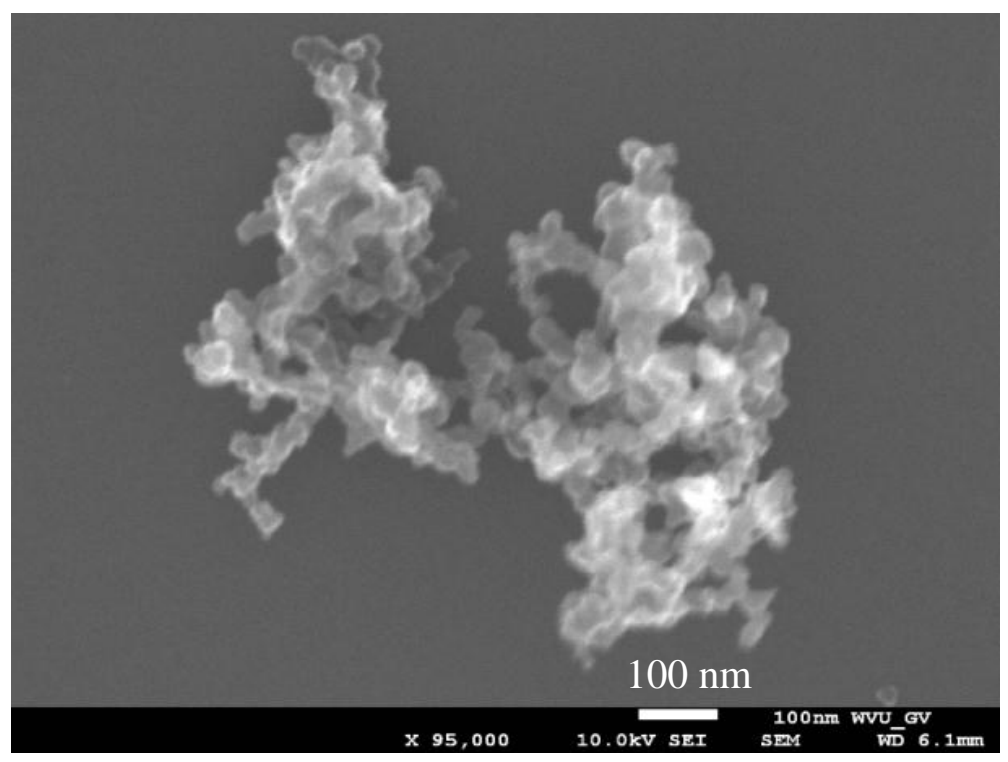

Figure 22: Coarse particle with branches observed at $50 \%$ load is $L_{\max }=1.02 \mu \mathrm{m}$ and $D=652 n m$ 
Figure 23 is a typical accumulation mode particle with numerous branches. The maximum length of the particle is $L_{\max }=773.5 \mathrm{~nm}$ and the projection equivalent diameter is $D=451.2 \mathrm{~nm}$.

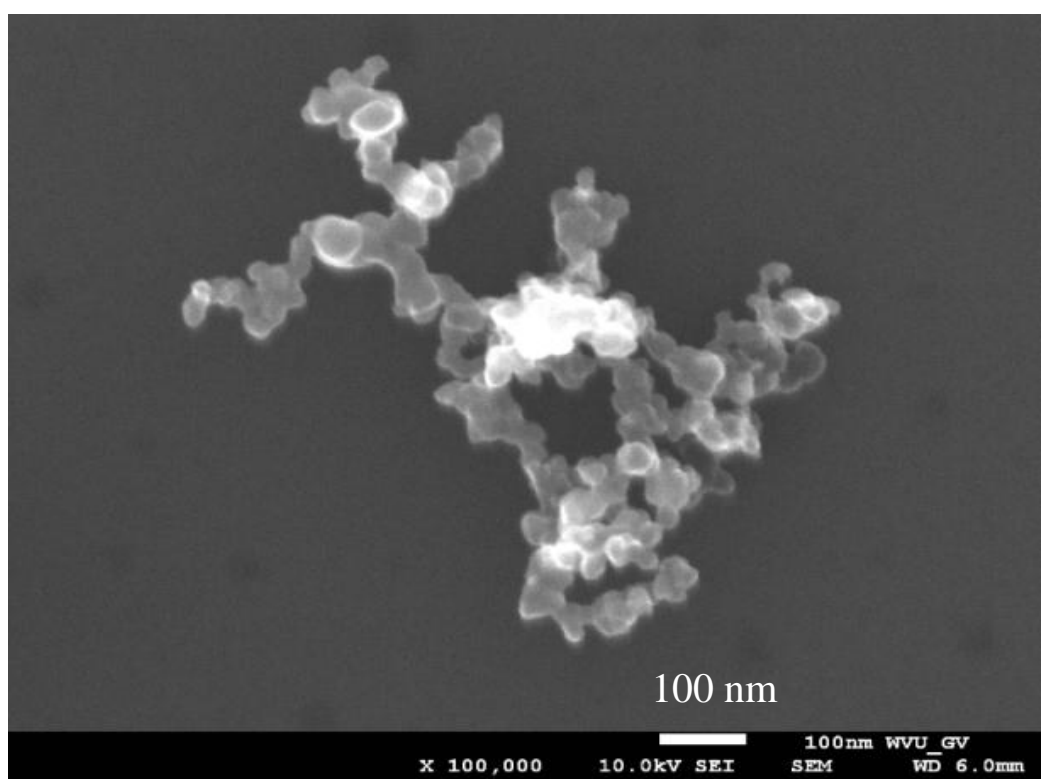

Figure 23: Coarse particle with many branches observed at $50 \%$ load $L_{\max }=773.5 \mathrm{~nm}$ and $D=451.2 \mathrm{~nm}$

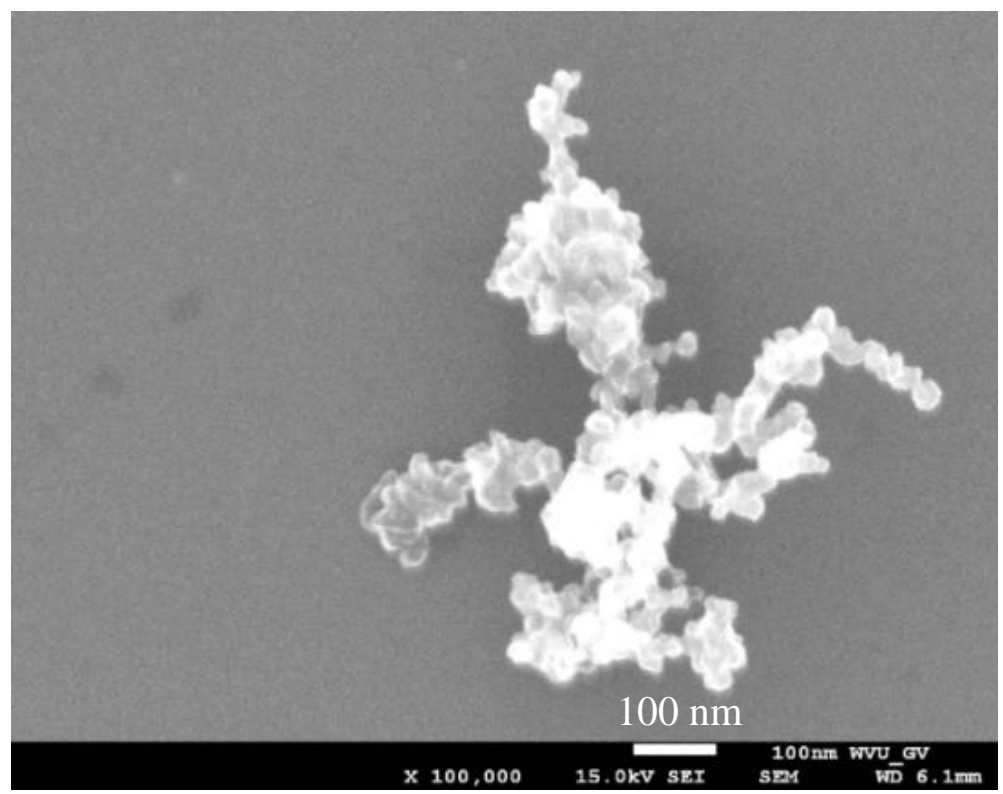

Figure 24: Branched PM particle produced observed at full load $L_{\max }=699 \mathrm{~nm}$ and $D=447.1 \mathrm{~nm}$

Figure 24 is a typical elongated chain like structure. The individual primary particles join with surrounding particles to form long chains. The chains spread out in a length wise manner in different directions and the agglomerate can have many chains attached to it. The maximum 
length of the particle is $L_{\max }=699 \mathrm{~nm}$ and the projection area equivalent diameter is $D=447.1 \mathrm{~nm}$. Figure 25 is a PM particle with long branches attached to one end of the particle.The maximum length of the particle is $L_{\max }=634.9 \mathrm{~nm}$ and the projection equivalent diameter is $D=352.6 \mathrm{~nm}$. The particles can take on complex 3D shapes spreading out in a random fashion.

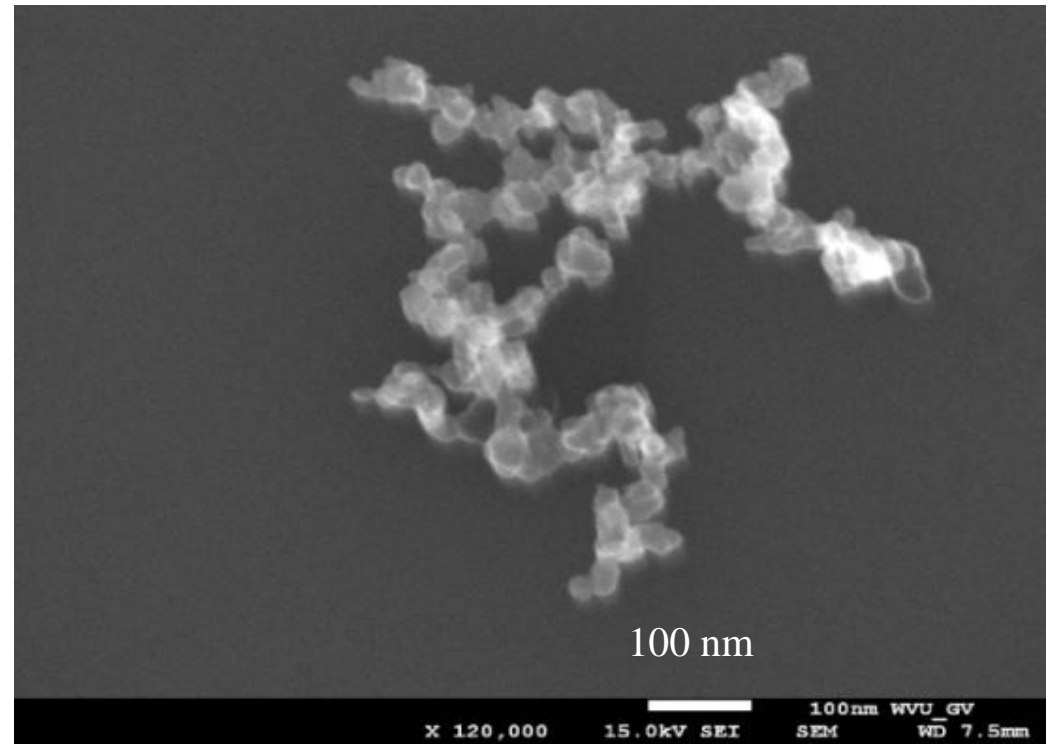

Figure 25: PM particle with many branches observed at $60 \%$ load $L_{\max }=634.9 \mathrm{~nm}$ and $D=352.6 \mathrm{~nm}$

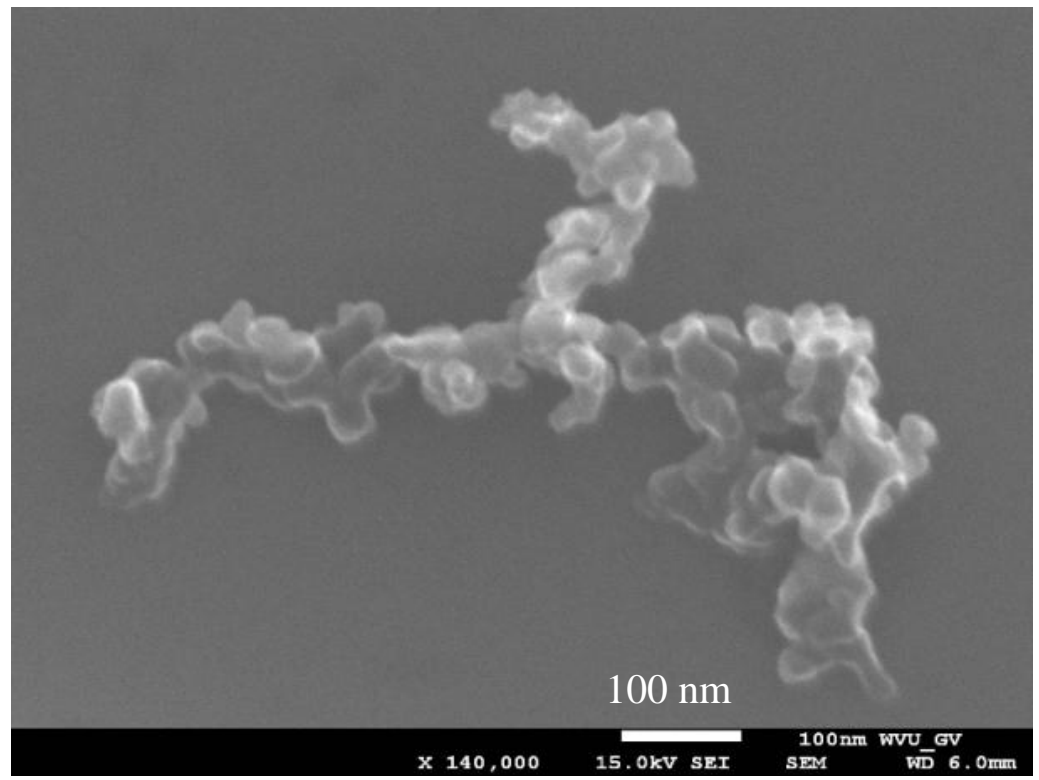

Figure 26: Chain like PM observed at 40\% load $L_{\max }=728.4 \mathrm{~nm}$ and $D=343.2 \mathrm{~nm}$ 
Figure 26 shows a branched PM observed at $40 \%$ load. It appears that a branch is attached to the PM particle in the middle. The maximum length of the particle is $L_{\max }=728.4 n m$ and the projection equivalent diameter is $D=343.2 \mathrm{~nm}$. Figure 27 is a typical grape like formation of an accumulation mode particle observed at $60 \%$ load. The maximum length of the particle is $L_{\max }=383.8 \mathrm{~nm}$ and the projection equivalent diameter is $D=233.5 \mathrm{~nm}$.

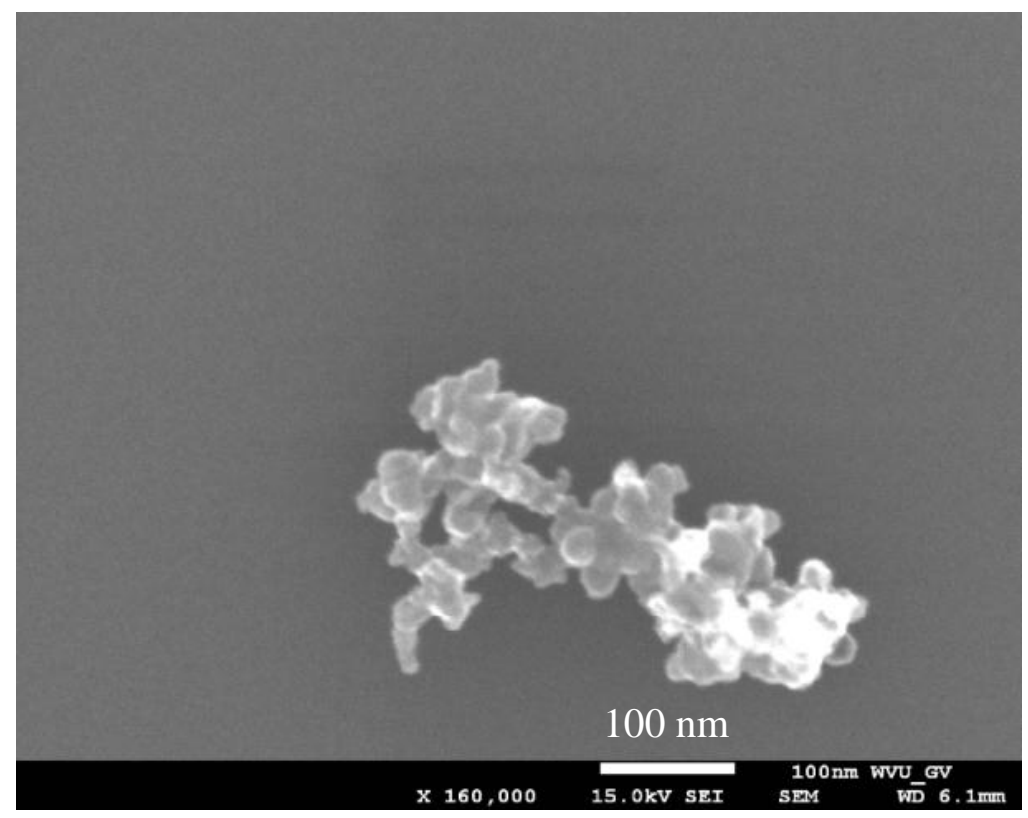

Figure 27: Accumulation mode PM observed at full load $L_{\max }=383.8 \mathrm{~nm}$ and $D=233.5 \mathrm{~nm}$

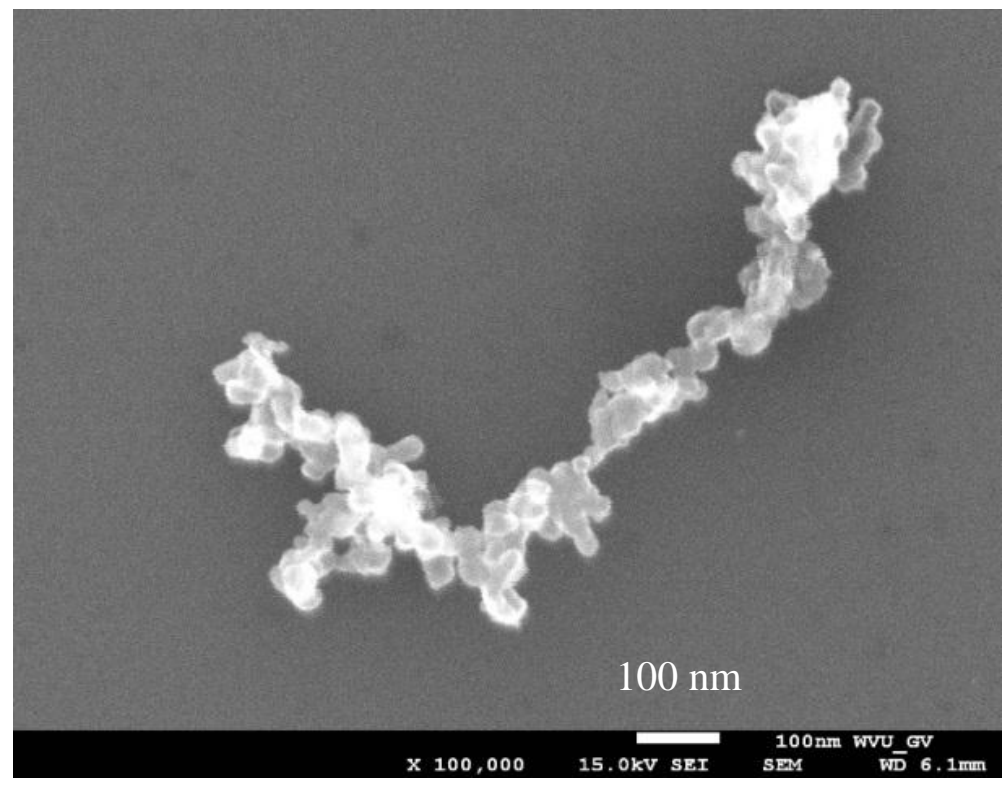

Figure 28: Long chain like PM observed at full load $L_{\max }=955.7 \mathrm{~nm}$ and $D=380.6 \mathrm{~nm}$ 
Figure 28 shows a long chain like PM particle observed at full load. This particle has a single branch attached to one end. The maximum length of the particle is $L_{\max }=955.7 \mathrm{~nm}$ and the projection equivalent diameter is $D=380.6 \mathrm{~nm}$.

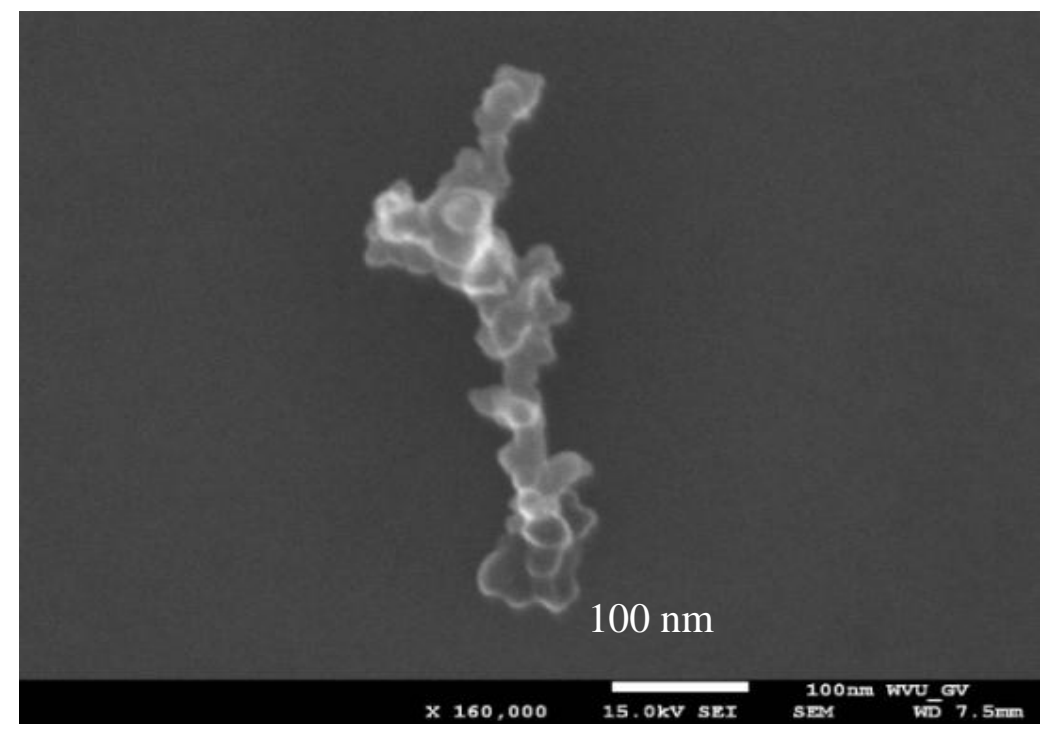

Figure 29: Long chain like PM observed at 60\% load $L_{\max }=383.8 \mathrm{~nm}$ and $D=233.5 \mathrm{~nm}$

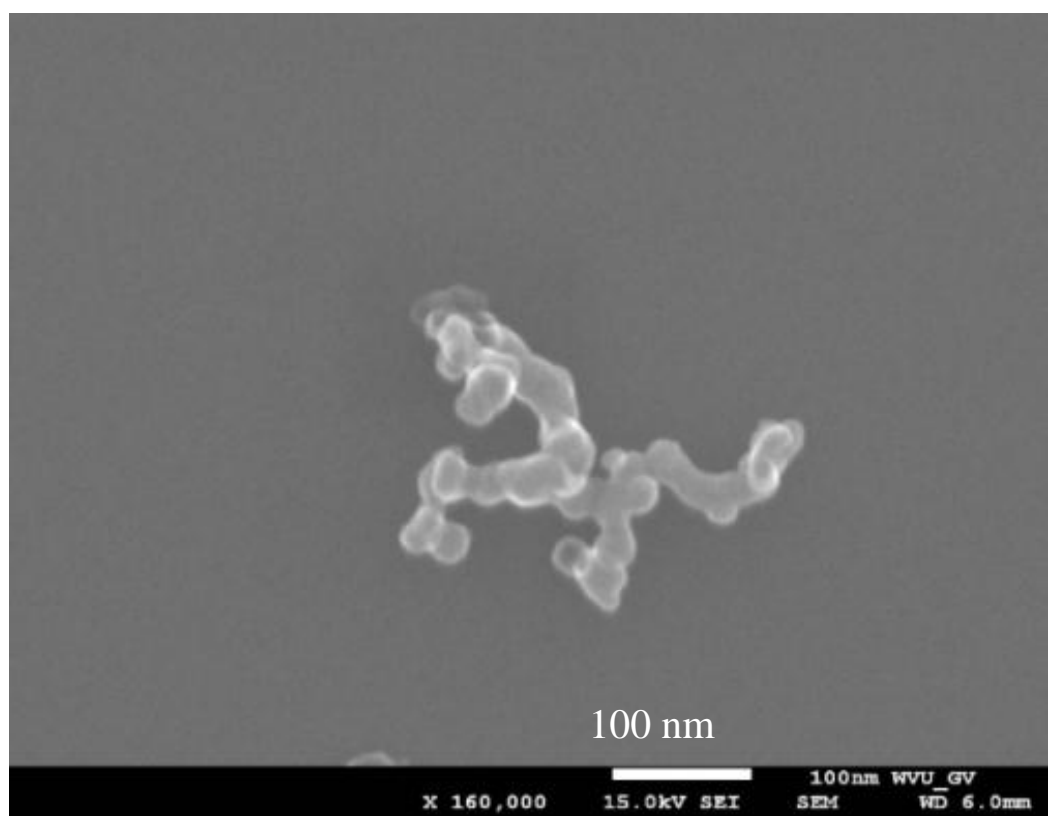

Figure 30: PM with small branches observed at 40\% load $L_{\max }=310.2 \mathrm{~nm}$ and $D=172.0 \mathrm{~nm}$ Figure 29 is a long chain like PM observed at 60\% load. This type of PM has single chain where maximum length of the particle is $L_{\max }=383.8 \mathrm{~nm}$ and the projection equivalent diameter is $D=233.5 \mathrm{~nm}$. Figure 30 is a PM particle with small branches spreading out in different 
directions. The maximum length of the particle is $L_{\max }=310.2 \mathrm{~nm}$ and the projection equivalent diameter is $D=172 \mathrm{~nm}$. Figure 31 is a PM particle with small branches. The maximum length of the particle is $L_{\max }=276.1 \mathrm{~nm}$ and the projection equivalent diameter is $D=159.7 \mathrm{~nm}$.

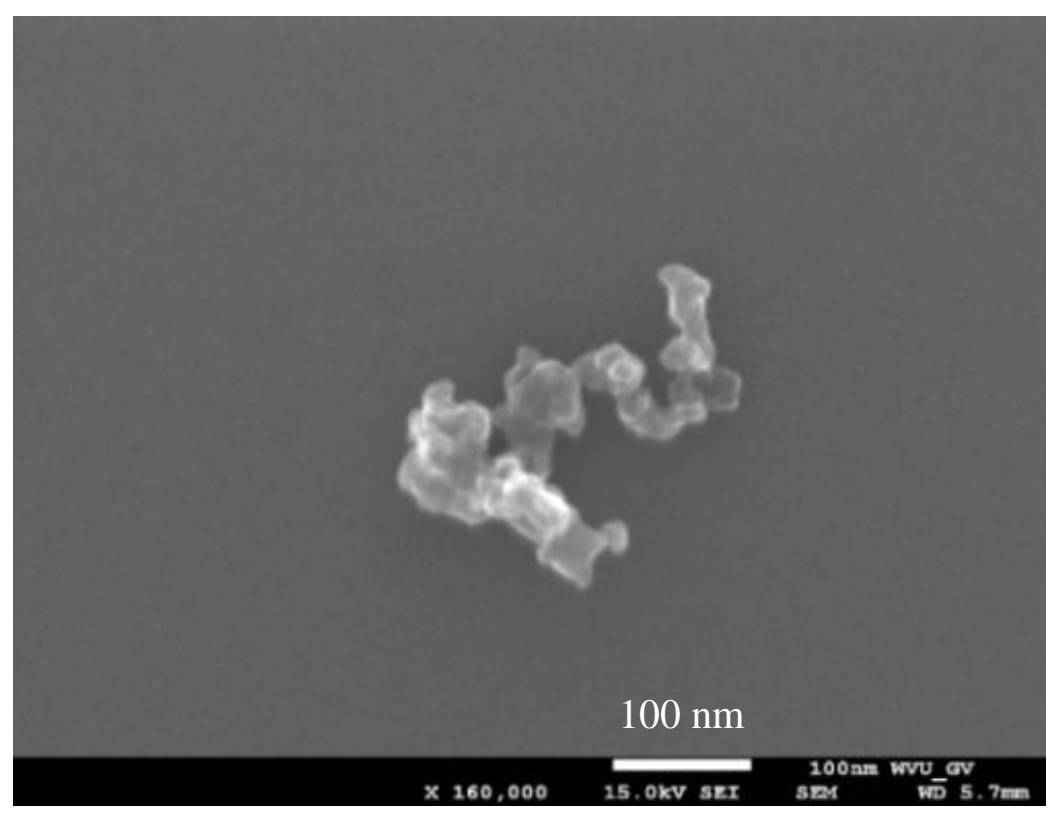

Figure 31: Chain like PM with small branches observed at $75 \%$ load $L_{\max }=276.1 \mathrm{~nm}$ and $D=159.7 \mathrm{~nm}$

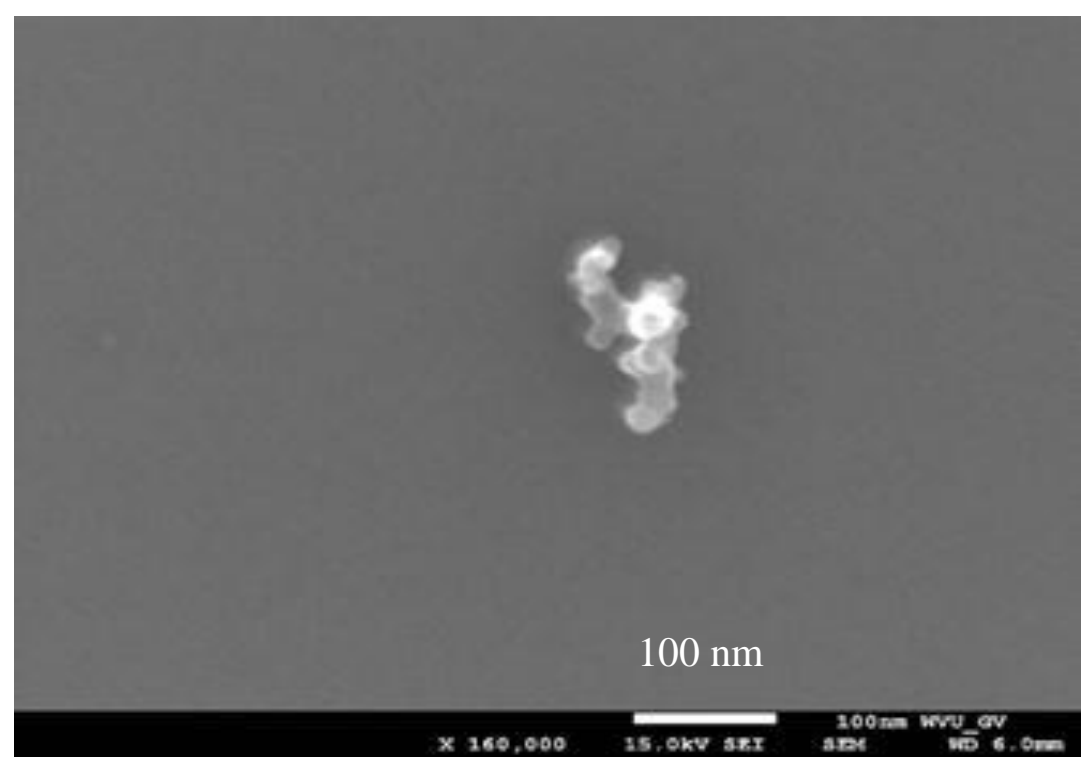

Figure 32: Chain like PM observed at full load $L_{\max }=161.8 \mathrm{~nm}$ and $D=92.9 \mathrm{~nm}$

Figure 32 is a small chain like PM with maximum length of the particle $L_{\max }=161.8 \mathrm{~nm}$ and the projection equivalent diameter is $D=92.9 \mathrm{~nm}$. Figure 33 is a chain like PM formed during $60 \%$ 
load. The maximum length of the particle is $L_{\max }=278.2 \mathrm{~nm}$ and the projection equivalent diameter is $D=152.4 \mathrm{~nm}$.

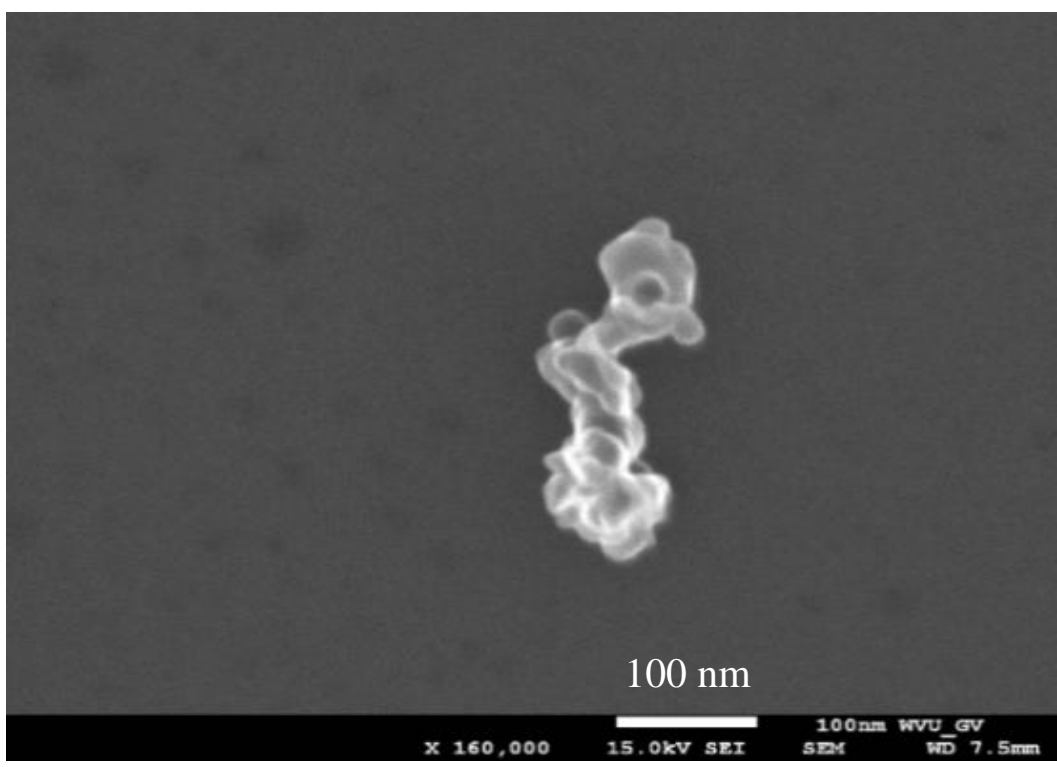

Figure 33: PM particle observed at 60\% load $L_{\max }=278.2 \mathrm{~nm}$ and $D=152.4 \mathrm{~nm}$

Nano particles were observed at different modes of the test as seen in the figures below. Figure 34 is a nano scale PM particle observed at $90 \%$ load. This has tiny projections spreading in different directions. This type of PM has a larger surface area where gas phase particles can condense and grow in size. The maximum length of the particle is $L_{\max }=144.7 \mathrm{~nm}$ and the projection equivalent diameter is $D=105.6 \mathrm{~nm}$. The particle is spherical in shape.

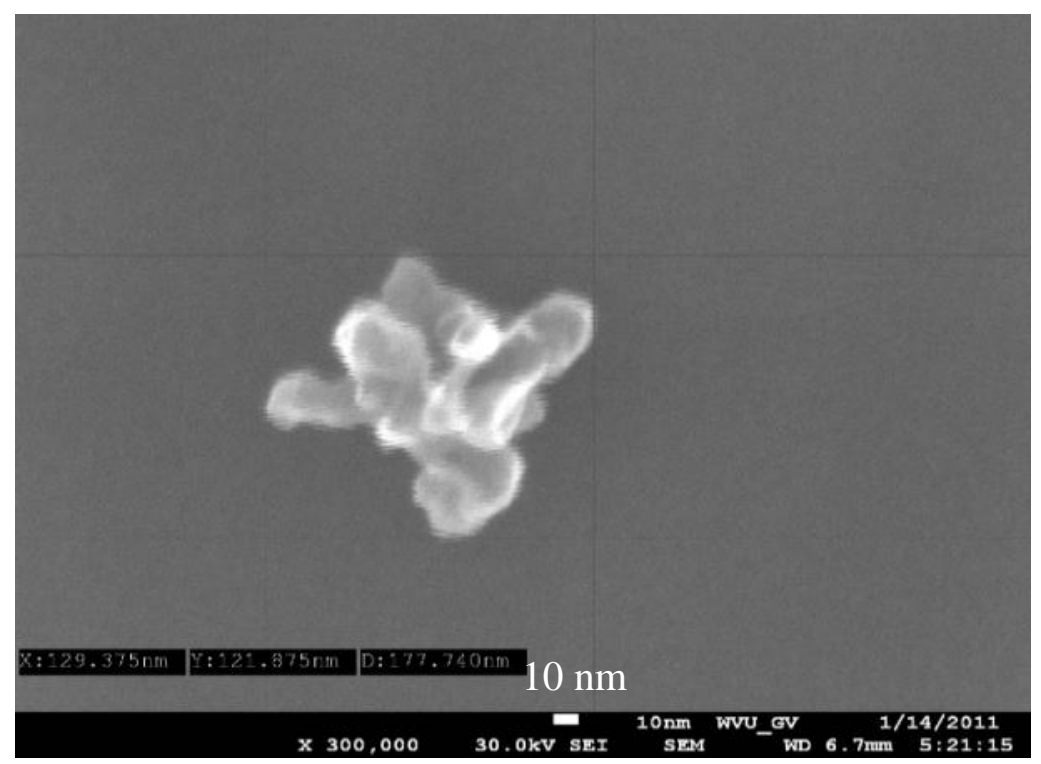

Figure 34: Nano particle observed at $90 \%$ load $L_{\max }=144.7 \mathrm{~nm}$ and $D=105.6 \mathrm{~nm}$ 
Figure 35 shows a nano particle observed at $75 \%$ load. The image was taken at a magnification of $\mathrm{X} 230000$. The maximum length of the particle is $L_{\max }=176.1 \mathrm{~nm}$ and the projection equivalent diameter is $D=100.3 \mathrm{~nm}$. The particle is elongated and not completely spherical.

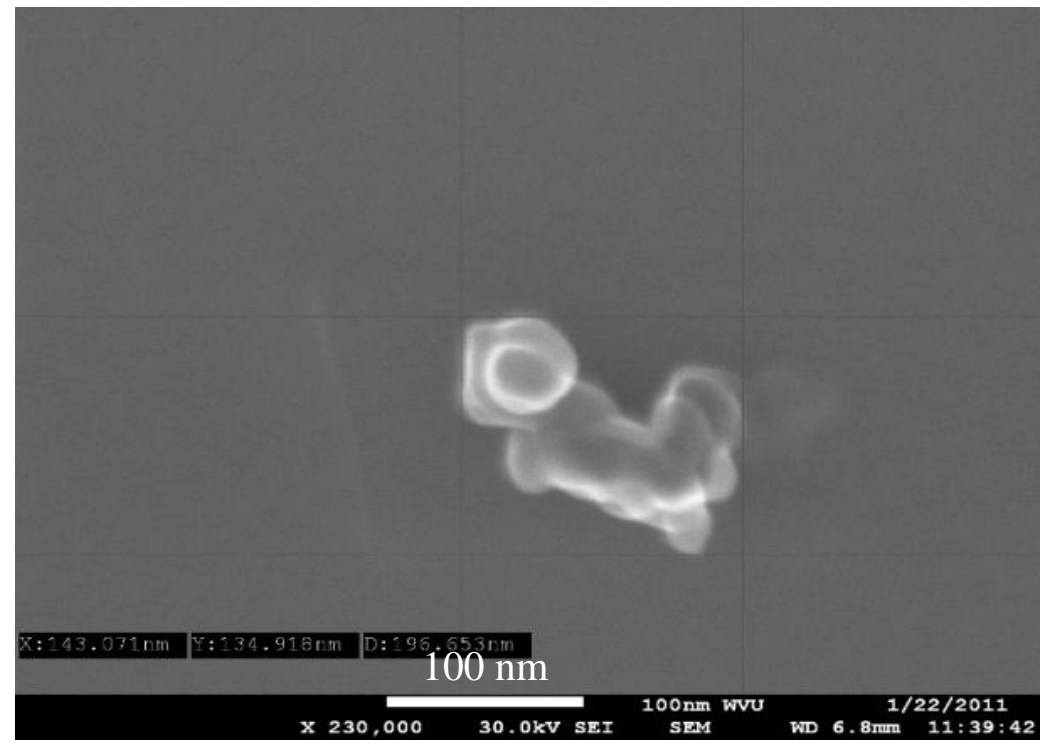

Figure 35: Nano particle observed at $75 \%$ load $L_{\max }=176.1 \mathrm{~nm}$ and $D=100.3 \mathrm{~nm}$

Figure 36 shows a particle which is almost spherical in shape and the primary particles are closely formed. The particle was observed at $60 \%$ load and has a maximum length $L_{\max }=132.5 \mathrm{~nm}$ and a projection equivalent diameter $D=107.6 \mathrm{~nm}$.

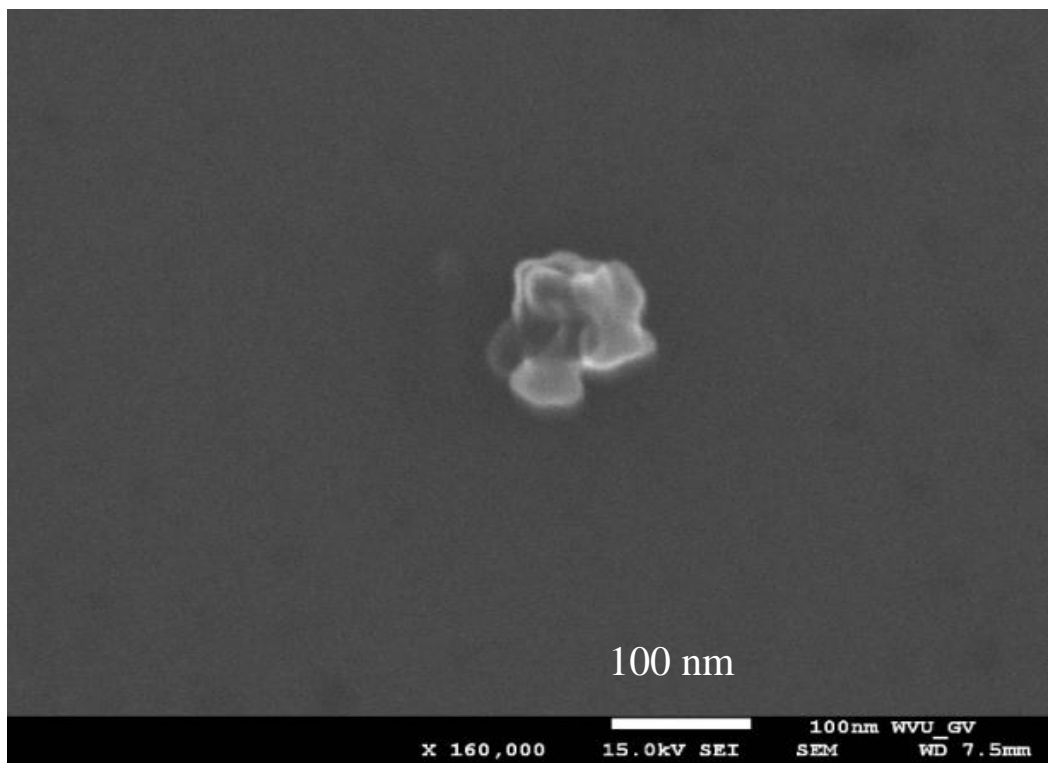

Figure 36: Almost Spherical PM observed at 60\% load $L_{\max }=132.5 \mathrm{~nm}$ and $D=107.6 \mathrm{~nm}$ 


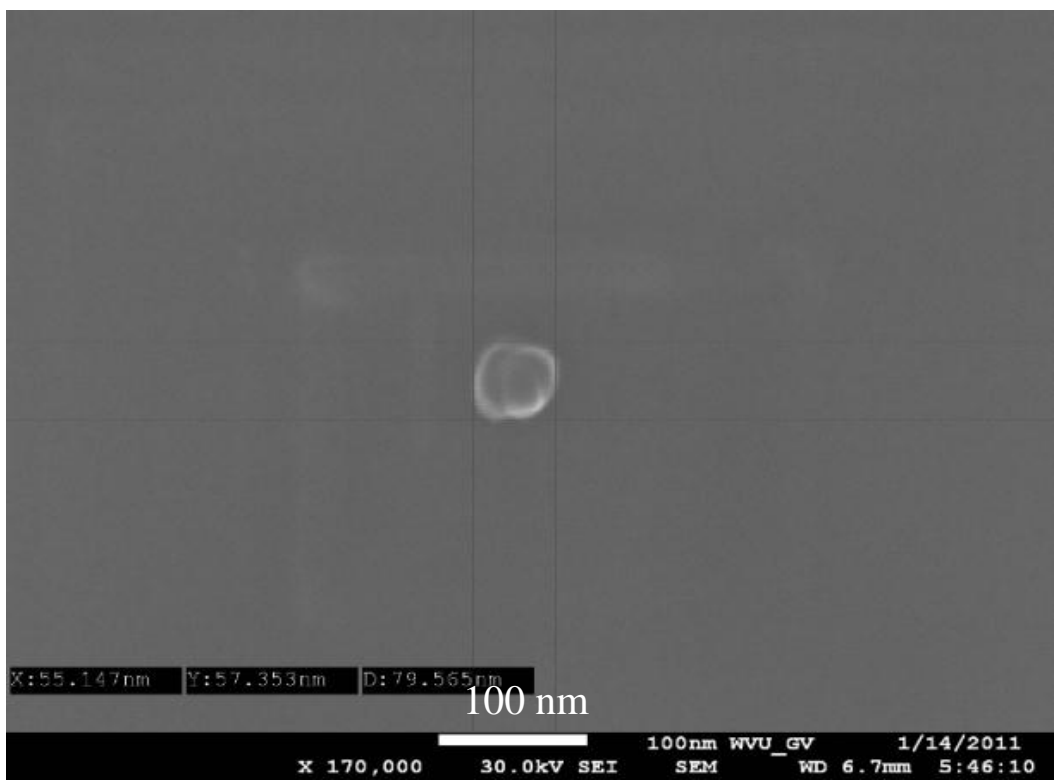

Figure 37: Spherical nano particles observed at 50\% load $L_{\max }=62.3 \mathrm{~nm}$ and $D=55.3 \mathrm{~nm}$

Figure 37 shows nano particle almost spherical in shape with a maximum length of the particle is $L_{\max }=62.3 \mathrm{~nm}$ and a projection equivalent diameter is $D=55.3 \mathrm{~nm}$. The $\mathrm{AR}$ and $\mathrm{RN}$ observed were 0.9 and 0.83 respectively, indicating a sphere like structure. These particles are nuclei mode particles and contain very few primary particles. These particles are usually very small measuring less than $100 \mathrm{~nm}$ in size. These particles have very small mass and usually escape the SEM and TEM grids as they do not have enough kinetic energy to deposit on the grids. Although the SMPS detected lot of particles in this size range the SEM and TEM analysis had very few particles in this size range.

\subsection{Projected area equivalent diameter}

The projected area equivalent diameter is an important parameter describing the size of a PM particle. The maximum length of the PM particle is usually a function of the projected area equivalent diameter. The projected area is calculated using the image processing software as described previously in Chapter 4. The projected area equivalent diameter is closely related to the mobility diameter of the particle as measured by the SMPS in the $50-220 \mathrm{~nm}$ mobility diameter range [51]. As shown in Figure 38, the maximum length of particle was approximately proportional to the projection area equivalent diameter observed at full load. As seen in Figure 38, the maximum length of some particles were much longer than others having comparable projected area equivalent diameter. For example, Figure 39 is a long chain like particle with maximum length of $955.7 \mathrm{~nm}$ and projected area equivalent diameter of $380.6 \mathrm{~nm}$. Figure 40 
shows the particle $\mathrm{B}$ in Figure 38 which has a long chain like structure $L_{\max }=557.0 \mathrm{~nm}$ and $D=201.0 n m$.

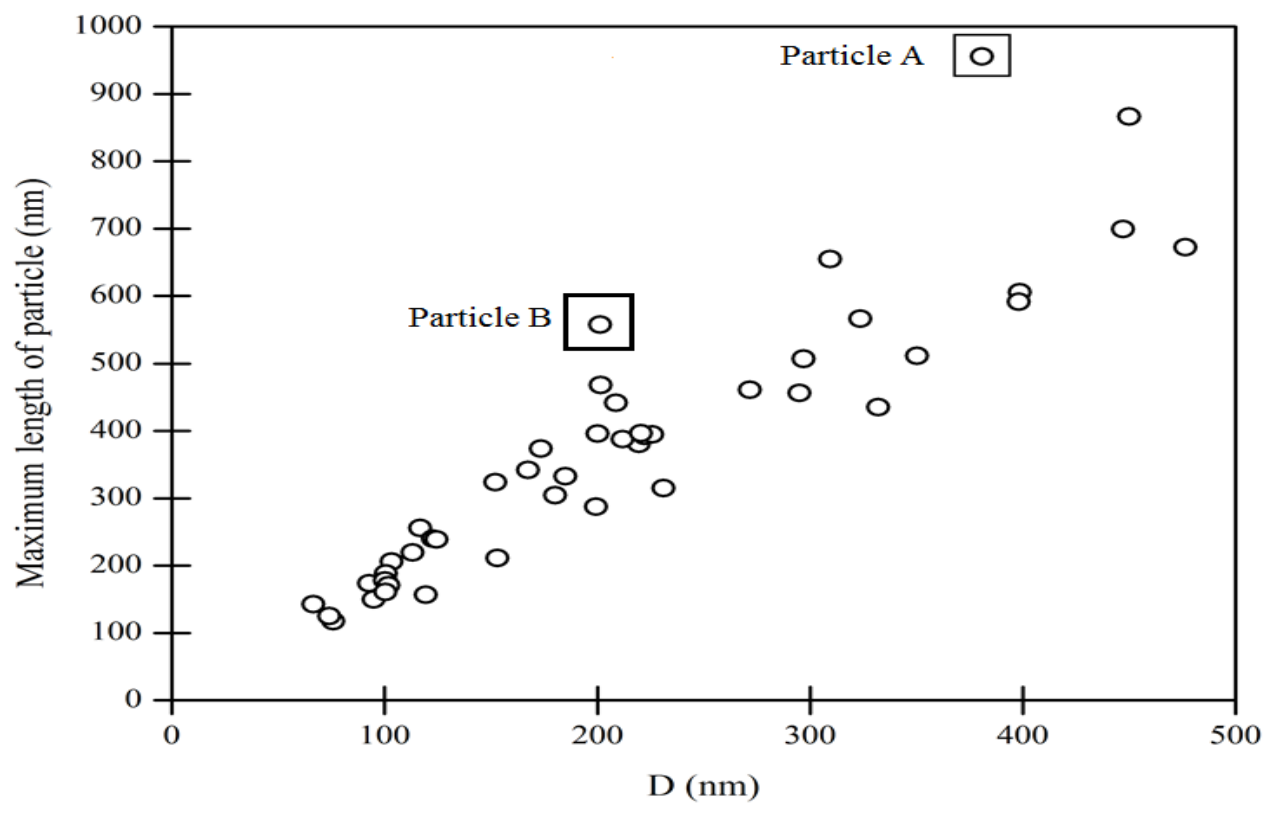

Figure 38: Distribution of maximum length of particle Vs projected area equivalent diameter observed at full load

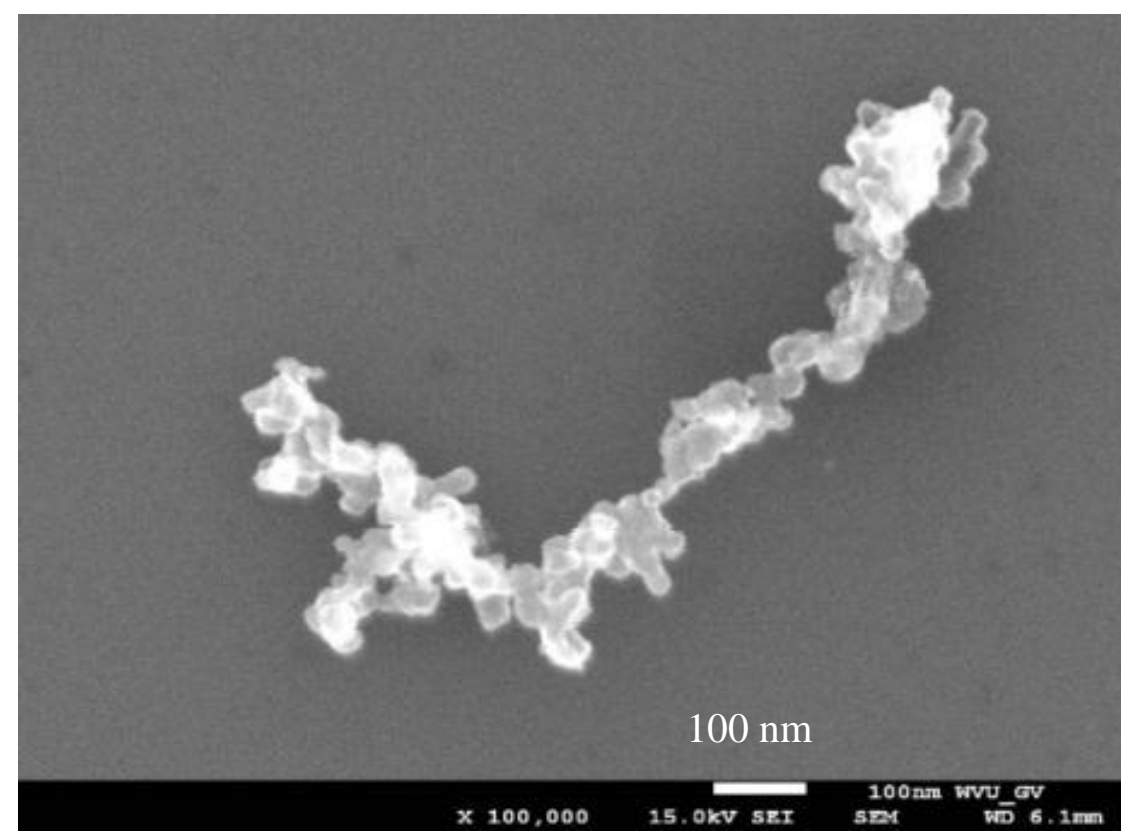

Figure 39: Particle A in Figure $38 L_{\max }=955.7 \mathrm{~nm}$ and $D=380.6 \mathrm{~nm}$ 


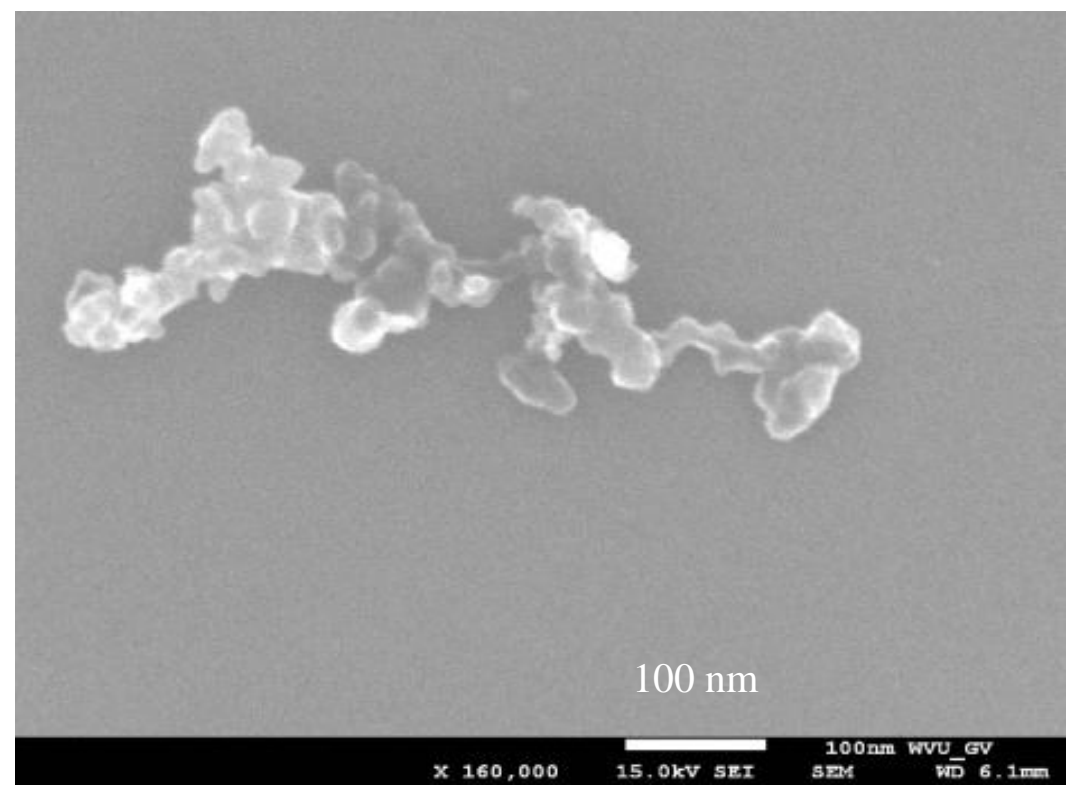

Figure 40: Particle B in Figure $38 L_{\max }=557.0 \mathrm{~nm}$ and $D=201.0 \mathrm{~nm}$

Figure 41 is the distribution of maximum length of particle vs. the projection area equivalent diameter during 95\% load. Very few images were observed at this load as the number of PM particles collected on the SEM grids was small.

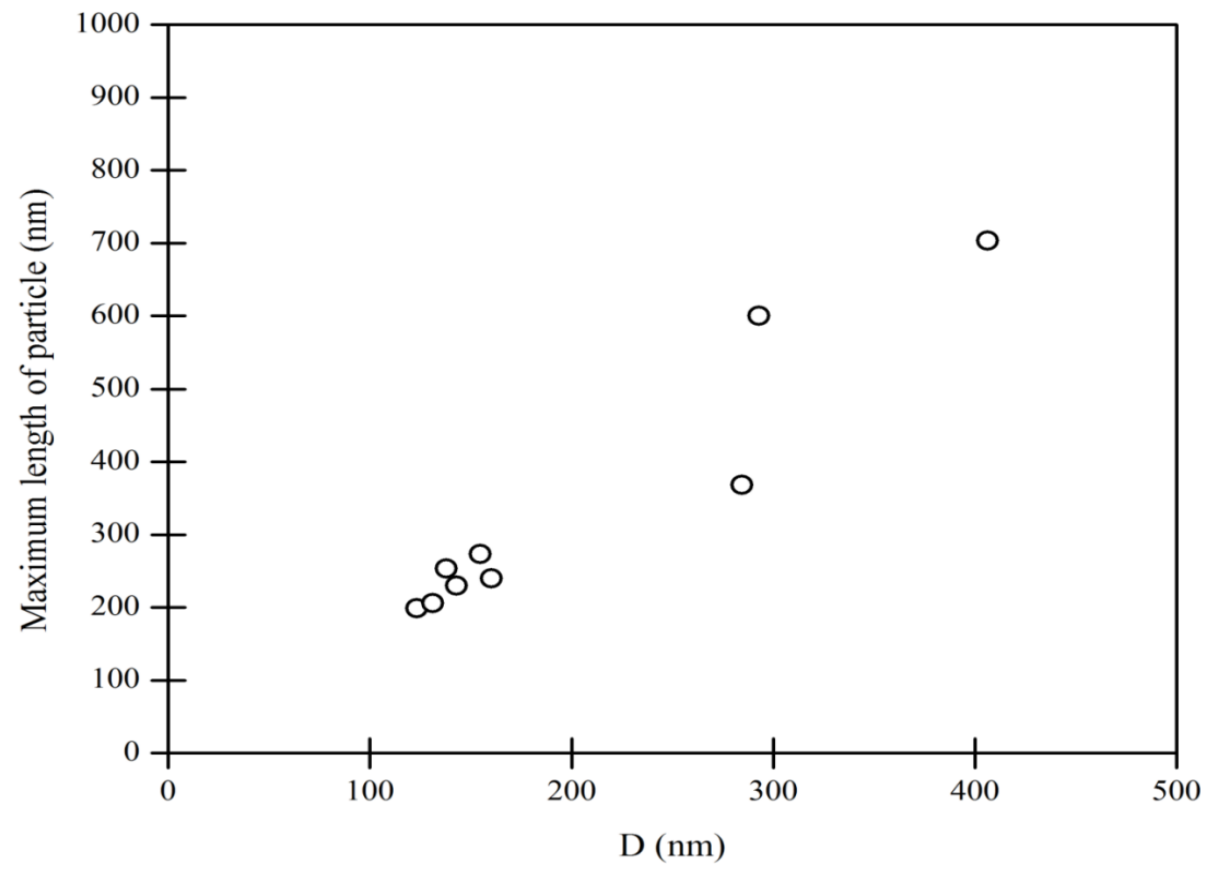

Figure 41: Variation of maximum length of PM particles with changes in the projected area equivalent diameter observed at $95 \%$ load 


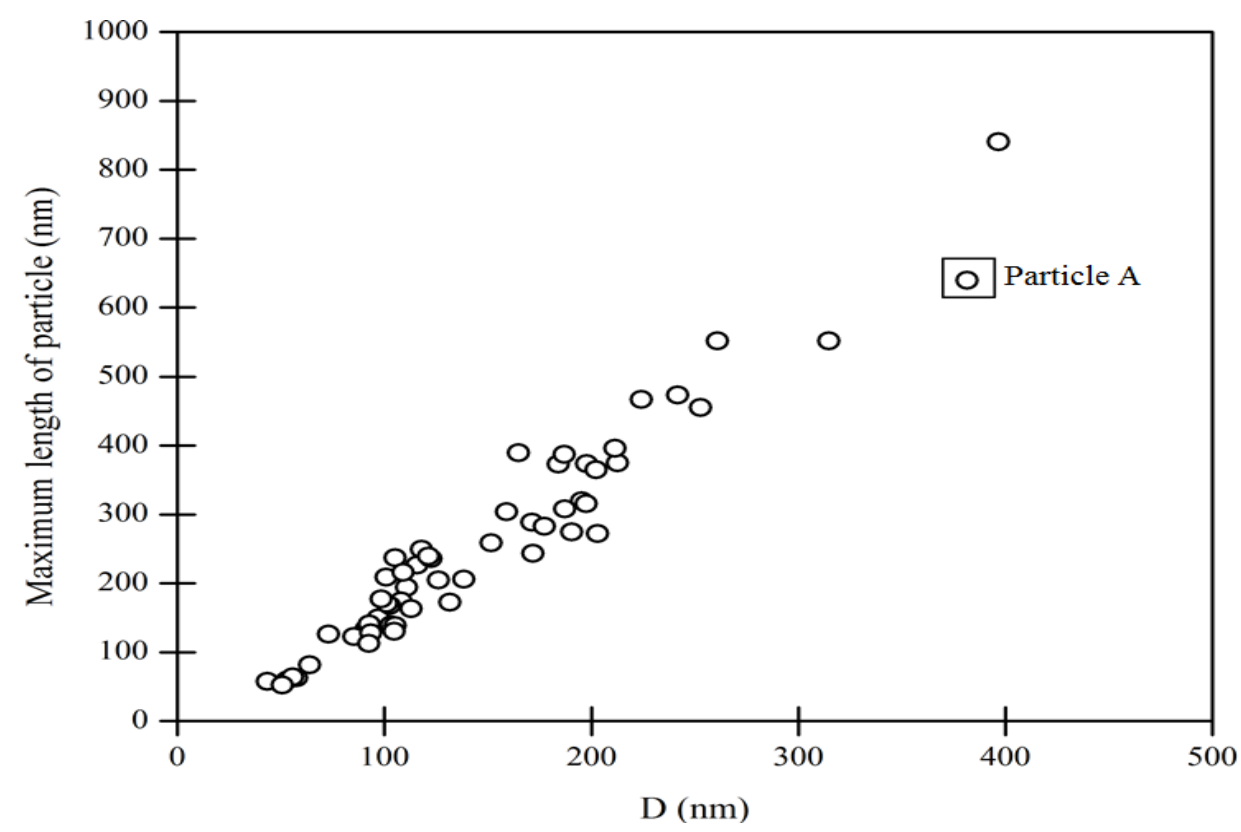

Figure 42: Variation of maximum length of PM particles with changes in the projected area equivalent diameter observed at $90 \%$ load

Figure 42 is the length distribution of maximum length of particle vs. the projection area equivalent diameter during $90 \%$ load. It was observed that most of the projected area equivalent diameter of the observed PM particles was smaller than $200 \mathrm{~nm}$ in diameter. Figure 43 is a particle observed at 90\% load with maximum length of $639.7 \mathrm{~nm}$ and projected area equivalent diameter of $381.5 \mathrm{~nm}$. This PM particle is shown in the box in Figure 42.

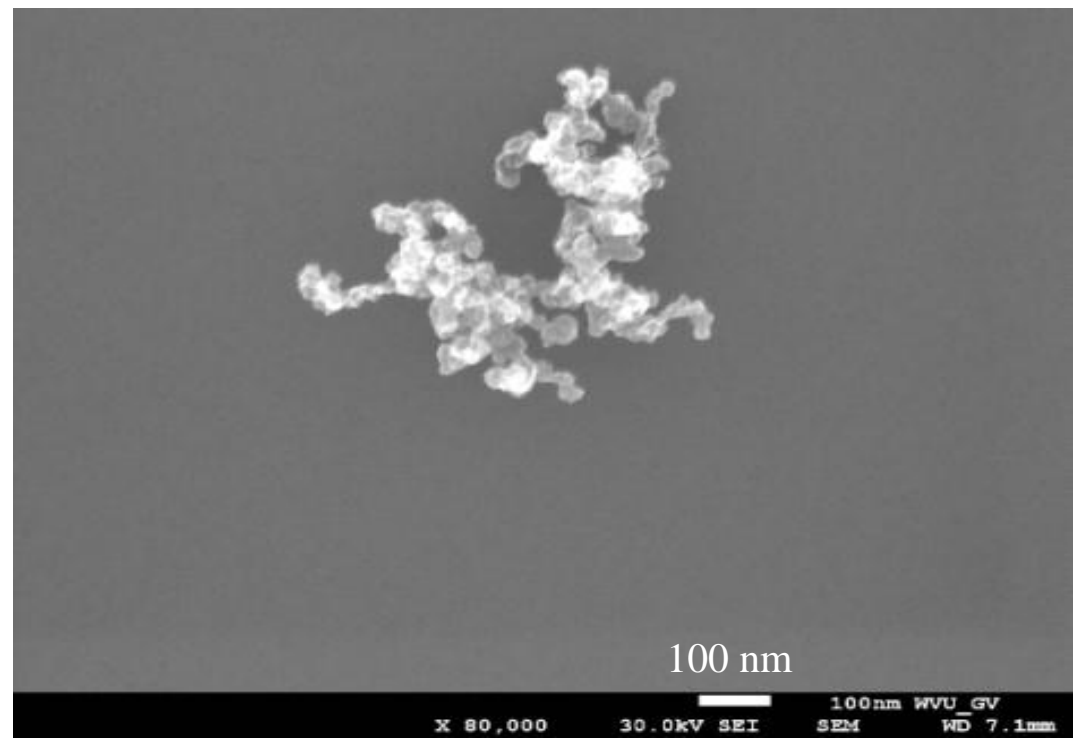

Figure 43: Particle A in Figure 42 with $L_{\max }=639.7 \mathrm{~nm}$ and $D=381.5 \mathrm{~nm}$ 


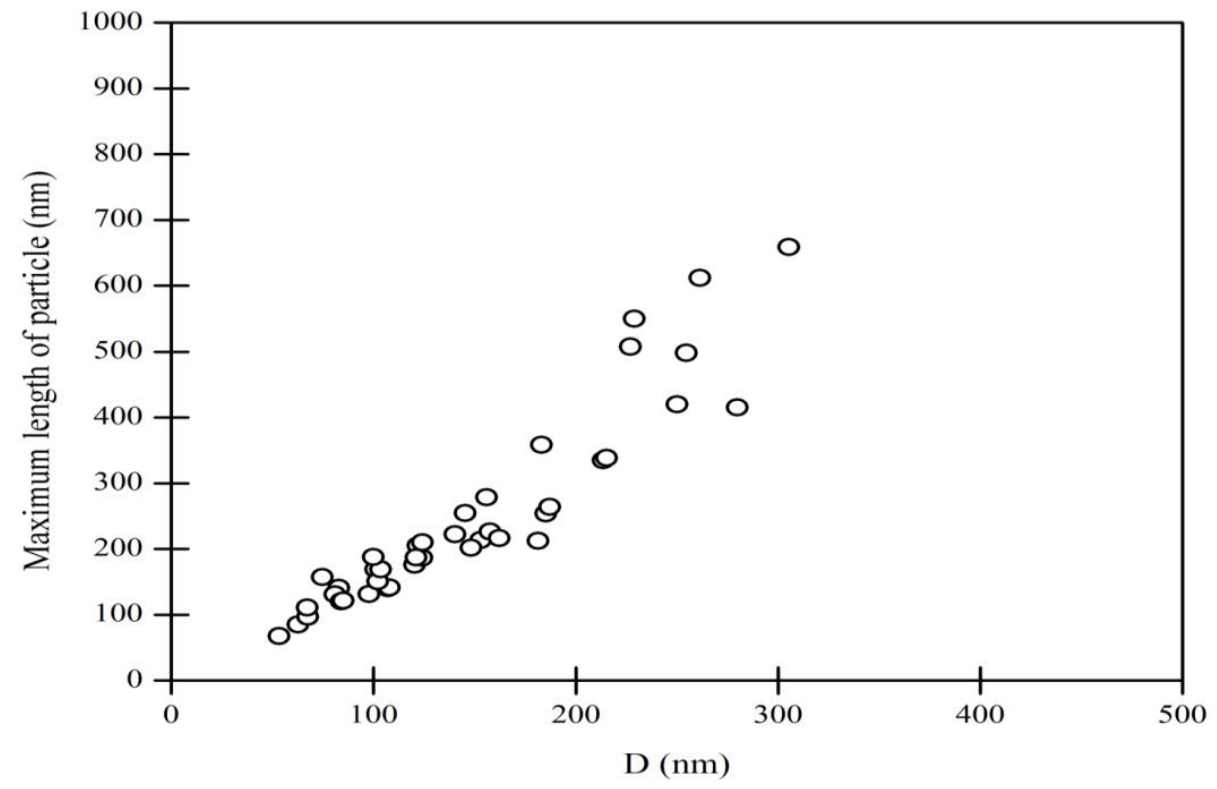

Figure 44: Variation of maximum length of PM particles with changes in the projected area equivalent diameter observed at $75 \%$ load

Figure 44 shows the distribution of maximum length of particle vs. the projection area equivalent diameter observed at $75 \%$ load. Most of the particles were accumulation mode with small number of nano particles present as shown in the plot. Figure 45 shows the variation of maximum length of PM particles with changes in the projected area equivalent diameter observed at $60 \%$ load.

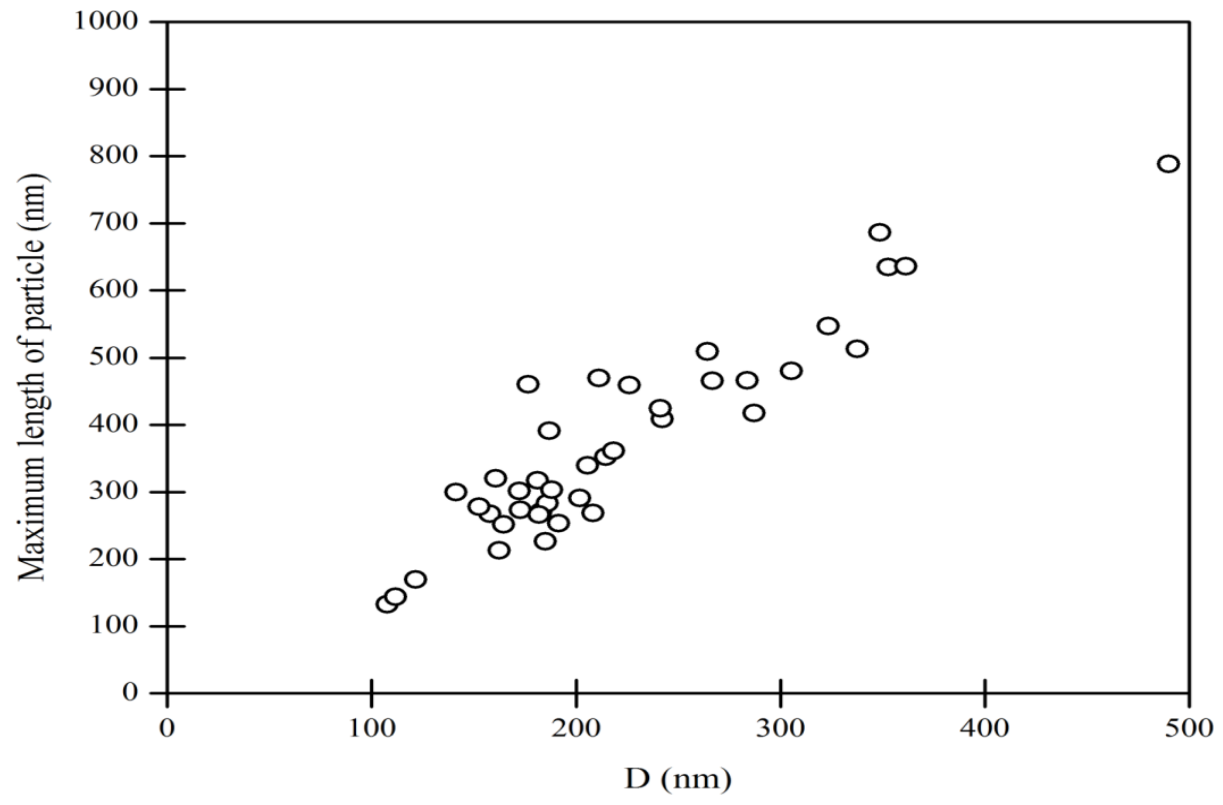

Figure 45: Variation of maximum length of PM particles with changes in the projected area equivalent diameter observed at $60 \%$ load 


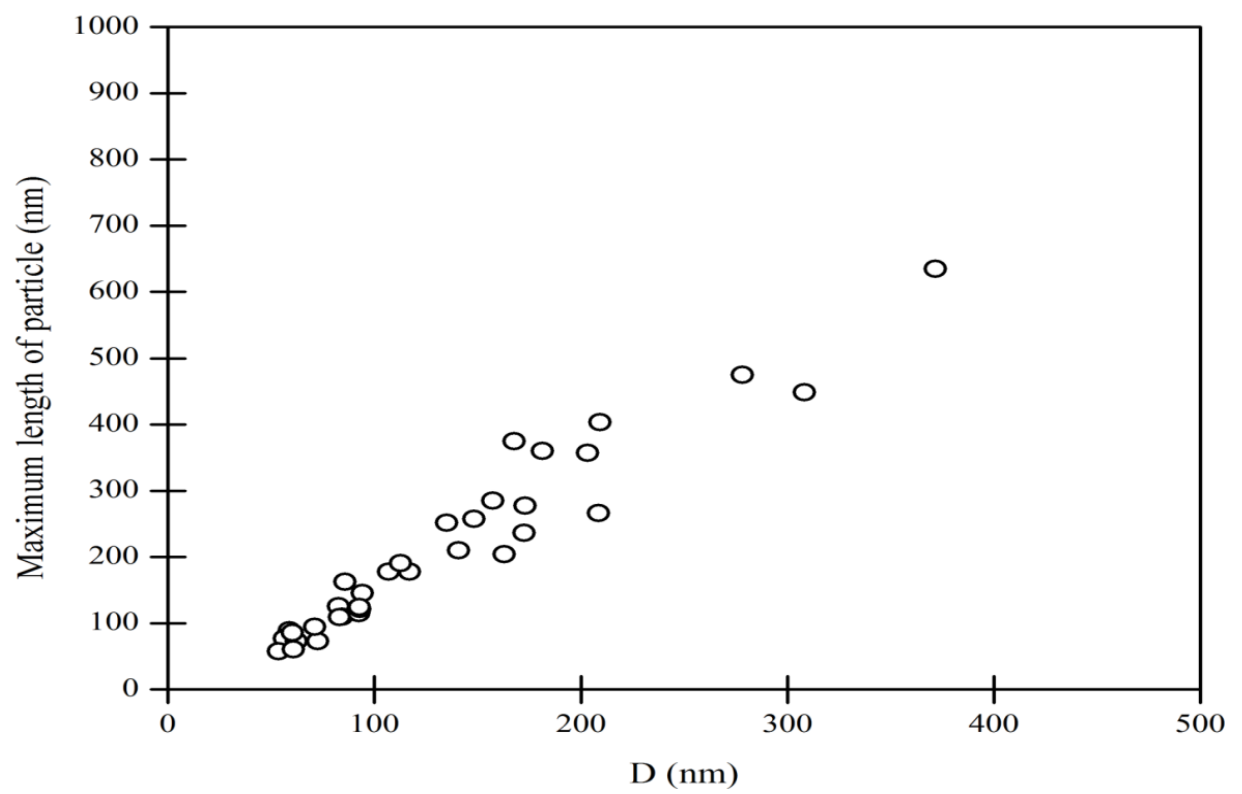

Figure 46: Variation of maximum length of PM particles with changes in the projected area equivalent diameter observed at $50 \%$ load

Figure 46 shows the length distribution of PM particles observed at 50\% load. Numerous accumulation mode particles less than $200 \mathrm{~nm}$ in projection area equivalent diameter were present in this mode. A large number of accumulation mode PM particles greater than $100 \mathrm{~nm}$ in projected area equivalent diameter was observed at $40 \%$ load as seen in Figure 47.

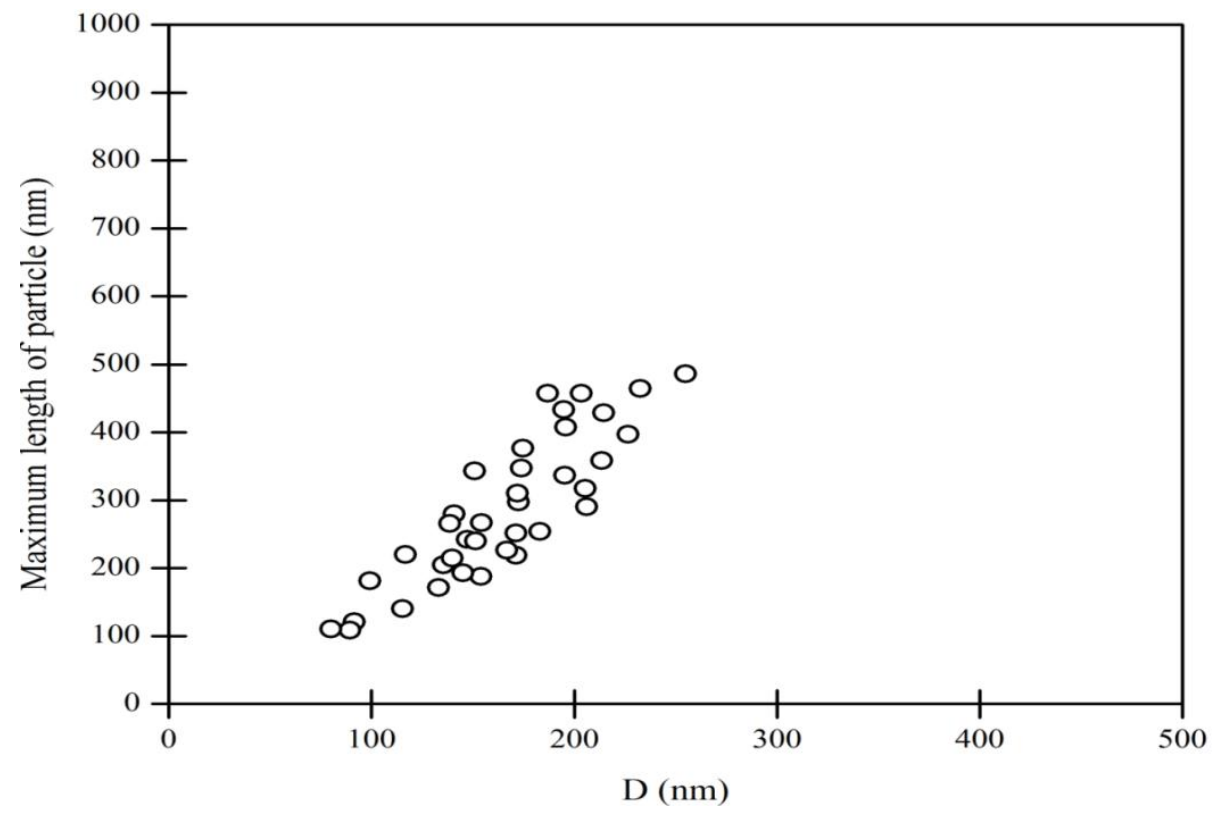

Figure 47: Variation of maximum length of PM particles with changes in the projected area equivalent diameter observed at $40 \%$ load 
The projection area equivalent diameter of the particles collected at $20 \%$ load was less than 200 $\mathrm{nm}$ in size. A large number of the particles were ultrafine particles with projection area equivalent diameter less than $100 \mathrm{~nm}$ as seen in Figure 48. Figure 49 is a chain like particle with $L_{\max }=212.7 \mathrm{~nm}$ and $D=68.4 \mathrm{~nm}$ respectively.

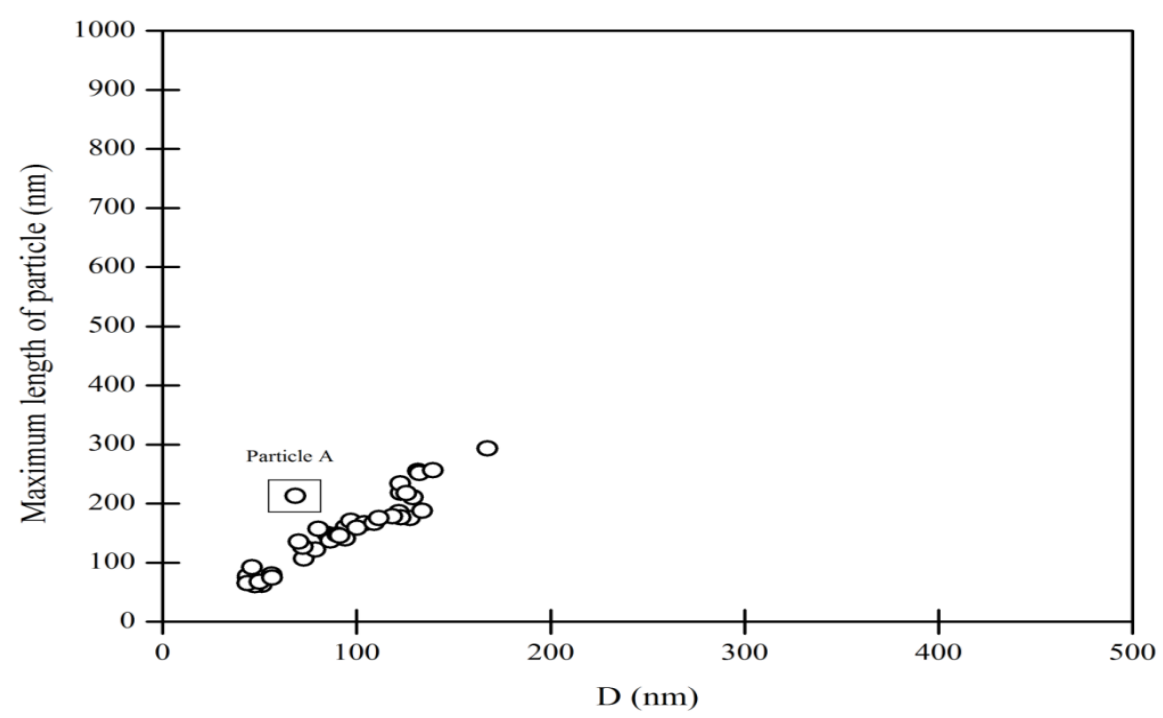

Figure 48: Variation of maximum length of PM particles with changes in the projected area equivalent diameter observed at $20 \%$ load

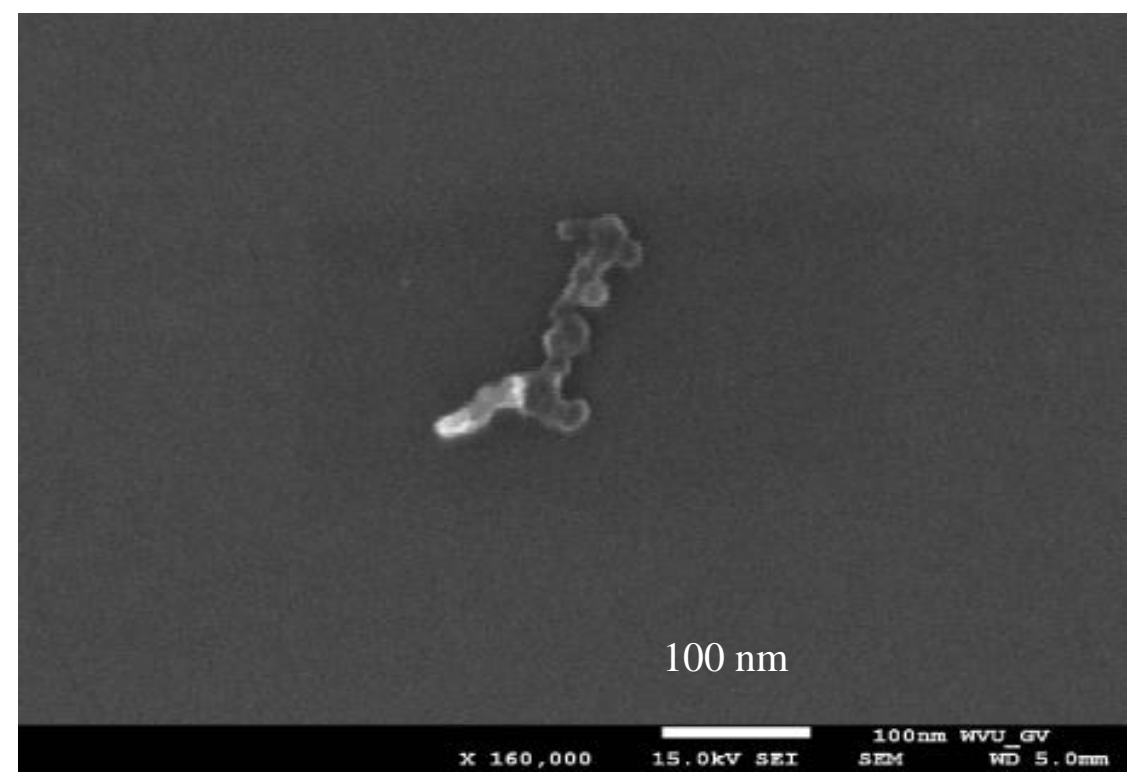

Figure 49: Particle A in Figure $47 L_{\max }=212.7 \mathrm{~nm}$ and $D=68.4 \mathrm{~nm}$ respectively 
Figure 50 shows the variation of the maximum length with changes in the projected area equivalent diameters of PM particles measured at all modes. It was found that most of the PM particles had projection area equivalent diameter less than $300 \mathrm{~nm}$. This value was large compared to the value measured by the SMPS which measured particles less than $224 \mathrm{~nm}$ in mobility diameter. As explained previously, the PM particles were pre classified in the SMPS and particles bigger than $224 \mathrm{~nm}$ were removed in the pre classifier. The smallest projected area equivalent diameter measured by the SEM was $43.7 \mathrm{~nm}$. Particles less than $43.7 \mathrm{~nm}$ were produced by the engine which was evident from the SMPS data. Particles in this size range could not be measured by the SEM because these particles had extremely small mass and did not have enough kinetic energy to deposit on the SEM and TEM grids.

Figure 51 shows the range of projection area equivalent diameter observed at different loads for the heavy duty engine. It was found that the projected area equivalent diameter increase with the increase in engine load, although the size range measured for the $75 \%, 90 \%$ and $95 \%$ were smaller than the PM particles observed during intermediate and full load, which could have been the limited number of PM particles collected on the SEM grids. For example the number of PM particles observed at $95 \%$ load and $60 \%$ load were 9 and 40 , respectively.

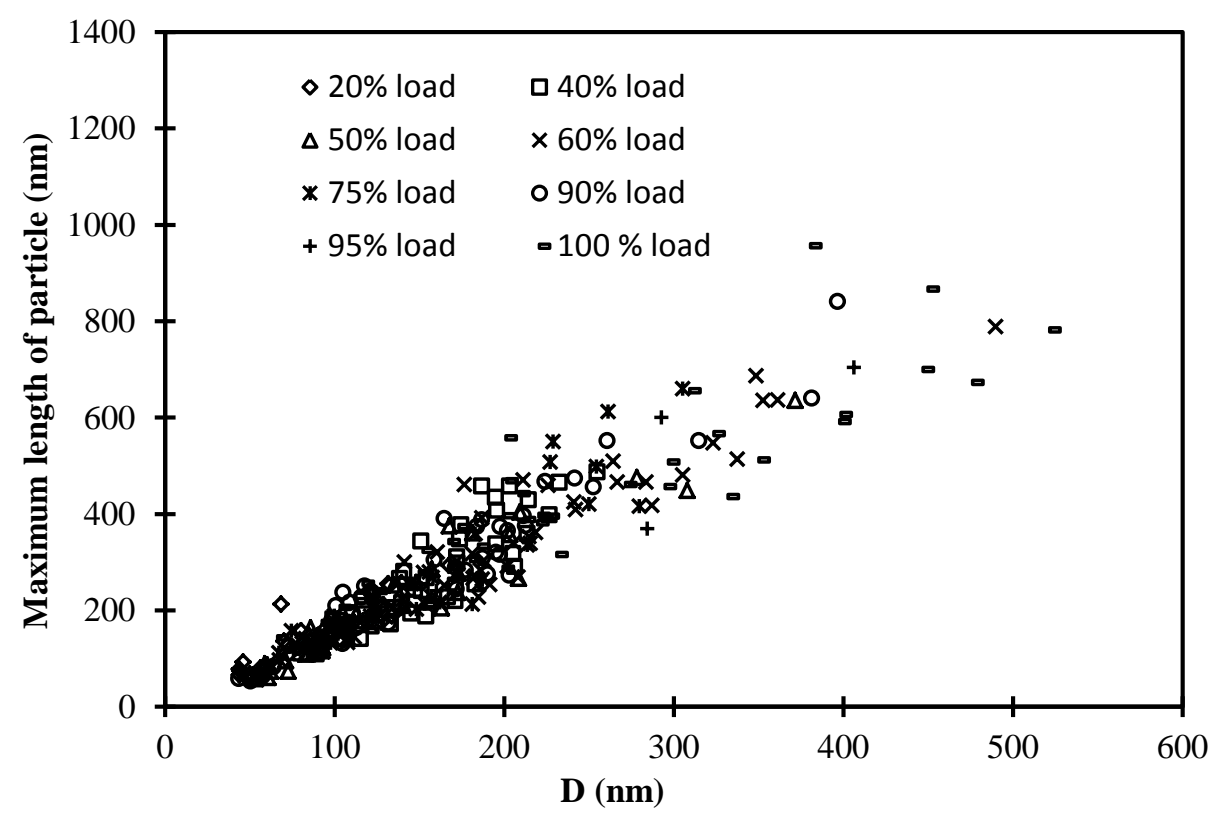

Figure 50: Variation of maximum length of PM particles with changes in the projected area equivalent diameter for heavy duty engine PM 


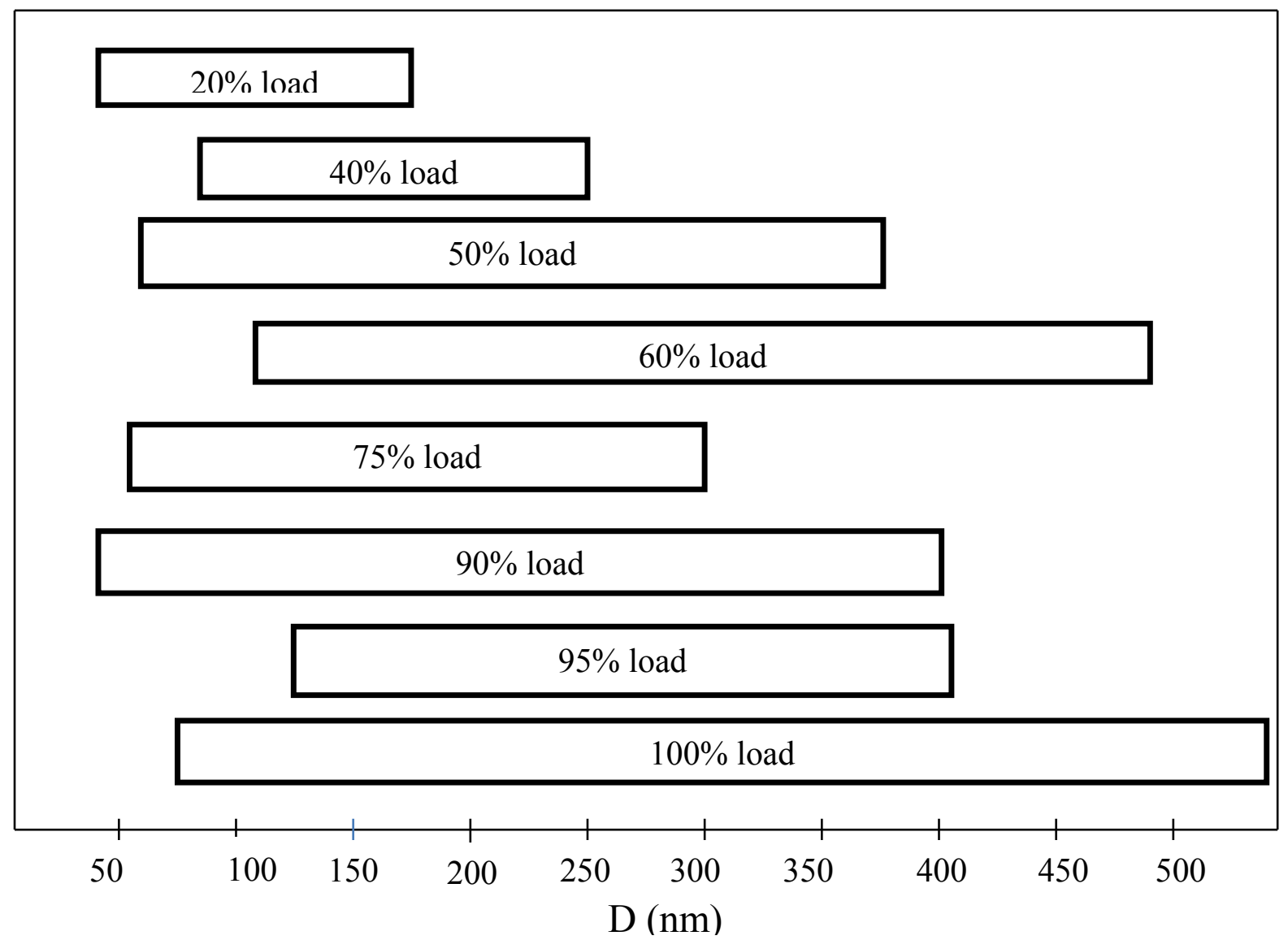

Figure 51: Range of projected area equivalent diameter of PM particles during different load

\subsection{Distribution of the primary particle size}

The diameters of primary particles were measured from the projected properties of SEM images. Around 220 primary particles of various sizes were randomly selected from various agglomerates and nano scale particles to determine the average diameter of the primary particles. The random selection eliminated any operator bias toward either bigger or smaller particles. In most cases the size distribution of the primary particles represented a Gaussian distribution.

Figure 52 is a histogram for $20 \%$ load. There are a large number of primary particles around 20 $\mathrm{nm}$ in diameter. The high SOF emitted during low load may nucleate and form nuclei mode particles. Figure 53 shows distribution of the primary particle diameter observed at $40 \%$ load. The peak diameter of the PM particle has shifted to larger diameter to the right. One of the main factors that affect the primary particle growth is the oxidation process. During low loads the combustion temperatures are low compared to high loads. This favors particle growth. The 
particle formation dominates the oxidation process and the primary particles grow in size $[38,39$, 46].

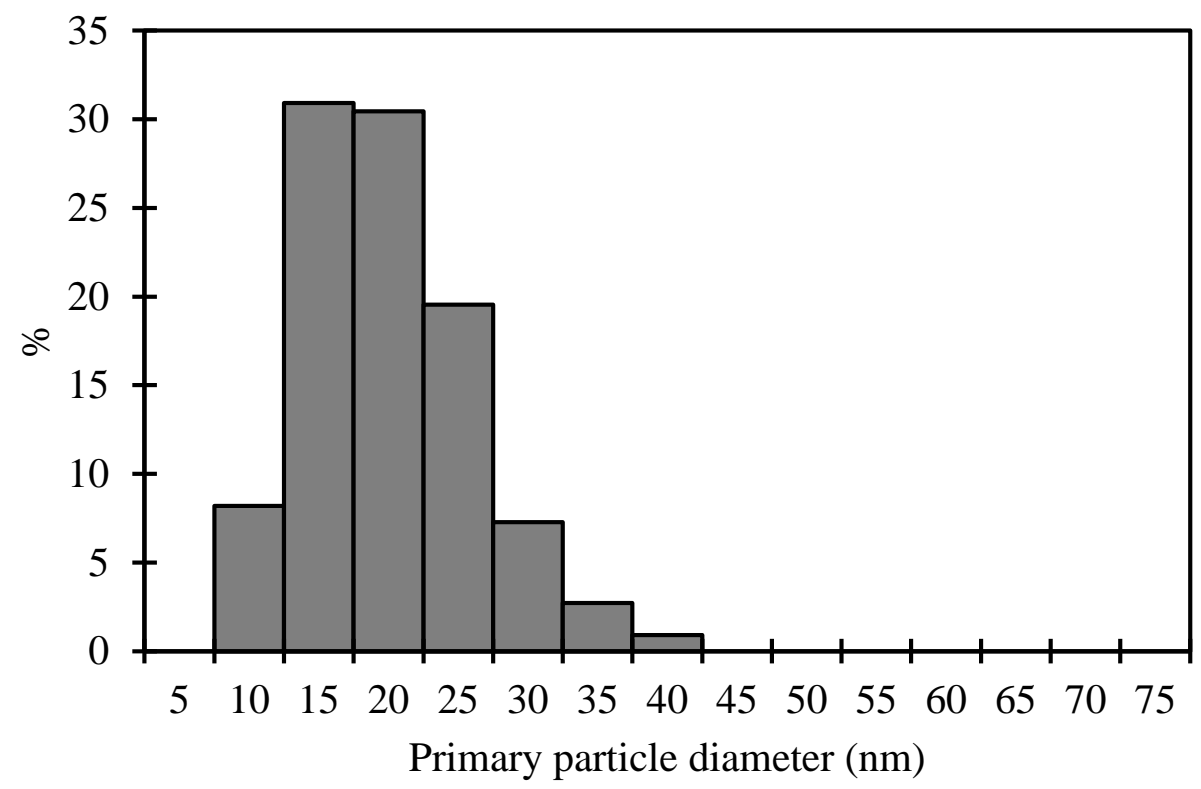

Figure 52: Distribution of the primary particle diameter observed at 20\% load

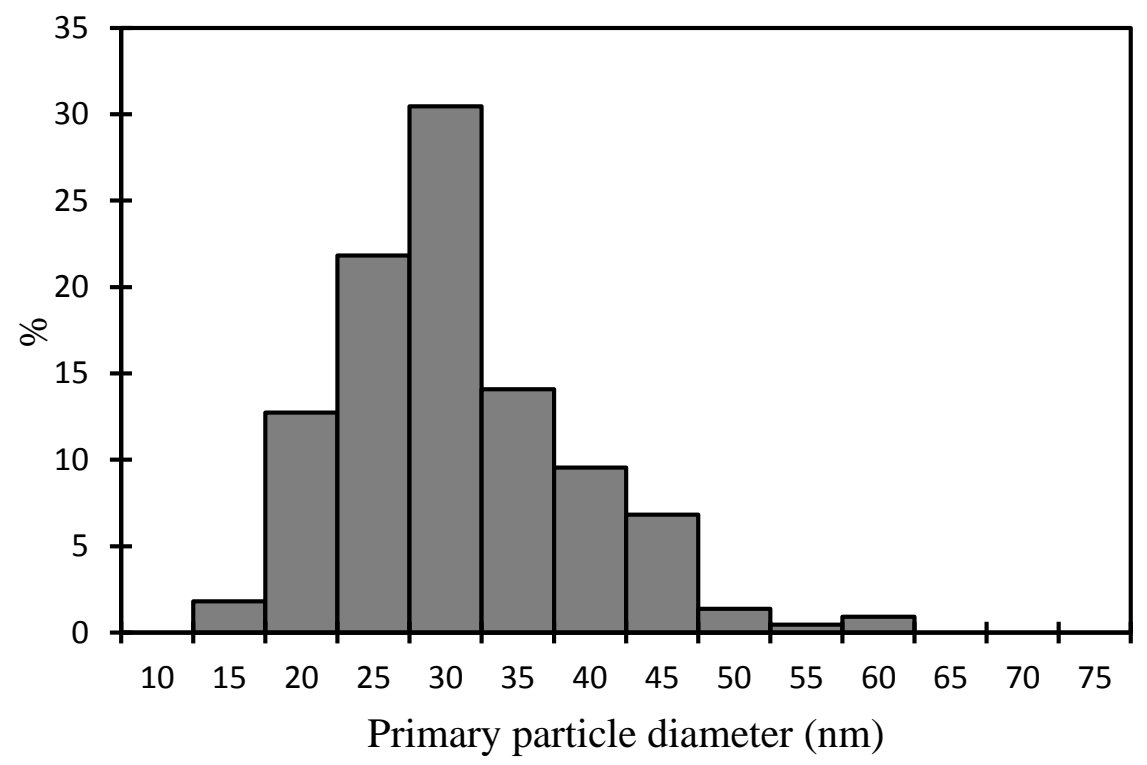

Figure 53: Distribution of the primary particle diameter observed at $40 \%$ load

Figure 54 and 55 shows distribution of the primary particle diameter observed at 50\% and $60 \%$ load respectively. The peak diameter of the primary PM particle shifts towards higher size as seen before in Figure 53. 


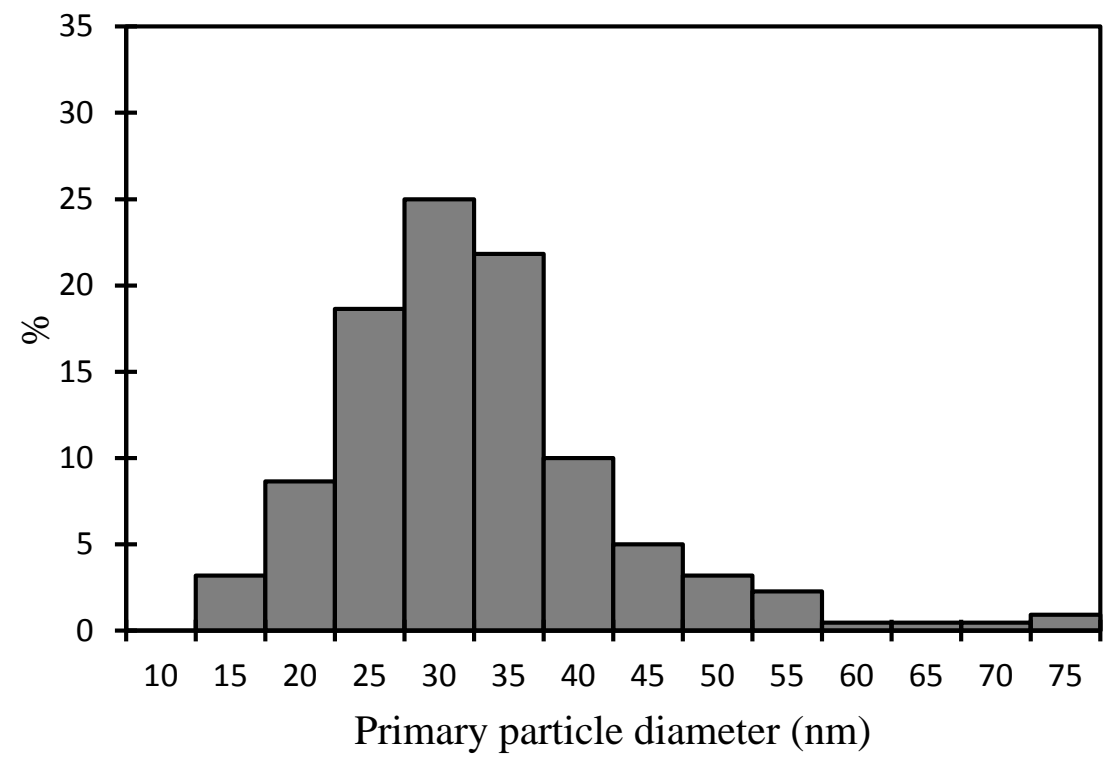

Figure 54: Distribution of the primary particle diameter observed at $50 \%$ load

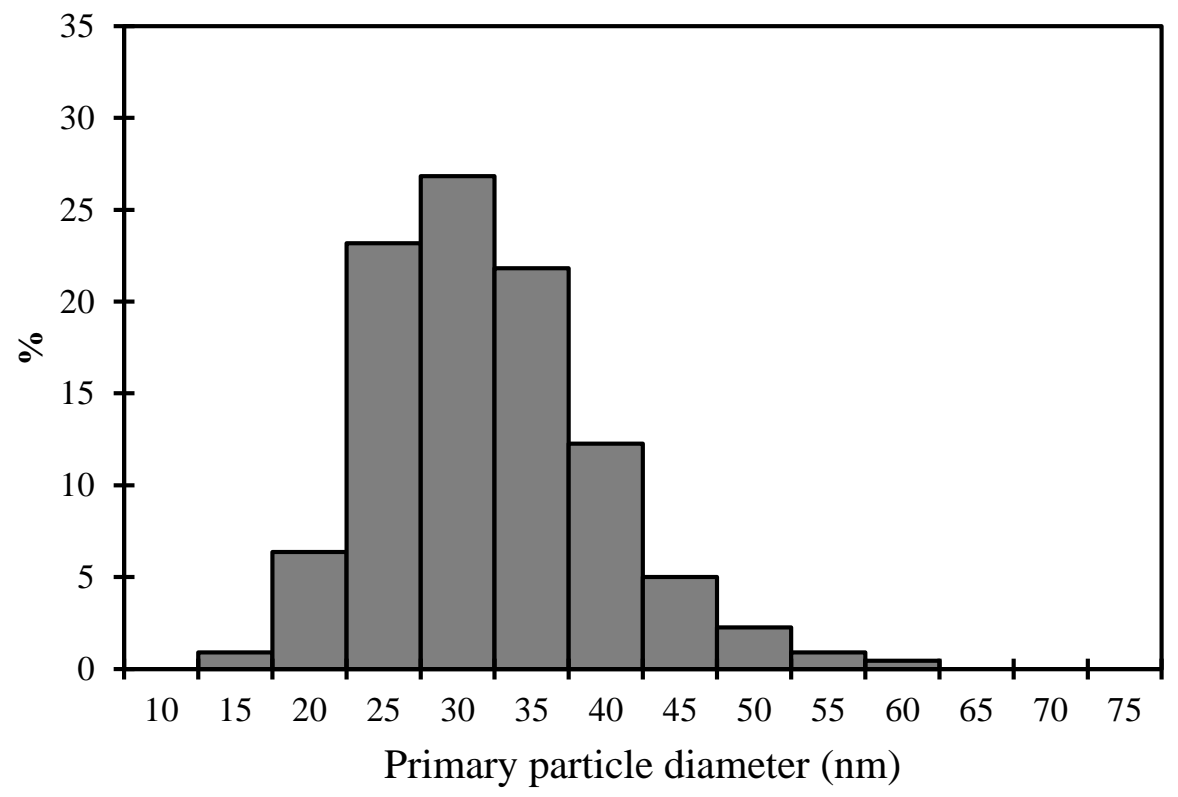

Figure 55: Distribution of primary particle diameter observed at 60\% load

The Figure 56 and 57 shows the distribution of the primary particle diameter observed at $75 \%$ and $90 \%$ load respectively. The peak diameter of the PM primary particles was found to shift towards the smaller diameter as seen in the histograms. This may be due to higher combustion temperatures which favor oxidation of PM particles $[38,39$, 46]. 


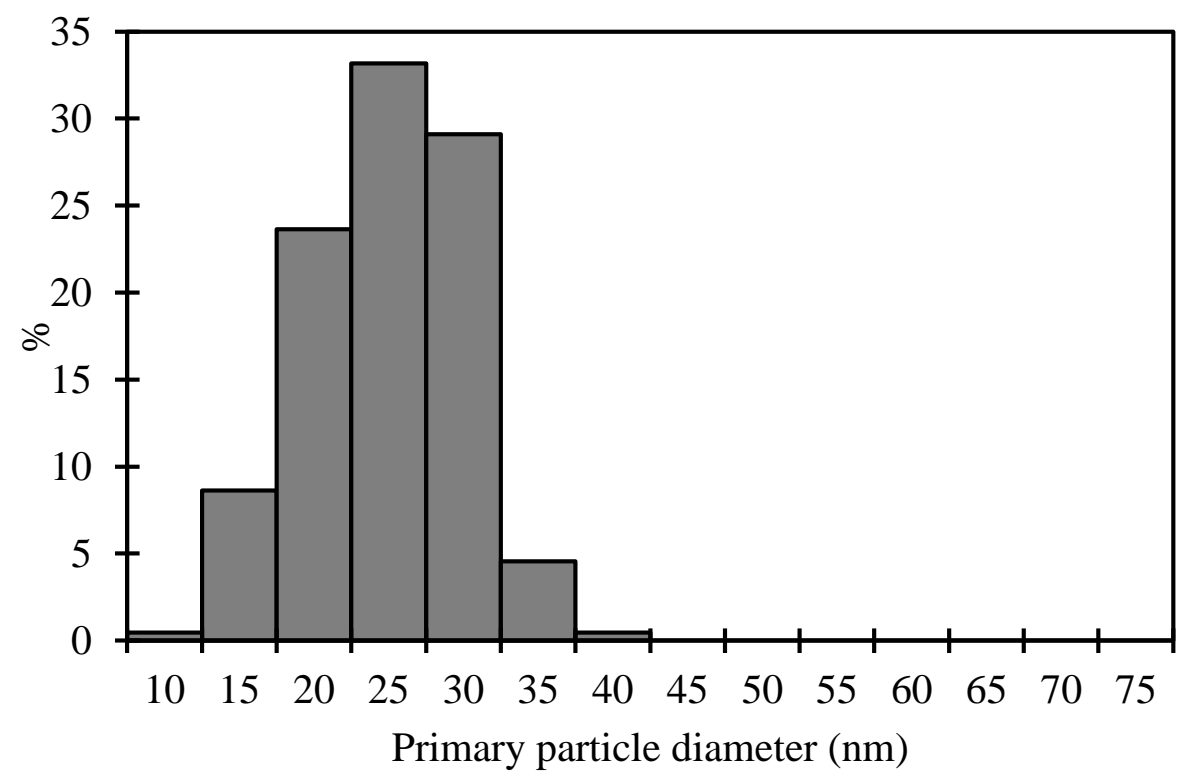

Figure 56: Distribution of the primary particle diameter observed at $75 \%$ load

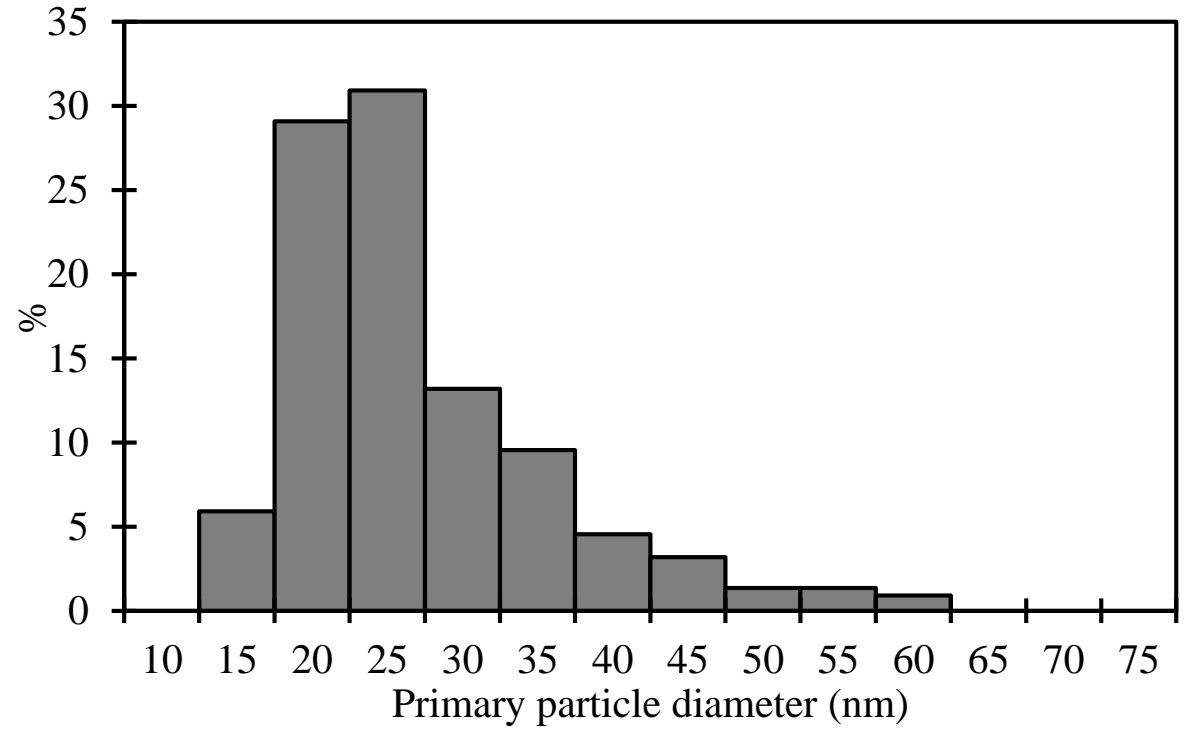

Figure 57: Distribution of the primary particle diameter observed at $90 \%$ load

The unusual shift of the peak diameter of the primary particle to the larger size in Figure 58 for the 95\% load cannot be explained. This might be due to less number of PM particles observed on the SEM grids during 95\% load. The size of the primary particles observed at full load has a peak towards small diameter as seen in Figure 59. 


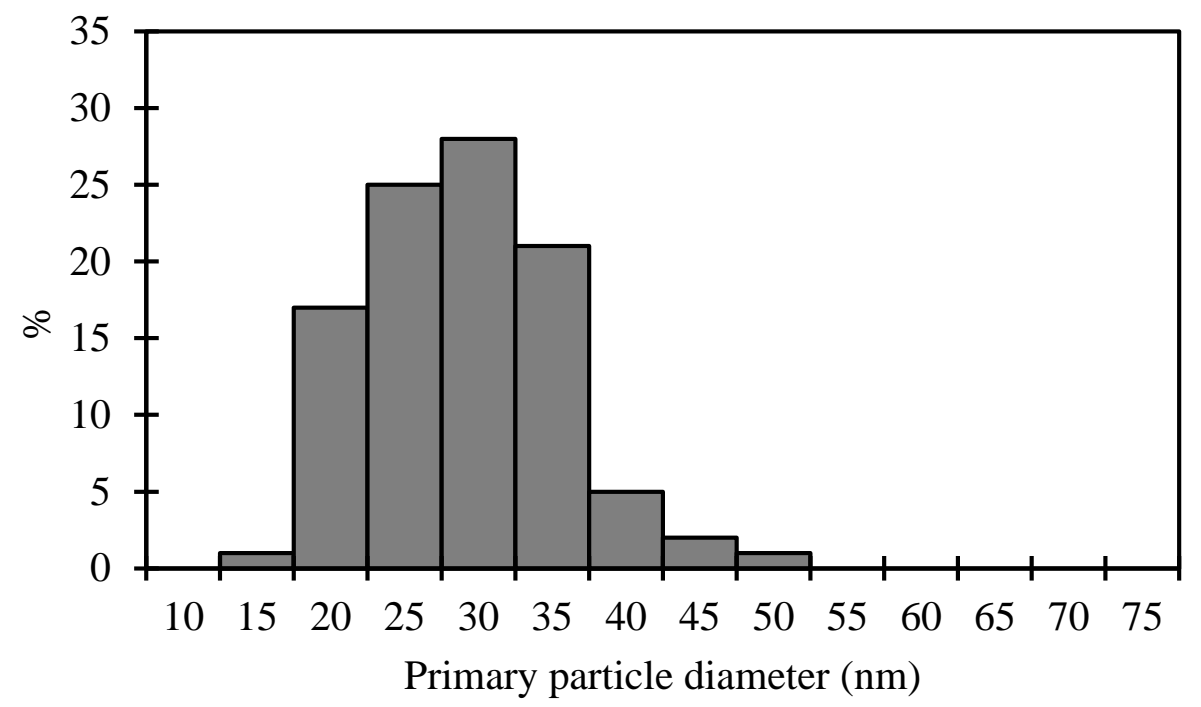

Figure 58: Distribution of the primary particle diameter observed at 95\% load

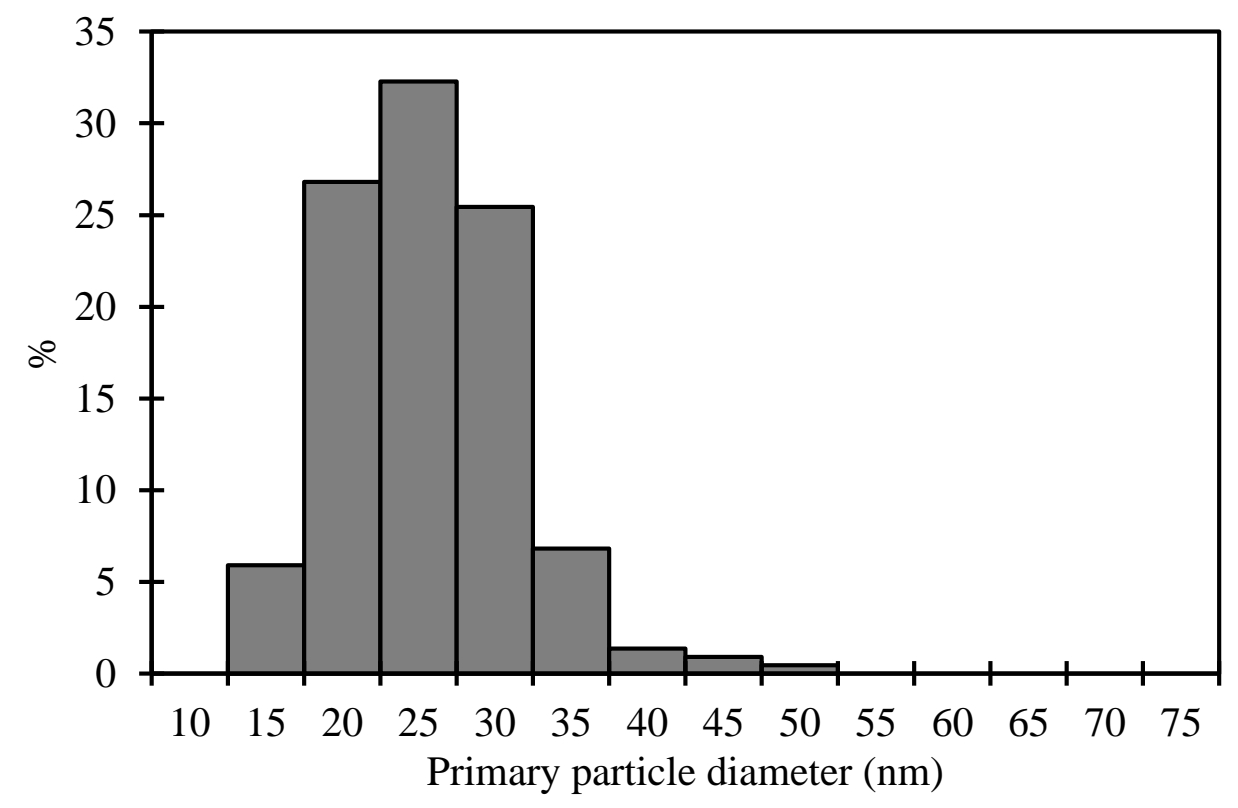

Figure 59: Distribution of primary particle diameter observed at full load

Figure 60 compares the primary particle diameter observed at 20\%, 50\% and 100\% load. The $20 \%$ load had smaller primary particle diameter. The 50\% load had the largest size of primary particle diameter among the three loads.

The average diameter of the primary particles from different loads is shown in the Table 5 and Figure 61 below. It was observed that the average size of particles near high loads is near constant with the exception of 95\% load. The average size of the particles increases as the load decreases which can be attributed to the lower combustion temperatures during low loads which 
favor the coagulation process. The lower size of the particles at $20 \%$ load may be as a result of high SOF which condense and grow to form nuclei mode particles.

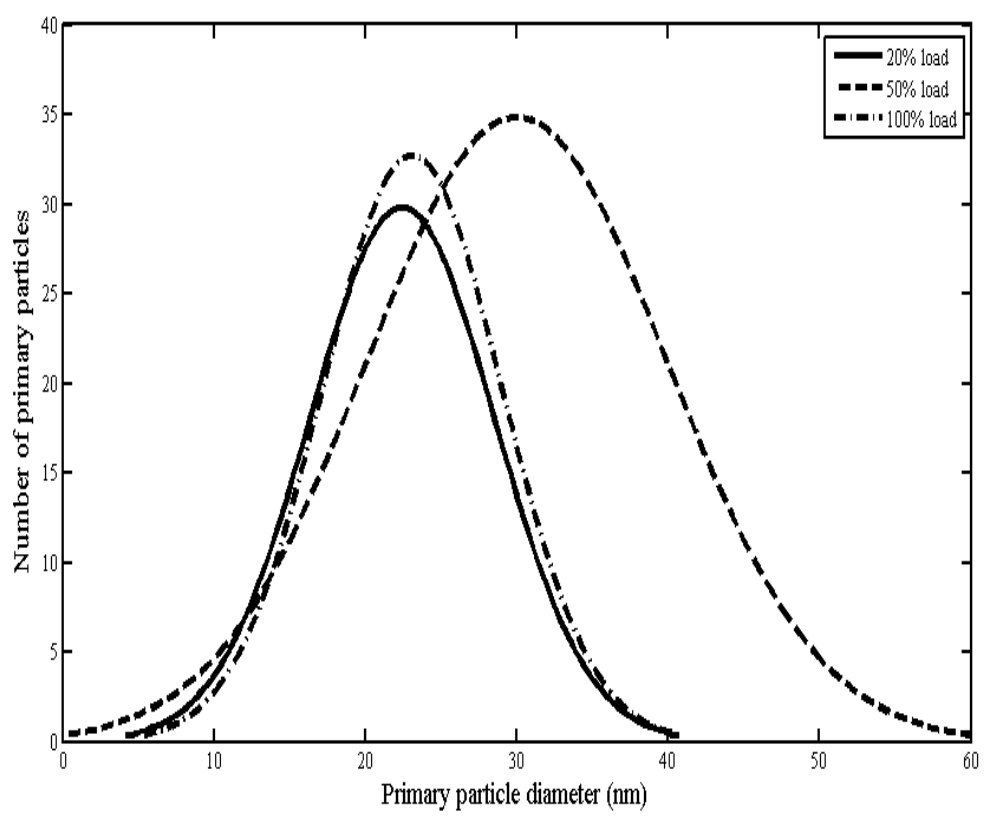

Figure 60: Comparison of primary particle diameter

Table 5: Average primary particle diameter

\begin{tabular}{|l|l|l|l|l|l|l|l|}
\hline Load & $20 \%$ & $40 \%$ & $50 \%$ & $60 \%$ & $75 \%$ & $90 \%$ & $100 \%$ \\
\hline $\begin{array}{l}\text { Average } \\
d_{p}(\mathrm{~nm})\end{array}$ & 22.43 & 28.16 & 30.01 & 29.36 & 22.64 & 24.3 & 23.09 \\
\hline
\end{tabular}

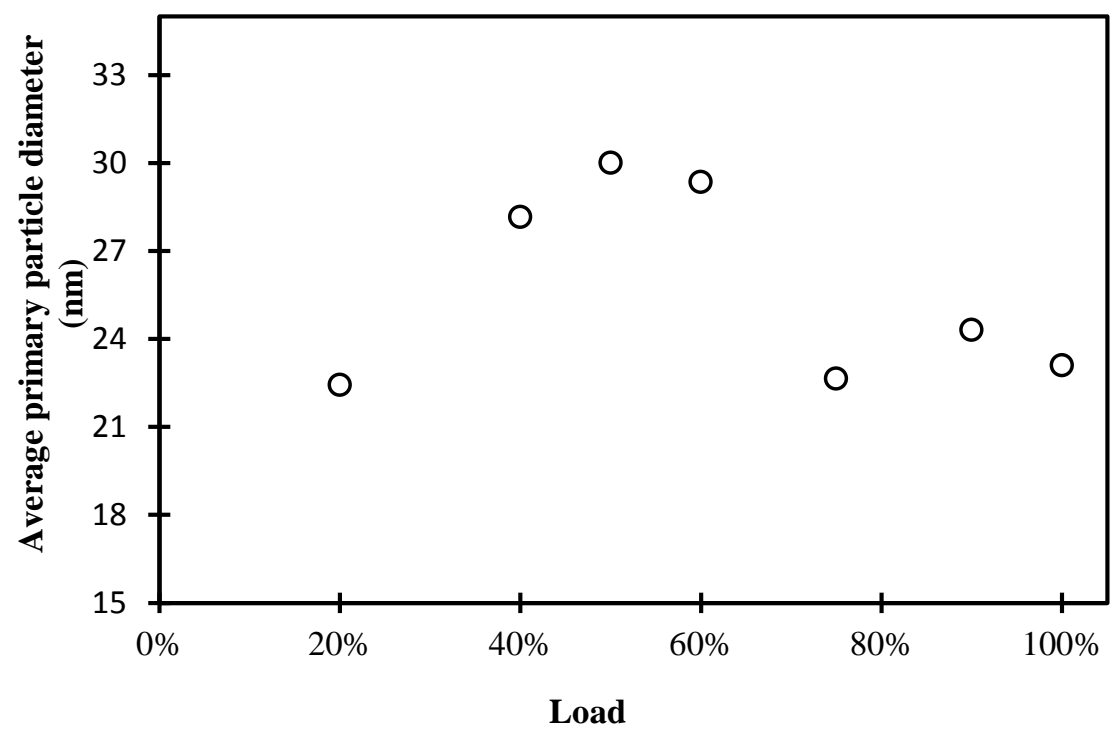

Figure 61: Variation of the average primary particle diameter with changes in engine load 


\subsection{Fractal dimension}

Although the observed primary particles are approximately spherical the PM particles have a complex 3D structure, the fractal dimension is widely used to describe the shape and structure of PM particles. In this research the fractal dimension of the agglomerates based on the maximum projected length is used in this study.

A plot of $\ln (n)$ vs. $\ln \left(\mathrm{L}_{\max } / \mathrm{d}\right)$ is shown in Figure 62. The slope of the linear fit gives the fractal dimension. The fractal dimension of the PM particles emitted from the heavy duty diesel engine is 1.82 which lies within the range of 1.75 to 1.88 for diesel agglomerates [44, 51]. Figure 63 and 64 shows PM particle during full load and 20\% load respectively. The full load PM particle as shown in Figure 63 is almost spherical with $D_{f l}=1.84$ and PM particle in Figure 64 is a long chain like PM with $D_{f l}=1.52$.

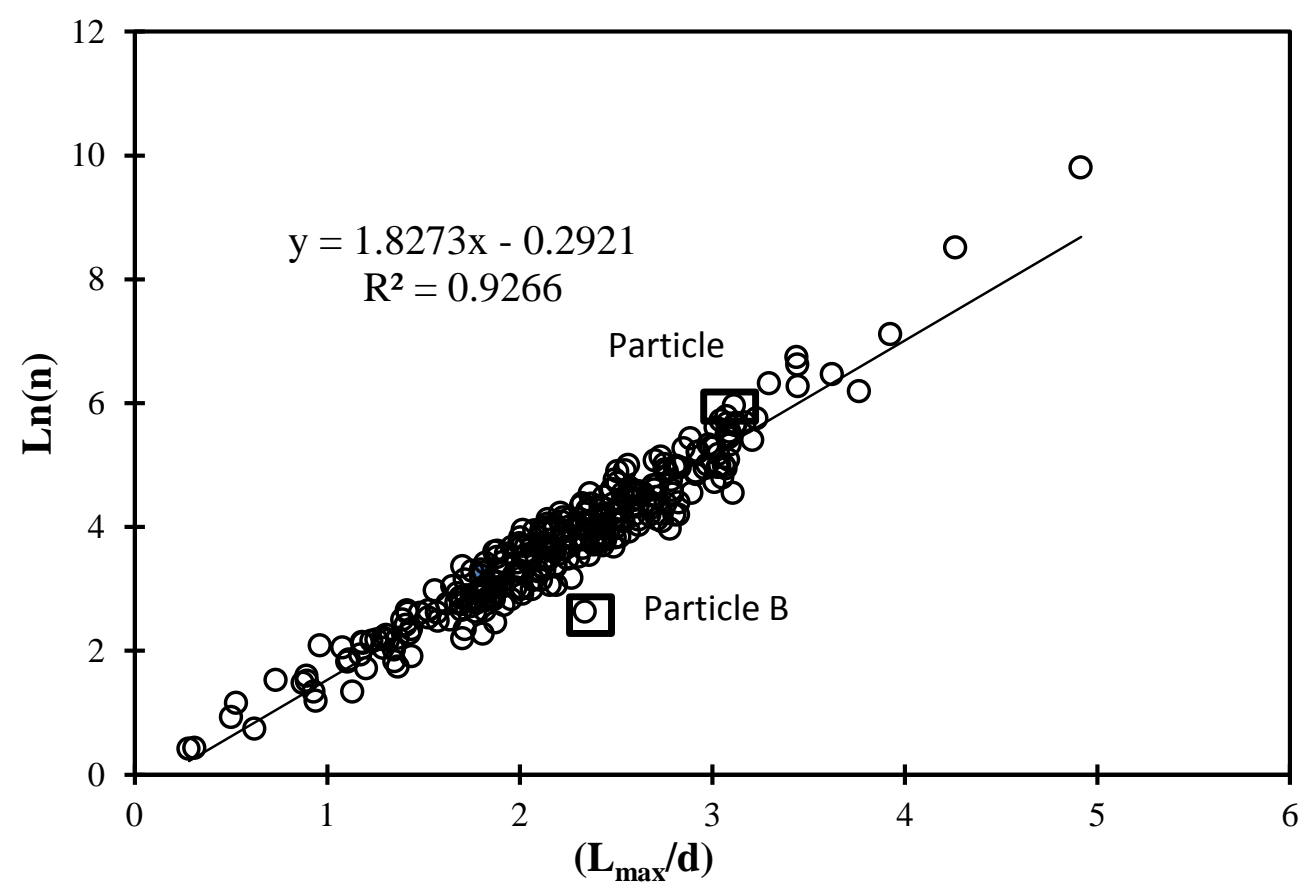

Figure 62: Plot of $\operatorname{Ln}(n)$ Vs. $\operatorname{Ln}\left(L_{\max } / d\right)$ 


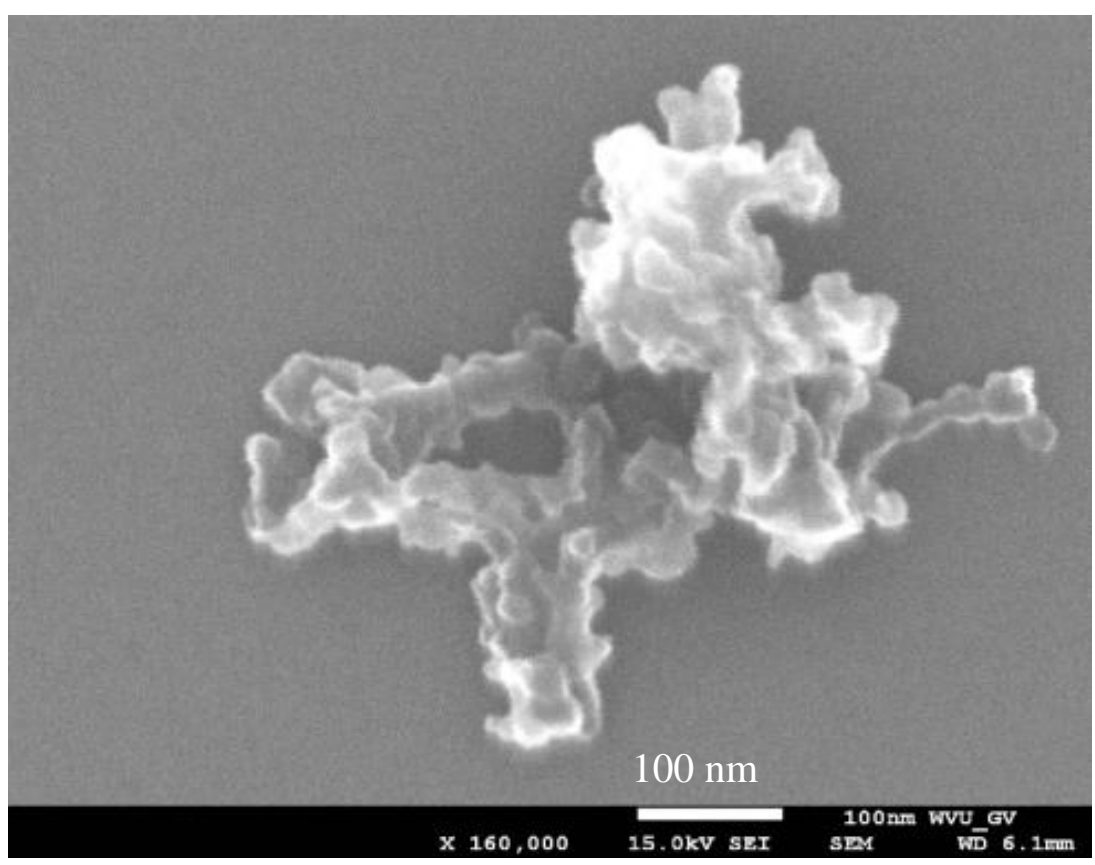

Figure 63: Particle A in Figure 62 observed at full load with $D_{f l}=1.84$

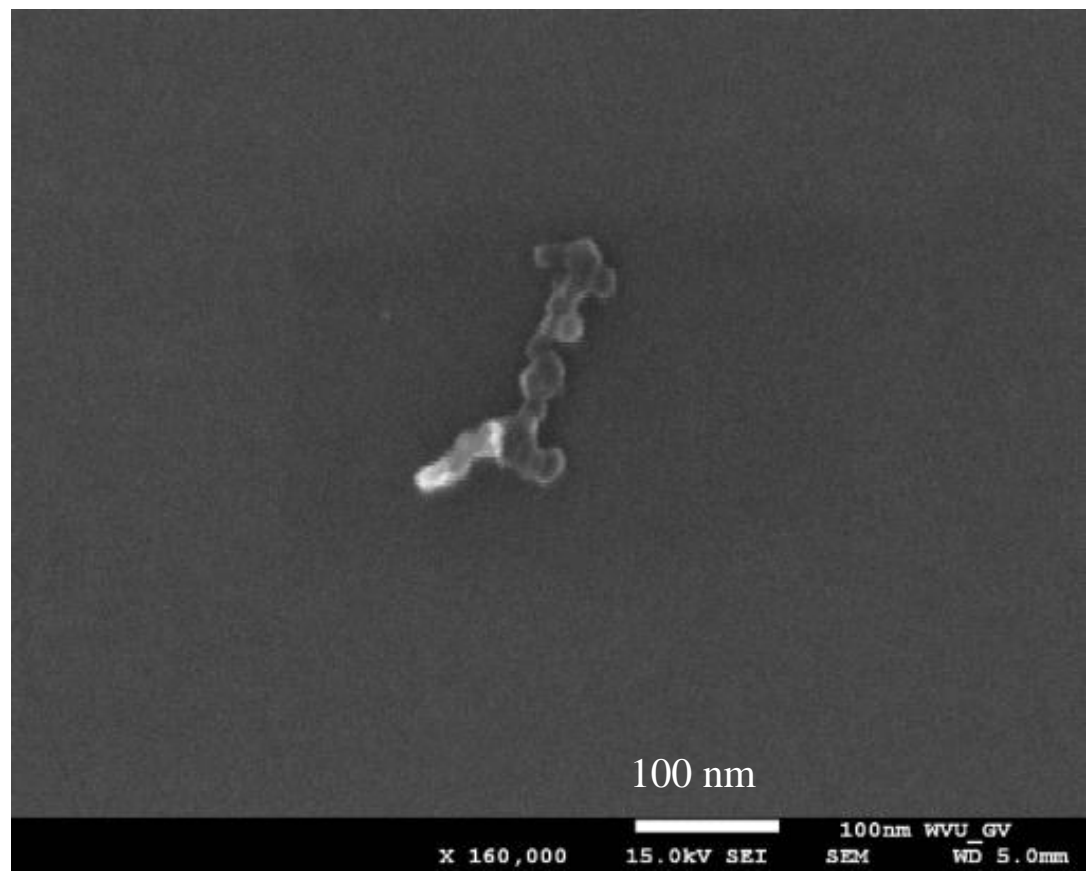

Figure 64: Particle B in Figure 62 observed at 20\% load with $D_{f l}=1.52$ 


\subsection{Shape descriptor}

The complex 3D shape of PM particles can also be described using shape descriptors [54]. There are two widely used shape descriptors including aspect ratio (AR) and roundness (RN) used for this study. Both are sensitive to elongation of PM particles. Using ImageJ these shape descriptors were calculated from the maximum projected width $\mathrm{W}_{\max }$, maximum projected length $\mathrm{L}_{\max }$ and projected area $A_{a}$, Figure 65 and 66 shows the variation of $A R$ and $R N$ with the change in projected area equivalent diameter. As the size increases both the variability and value of the aspect ratio are reduced, indicating formation of long chain like particles. A more pronounced change can be seen for roundness where the values and variability decreases as the size of the particle increase, indicating more elongated particles at large sizes. With the increase in size of $\mathrm{PM}$, the value of $\mathrm{AR}$ and $\mathrm{RN}$ were observed to shift towards small values indicating the formation of chain like particles. As shown in Figure 65 about 56.9\% of the PM particles had AR between 0.2 and 0.6 and about $11 \%$ of the PM particles had AR between 0.8 and 1.0. As seen in Figure 66 about $87.7 \%$ of the PM particles had RN between 0.2 and 0.6 indicating long particles. Only $1.2 \%$ of the PM particles had RN between 0.8 and 1.0 .

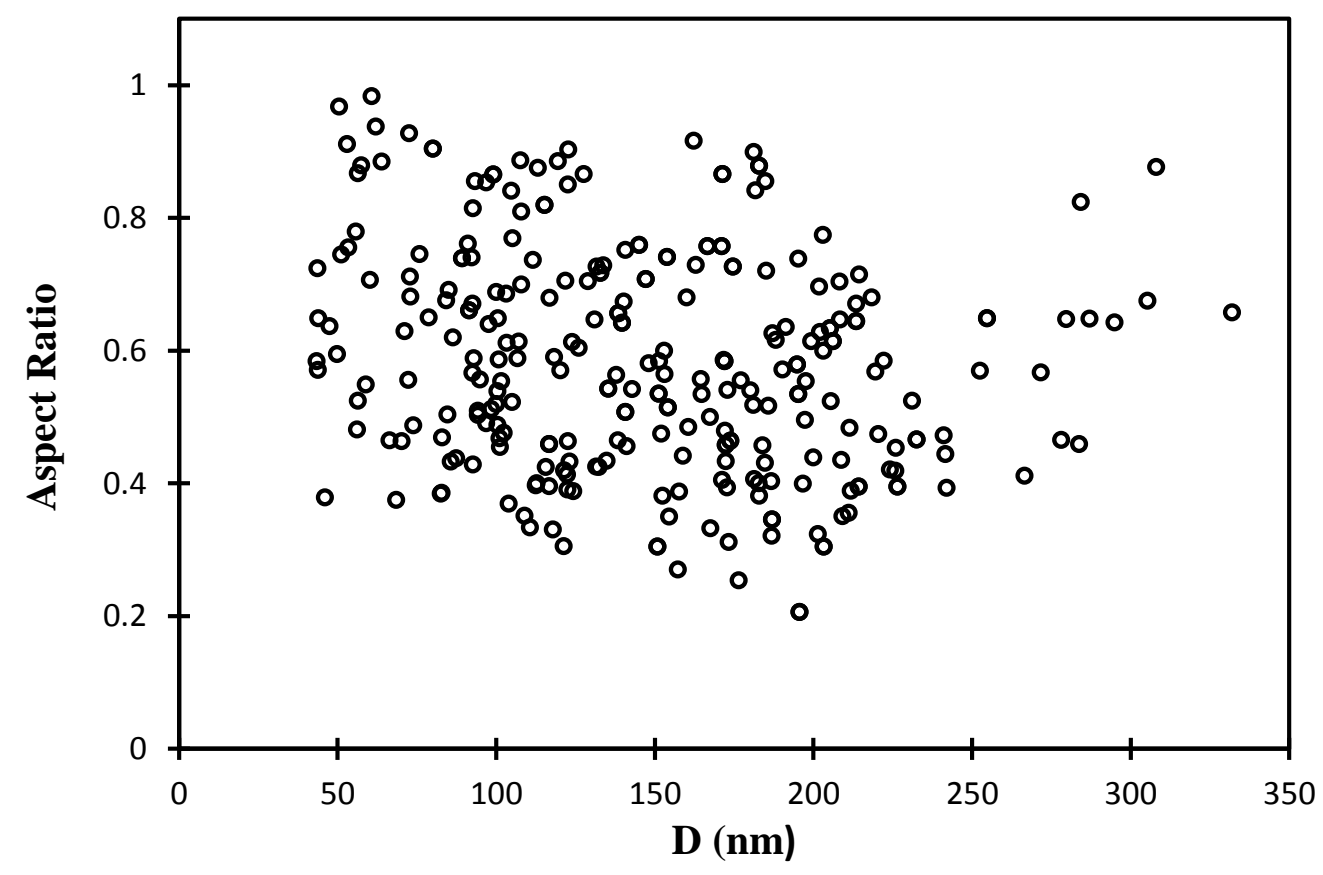

Figure 65: Aspect ratio of PM particles from heavy duty diesel engine 


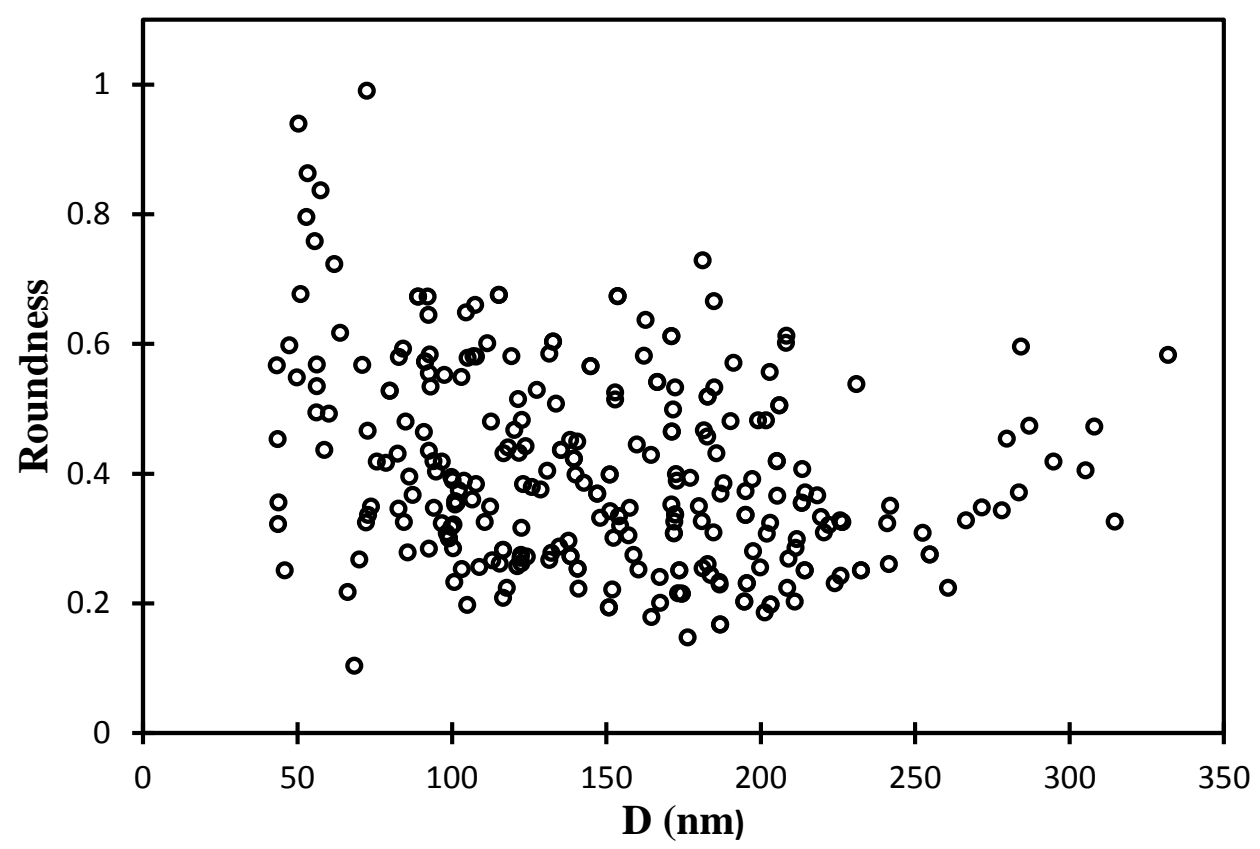

Figure 66: Roundness of PM particles from heavy duty diesel engine

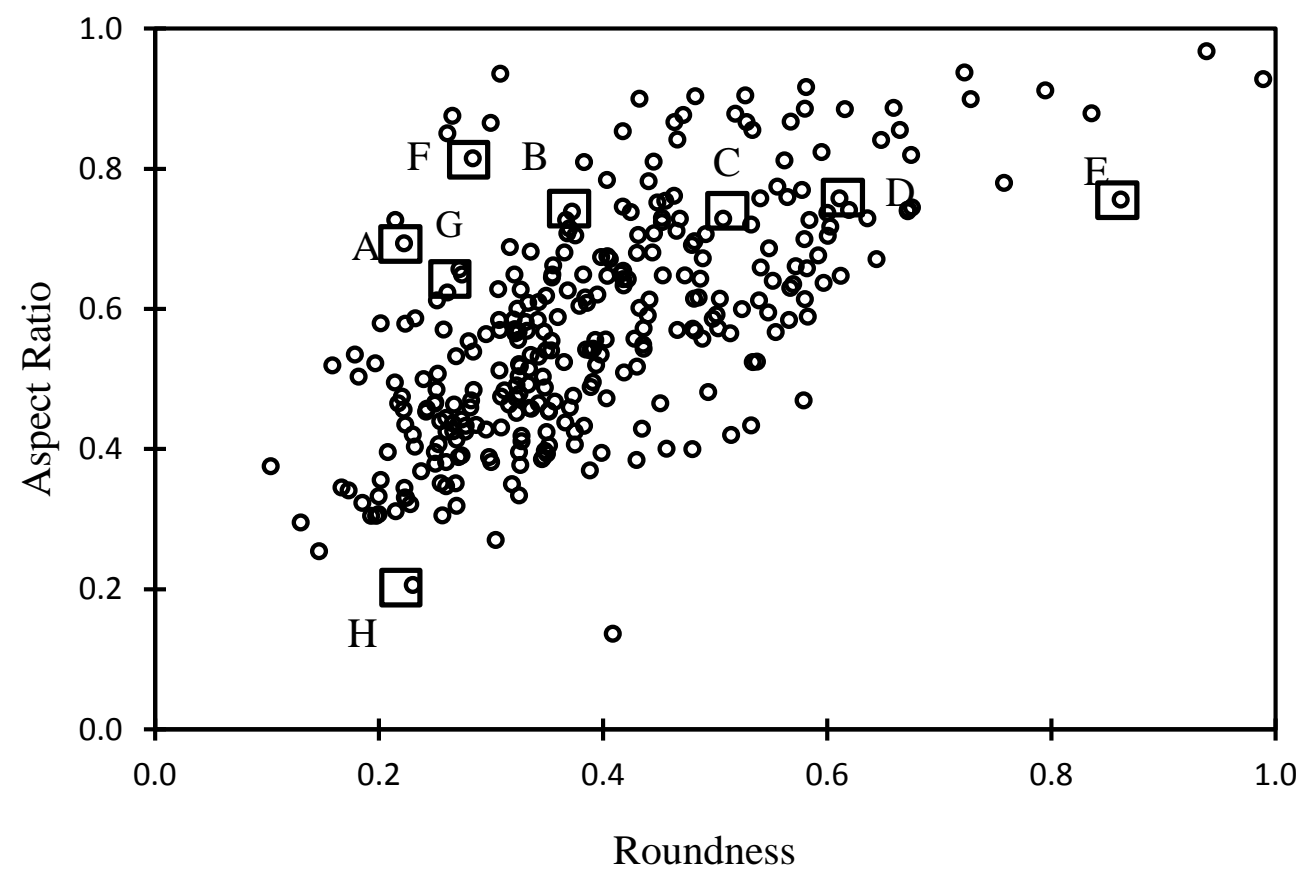

Figure 67: Roundness vs. Aspect ratio

Figure 67 shows the relationship between roundness and aspect ratio. Almost all the particles are long chain like PM with few particles exhibiting spherical shape with aspect ratio and roundness 
approaching the value 1 . Figure 68 to 75 shows different PM particle where roundness changes with small change in aspect ratio.

Figure 68 shows a PM particle from full load with as $R N=0.22$ and $A R=0.69$. Figure 69 is an accumulation mode PM particle observed at $75 \%$ load with $R N=0.36$ and $A R=0.72$ Figure 70 is a particle observed at $20 \%$ load with $A R=0.72$ and $R N=0.5$

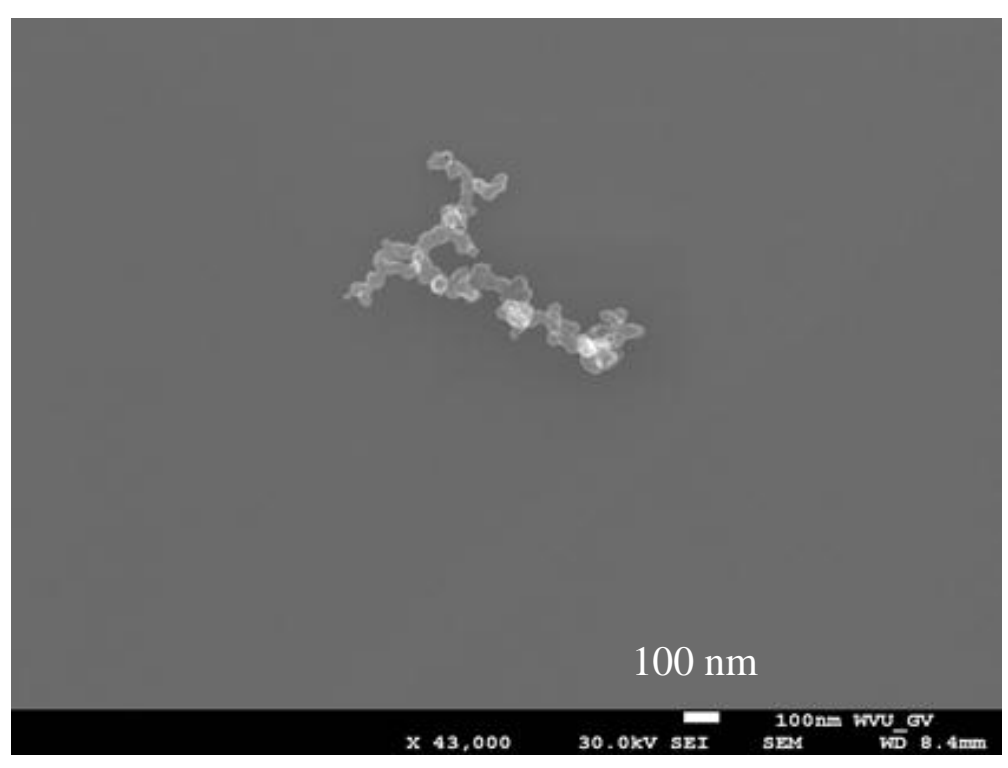

Figure 68: Particle A in Figure 67 observed at $90 \%$ load $A R=0.69$ and $R N=0.22$.

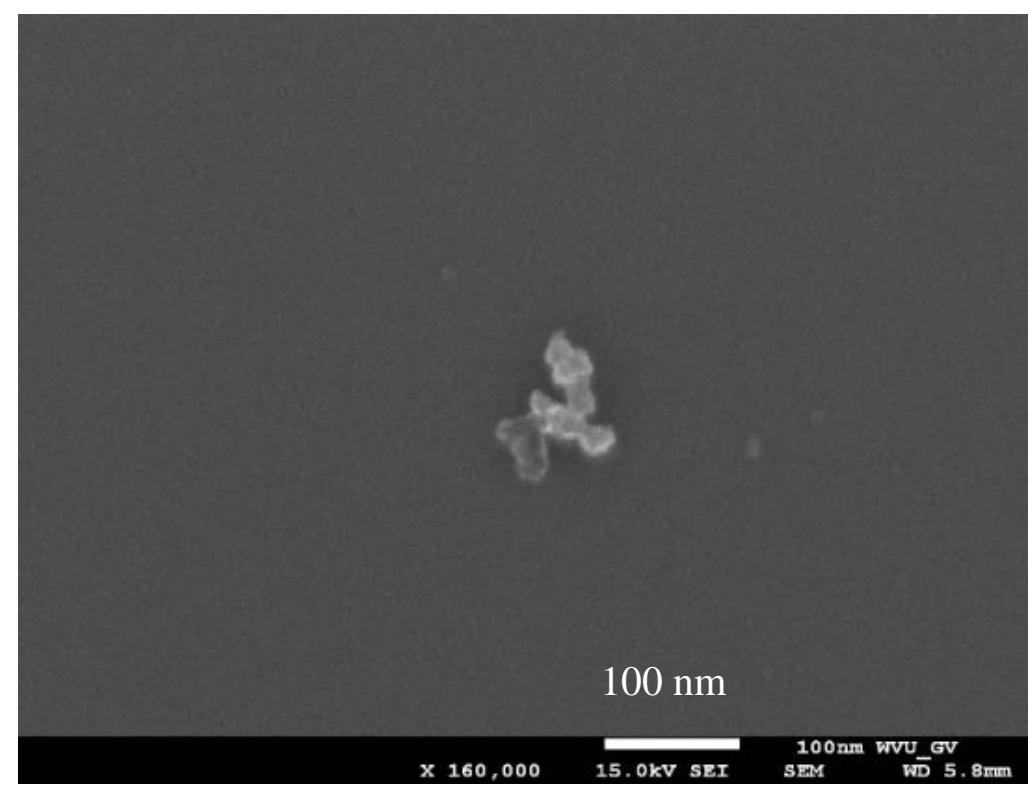

Figure 69: Particle B in Figure 67 observed at $75 \%$ load $A R=0.72$ and $R N=0.36$ 


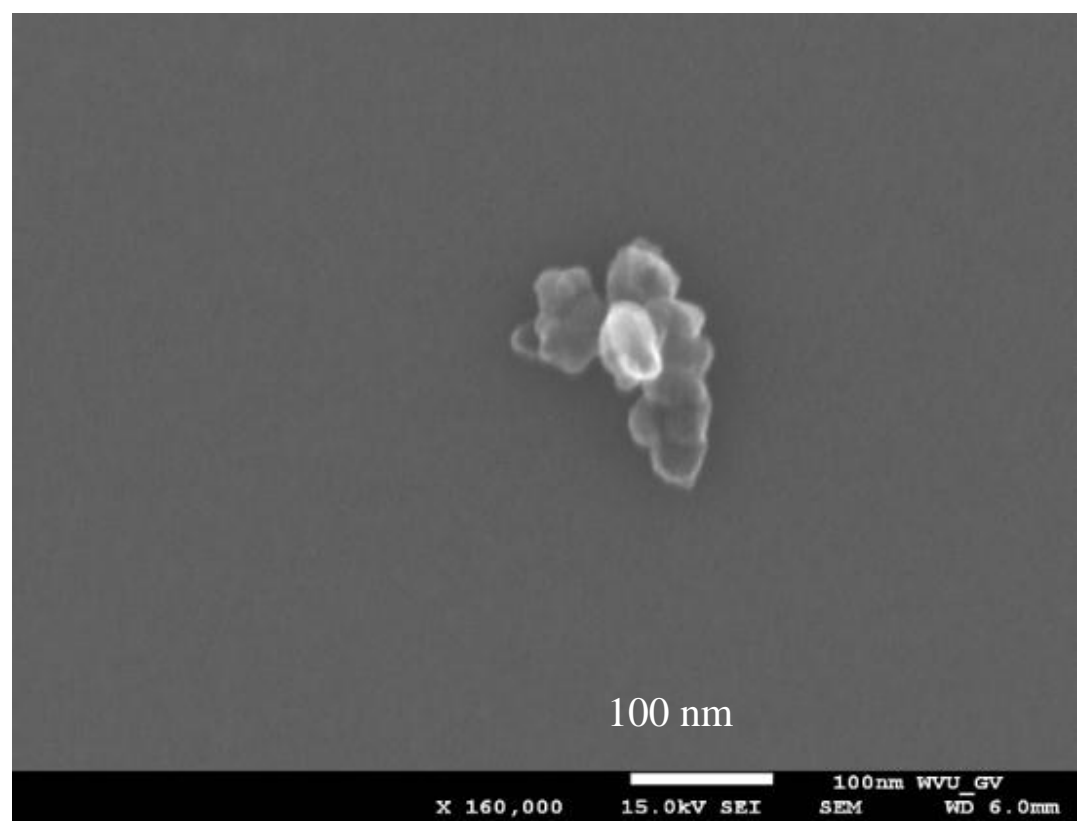

Figure 70: Particle C in Figure 67 observed at 20\% load $A R=0.72$ and $R N=0.5$

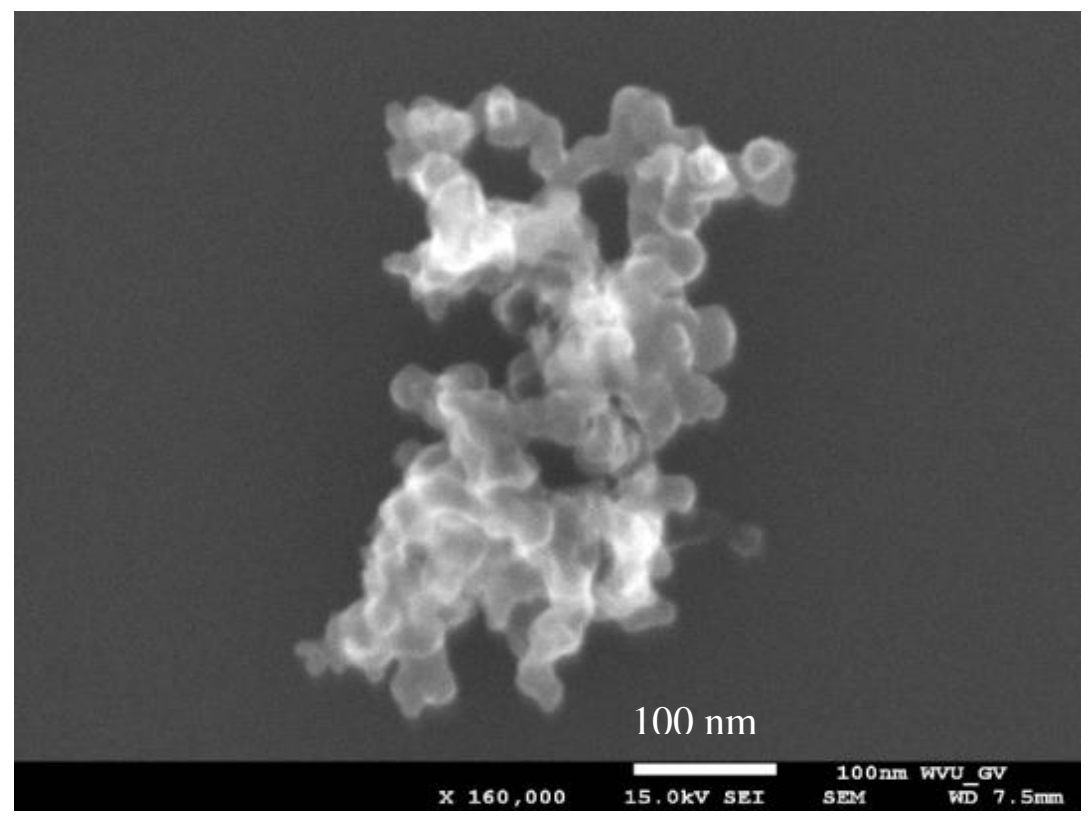

Figure 71: Particle D in Figure 67 observed at 40\% load $A R=0.75$ and $R N=0.61$

Figure 71 shows a particle observed at $40 \%$ load with $\mathrm{AR}=0.75$ and $\mathrm{RN}=0.61$. Figure 72 shows PM particles with $A R=0.75$ and $R N=0.86$ respectively. The particles are spherical in shape. Figure 73, 74 and 75 shows the variation of AR for particles having same RN value. It is observed that as the AR value decreases the particle becomes narrow and chain like. The 
comparison of fractal dimension, AR and RN for the PM particles in Figure 68 to Figure 75 is shown in Table 6.

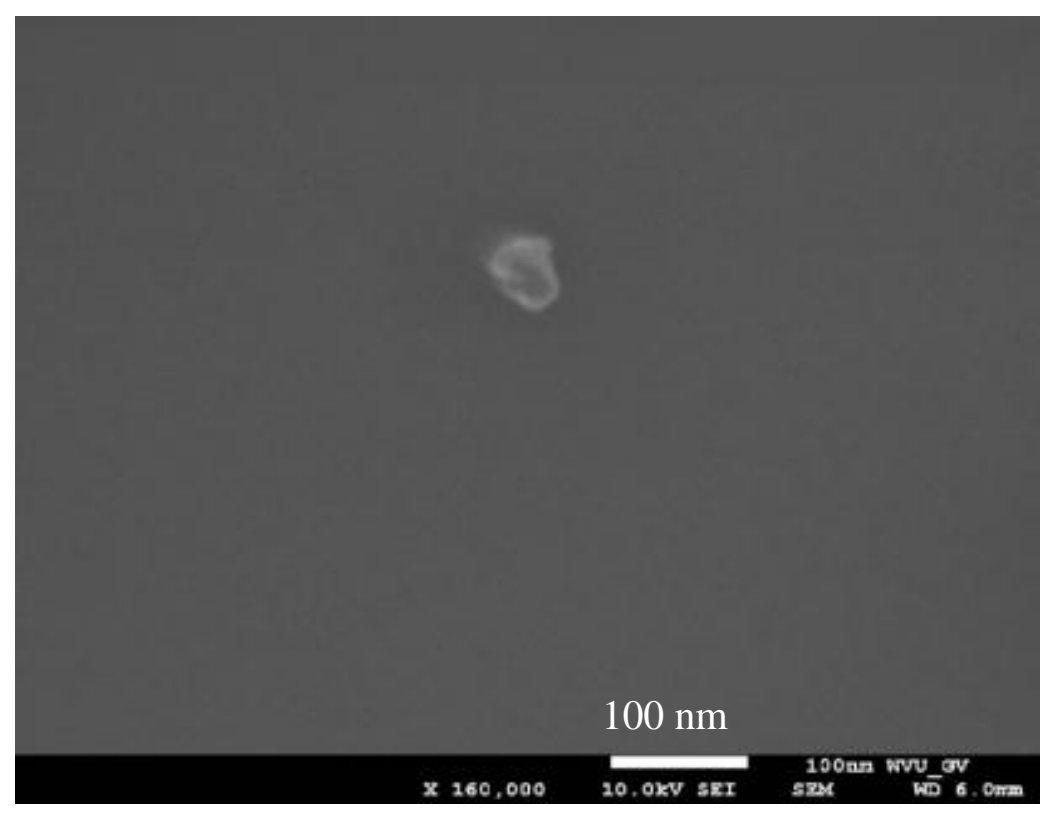

Figure 72: Particle $\mathbf{E}$ in Figure 67 observed at 50\% load $A R=0.75$ and $R N=0.86$

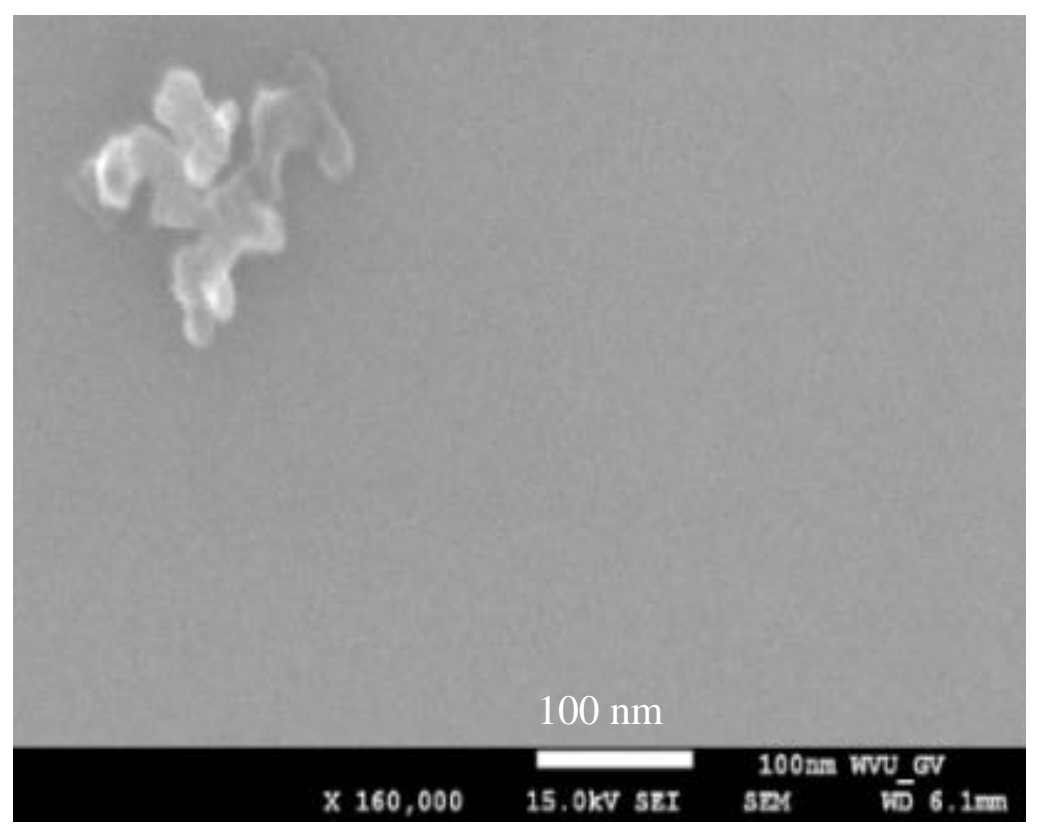

Figure 73: Particle F in Figure 67 observed at full load $A R=0.81$ and $R N=0.28$ 


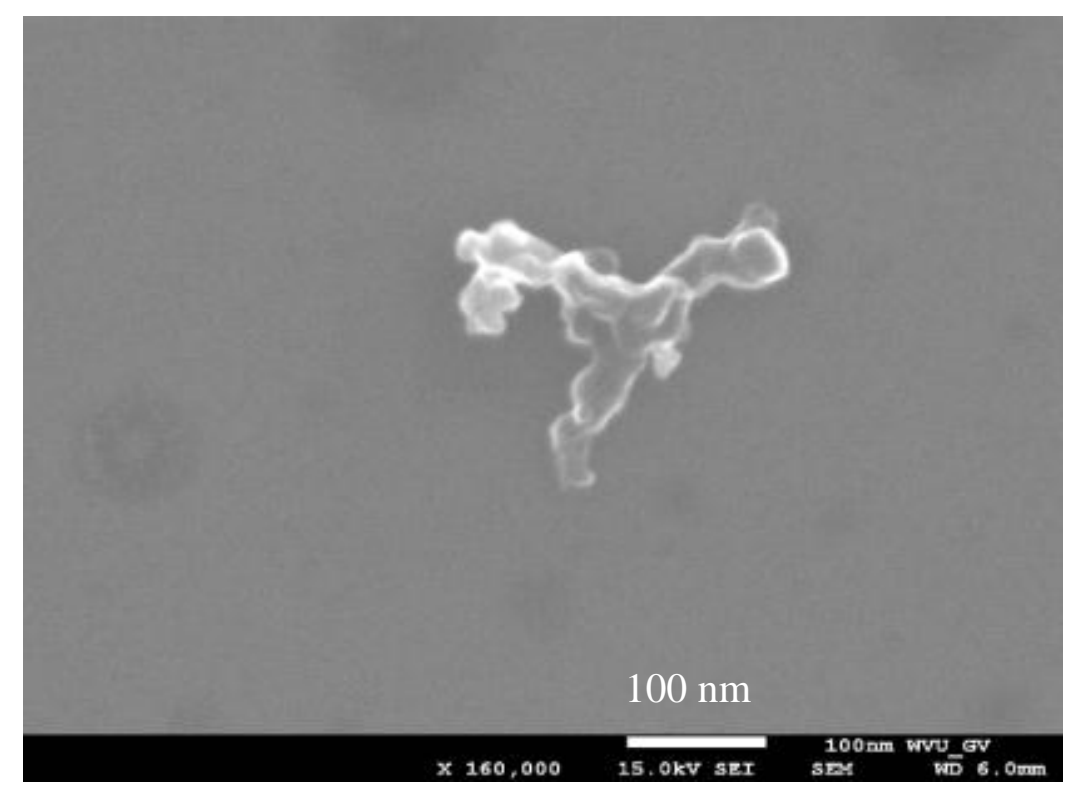

Figure 74: Particle G in Figure 67 observed at $40 \%$ load $A R=0.65$ and $R N=0.27$

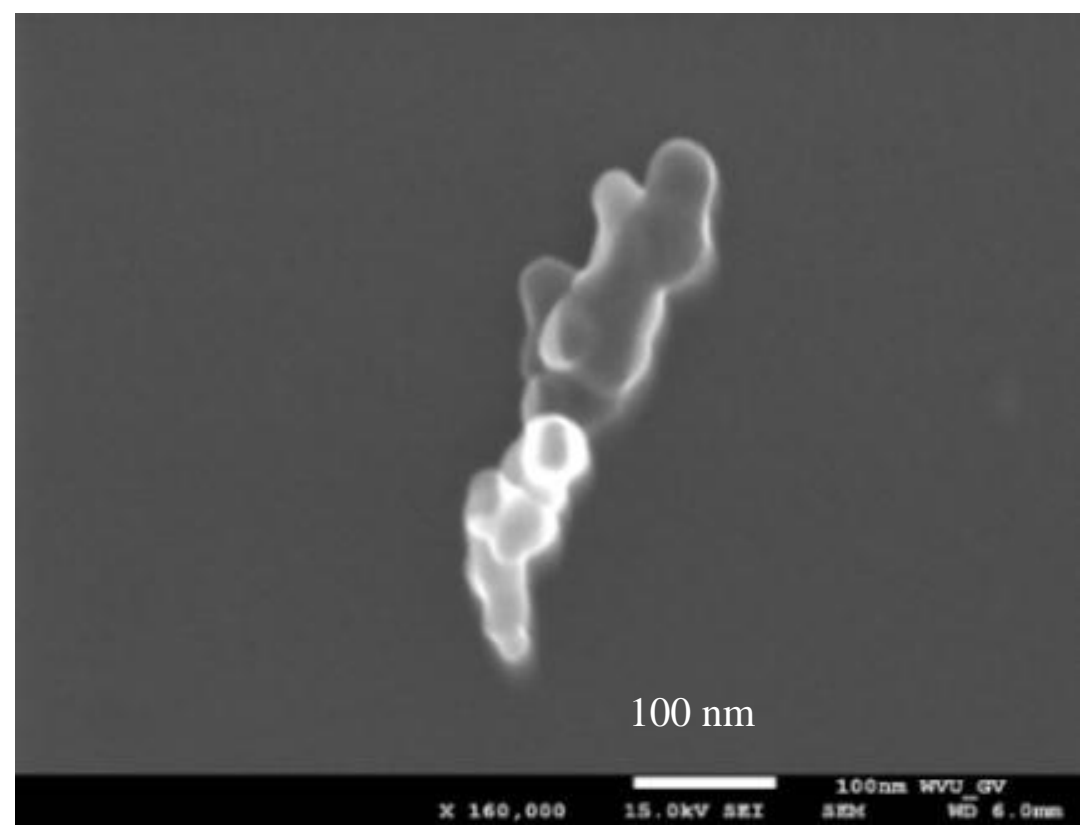

Figure 75: Particle $\mathbf{H}$ in Figure 67 observed at $40 \%$ load $A R=0.23$ and $R N=0.20$

Table 6: Comparison of $D_{f l}, A R$ and $R N$ for PM particles

\begin{tabular}{|c|c|c|c|c|c|c|c|c|}
\hline Particle & $\mathrm{A}$ & $\mathrm{B}$ & $\mathrm{C}$ & $\mathrm{D}$ & $\mathrm{E}$ & $\mathrm{F}$ & $\mathrm{G}$ & $\mathrm{H}$ \\
\hline $\mathrm{D}_{\mathrm{fl}}$ & 1.6 & 1.52 & 1.76 & 1.75 & 1.69 & 1.67 & 1.67 & 1.5 \\
\hline $\mathrm{AR}$ & 0.69 & 0.72 & 0.72 & 0.75 & 0.75 & 0.81 & 0.65 & 0.23 \\
\hline $\mathrm{RN}$ & 0.22 & 0.36 & 0.50 & 0.61 & 0.86 & 0.28 & 0.27 & 0.2 \\
\hline
\end{tabular}




\subsection{TEM image}

PM particles from the heavy duty diesel engine were analyzed using high resolution TEM. Figure 76 and 77 shows a typical micrograph of PM particle observed using TEM. The agglomerate is made of hundreds of spherical primary particles.

The primary particles exhibit two types of crystalline structure. The first one had graphitic structure in concentric layers roughly parallel and equidistant as shown in Figure 78. This structure is similar to that of an onion. The second type of structure is similar to that of the first one with concentric rings on the outside, but with several spherical nuclei in the core region surrounded by graphitic layers. This structure is shown in Figure 79. The spherical nuclei are shown by the arrows.

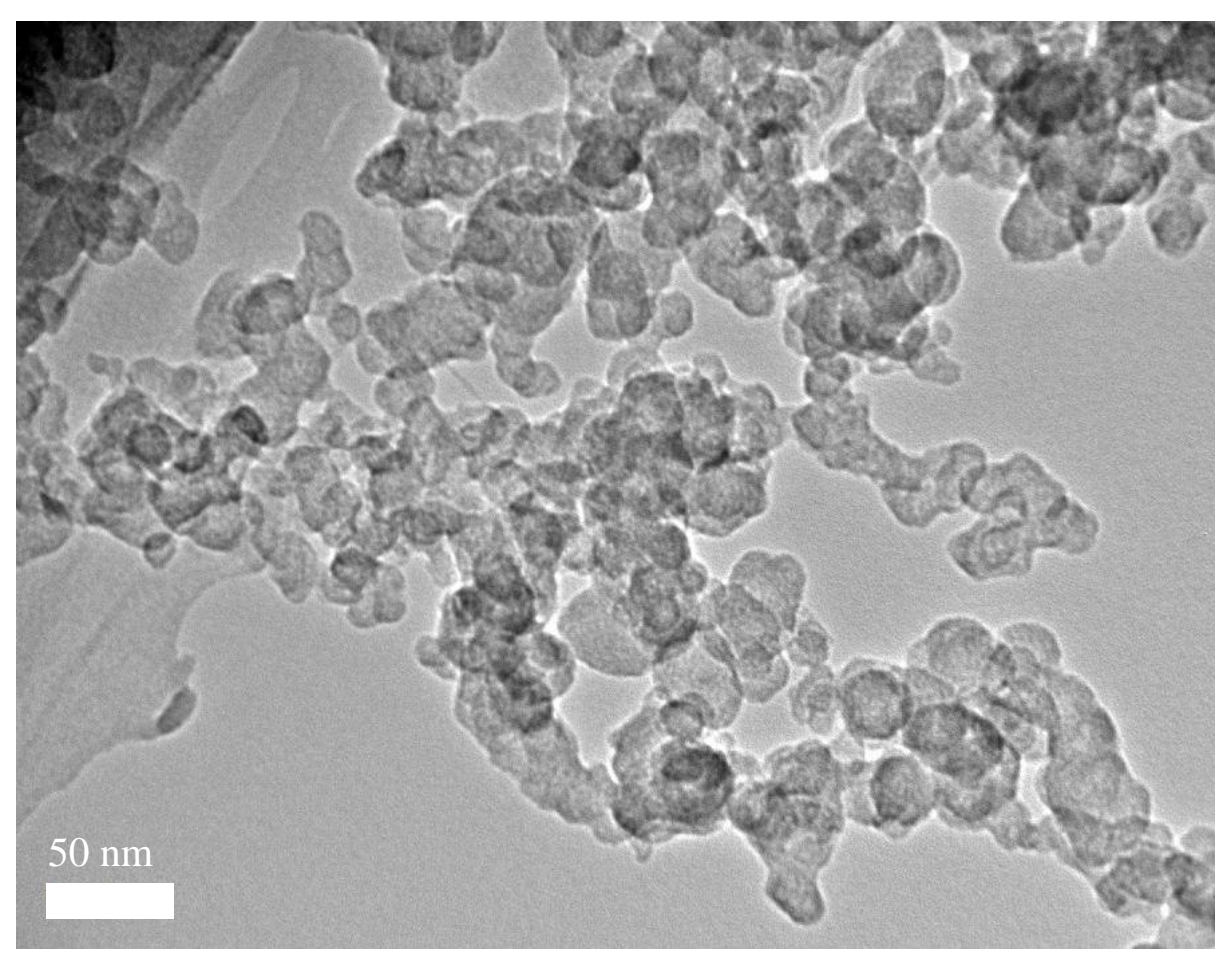

Figure 76: PM agglomerate when operated at full load as seen using TEM 


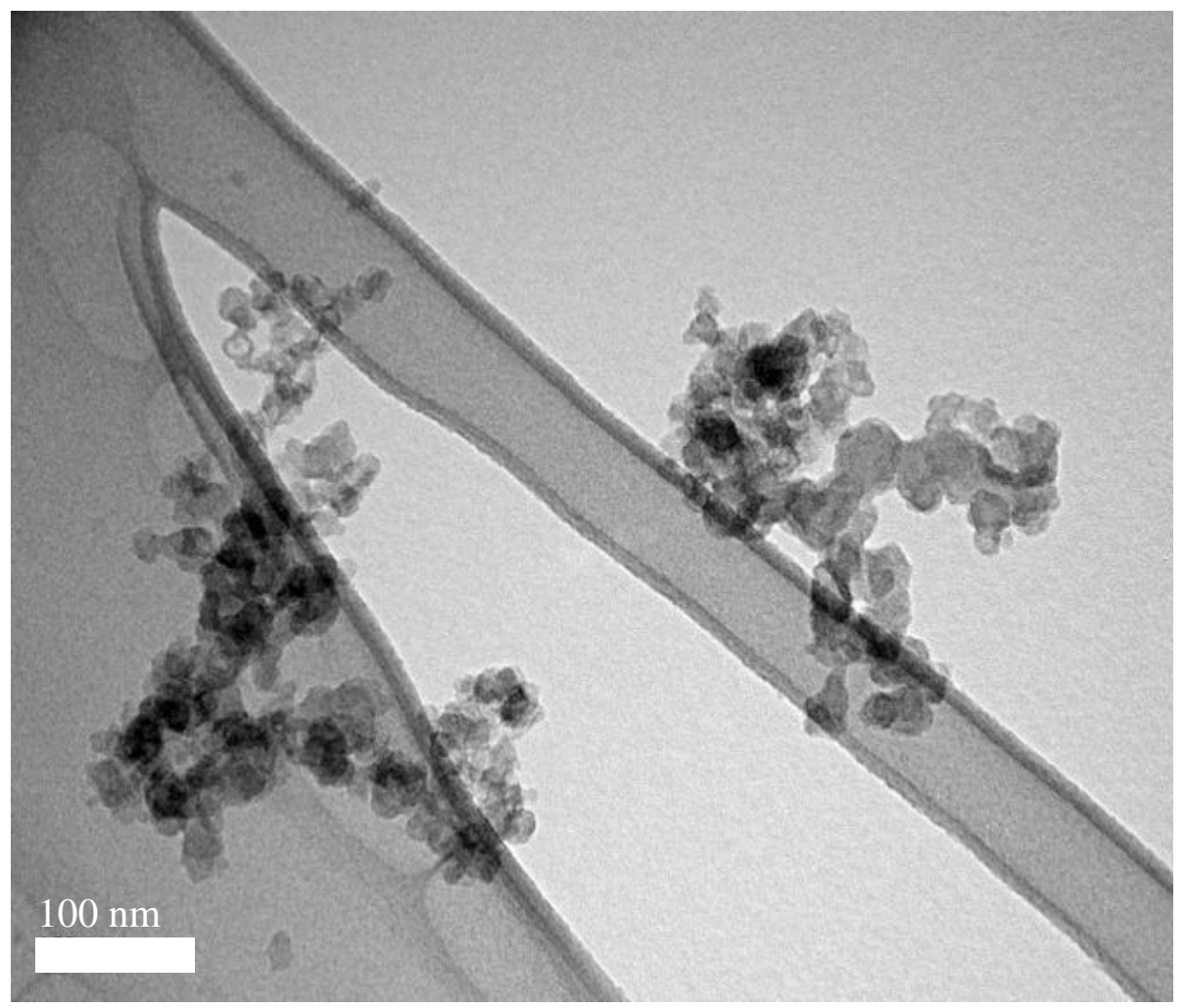

Figure 77: PM agglomerate observed at $95 \%$ load

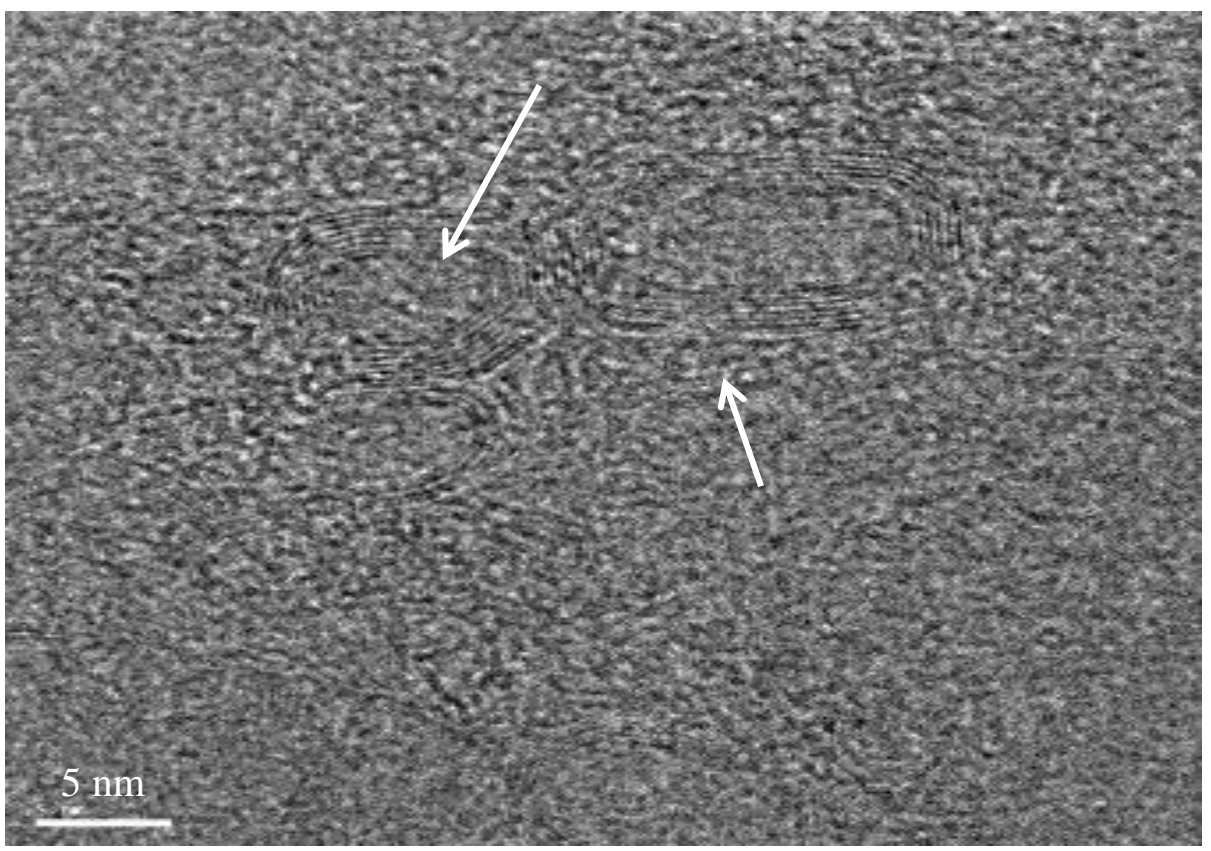

Figure 78: Primary particle with concentric ring structure observed at $75 \%$ load 


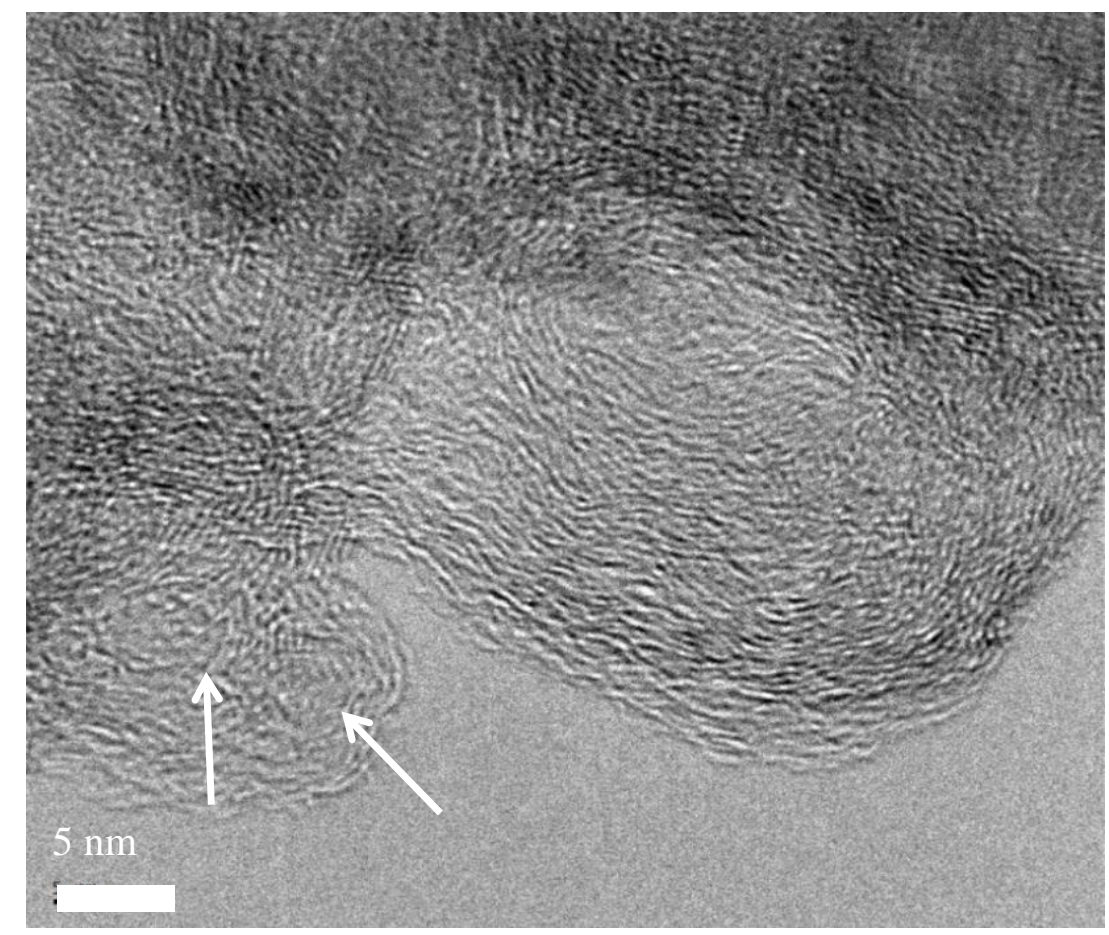

Figure 79: Primary particle observed at $90 \%$ load with multiple nuclei in the core

Figure 80 shows the highly bent grapheme layers resembling a fullerene. This structure is formed by the deposition of gas phase hydrocarbons particularly PAHs on soot particles followed by internal rearrangement of solid phase carbon [37]. This type of structure is more reactive due to surface functionality and hence the oxidation temperature of the fullerene like particles is less than the more stable carbon black [36].

Carbon nanotubes in the PM from the diesel engine were observed at high load as shown in Figure 81. This type of structure was previously observed when investigating the oxidation process of PM from an engine operating on $100 \%$ biodiesel [54]. As shown in Figure 81 the structure consists of long concentrically arranged graphitic layers with amorphous inner core. As the oxidation proceeds the outermost layers are oxidized through surface burning. Once sufficient micro pores are developed, inner core oxidation takes place and the soot undergoes significant mass loss in the inner core and the inside hollows out. The intermediate layers which are less graphitic than the outer layers but more graphitic than the inner core undergo structural rearrangement and coalesce where the circular layers become much flatter and longer [54]. 


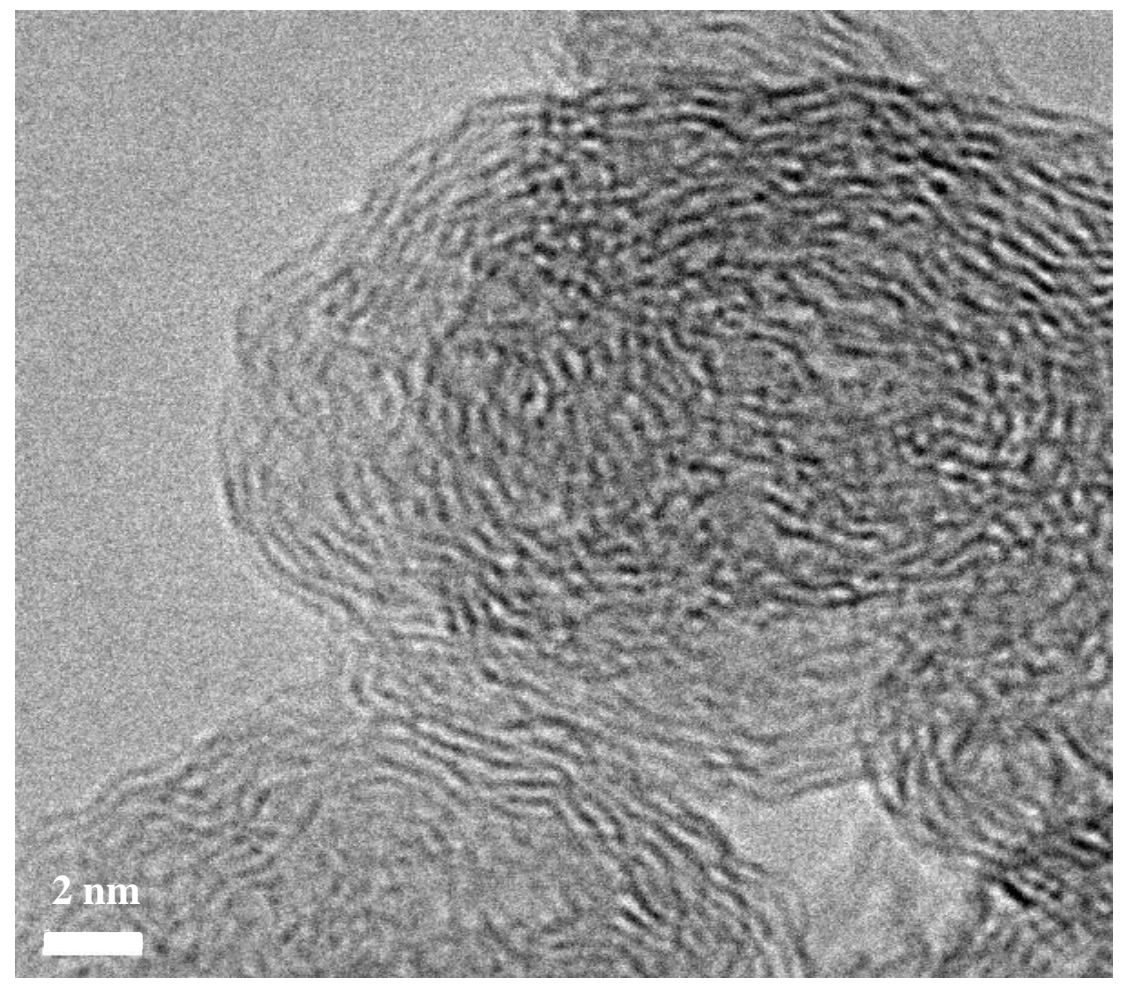

Figure 80: Fullerene like structure observed at $95 \%$ load

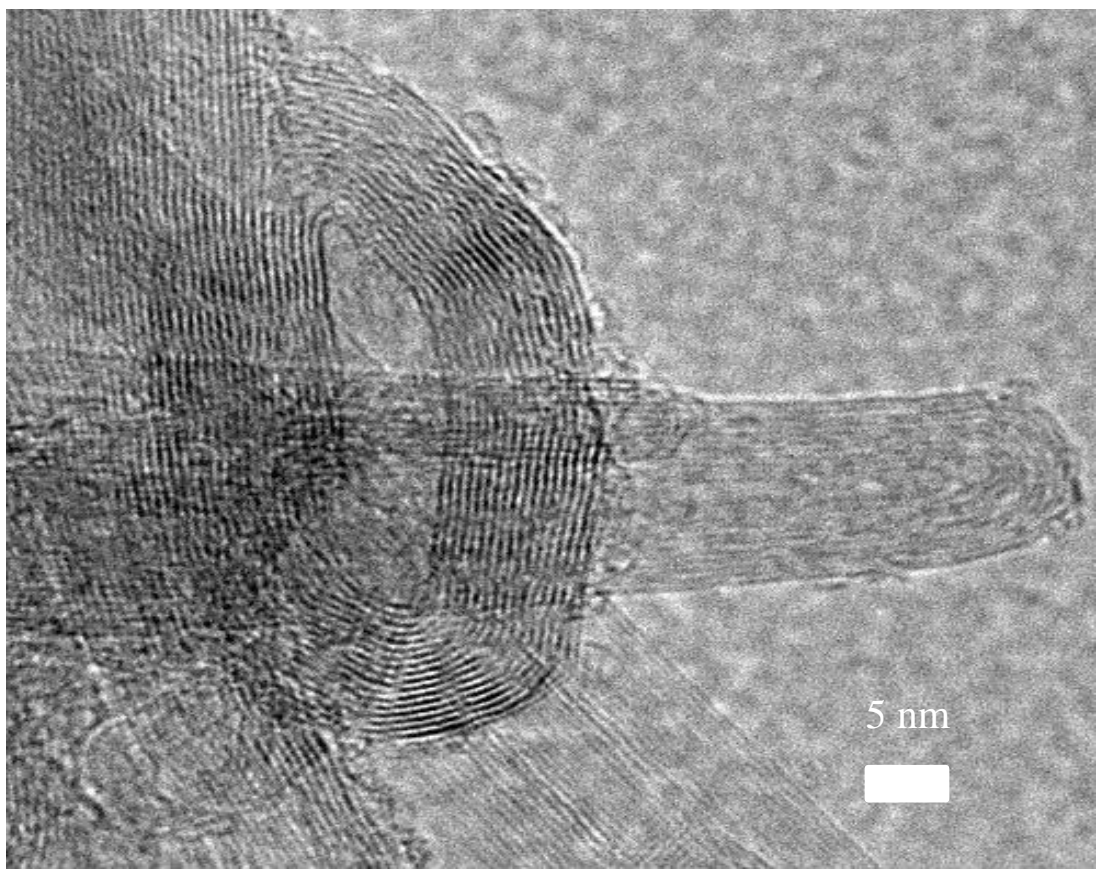

Figure 81: Carbon nano tubes

Energy dispersive $\mathrm{X}$ ray spectroscopy (EDS) was performed to examine the composition of PM particles. Figure 82, 83 and Table 7 shows the elemental composition of PM particles observed at $100 \%$ and $95 \%$ load respectively. Carbon was the main element of the PM particles. Other 
trace elements including Calcium, Magnesium, Zinc, Aluminum, Phosphorous, Sulfur, Iron, Oxygen and Silicon were also present in the sample. The possible source of metal emissions could be due to engine wear. $\mathrm{Ca}$ and $\mathrm{Mg}$ are additives of lubricating oil to prevent the formation of sludge [56]. Si is an antifoaming agent used in lubricating oil [56]. $\mathrm{P}$ and $\mathrm{Cu}$ is an antioxidant added in oil [56]. Zn, P and S are anti-wear additives in oil [56]. The increased concentration of $\mathrm{Cu}$ in Table 8 is because of the fact that the TEM grid is made of copper and is shown in the EDS spectrum.

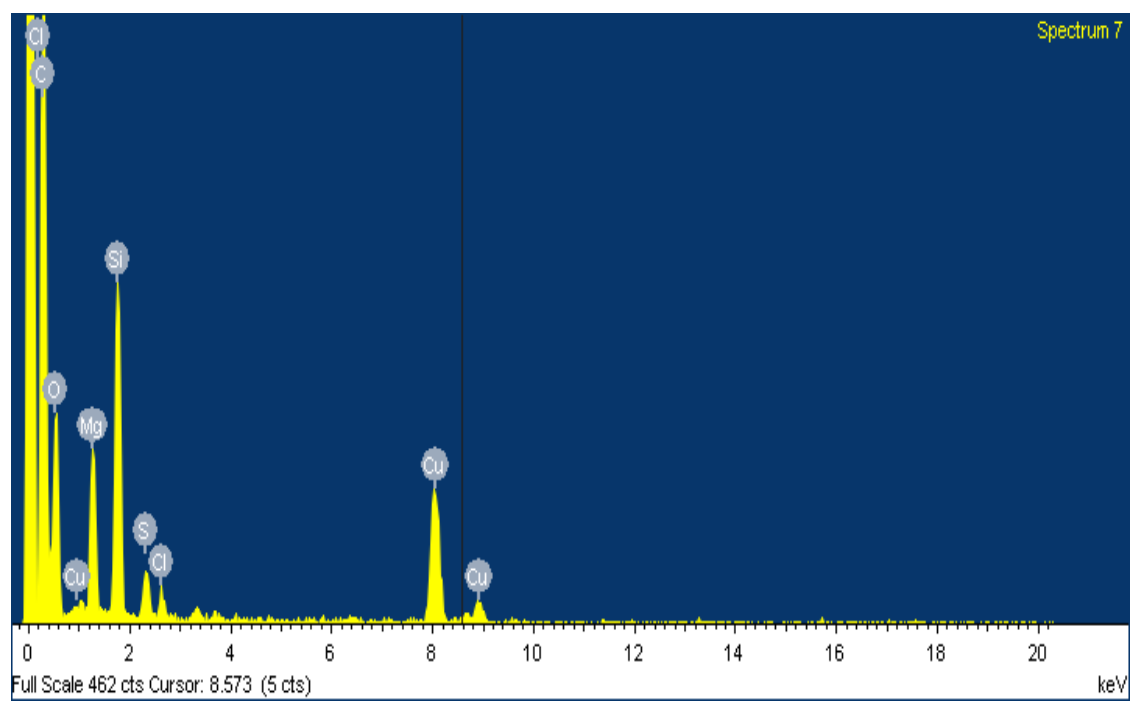

Figure 82: Composition of PM particles observed at full load

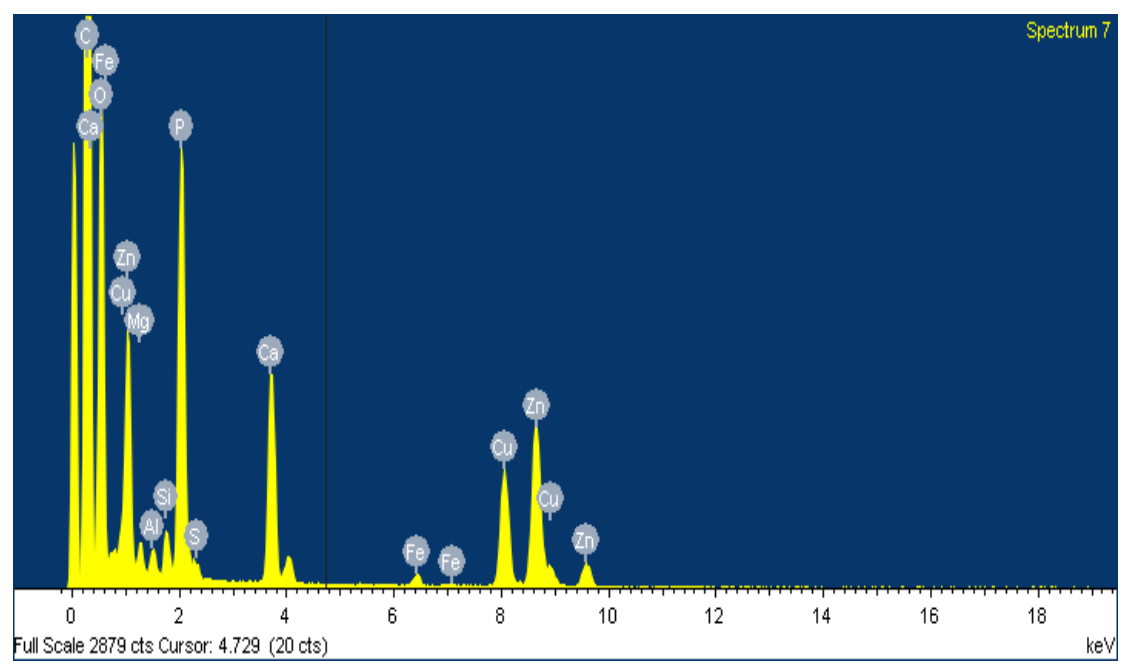

Figure 83: Composition of PM particles observed at 95\% load 
Table 7: Composition of heavy duty diesel engine PM

\begin{tabular}{|c|c|c|c|c|c|c|c|c|c|c|c|c|c|c|c|}
\hline $\begin{array}{c}\text { Compositio } \\
\text { n (\%) }\end{array}$ & $\mathrm{C}$ & $\mathrm{O}$ & $\begin{array}{c}\mathrm{M} \\
\mathrm{g}\end{array}$ & $\mathrm{Ca}$ & $\mathrm{Al}$ & $\mathrm{Si}$ & $\mathrm{P}$ & $\mathrm{S}$ & $\mathrm{Fe}$ & $\mathrm{Cl}$ & $\mathrm{Cu}$ & $\mathrm{Zn}$ & $\mathrm{K}$ & $\mathrm{Au}$ & $\mathrm{Pd}$ \\
\hline $100 \%$ load & $\begin{array}{c}67 . \\
9\end{array}$ & $\begin{array}{c}13 . \\
4\end{array}$ & 5.1 & 0 & 0 & 8.3 & 0 & 1.2 & 0 & 0.6 & 3.5 & 0 & 0 & 0 & 0 \\
\hline $95 \%$ load & $\begin{array}{c}72 . \\
0\end{array}$ & $\begin{array}{c}15 . \\
1\end{array}$ & 0.4 & 2.3 & 0.3 & 0.6 & 5.6 & 0.1 & 0.1 & 0 & 1.3 & 2.2 & 0 & 0 & 0 \\
\hline
\end{tabular}

Carbon was the most abundant element measured in the PM. Different elements in different concentration was found in the PM samples. For the same PM sample, the elements and concentration of each element are not identical and sometimes show significant difference as shown in Table 8. The PM composition was not homogeneous and elements found at one point were present in a different concentration at another point or were not present at all as shown in Table 8.

Table 8: Elemental composition of PM particle when operated at full load

\begin{tabular}{|l|l|l|l|l|l|l|l|l|l|l|l|l|l|l|l|}
\hline $\begin{array}{c}\text { Compositio } \\
\text { n (\%) }\end{array}$ & $\mathrm{C}$ & $\mathrm{O}$ & $\begin{array}{l}\mathrm{M} \\
\mathrm{g}\end{array}$ & $\mathrm{Ca}$ & $\begin{array}{l}\mathrm{A} \\
\mathrm{l}\end{array}$ & $\mathrm{Si}$ & $\mathrm{P}$ & $\mathrm{S}$ & $\begin{array}{l}\mathrm{F} \\
\mathrm{e}\end{array}$ & $\mathrm{Cl}$ & $\mathrm{Cu}$ & $\mathrm{Zn}$ & $\mathrm{K}$ & $\mathrm{Au}$ & $\mathrm{Pd}$ \\
\hline Position 1 & $\begin{array}{l}39 . \\
5\end{array}$ & 0 & 0 & 0 & 0 & 0 & 0 & 0 & 0 & 0 & $\begin{array}{l}29 . \\
8\end{array}$ & 0 & 0.6 & $\begin{array}{l}18 . \\
6\end{array}$ & $\begin{array}{l}11 . \\
5\end{array}$ \\
\hline Position 2 & $\begin{array}{l}67 . \\
9\end{array}$ & $\begin{array}{l}13 . \\
4\end{array}$ & 5.1 & 0 & 0 & 8.3 & 0 & 1.2 & 0 & 0.6 & 3.5 & 0 & 0 & 0 & 0 \\
\hline Position 3 & $\begin{array}{l}86 . \\
8\end{array}$ & 5.6 & 0 & 0.4 & 0 & 0 & 0 & 1.7 & 0 & 1.0 & 3.7 & 0.3 & 0.5 & 0 & 0 \\
\hline
\end{tabular}

\subsection{Scanning mobility particle sizer (SMPS) data for heavy duty engine}

Particle sizing was carried out during all modes of steady state testing for the heavy duty engine using an SMPS. As shown in Table 10 in order to ensure repeatability, three scans of the SMPS was conducted for each mode and the mean value of the three scans was reported. The secondary dilution ratio was 24 and the primary dilution ratio changed for different modes. Nuclei mode particles increased during 20\% load as shown in Figure 84. This was due to combustion of lubricating oil which enters the combustion chamber because of low pressure during low load. Table 9 shows the geometric mean diameter of the particles during different loads. Figure 85 
shows the distribution of particles during full load. The total number of particles during full load was small compared to $20 \%$ load. The number concentration of particles shown in Figure 86 is corrected for primary dilution ratio and the secondary dilution ratio. It was observed that the number concentration of the particles increased with a decrease in load. The highest number of particles were measured during $20 \%$ load.

The SEM measures the physical diameter whereas the SMPS measures the mobility diameter as discussed previously. The mobility diameter was small compared to the physical diameter. The assumption of spherical particle shape in SMPS measurement should contribute to this apparent difference [42]. For the size range between 1 and $43 \mathrm{~nm}$, the diameter measured by the SMPS was less. This was due to the fact that very few nano particles were collected on the SEM grids whereas the SMPS measured particles in the range of 1-225 $\mathrm{nm}$.

Table 9: Number concentration of PM particles

\begin{tabular}{|c|l|l|l|l|l|l|l|l|}
\hline Load (\%) & 20 & 40 & 50 & 60 & 75 & 90 & 95 & 100 \\
\hline GMD (nm) & 22.46 & 40.06 & 41.00 & 43.44 & 38.6 & 38.99 & 37.04 & 40.32 \\
\hline $\begin{array}{c}\text { PM Concentration } \\
\left(\begin{array}{c}\text { (million } \\
\text { particles/cm }\end{array}{ }^{3}\right)\end{array}$ & 55.73 & 31.03 & 27.47 & 26.47 & 21.76 & 20.61 & 17.41 & 29.83 \\
\hline
\end{tabular}

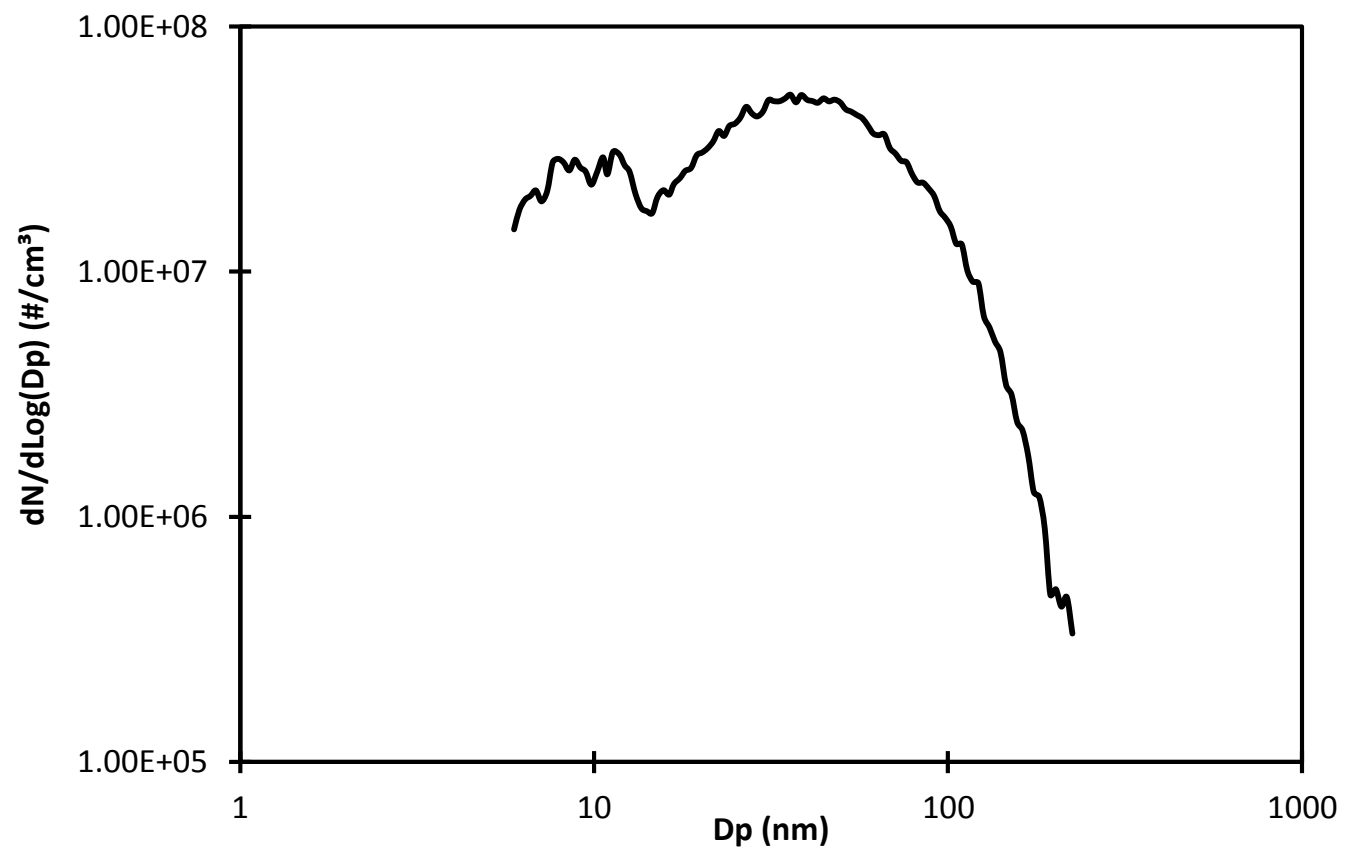

Figure 84: PM distribution observed at $20 \%$ load 


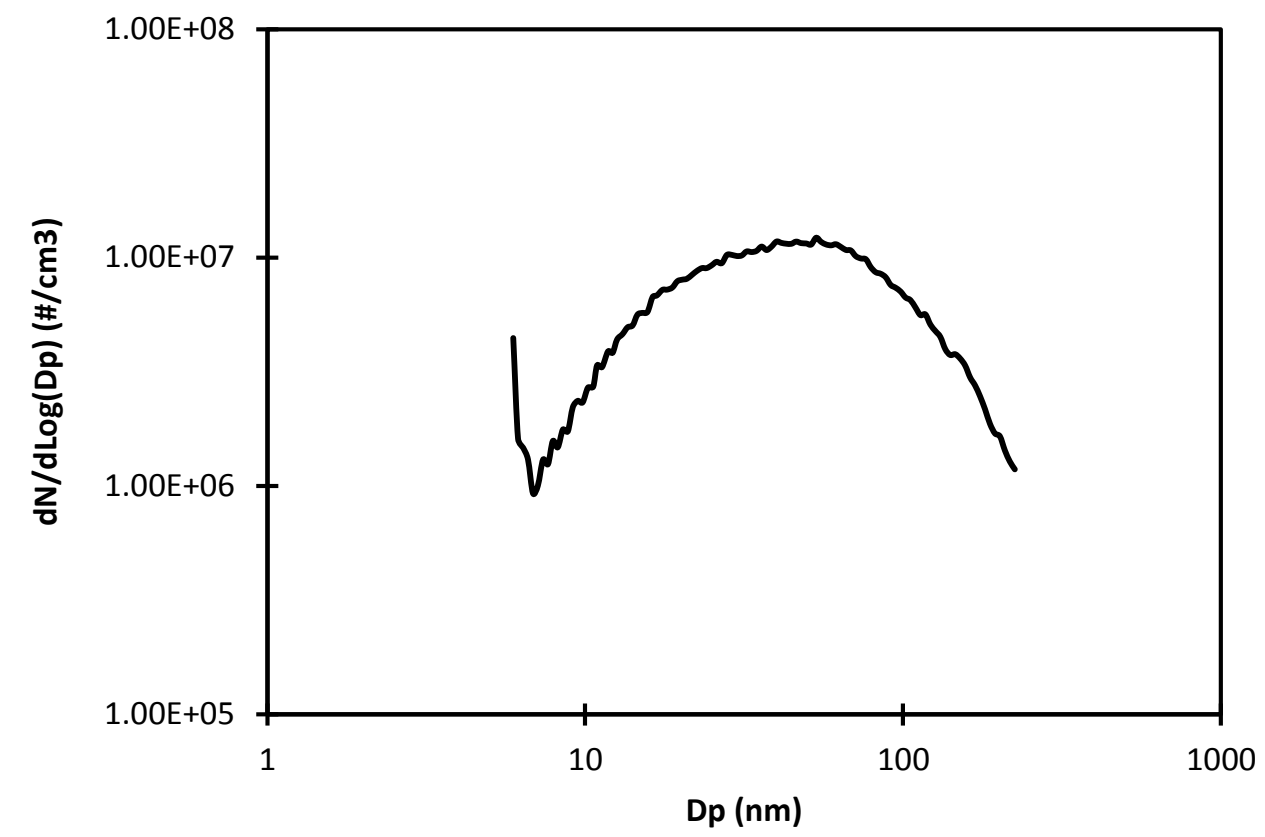

Figure 85: PM distribution observed at full load

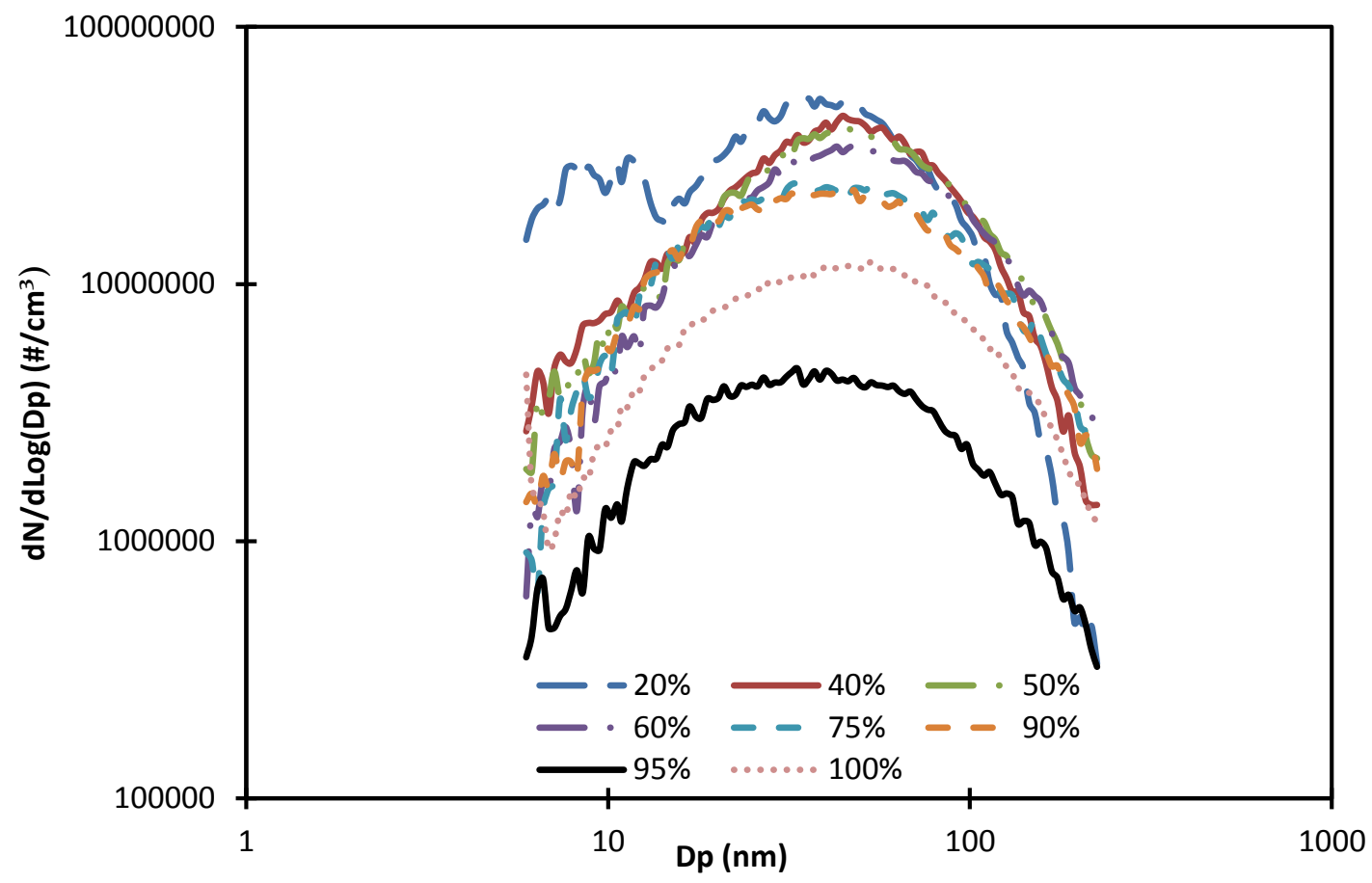

Figure 86: PM distribution at different loads

For the diameter in the range of $43-225 \mathrm{~nm}$, the SEM values were large compared to the SMPS values as seen in Table 10 . 
Table 10: Comparison of average size measured by SEM and geometric mean diameter measured by SMPS

\begin{tabular}{|c|c|c|c|c|c|c|c|c|}
\hline Load \% & 20 & 40 & 50 & 60 & 75 & 90 & 95 & 100 \\
\hline SEM (nm) & 87.9 & 164.7 & 134 & 235.9 & 199.2 & 142.1 & 192.5 & 270.1 \\
\hline SMPS(1-225nm) & 31.2 & 40.1 & 42.2 & 44 & 39.4 & 38.7 & 36.9 & 40.4 \\
\hline SMPS(43-225nm) & 68.9 & 75 & 79.2 & 81.1 & 82.5 & 82.4 & 80.9 & 83.1 \\
\hline
\end{tabular}




\section{Chapter 6}

\section{Morphology of PM Particles of Light Duty Engine}

The light duty engine was run at conventional diesel operation mode and PCCI mode. Three steady state tests were conducted, two at conventional mode and one at PCCI mode as shown in Table 11. The PCCI mode was achieved through a split injection strategy. The fuel injection used to achieve the PCCI mode is shown in Table 12.

Table 11: Test cycle for GM Z19DTH light duty engine

\begin{tabular}{|c|c|c|c|}
\hline Mode & Baseline 1 & Baseline 2 & PCCI mode \\
\hline Speed $(\mathrm{rpm})$ & 2100 & 2100 & 2100 \\
\hline Torque $(\mathrm{Nm})$ & 52 & 108 & 52 \\
\hline EGR $(\%)$ & 30 & 30 & 30 \\
\hline BMEP $(\mathrm{KPa})$ & 350 & 700 & 350 \\
\hline
\end{tabular}

Table 12: Fuel injection for PCCI mode

\begin{tabular}{|c|c|c|c|c|}
\hline Pilot injection & Main SOI & Fuel split & EGR & Rail pressure \\
\hline $46^{\circ}$ BTDC & $3^{\circ}$ ATDC & $33 \%$ (pilot) & $30 \%$ & $160 \mathrm{MPa}$ \\
\hline
\end{tabular}

\subsection{Featured PM particle morphology for light duty engine}

The PM particles of the light duty engine from both modes were similar to the PM particles emitted from the heavy duty engine. The PM particles were fine particles consisted of both nuclei mode particles and accumulation mode particles. PM particles larger than 1 micron, previously observed in heavy duty cycle were not observed. Figure 87 shows a nano particle observed at baseline 1 test. Figure 88 shows a chain like PM with small branches attached on the sides, observed at baseline 1 test. An accumulation mode PM particle with multiple branches is shown in Figure 89. Figure 90 shows accumulation mode particle with multiple branches attached on the sides. 


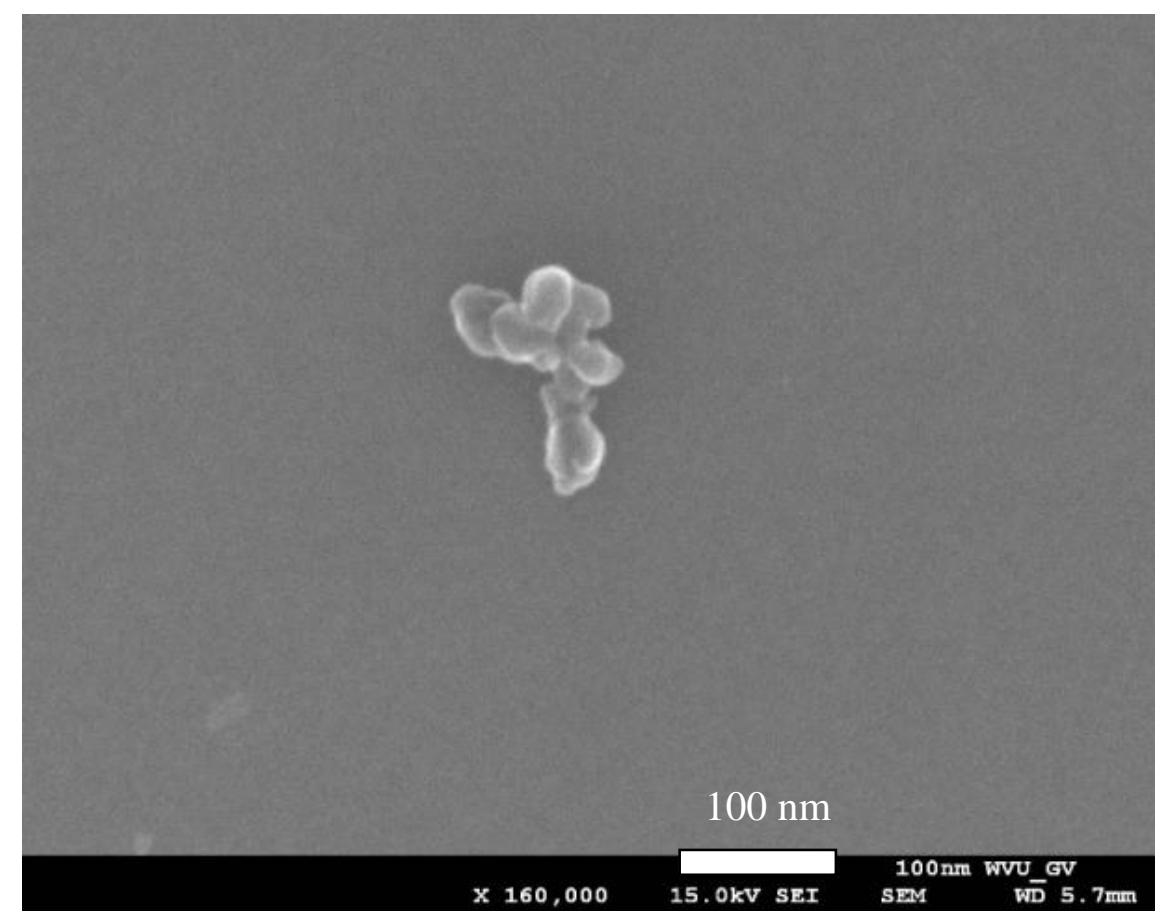

Figure 87: PM particles observed at baseline 1 test

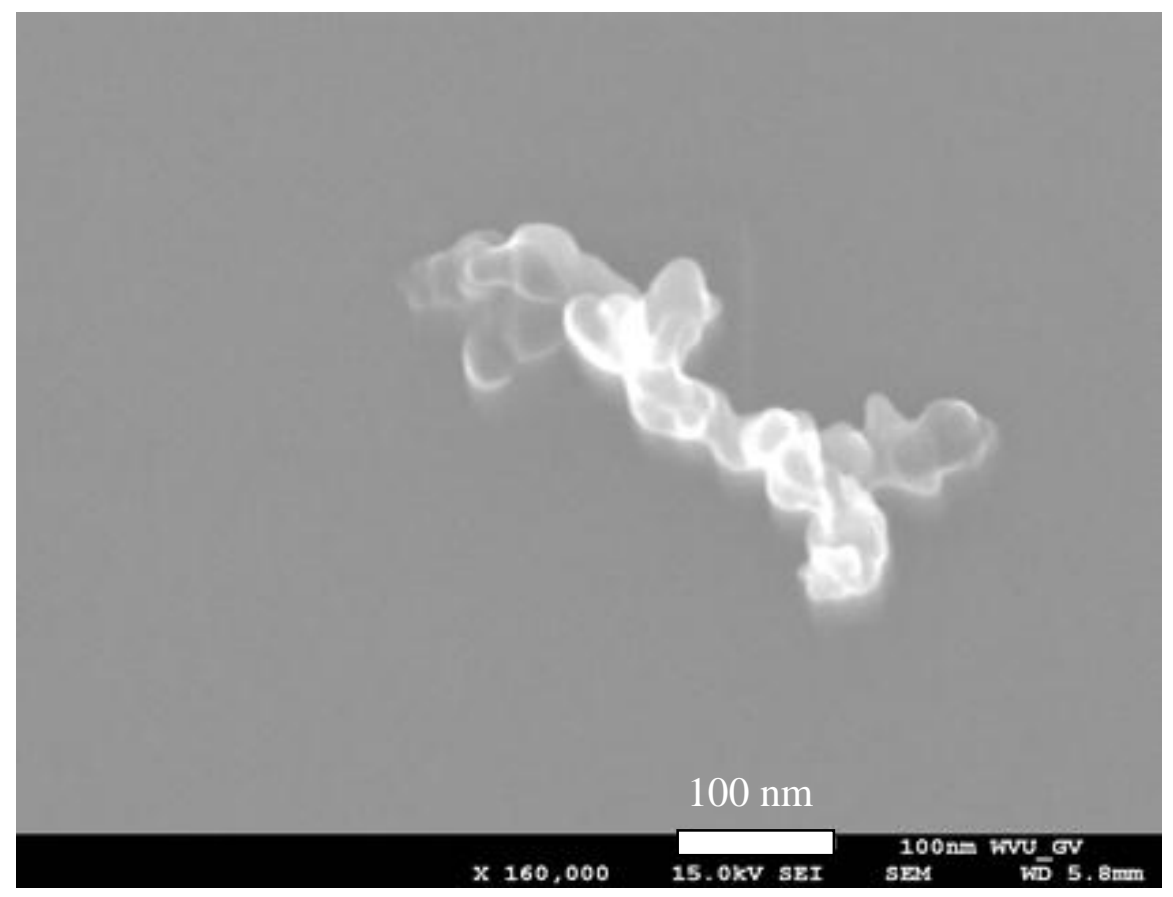

Figure 88: Chain like PM particle observed at baseline1 test 


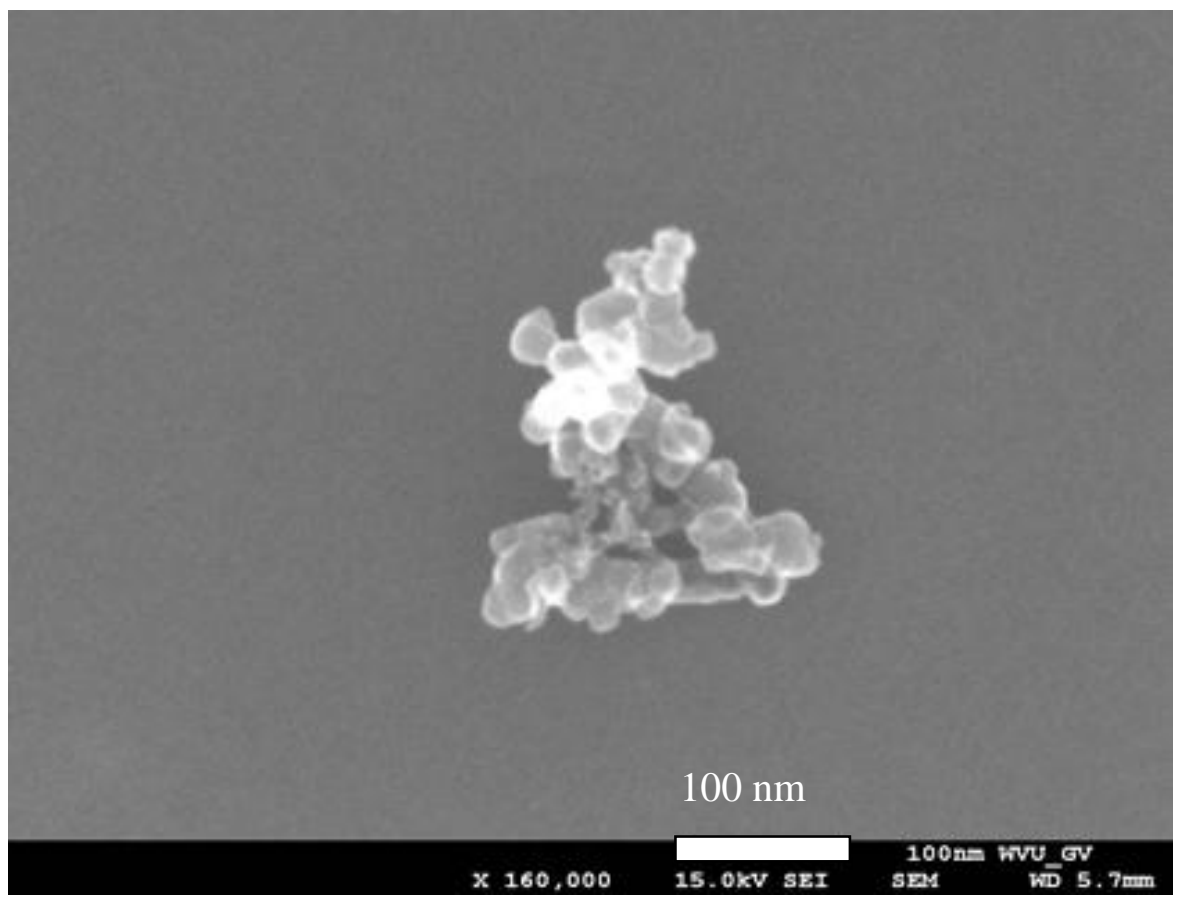

Figure 89: Clustered PM particle observed at baseline 1 test

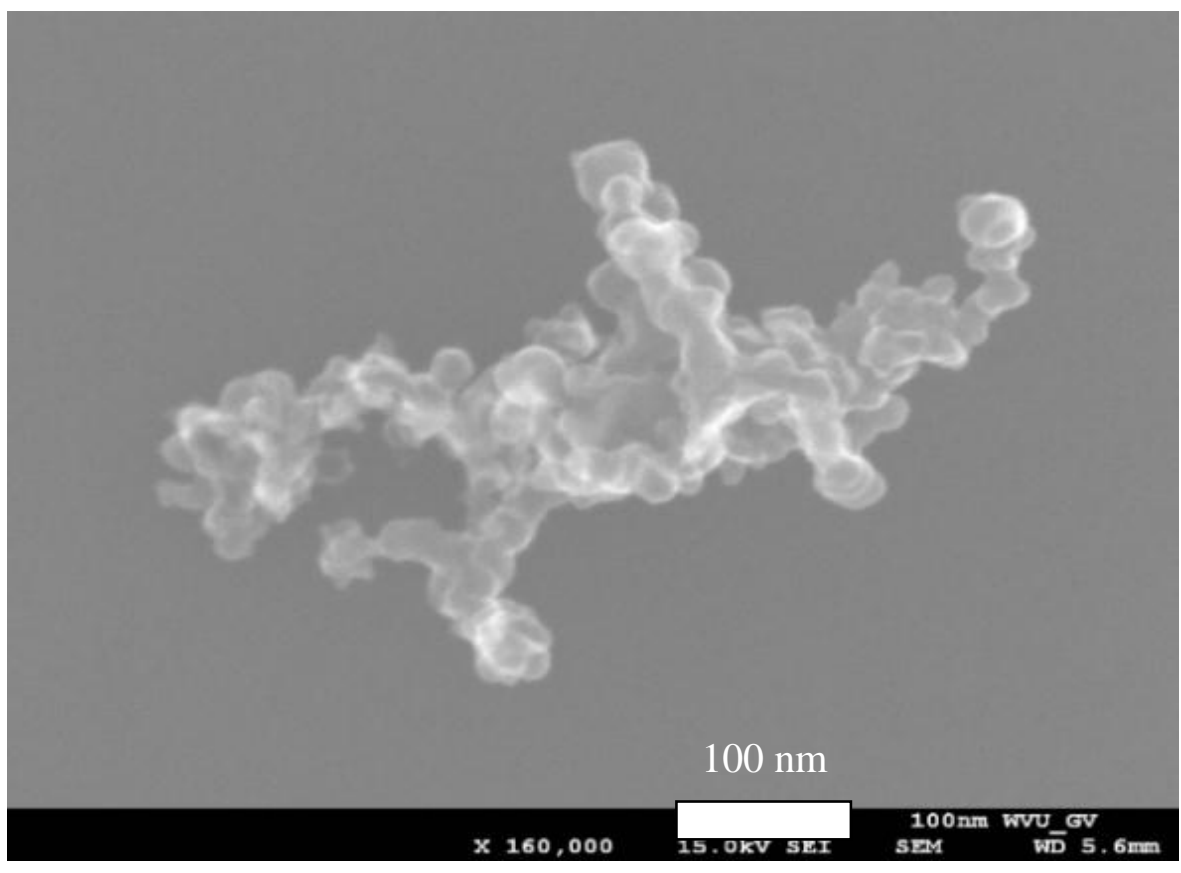

Figure 90: Chain like PM particle observed at baseline 2 test

Spherical PM particle observed at baseline 2 test is shown in Figure 91. The primary particles are closely packed to form a compact structure. Figure 92 is a long chain like particle observed during PCCI mode. The primary particles can be distinguished clearly from one another. Figure 93 shows an accumulation mode PM particle with no branches, the PM particle resembles a 
sphere. Figure 94 shows long chain like PM particle observed during PCCI mode with short branches. The PCCI mode emitted less number of PM particles compared with baseline test. The size range of PM particles from the PCCI mode was small compared with the size range of baseline PM particles.

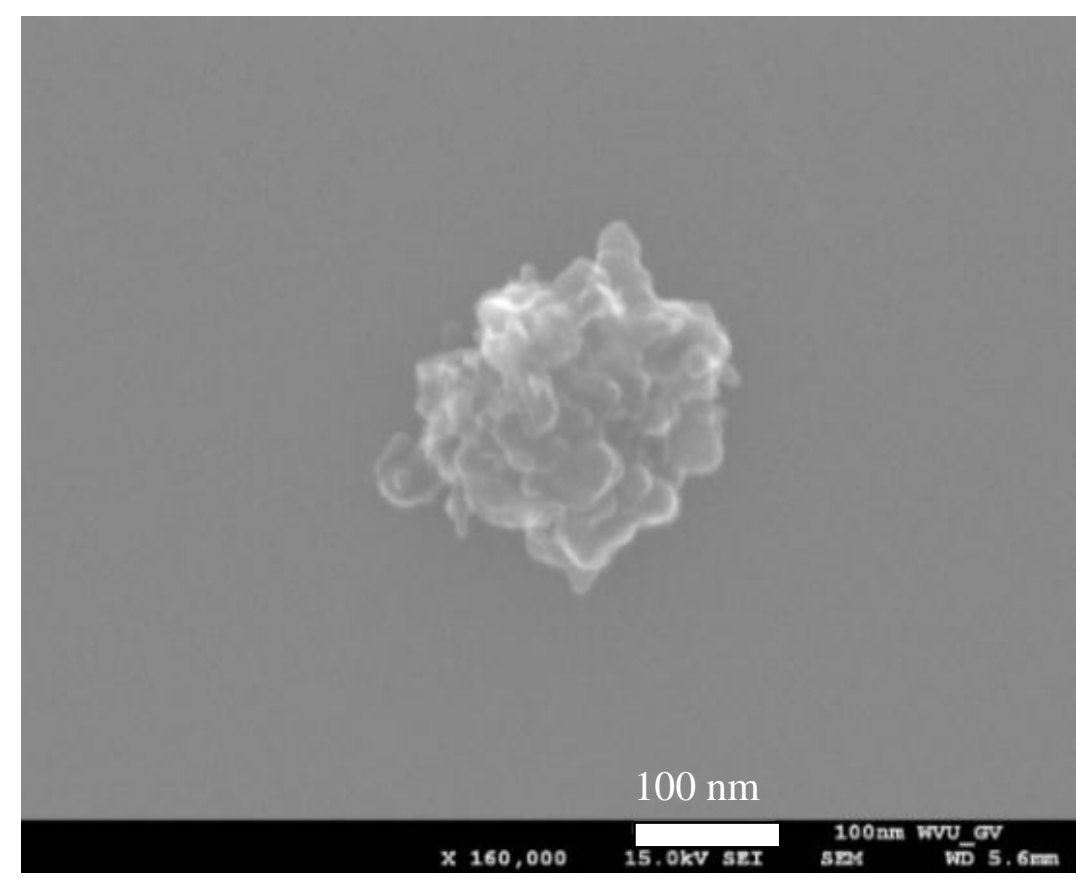

Figure 91: Spherical PM particle observed at baseline 2 test

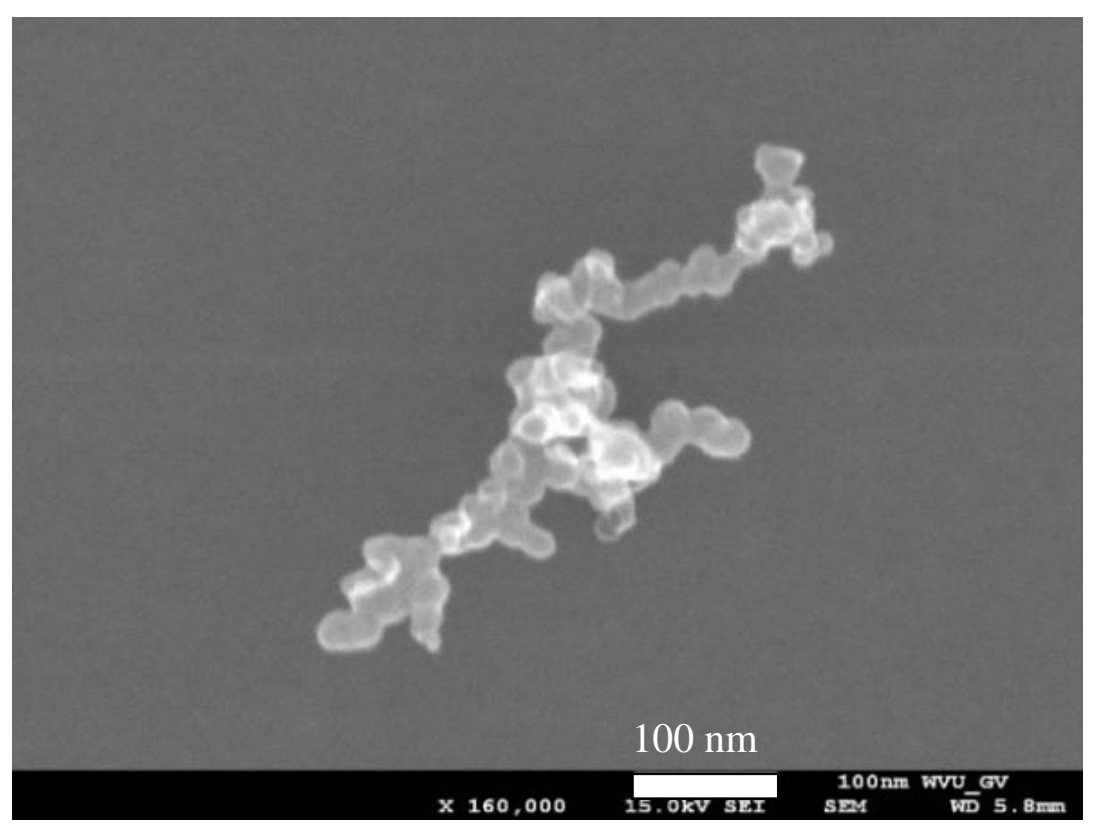

Figure 92: Chain like PM from PCCI mode 


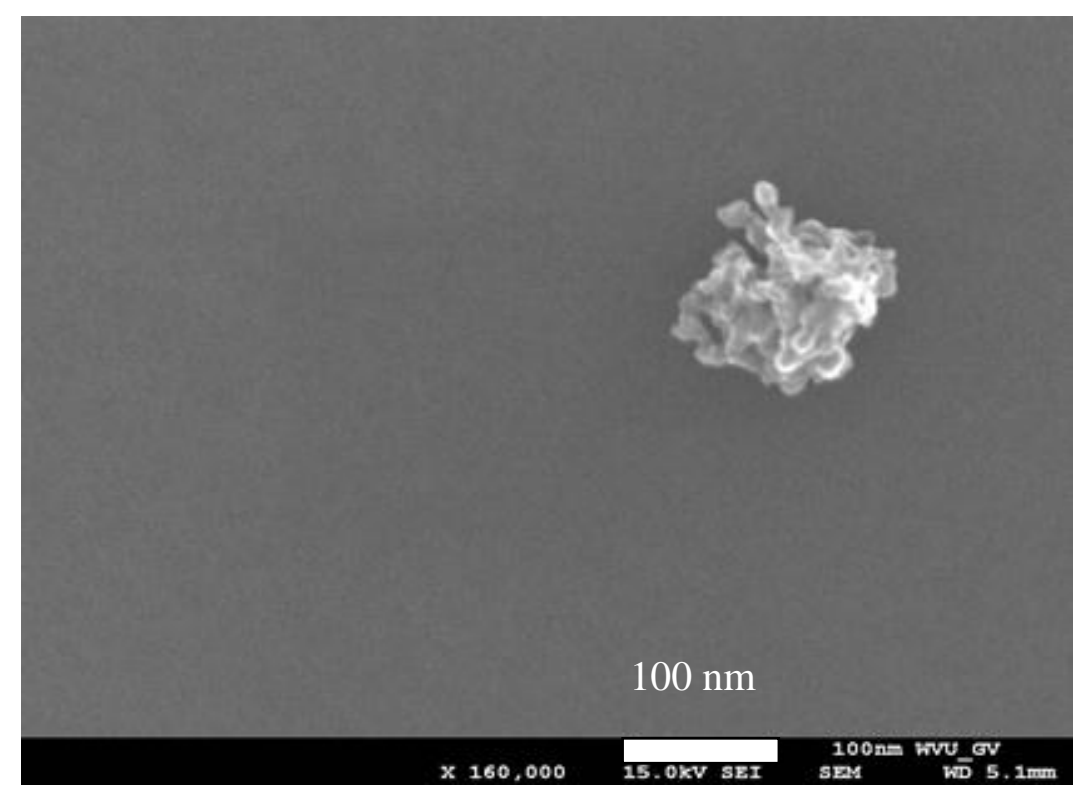

Figure 93: Spherical PM particle from PCCI mode

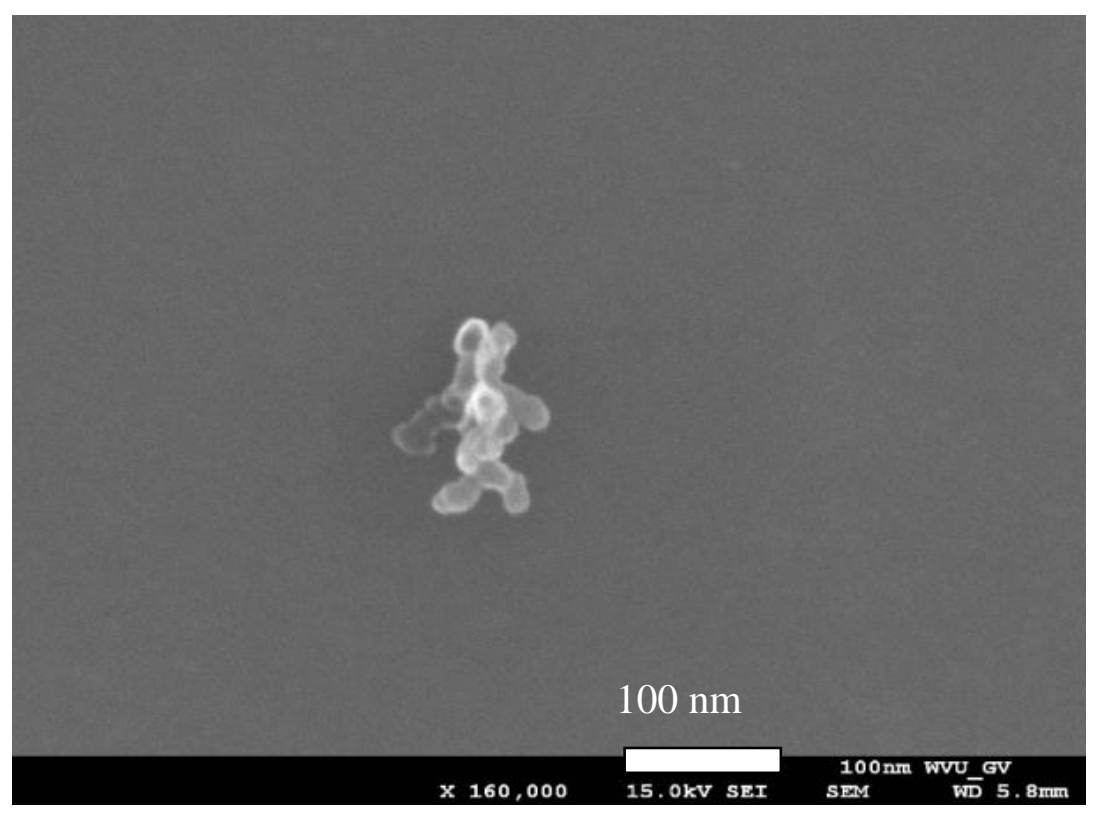

Figure 94: PM with branches observed at PCCI mode

\subsection{Projected area equivalent diameter}

The particles emitted from the light duty engine are fine particles. Most of the particles lay between accumulation mode and nuclei mode particles. It was observed that most of the PM particles from the light duty engine were less than $300 \mathrm{~nm}$ in diameter as shown in Figure 95 and 96. 


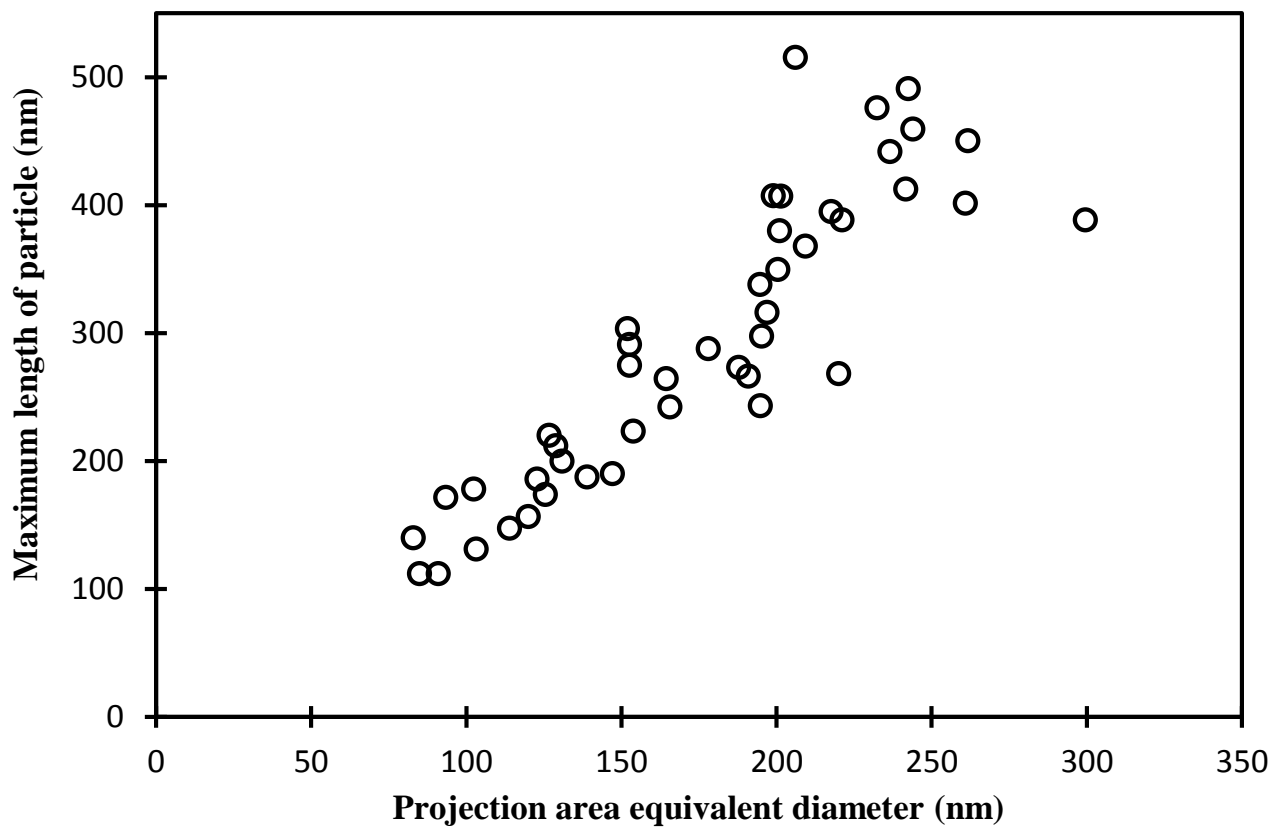

Figure 95: Variation of maximum length of PM particles with changes in the projected area equivalent diameter observed at baseline 2

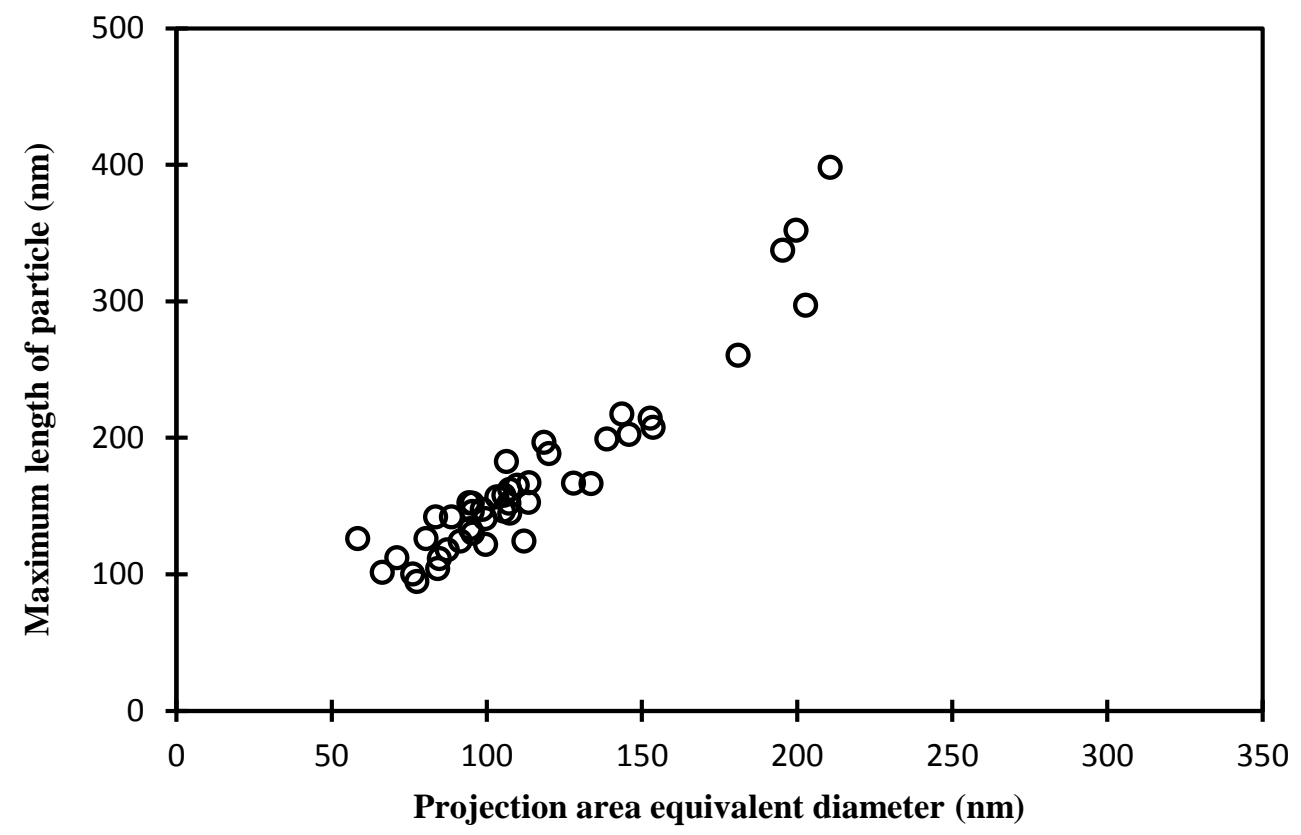

Figure 96: Variation of maximum length of PM particles with changes in the projected area equivalent diameter observed at baseline 1 


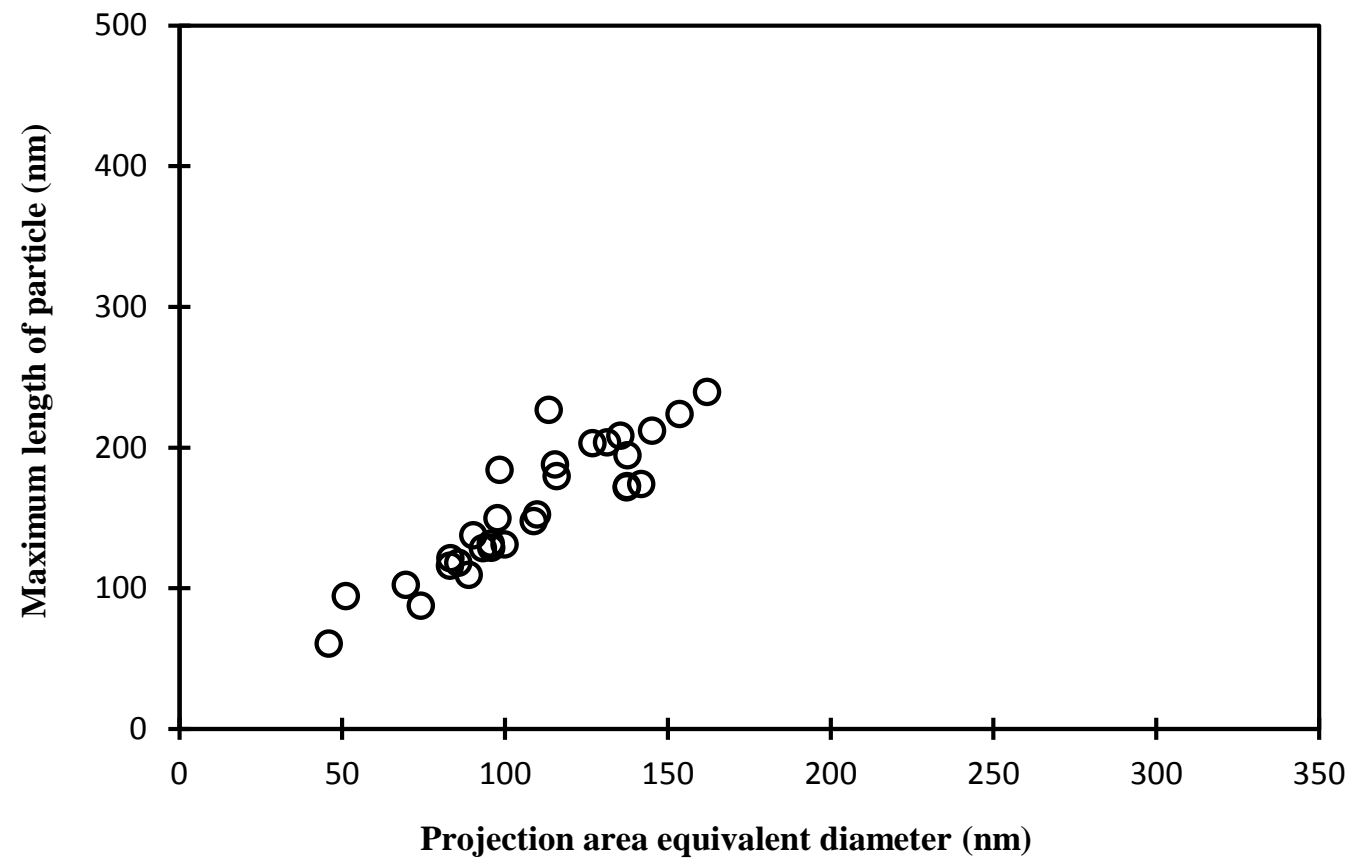

Figure 97: Variation of maximum length of PM particles with changes in the projected area equivalent diameter observed at PCCI mode

The maximum length of particles from the PCCI mode shown in Figure 97 was smaller compared to baseline mode 1 for the same load as shown in Figure 96.

\subsection{Primary particle size distribution}

The diameters of primary particles were measured from the projected properties of SEM images. Around 220 particles of various sizes were randomly selected from various agglomerates to determine the average diameter of the primary particle. The size distribution of the primary particles featured a Gaussian distribution. Figure 98 is the distribution of primary particles during baseline 1 test. The peak is at $15-20 \mathrm{~nm}$ range. The Figure 99 is the distribution for baseline 2 test. The peak is at $25-30 \mathrm{~nm}$. Figure 100 shows the peak of the primary particles at $15-20 \mathrm{~nm}$ during PCCI mode. 


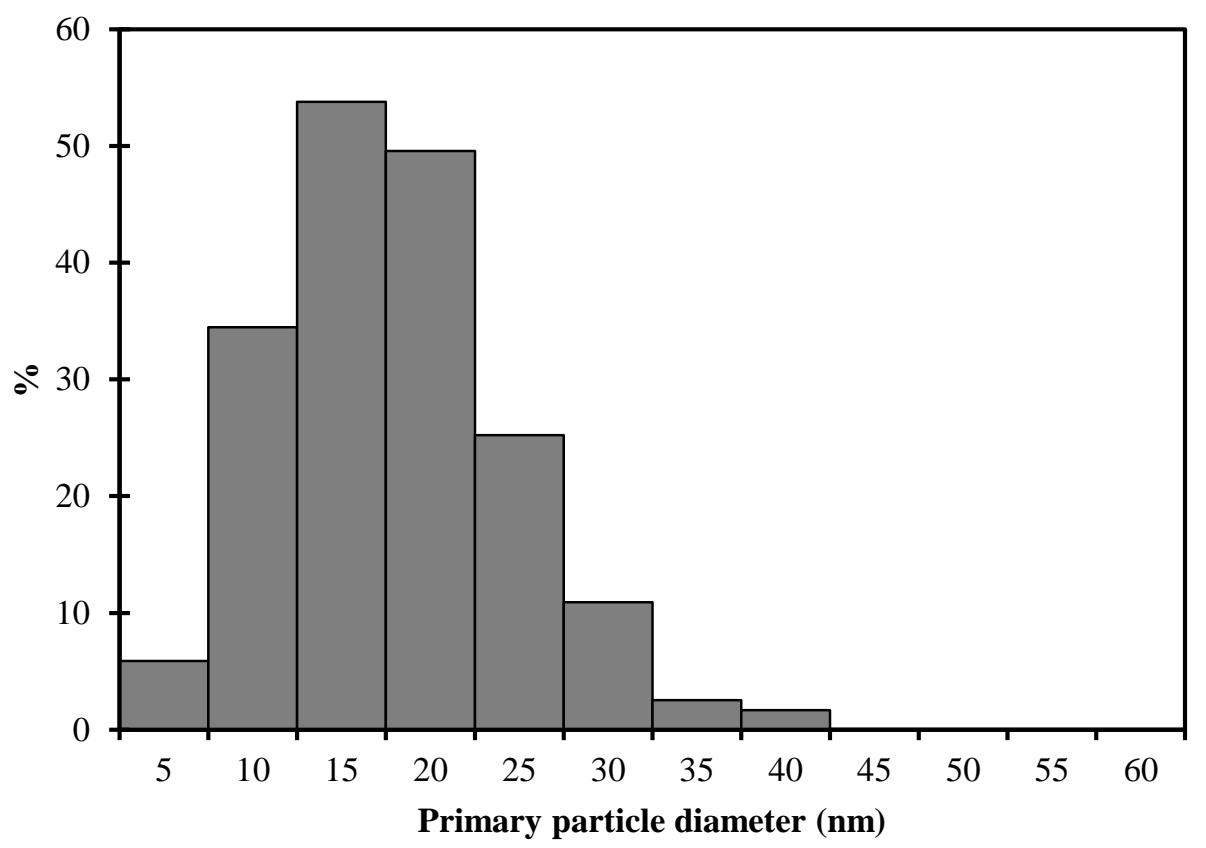

Figure 98: Distribution of the primary particle diameter observed at baseline 1

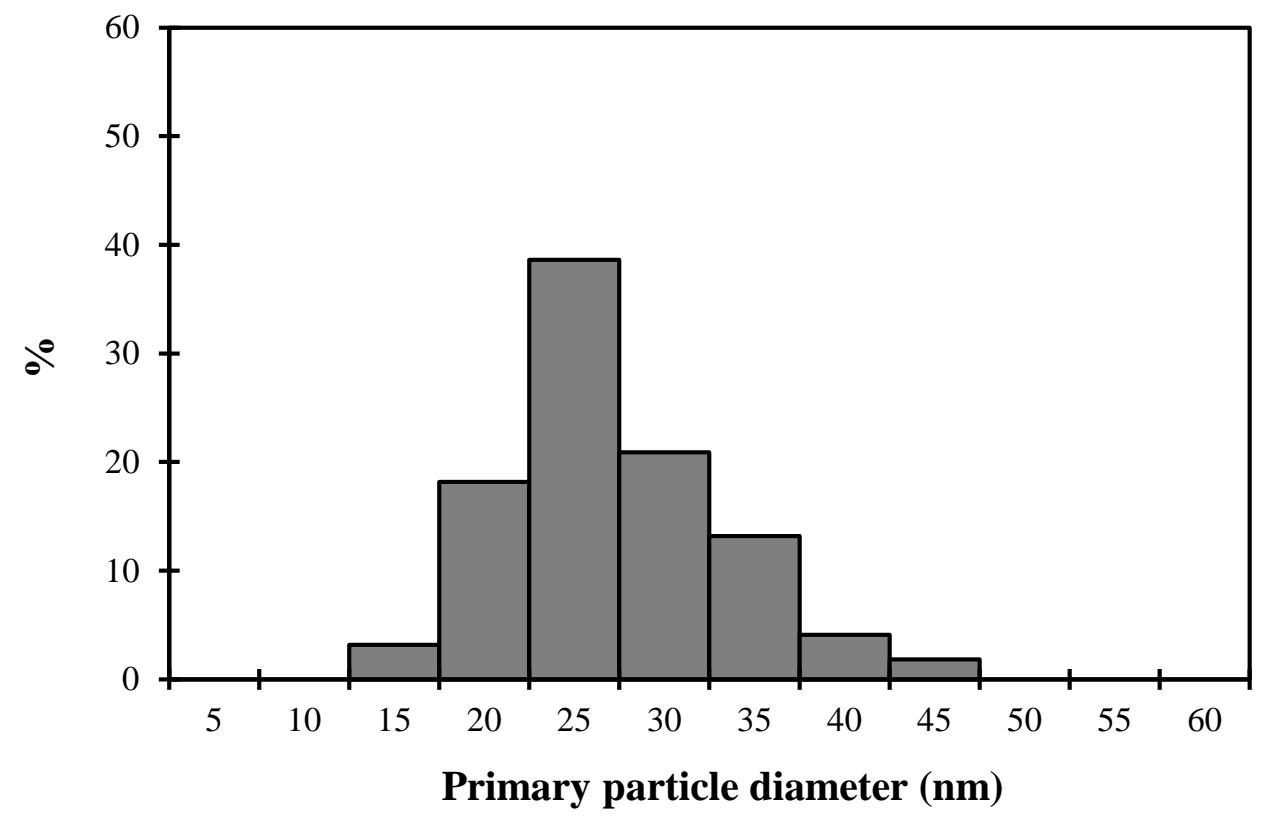

Figure 99: Distribution of the primary particle diameter observed at baseline 2 


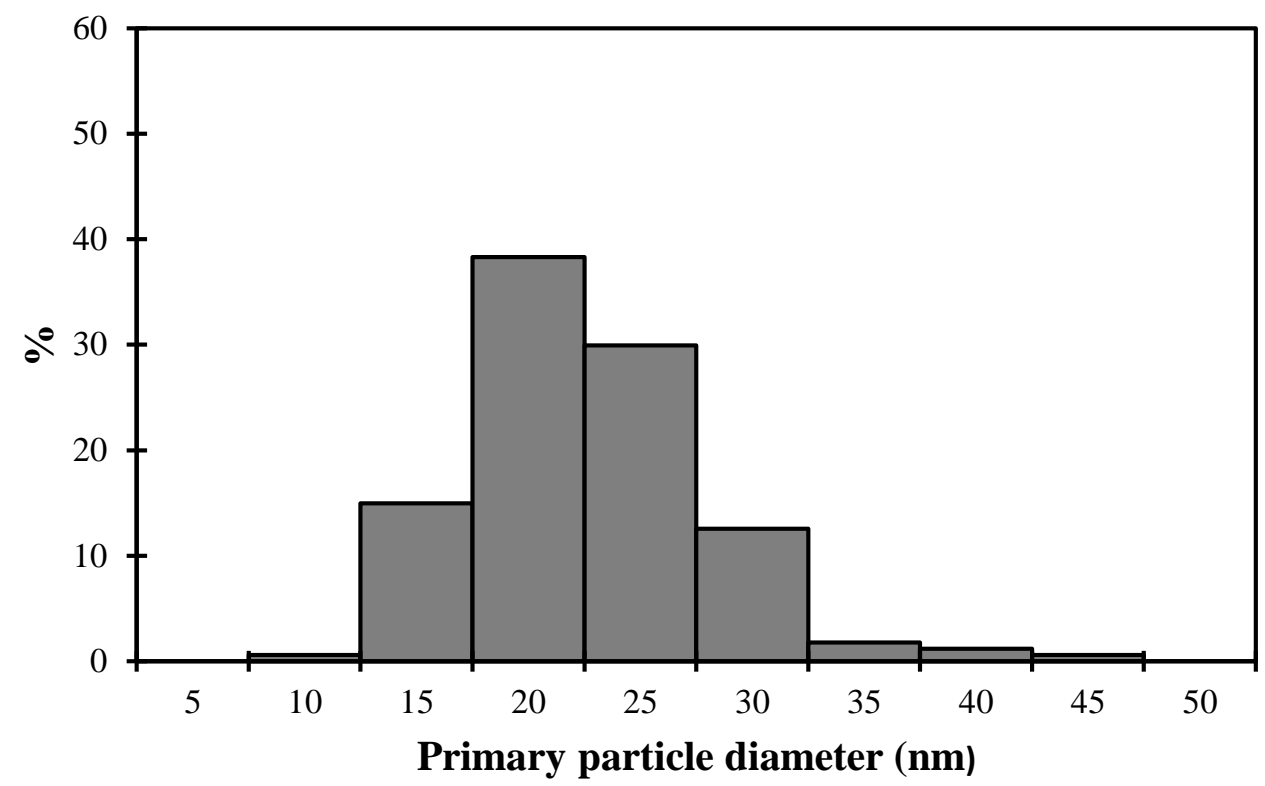

Figure 100: Distribution of the primary particle diameter observed at PCCI mode

Figure 101 and Table 13 show the average diameter of primary particles for different modes. The average primary particle diameter were $20.2 \mathrm{~nm}, 20.3 \mathrm{~nm}$ and $24.5 \mathrm{~nm}$ for PCCI, baseline 1 and baseline 2 test respectively. The average size of the primary particle diameter shifted to higher value for the baseline 2 test. The average size of primary particle was similar for the PCCI mode and baseline 1 mode.

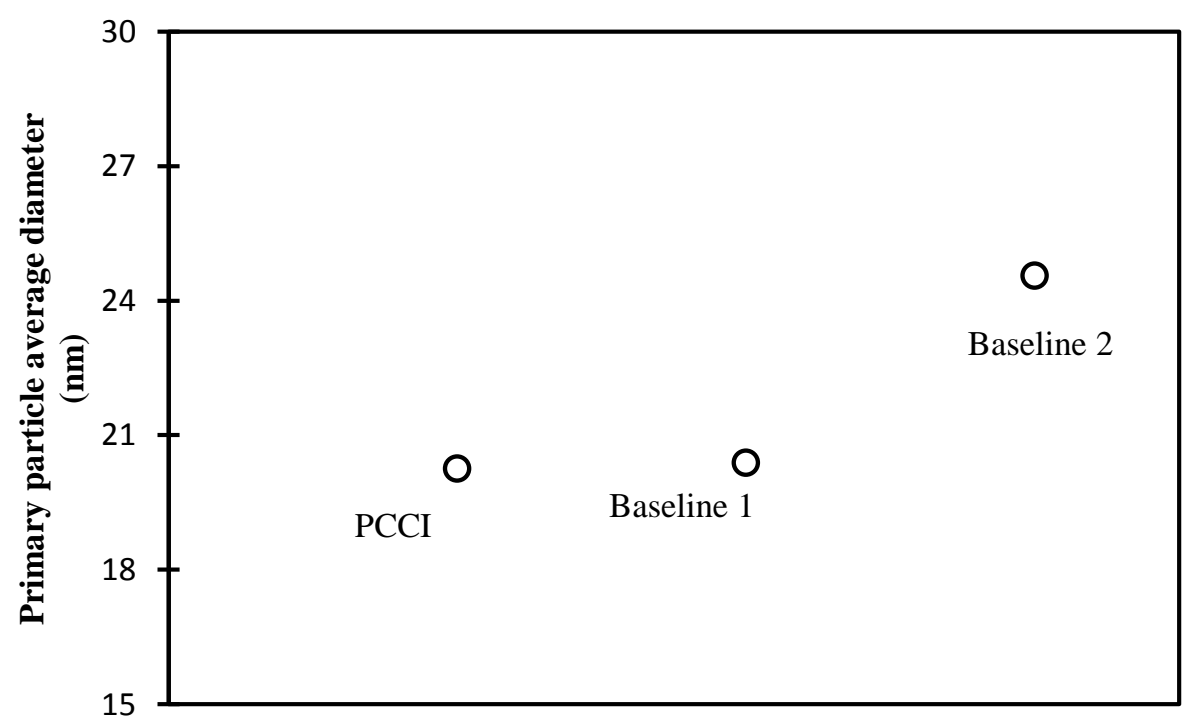

Figure 101: Average diameter of the primary particle of light duty engine 
Table 13: Average primary particle diameter for light duty engine

\begin{tabular}{|c|c|c|c|}
\hline Mode & Baseline 1 & Baseline 2 & PCCI \\
\hline $\begin{array}{c}\text { Average primary } \\
\text { particle diameter }(\mathrm{nm})\end{array}$ & 20.3 & 24.5 & 20.2 \\
\hline
\end{tabular}

\subsection{Fractal dimension}

A plot of $\operatorname{Ln}(n)$ vs. $\operatorname{Ln}\left(\mathrm{L}_{\max } / \mathrm{d}\right)$ is shown in Figure 102. The slope of the linear fit gives the fractal dimension. The fractal dimension of the particles emitted from the diesel mode is 1.65 which is within the range of 1.46 to 1.7 for light duty diesel agglomerates [45]. The fractal dimension of PM particles formed during PCCI mode was 1.70 as shown in Figure 103. The fractal dimension of the PM particles from the light duty engine were smaller that the values from the heavy duty engine, indicating that the PM from the light duty engine were more elongated compared to that of PM particles from the heavy duty engine. It must be noted that only one test was conducted for the PCCI mode and only 30 images were taken for the PCCI mode. Figure 104 shows the particles from baseline 1 test. The fractal dimension was 1.84 indicating that PM was more spherical during baseline 1 test.

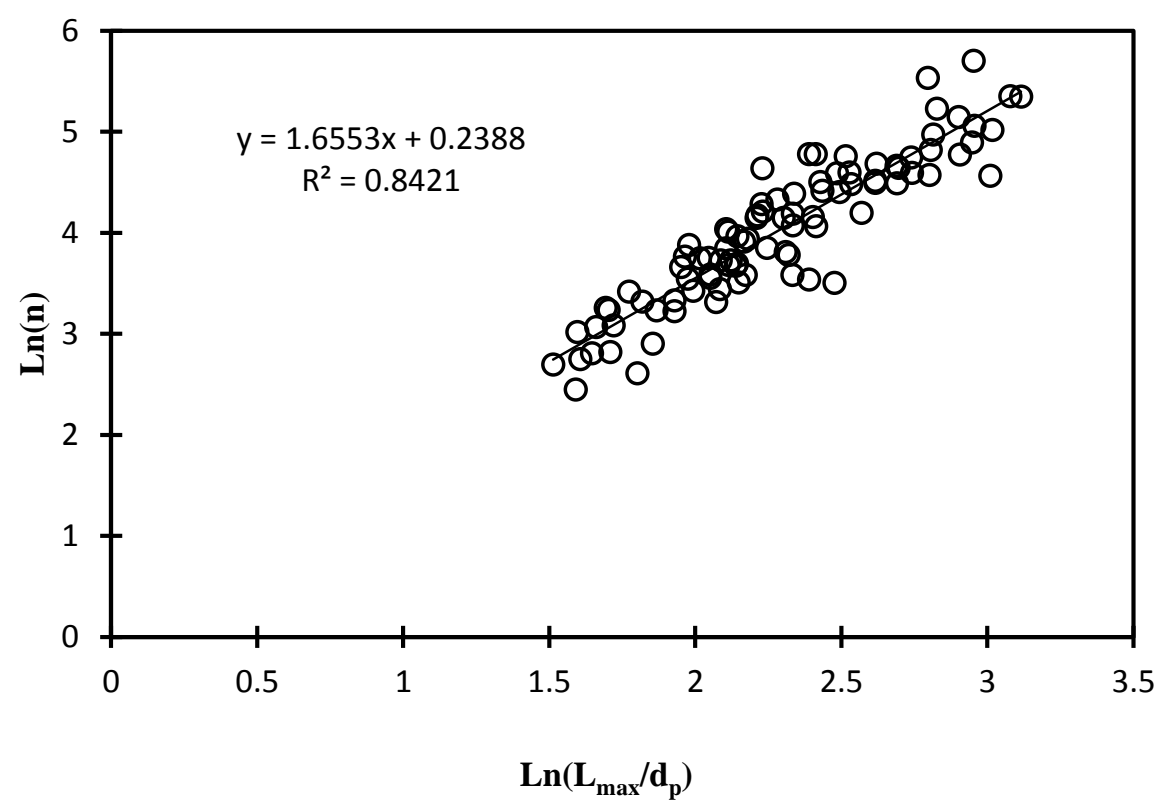

Figure 102: Baseline fractal dimension $D_{f}=1.65$ 


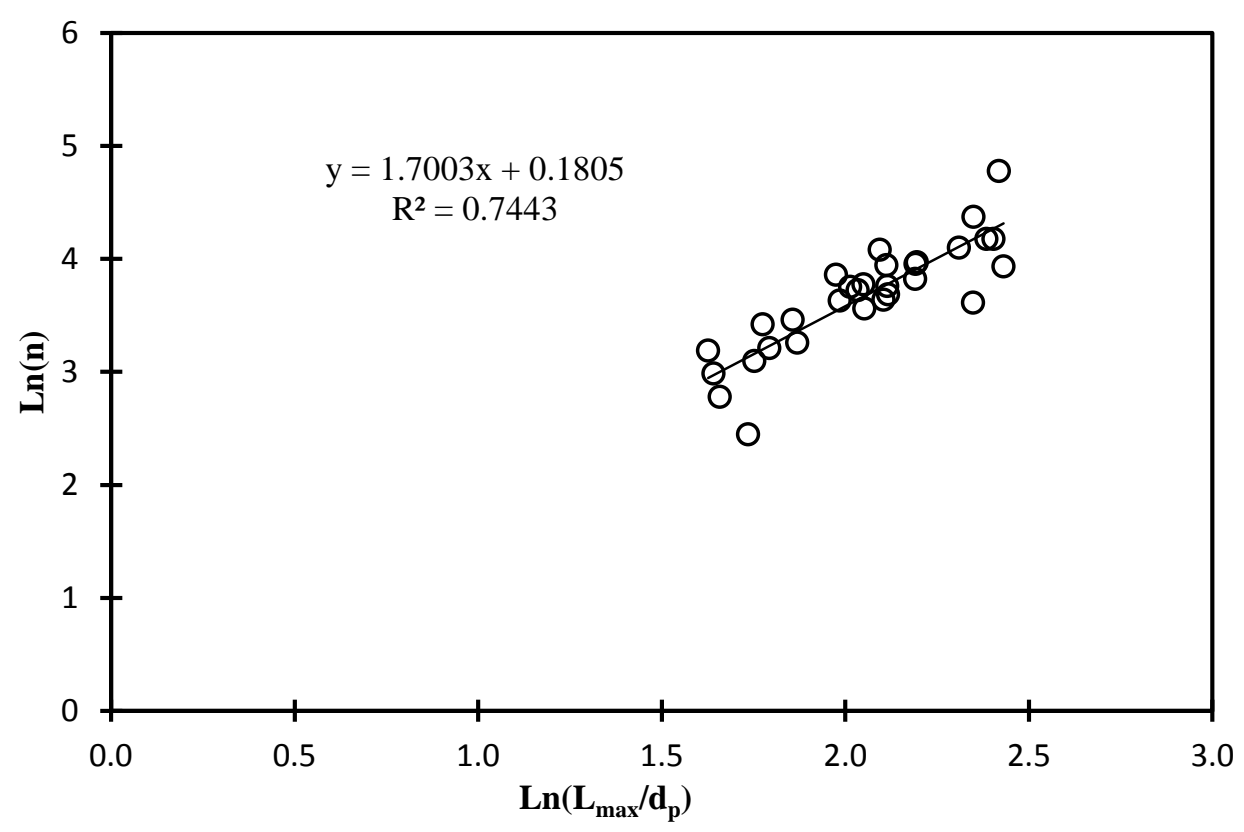

Figure 103: PCCI mode fractal dimension $D_{f}=1.7$

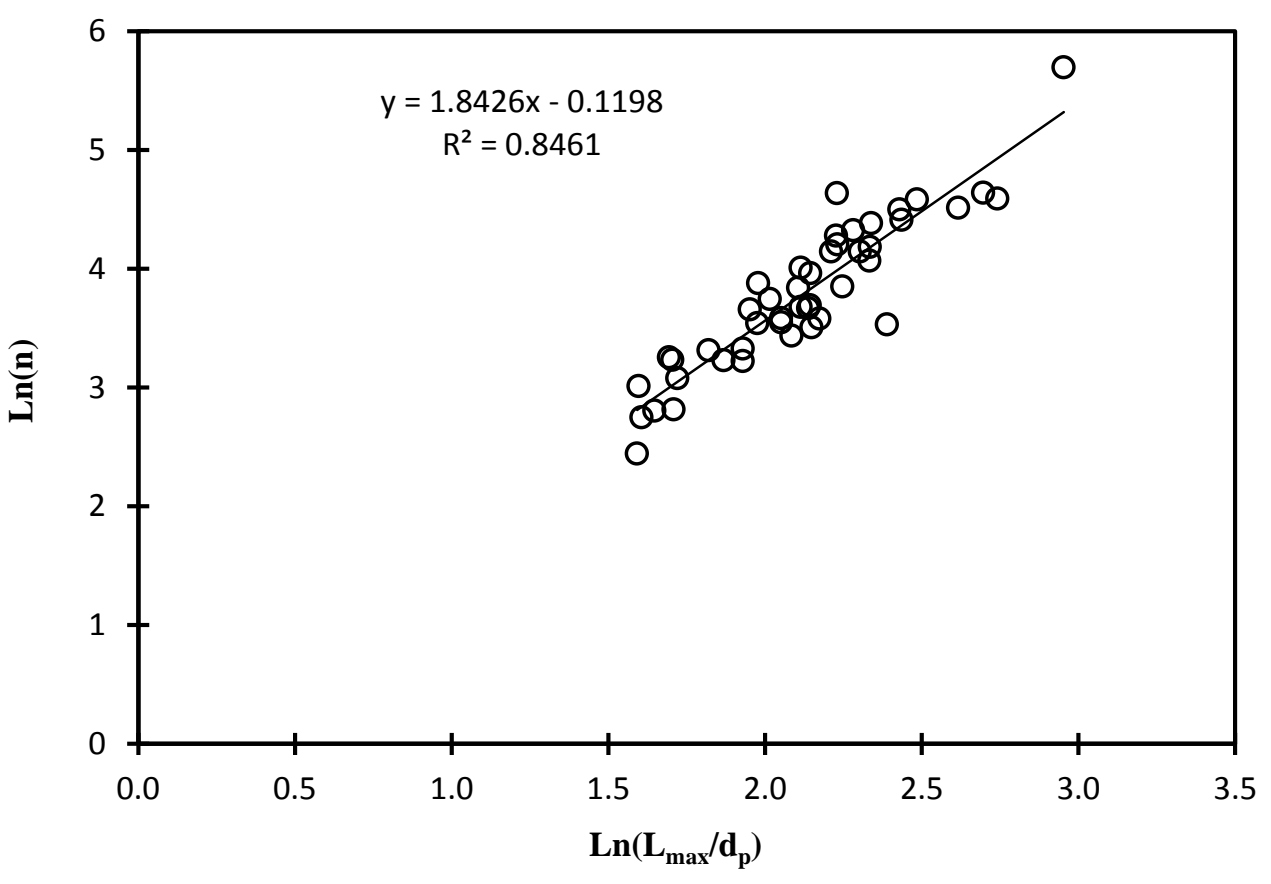

Figure 104: Fractal dimension of PM observed at baseline 1 


\section{Chapter 7}

\section{Conclusions and Recommendations}

\subsection{Conclusion}

This research investigated the effect of engine load and combustion mode on the size, shape and microstructure of PM particles of two diesel engines using a scanning mobility particle sizer (SMPS), and electron microscopes including scanning electron microscope (SEM) and transmission electron microscope (TEM). The effect of engine load on the morphology of PM particle was examined using a 2004 MACK MP7-355E heavy-duty engine. The effect of combustion mode on PM morphology was preliminarily examined using 2005 Opel 1.9 L lightduty diesel engine. SEM images were processed to investigate the shape, size and morphology of the PM particle. The TEM images were further processed to obtain the micro-structure and chemical composition of PM particles. Based on the data obtained in this research, the following conclusions can be drawn:

1. The SEM images revealed the diverse morphology of PM particles of diesel engines. Significant number of nuclei mode sphere-like small nano-scale PM particles was observed when operated at very low load. The medium and large particles observed were long, chainlike PM particles with numerous branches. The operation at higher load tended to produce more large PM particles than lower load operation.

2. The fractal dimension of PM particle from heavy-duty diesel engine was 1.82 indicating spherical structure and light duty diesel engine was 1.7, indicating the elongated structure of PM particles emitted from light-duty diesel engines.

3. The aspect ratio and roundness were used as the shape descriptor of PM particles. The PM particles having both $\mathrm{AR}$ and $\mathrm{RN}$ around one were found to represents small sphere-like compact PM particles. The PM particles which featured small values of AR and RN represented long-chain PM particles.

4. The primary particle diameter size distribution of both the engines follows Gaussian distributions. The primary particle size of the heavy duty diesel engine increased for intermediate loads. The average size of primary particles observed at different load are $23.09 \mathrm{~nm}$ (100\% load), $26.61 \mathrm{~nm}$ (95\% load), $23.74 \mathrm{~nm}$ (90\% load), $22.64 \mathrm{~nm}$ (75\% load), 
$29.36 \mathrm{~nm}$ (60\% load), $30.01 \mathrm{~nm}$ (50\% load), $28.16 \mathrm{~nm}$ (40\% load), and $22.4 \mathrm{~nm}$ ( $20 \%$ load) respectively.

5. The geometric mean diameter of PM particles of the heavy duty engine as measured by SMPS were $31.2 \mathrm{~nm}$ (20\% load), $40.1 \mathrm{~nm}$ (40\% load), $42.2 \mathrm{~nm}$ (50\% load), $44 \mathrm{~nm}$ (60\% load), $39.4 \mathrm{~nm}$ (75\% load), $38.7 \mathrm{~nm}$ (90\% load), $36.9 \mathrm{~nm}$ (95\% load), and $40.4 \mathrm{~nm}$ (100\% load) respectively.

6. The smallest PM particle observed using SEM was $43 \mathrm{~nm}$. The PM particles smaller than 43 $\mathrm{nm}$ observed using SMPS were not observed using SEM. This could be due to the limitation of the SEM PM particle sampling method.

7. The microstructure of primary PM particles from the heavy duty engine exhibited two types of structure. The first type features concentric graphitic layers roughly parallel and equidistant similar to the structure of an onion. The second type had similar concentric microstructure on the outside layers with the core region containing multiple spherical nuclei surrounded by graphitic layers, indicating that the nuclei mode particles may have fused together followed by surface growth.

8. The carbon nano tube structure consists of long concentrically arranged graphitic layers with amorphous inner core. The presence of iron may act like a catalyst and trigger the formation of carbon nano-tubes. The high temperature oxidizes the outer layers and develops micro pores through which the amorphous inner core oxidizes and hollows out the inner core. The intermediate core which is more graphitic than the inner core undergoes structural rearrangement and coalescence where the wavy layers become much flatter and longer [54].

9. The PM particles observed were consisted of mainly of carbon as well as elements originated from oil additives such as $\mathrm{Ca}, \mathrm{Mg}, \mathrm{Zn}, \mathrm{P}$ and $\mathrm{Si}$, and metallic elements due to wear of engine components such as $\mathrm{Al}$ and $\mathrm{Fe}$, and $\mathrm{S}$ originated from both fuel and lubrication oil. The compositions of PM particles were also found to vary significantly from particle to particle observed under same load, indicating the random burning of lubrication oil and its effect on the formation of PM particles.

\subsection{Recommendation}

- PM particle size observed under SEM was larger than $43 \mathrm{~nm}$. The PM particles smaller than $43 \mathrm{~nm}$ observed using SMPS were not observed using SEM. This might be due to the limitation of the approach used to sample PM particles for SEM and TEM. Since the 
exhaust gas cannot flow through the SEM and TEM grid, the small PM particles do not have sufficient kinetic energy to impinge on the TEM and SEM grid. The author recommends using a custom build sampling system like a thermophoretic sampling system or an electrostatic precipitator for the collection of PM on these grids which increases the amount of small particles collected.

- The diesel PM filter has been recognized as an effective aftertreatment system to dramatically reduce the PM emissions of diesel engine. However, the DPF has difficulty to remove the nuclei scale small PM particles. Plus, the PM filter emitted a large amount of small PM particles during its regeneration process. The author recommends characterizing the PM emissions of modern diesel engine equipped with DPF system especially the regeneration process. The effect of regeneration process on the morphology of PM particles needs to be explored.

- The internal combustion engines operated on low temperature combustion were demonstrated to produce much less PM than traditional diesel engines. The preliminary data obtained in this research demonstrated that PM particles of PCCI engine were smaller than that of diesel operation. The author recommends conducting detailed investigation of combustion mode and approaches to obtain low temperature combustion on the morphology of PM particles of LTC engines. 


\section{Reference}

1. Heyder, J., Gebhart1 J. and Stahlhofen1 W., "Diameters of airborne particles," Journal of Water, Air, \& Soil Pollution, Vol.3-4, pp.567-572, 1974

2. Stern, A., Wohlers, H., Boubel, R., and Lowry, W., Fundamentals of Air Pollution. $3^{\text {rd }}$ Edition, Academic Press, Orlando, Florida, 19

3. Jacobson, M. Z., "Strong radiated heating due to the mixing state of black carbon in atmospheric aerosols,” Journal Nature, Vol. 409, pp.695-697, 2001

4. Chianelli, R.R., Yacaman, M.J., Arenas, J., Aldape, F., "Atmospheric nanoparticles in photocatalytic and thermal production of atmospheric pollutants," Journal of Hazardous Substances Research 1, pp.1-16, 1998

5. Abdul-Khalek, I. S., Kittelson, D. B, Graskow, B. R., Wei, Q., Brear, F., "Diesel exhaust particle size: Measurement issues and trends," SAE Paper No. 980525, 1998

6. “Diesel Emissions," www.epa.gov, 2002

7. "Diesel exhaust: Critical analysis of emissions, exposure and health effects," Health Effects Institute special report, 1995

8. Koltsakis, G., Stamatelos, A.M., "Catalytic automotive exhaust aftertreatment," Journal of Progress in Energy and Combustion Science, Vol 23, pp.1-39, 1997

9. Byers, J.B., "Measurement of particulate matter size, concentration and mass emissions from in use heavy duty vehicles," West Virginia University 1999

10. Lippmann, M., Gurman, J., and Schlesinger, R., "Role of particle deposition in occupational lung disease," Aerosols in the Mining and Industrial Work Environment Volume 1: Fundamentals and Status, Edited by Virgil A. Marple and Benjamin Y. H. Liu, Ann Arbor Science Publishers, Ann Arbor, Michigan,Vol. 1, pp. 119-138, 1983

11. Martonen, T., and Lowe, J., "Assessment of aerosol deposition patterns in human respiratory tract casts," Aerosols in the Mining and Industrial Work Environment Volume 1: Fundamentals and Status, Edited by Virgil A. Marple and Benjamin Y. H. Liu, Ann Arbor Science Publishers, Ann Arbor, Michigan, Vol. 1, pp. 151-164, 1983

12. Salve, S. and Holgate, S. T. "Mechanisms of particulate matter toxicity," Journal of Clinical and Experimental Allergy, Vol. 29, pp. 1187-1194, 1999 
13. Jung, H., Guo, B., Anastasio, C. and Kennedy, I.M. "Quantitative measurements of the generation of hydroxyl radicals by soot particles in a surrogate lung fluid," Journal of Atmospheric Environment, Vol. 40,pp. 1043-1052, 2006

14. Halliwell, B., Gutteridge, J. M. C. "Free Radicals in Biology and Medicine," Oxford University Press, Oxford, 1999

15. Soto, K. F., Murr, L. E. and Garza, K. M. “ Cytotoxic responses and potential respiratory health effects of carbon and carbonaceous nanoparticles in the Paso del Norte airshed environment:, International Journal of Environmental Research and Public Health, Vol. 5(1), pp. 12-25, 2008

16. Moskal, A., Makowski, L., Sosnowski, T.R., Gradon, L., "Deposition of fractal like aerosol aggregates in a model of human nasal cavity," Inhalation Toxicology, Vol 18, No. 10, pp. 725-731, 2006

17. Frew, A. J., Salvi, S.S., "Diesel exhaust particles and respiratory allergy," Clinical Experimental Allergy, Vol 27, pp.237-239, 1997

18. Kumar, V., Abbas, K, A., Fausto, N., Aster, J., "Robbins and Cotran pathologic basis of disease, professional edition," $8^{\text {th }}$ Edition, 2010

19. Sato, H., Sone, H., Sagai, M., Suzuki, T. K. and Aoki, Y., "Increase in mutation frequency in lung of Big Blue exposure to diesel exhaust” Journal Carcinogens, Vol 21, No.4, pp. 653661,2000

20. W. Addy Majewski][ http://www.dieselnet.com/tech/engine_control.html

21. Wu, Y., Clark, N., Carder, D., Shade, B., "Nano particle matter evolution in a CFR1065 dilution tunnel," SAE Paper No. 2009-01-2672, 2009

22. Khalek, I, A., Kittelson, D., Brear, F., "The influence of dilution conditions on diesel exhaust particle size distribution measurements," SAE Paper No. 1999-01-1142, 1999

23. Khalek, I, A., Kittelson, D., Brear, F., “ Nanoparticle growth during dilution and cooling of diesel exhaust: Experimental investigation and theoretical assessment" SAE Paper No. 200001-05151, 2000

24. Natti, K.C., Henein, N. A., Poonawala , Y., Bryzik, W., "Particulate matter characterization studies in an HSDI diesel engine under conventional and LTC regime," SAE Paper No. 2008-01-1086,2008 
25. Kolodziej, C., Wirojsakunchai, E., Foster, D. E. , Schmidt, N., Kamimoto, T., Kawai, T., Akard, M., Yoshimura, T., "Comprehensive characterization of particulate emissions from advanced diesel combustion," SAE Paper No. 2007-01-1945, 2007

26. Henein, N. A., Singh, I. P., Zhong, L., Lai, M-C.and Bryzik, W., (2003), "New integrated “O.P.E.R.A.S.” strategies for low emissions in HSDI diesel engines," SAE Paper No. 200301-0261, 2003

27. Natti, K. C., Bhattacharyya, A., Kastury, A., Henein, N. A., and Bryzik, W., "An analysis of regulated and unregulated emissions in an HSDI diesel engine under the LTC regime," SAE Paper No. 2007-01-0905, 2007

28. Li, H., Neil, W, S., Chippior, W., Graham, L., Connolly, T., and Taylor, J, D., “An experimental investigation on the emission characteristic of HCCI engine operation using nheptane," SAE Paper No. 2007-01-1854

29. Bugarski, D., "Characterization of particulate matter and hydrocarbon emissions from in use heavy duty diesel engines,” West Virginia University, 1999

30. Heinz, B., Majewski, W, A., “ PM measurement: In-situ method,"[http://www.dieselnet.com/tech/measure_pm_ins.html]

\section{1. http://www.dieselnet.com/tech/measure_opacity.html}

32. Marple, V.A., Rubow, K.L., Behm, S.M., "A micro orifice uniform deposit impactor (MOUDI): description, calibration, and use," Journal of Aerosol Sci. Technology, 14, pp.434-446, 1991

33. Andersson, J.D., Wedekind, B., "DETR/SMMT/CONCAWE particulate research programme," Ricardo Consulting Engineers, Summary Report DP01/0515, 2001

34. Choi, B.C., Se-Hyun, J., Juhng, W.N., "ELPI measurement of particulate matter from HSDI diesel engine with diesel oxidation catalyst," SAE Paper No. 2003-02-3159, 2003

35. Biskos, G. , Reavell, K. and Collings, N., "Description and theoretical analysis of a differential mobility spectrometer," Aerosol Science and Technology, 39: 6, pp.527 - 541, 2005

36. Su, D. S., Muller, J. O., Jentoft, R. E., Rothe. D., Jacob, E. and Schlogl, R. "Fullerene-like soot from EURO-IV diesel engine: Consequences for catalytic automotive pollution control" Journal of Topics in Catalysis, Vol. 30/31, pp. 241-245, 2004 
37. Greico, W. J., Howard, B.,Rainey, L. C. and Sande, J. B. V. "Fullerenic carbon in combustion-generated soot," Journal of Carbon, Vol. 38, pp. 697-614, 2000

38. Mustafi, N.N.; Robert R. Raine, R.R., "Electron microscopy investigation of particulate matter from a dual fuel engine," Journal of Aerosol Science and Technology 43:9, pp. 951960, 2009

39. Zhu, J., Lee, K., "Effects of exhaust gas recirculation on particulate morphology for a lightduty diesel engine," SAE Paper No. 2005-01-0195, 2005

40. Nord, K., Haupt, D., Ahlvik, P. and Egeback, K. E., "Particulate emissions from an ethanol fueled heavy-duty diesel engine equipped with EGR, catalyst and DPF," SAE Paper No.2004-01-1987, 2004

41. Zhu, J., Lee, K.O., Yozgatligil, A., and Choi, M., "Effects of engine operating conditions on morphology, microstructure, and fractal geometry of light-duty diesel engine particulates," Proceedings of the Combustion Institute, Vol.30, Issue 2, pp. 2781-2789, 2005

42. Zhu, J., Lee, K., Panov, A., Akers, J., and Habeger, C., "An investigation of particulate morphology, microstructures, and fractal geometry for a diesel engine- simulating combustor," SAE Paper No. 2004-01-3044, 2004

43. Lee, K.O., Cole, R., Sekar, R., Choi, M.Y.; Kang, J., Bae, C.S., Shin, H.D., "Morphological investigation of the microstructure, dimensions, and fractal geometry of diesel particulates," Proceedings of Combustion Institute, Vol 29, Issue-1, pp. 647-653,2002

44. Lee, K.O.; Cole, R., Sekar, R.; Choi, M.Y., Zhu, J., Kang, J., Bae, C., "Detailed characterization of morphology and dimensions of diesel particulates via thermophoretic sampling," SAE Paper No.2001-01-3572, 2001

45. Lee, K.O.; Zhu, J., Ciatti, S., Yozgatligil, A. and Choi, M., "Sizes, graphitic structures and fractal geometry of light-duty diesel engine particulates," SAE Paper No. 2003-01-3169, 2003

46. Zhu, J., Lee, K.O., Yozgatligil, A., and Choi, M., "Effects of engine operating conditions on morphology, microstructure, and fractal geometry of light-duty diesel engine particulates," Proceedings of the Combustion Institute, Vol.30, Issue 2, pp. 2781-2789, 2005 47. "Model 3080 Electrostatic Classifier-Instruction Manual," TSI Inc., 2002.

48. "Model 3025A Ultrafine Condensation Particle Counter-Instruction Manual," TSI Inc.,2002. 49. JEOL JSM $7600 \mathrm{~F}$ instruction manual 
50. JEOL JEM-2100 instruction manaual

51. Park, K., Kittelson, D., and McMurry, P. "Structural properties of diesel exhaust particles measured by transmission electron microscopy (TEM): Relationships to particle mass and mobility," Journal of Aerosol Science. Technology, 38 (9), pp 881-889, 2004

52. Oh, C., Sorensen, and C.M., "The effect of overlap between monomers on the determination of fractal cluster morphology," Journal of Colloid Interface Science, 193(1): pp 17-25, 1997

53. Megaridis, C. M., and Dobbins, R. A., "Morphological description of flame generated materials," Journal of Combustion Science and Technology, 71, pp: 95-109, 1990

54. Chakrabarty, R. K., Moosm“uller, H., Arnott, W. P., Garro, and M. A., Walker, "Structural and fractal properties of particles emitted from spark ignition engines," Journal of Environmental. Science and Technology, 40(21): pp 6647- 6654, 2006

55. Song, J., Alam, M., Boehman, A. L., and Kim, U., "Examination of the oxidation behavior of biodiesel soot," Journal of Combustion and Flame, Vol. 146, pp. 589-604, 2006

56. Jääskeläinen, H., and Majewski, W. A., "Diesel engine lubricants," [http://www.dieselnet.com/tech/lube.html\#class] 